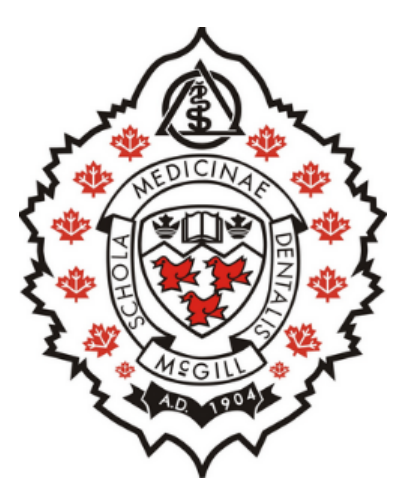

Faculty of Dentistry

McGill University

Montreal, Quebec, Canada

December, 2019

A thesis submitted to McGill University in partial fulfillment of the requirements of the degree of Master of Science, Dental Sciences

(C) Mohammed Mahri 2019 


\section{Table of content}

Table of content $\quad$ i

Dedication $\quad$ iv

A brief abstract in English $\quad v$

A brief abstract in French vii

Acknowledgment $\quad$ ix

Contribution of Authors $\quad$ xi

Chapter 1: Introduction and Research Rationale $\quad 1$

1.1 Thesis outline $\quad 1$

1.2 Research rationale, hypothesis, and objectives 1

Chapter 2: Literature Review 3

2.1 Bone $\quad 3$

2.1.1 Bone Cells $\quad 3$

2.1.2 Bone Development 4

2.1.3 Bone Remodeling $\quad 4$

2.1.4 Bone Healing $\quad 5$

2.2 Osseointegration $\quad 6$

$\begin{array}{ll}2.3 \text { Systematic reviews } & 7\end{array}$

2.4 Evidence mapping review $\quad 8$

2.5 Machine Learning (ML) and Systematic Reviews 9

Chapter 3: Osseointegration Pharmacology: A Systematic Mapping Using Artificial Intelligence 12

$\begin{array}{ll}3.1 \text { Abstract } & 12\end{array}$

3.2 Introduction $\quad 14$

3.3 Materials and Methods $\quad 17$

$\begin{array}{ll}\text { 3.3.1 Study design } & 17\end{array}$

3.3.2 Search strategy 18

$\begin{array}{lr}\text { 3.3.3 Eligibility criteria } & 19\end{array}$

3.3.4 Screening Method $\quad 20$

3.3.5 Development of a method for automatization of data screening 20

3.3.6 Validation of the method for data screening $\quad 22$

3.3.7 Data Extraction $\quad 22$

3.3.8 Quality assessment and risk of bias 23

3.3.9 Evidence mapping presentation 23

$\begin{array}{ll}3.4 \text { Results } & 24\end{array}$

3.4.1 Study Selection $\quad 24$

3.4.2 Building the algorithm and improving its selection performance 25

3.4.3 Performance of the algorithm 26

3.4.4 Validation of the method for data screening $\quad 27$

3.4.5 The drugs effects on bone-implant osseointegration 35

$\begin{array}{ll}\text { 3.4.5.1 Anti-osteoporosis Drugs } & 35\end{array}$

3.4.5.1.1 Bisphosphonate $\quad 36$

3.4.5.1.1.1 Zoledronic Acid 36

3.4.5.1.1.2 Alendronate $\quad 38$

3.4.5.1.1.3 Disodium Diphosphonate $\quad 39$

3.4.5.1.1.4 Ibandronate $\quad 40$ 
3.4.5.1.1.5 Clodronate $\quad 40$

3.4.5.1.1.6 Risedronate $\quad 40$

3.4.5.1.1.7 Pamidronate $\quad 41$

3.4.5.1.1.8 TRK-530 (Bisphosphonate) 41

3.4.5.1.1.9 YM-175 (Bisphosphonate) 41

3.4.5.1.1.10 Etidronate $\quad 42$

3.4.5.1.2 Parathyroid Hormone Replacement Therapy (PTH) 42

3.4.5.1.3 Vitamin D $\quad 43$

3.4.5.1.4 Anti-Sclerostin antibody $\quad 44$

3.4.5.1.5 Anti-RANKL $\quad 44$

3.4.5.1.6 Strontium ranelate $\quad 45$

3.4.5.2 Analgesics $\quad 45$

3.4.5.2.1 NSAID $\quad 45$

3.4.5.2.1.1 Meloxicam $\quad 45$

3.4.5.2.1.2 Diclofenac sodium 46

3.4.5.2.1.3 Aspirin 46

3.4.5.2.1.4 Ibuprofen $\quad 47$

3.4.5.2.1.5 Celecoxib 47

3.4.5.2.1.6 Indomethacin $\quad 47$

$\begin{array}{ll}\text { 3.4.5.2.1.7 Naproxen } & 48\end{array}$

$\begin{array}{ll}\text { 3.4.5.2.1.8 Rofecoxib-A } & 48\end{array}$

3.4.5.2.1.9 Parecoxib 48

$\begin{array}{ll}\text { 3.4.5.2.1.10 Flurbiprofen } & 49\end{array}$

3.4.5.2.2 Prostaglandin EP4 receptor agonist $\quad 49$

3.4.5.2.3 Cannabinoids $\quad 49$

3.4.5.2.4 Local anesthesia: Bupivacaine without vasoconstriction $\quad 49$

3.4.5.3 Anti-Psycholeptics Drugs $\quad 50$

$\begin{array}{ll}\text { 3.4.5.3.1 Melatonin } & 50\end{array}$

$\begin{array}{ll}\text { 3.4.5.3.2 Lithium chloride } & 50\end{array}$

3.4.5.4 Antidepressant $\quad 50$

3.4.5.4.1 Selective Serotonin reuptake Inhibitors (SSRIs) 50

3.4.5.5 Drugs Used in Addictive Disorders $\quad 51$

3.4.5.5.1 Nicotine $\quad 51$

3.4.5.5.2 Alcohol $\quad 51$

3.4.5.6 Systemic Hormonal Replacements Drugs $\quad 51$

3.4.5.6.1 Sex Hormone Replacement $\quad 51$

3.4.5.6.1.1 Estradiol $\quad 52$

3.4.5.6.1.2 Dihydrotestosterone $\quad 53$

3.4.5.6.1.3 Raloxifene $\quad 53$

3.4.5.6.2 Thyroid Hormone Replacement $\quad 53$

3.4.5.6.2.1 Calcitonin $\quad 53$

3.4.5.6.2.2 Levothyroxine $\quad 54$

3.4.5.6.3 Oxytocin $\quad 54$

3.4.5.6.4 Corticosteroids $\quad 54$

3.4.5.6.4.1 Methylprednisolone $\quad 55$

3.4.5.6.4.2 Prednisolone $\quad 55$

3.4.5.6.4.3 Glucocorticosteroid $\quad 55$

3.4.5.7 Chemotherapy $\quad 55$ 
3.4.5.7.1 Cisplatin

3.4.5.7.2 Methotrexate $\quad 56$

3.4.5.7.3 Doxorubicin $\quad 56$

$\begin{array}{ll}\text { 3.4.5.7.4 Ifosfamide } & 57\end{array}$

$\begin{array}{ll}\text { 3.4.5.8 Anti-Angiogenic } & 57\end{array}$

3.4.5.8.1 TNP-470 $\quad 57$

3.4.5.8.2 Anti-vascular endothelial growth factor (Anti-VEGF) 57

3.4.5.8.3 Ranibizumab $\quad 58$

$\begin{array}{ll}\text { 3.4.5.9 Antibiotic } & 58\end{array}$

3.4.5.10 Anti-Diabetic $\quad 58$

3.4.5.10.1 Insulin $\quad 59$

3.4.5.10.2 Metformin $\quad 59$

3.4.5.10.3 Aminoguanidine $\quad 60$

3.4.5.11 Cardiovascular System Drugs $\quad 60$

$\begin{array}{ll}\text { 3.4.5.11.1 Antihypertensive } & 60\end{array}$

3.4.5.11.1.1 Propranolol $\quad 60$

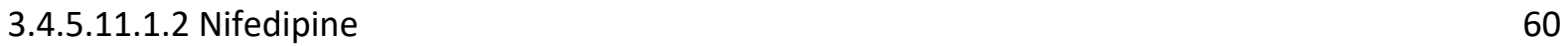

$\begin{array}{ll}3.4 .5 .11 .2 \text { Statins } & 61\end{array}$

3.4.5.12 Blood Drugs $\quad 62$

3.4.5.12.1 Anti-Hemorrhagic: Aprotinin $\quad 62$

3.4.5.12.2 Anti-Thrombotic: Warfarin $\quad 62$

3.4.5.13 Immunosuppression $\quad 62$

3.4.5.13.1 Cyclosporin A $\quad 62$

3.4.5.13.2 FK-506 $\quad 63$

3.4.5.14 Anti-Gastric: $\quad 63$

3.4.5.14.1 Proton Pump Inhibitors (PPI) 63

3.4.5.15 Hyperbaric oxygen (HBO) $\quad 64$

$\begin{array}{ll}\text { 3.4.6 Synthesis of results } & 64\end{array}$

3.4.7 Discussion $\quad 66$

3.4.8 Limitations, Strength and future work $\quad 70$

$\begin{array}{ll}3.4 .9 \text { Conclusions } & 71\end{array}$

$\begin{array}{ll}\text { 3.4.10 Acknowledgments } & 71\end{array}$

$\begin{array}{ll}\text { References } & 72\end{array}$

$\begin{array}{lr}\text { Appendices } & 89\end{array}$

Appendix A: Search Strategies $\quad 89$

Appendix B: Studies Characteristics $\quad 97$

Appendix C: Quality assessment of animal studies $\quad 117$

Appendix D: Quality assessment of RCTs 129

Appendix E: Quality assessment of observational studies $\quad 130$ 


\section{Dedication}

I would like to dedicate my thesis to my sweet and loving parents (mother and father) for their endless love and support throughout this thesis. It is also dedicated to my wife (Tahani) and my daughter (Naya), for all the wonderful things, loves and supports they bring to my life. It is also dedicated to my brothers (Ahmed, Ibrahim, Abdullah), sisters (Zainab, Amnah, Fatimah, Hana, Entissar, Hanan), my best friend Raoof Abbas 


\begin{abstract}
Introduction

There is growing evidence associating patient systemic conditions and medications to the success of osseointegrated medical devices such as dental implants and hip prosthesis. However, bibliographic assessment of these associations cannot be fully achieved with conventional systematic reviews due to the broad scope of the question addressed. Evidence mapping methods are better suited to such a task; however, evidence mapping can be very resource-intensive.

Artificial intelligence can be used to reduce the workload associated with systematic reviews (SR) and systematic mappings (SM). However, the available methods are limited in their ability to reduce the workload and their sensitivity and specificity. A limiting factor is the quality of the training datasets used for machine learning.
\end{abstract}

\title{
Hypothesis
}

Systematic mapping of the effect of medications on bone-implant osseointegration can be successfully achieved using a machine learning (ML) algorithm trained with similar and nonsimilar training datasets.

\section{Objective}

The objective of this study was to develop a method for systematic mapping of the literature using a machine learning algorithm trained with similar and non-similar training datasets and use this to identify the effect of medications on bone-implant osseointegration.

\section{Methods}


To produce high-quality training datasets for machine learning, we conducted precise search strategies to produce similar and non-similar articles using PubMed. The articles were screened manually and classified into include and excluded articles. The inclusion criteria were clinical and animal studies that assessed the effect of systemic medication on bone-implant osseointegration.

The dataset of included and excluded articles screened manually were used to train a machinelearning algorithm based on Support Vector Machines (SVM). The algorithm produced was validated against a published systematic review with a search strategy that falls within the scope of ours. Then, the trained algorithm was used to screen articles identified with a highly sensitive search strategy (543927 articles).

\section{Results}

Our algorithm was able to screen half-million published articles and reduce the workload by $95 \%$ with an accuracy of $95 \%$, a False Positive Rate (TFP) of $95 \%$, a sensitivity of $93 \%$, and a specificity of $95 \%$. The number of articles retrieved and included for the final analysis was 268 articles. In these articles, we identified 31 drug families that have been studied for their effect on osseointegration.

\section{Conclusion}

Partial automation of systematic mappings can be successfully achieved with similar and nonsimilar training datasets classified by MeSH-terms. This method allowed us to perform a systematic mapping on the effect of medications on bone-implant osseointegration, and we identified 31 drugs that affect osseointegration. 


\section{Résumé}

Introduction : Il existe un nombre croissant de publication associant les patients polymédiqués à un risque plus important de non ostéointégration des implants dentaires et des prothèses de hanche. Cependant, la littérature contient un nombre très important de publication sur le sujet, ce qui rend l'analyse systématiques très compliqué. Récemment, des méthodes de cartographie de la littérature (ou mapping review) ont été proposé pour réaliser ce genre de synthèse. Cependant, ce type de travail nécessite beaucoup de temps et de ressources. Ainsi, l'intelligence artificielle pourrait être utilisée pour réduire la charge de travail demandé lors de la réalisation de ce type de cartographies systématiques. Les méthodes disponibles sont actuellement limitées en termes de performance, notamment en termes de sensibilité et leur spécificité. Ces performances s'expliquent principalement par la qualité et le nombre de données utilisés pendant la phase d'apprentissage de l'algorithme.

Hypothèse : Nous pensons qu'il est possible de réaliser une cartographie systématique de l'effet des médicaments sur l'ostéointégration des implants osseux en utilisant un algorithme d'apprentissage automatique formé avec des données de formation similaires et non similaires.

Objectif : Lors de ce travail, nous souhaitons développer une méthode de cartographie systématique de la littérature à l'aide d'un algorithme d'apprentissage automatique formé à partir d'ensembles de données de formation similaires et non similaires, et de l'utiliser pour identifier l'effet des médicaments sur l'ostéointégration des implants en os.

Matériels et Méthodes : Afin de produire des articles similaires et non similaires, un protocole de recherche précis a été développé pour extraire des articles à partir de la base de données PubMed. Les articles ont d'abord été triés et classés manuellement pour rechercher les articles similaires et 
non similaires. Les critères d'inclusion étaient des études cliniques et animales évaluant l'effet d'un médicament systémique sur l'ostéointégration des implants osseux. Les articles inclus et exclus ont été utilisés pour former un algorithme d'apprentissage automatique basé sur des machines à vecteurs de support. L'algorithme a été ensuite validé par comparaison avec une revue systématique préalablement publiée. Enfin, l'algorithme a été utilisé pour sélectionner les articles identifiés par une stratégie de recherche extrêmement sensible.

Résultats : L'algorithme a été capable d'analyser un demi-million d'articles publiés et de réduire la charge de travail de $93 \%$ avec une précision de $95 \%$, un taux de faux positifs (TFP) de $95 \%$, une sensibilité de $93 \%$ et une spécificité de $95 \%$, en comparaison avec la revue systématique déjà publiée. Le nombre d'articles récupérés et inclus pour l'analyse finale était de 266 articles. Dans ces articles, nous avons identifié 31 familles de médicaments qui ont été étudiés pour leur effet sur l'ostéointégration.

Conclusion : Ce travail a permis de créer un algorithme capable d'identifier et de sélectionner avec succès un ensemble d'article à partir des termes $\mathrm{MeSH}$, avec une précision très proche de celle réalisé par le travail préalablement. Cette méthode nous a permis de réaliser une cartographie systématique de l'effet 31 médicaments sur l'ostéointégration des implants osseux. 


\section{Acknowledgment}

In the Name of Allah, the Most Beneficent, the Most Merciful.

First and foremost, I would like to praise Allah for his never-ending grace, mercy, and for providing me the strength, support, and opportunity to complete this thesis.

The inspiration and support of a number of wonderful individuals who have made this thesis possible, all my appreciation to all of them for being part of this part of my life and making this thesis possible.

I would like to express my sincere and deep appreciation to my supervisor, Dr. Faleh Tamimi. It has been an honor to be one of his M.Sc. students. I am grateful for his patience, motivation, support, and immense knowledge.

I express my warmest gratitude to my committee members: Dr. Jocelyne Feine and Dr. Svetlana Komarova for their support, encouragement, and their insightful suggestions and comments.

Also, I would like to thank Rania Rodan, Ammar Daer, Francisco Berrizbeitia, Nicole Shen, Doaa Taqi, Matthew Faigan, Kevin Yang Wu, Mothare Ahmadi, Elham Emami, Haider Al-waeli, and all of our lab members, who supported and helped me along the way.

Finally, I am most grateful to my family and my friends for their constant and unconditional support, love, prayers, and inspiration.

And above all, I would like to express my unfailing gratitude and love to my beautiful wife, Tahani. She has been a true and great supporter. And I truly thank her for standing by my side in every situation and helping me achieving my dreams. Without her unconditional love, unlimited support, and limitless patience, I could not finish this journey. 
This work was financially supported by faculty of dentistry, Jazan University, and the Saudi Arabian Cultural Bureau in Ottawa, Canada. 


\section{Contribution of Authors}

This thesis includes one manuscript entitled "Osseointegration Pharmacology: A Systematic Mapping Using Artificial Intelligence.”

Authors: Mohammed Mahri, Nicole Shen, Francisco Berrizbeitia, Rania Rodan, Ammar Daer, Matthew Faigan, Doaa Taqi, Kevin Yang Wu, Mothare Ahmadi, Maxime Ducret, Elham Emami, Faleh Tamimi.

Contribution: M.M. wrote the manuscript, performed data extraction and data screening, collected and analyzed the data and performed statistical analysis, helped in applying artificial intelligence (AI) for collecting data, and also for quality assessments. F.B. wrote the AI scripts, N.S. applied the AI for the collecting data and helped in data extraction, and R.R. and A.D. wrote the quality assessment and helped in data extraction. M.A. assisted in quality assessments. K.Y.W. collected data for the method. M.F. helped in data extraction. F.T. prepared and supervised the work, provided scientific guidance, and reviewed the manuscript. D.T. and M.D. reviewed the manuscript.

Originality: This is the first study to use a semi-automated evidence mapping review to synthesize the effect of drugs on bone-implant osseointegration. The results of this study revealed that drugs known to affect the metabolic activities involved in the process of osseointegration could affect osseointegration. 


\section{Chapter 1: Introduction and Research Rationale}

\subsection{Thesis outline}

This thesis consists of three chapters. The first chapter includes the thesis outline, the research rationale, the hypothesis, and the objectives. The second chapter includes the literature review introducing bone composition and physiology as well as the concepts of osseointegration, systematic reviews, and systematic mapping reviews. And the third chapter includes one manuscript entitled "Osseointegration Pharmacology: A Systematic Mapping Using Artificial

\section{Intelligence."}

\subsection{Research rationale, hypothesis, and objectives}

Osseointegration plays an essential role in the success of many bone-anchored medical devices such as orthopedic prosthesis, auditory devices, and dental implants $(1,2)$. Bone healing and metabolism play a crucial role in the process of osseointegration and in determining the success or failure of bone-anchored implants. Failure of osseointegration can lead to serious deleterious outcomes with orthopedics, auditory, and dental implants such as impairments of function and aesthetic, infections, pain, bone loss, and implant failure $(1,2)$. Some systemic drugs have been found to influence bone metabolism and affect bone-implant osseointegration (3). This raises the question of how relevant are the possible side effects of medications on osseointegration. Addressing this question could help us better understand the biological mechanisms of osseointegration and improve clinical decision making (4). However, complex open questions such as “what drugs affect osseointegration?" are too extensive for a conventional systematic review to address. Evidence mapping reviews were developed to address this type of question and help clinicians, patients, and researchers make better evidence-based decisions (4). However, the size of the healthcare scientific literature is enormous; thus, full systemic mapping and subject-wide 
evidence synthesis are usually not feasible. So, very recently, Machine Learning has been introduce for fully or semi-automated evidence mapping reviews and this approach has achieved very promising results $(5,6)$.

Accordingly, we hypothesize that systematic mapping of the effect of medications on bone-implant osseointegration can be successfully achieved using machine learning (ML).

\section{The specific objective of this thesis:}

The objective of this study was to provide a systematic evidence mapping of the literature to address the question: "What drugs could affect bone-implant osseointegration?". More specifically, this thesis aimed to identify the list of drugs known to impair and enhance osseointegration. To achieve this, we developed a method to generate a ML classifier for automated article screening for systematic mappings. 


\section{Chapter 2: Literature Review}

\subsection{Bone}

Bone is a mineralized dense, supportive connective tissue. It is essential for protecting vital organs, storing minerals, producing hematopoietic cells, and enabling locomotion (7). It plays an important biological role in regulating mineral homeostasis and energy metabolism. Also, bone cooperates with other vital tissues and organs such as the hypothalamus, the adipose tissue, the kidney, the vasculature, and the parathyroid gland, among others, in order to carry out metabolic processes that keep the human body in balance (7).

The structure of bone consists of the periosteum, the compact bone, the spongy bone, and the medullary cavity $(8,9)$. The periosteum is the outer layer that covers the bone surface, and it consists of dense irregular connective tissue, nerve fibers, blood, and lymph vessels (9). The compact bone consists of a very dense lamellar bone without trabeculae that contain several canals to provide access for nerves, blood vessels, and lymphatic ducts (9). The spongy bone consists of trabeculae made of irregularly arranged lamellae and osteocytes interconnected by canaliculi that work as struts (9). The medullary cavity is the innermost part of the bone, and it is an open cavity filled with red and/or yellow bone marrow. This area is involved in the formation of hematopoietic cells and other specialized cells, such as mesenchymal stem cells and osteoprogenitor cells $(8,9)$.

\subsubsection{Bone Cells}

There are three main types of bone cells:

A. Osteoblasts are mature bone cells responsible for synthesizing new bone. Osteoblasts produce osteoid, an extracellular matrix of collagen and non-collagenous proteins as well as proteoglycans, glycoproteins that are eventually calcified (10). Osteoblasts rely on a variety of 
transmembranous proteins (e.g., integrins, connexins, cadherins cytokines), hormones, and growth factors that maintain their cellular function and responsiveness to metabolic and mechanical stimuli. They are located at the bone surface forming a tight layer of single nucleus cells (11). Human osteoblasts live up to 8 weeks until some of these cells get trapped in their calcified matrix and then develope into osteocytes (11).

B. Osteocytes are mature cells that maintain the bone matrix. They are derived from osteoblast but have a different morphology and function. In terms of morphology, the nucleolus-to-cytoplasm ratio of osteocytes is large compared to osteoblasts. Also, osteocytes have fewer ribosomes and smaller endoplasmic reticula (11). Osteocytes have a large number of cytoplasmic extensions that keep them connected to each other and with bone-lining cells (11).

C. Osteoclasts are multinucleated, giant, highly migratory, and polarized cells that secrete acids and protein-digesting enzymes. Their main function is osteolysis, which is the dissolution of the bone matrix and release of stored minerals. Often, they are found lining in the endosteum and bone marrow (11).

\subsubsection{Bone Development}

Bone formation relies mainly on two distinct processes, endochondral ossification and intramembranous ossification (12) (9). Endochondral ossification is the process of bone formation that occurs by replacing hyaline cartilage structures with calcified bone, and it is responsible for the formation of the long bone. Intramembranous ossification is the process of bone formation that occurs by mesenchymal tissue, and then these mesenchymal stem cells differentiate into osteoblasts, which secrete osteoid that later on calcifies to form bone, such as skull, maxilla, and clavicles formation (9).

\subsubsection{Bone remodeling}


Bone remodeling is the process that involves an ongoing cycle of bone resorption and formation, which is essential for maintaining bone mechanical strength. Bone remodeling is modulated by two types of cells: osteoclasts that resorb bone (breaking down the old bone) and osteoblasts that are responsible for synthesizing new bone $(11,13)$. Bone remodeling should be tightly regulated; otherwise, imbalanced bone resorption and bone formation may lead to medical condition with either excess bone loss such as osteoporosis or excess bone formation such as osteopetrosis (13).

\subsubsection{Bone Healing}

Bone healing is a physiological process that aims to repair bone fracture (14). There are two histological types of bone healing: primary and secondary bone healing (14). Primary healing is rare and needs high stability and absolute contact of the bone fragments in order to directly re-establish an anatomically and biomechanically competent lamellar bone structure $(14,15)$. Secondary bone healing, the most common healing process, occurs in the vast majority of bone injuries, and it consists of two mechanisms intramembranous and endochondral ossification $(14,15)$.

Bone healing involves four distinct but overlapping stages: Haemostasis, Inflammation, Proliferation, and Remodeling (16), details underneath:

A- Haemostasis stage: This stage begins upon trauma immediately after bleeding, and its duration takes from minutes to hours. During this stage, a series of biological processes occur, such as coagulation and platelet activation. Also, proteins, as well as growth and differentiation factors (e.g., heparin-binding domains by heparin hydrolases from blood platelets) that are stored in the bone matrix, become soluble and active $(17,18)$. 
B- Inflammatory stage: This stage starts minutes after bone injury and lasts for a few days (18). During this stage, a series of biological processes occur, such as cytokine release, and the onset of the macrophage-mediated inflammation, resulting in the formation of granulation tissue (16).

C- Proliferative stage: This stage begins three days after injury, and it can continue for up to 5-6 weeks. This stage is characterized by neovascularization and cell differentiation at the injury site, followed by cell proliferation and activation. Fibroblasts begin to produce an immature connective tissue matrix to support vascular ingrowth $(16,19)$. Subsequently, osteoblasts arrive at the site and start secreting a collagen matrix and osteoid in order to form immature woven bone $(16,19)$.

D- Remodeling (maturation) stage: This is the last stage of bone healing, and it takes place over months to years in order to restore the bone into its original shape, structure, and mechanical strength $(16,19)$. Remodeling of the immature bone matrix involves resorption and deposition of bone in response to mechanical stress (19).

\subsection{Osseointegration}

The term osseointegration derives from the Greek word 'osteon,' which means bone, and the Latin word'integrate,' which means 'to make whole' (20). The first definition of osseointegration was provided by Professor Branemark as an intimate contact between the surface of an implant and bone without interposed soft tissue layers (20). These implants are mainly made of titanium due to its excellent biocompatibility, good resistance to corrosion, and lack of toxicity, and ability to create a firm and lasting connection with the recipient bone $(1,2)$. On the other hand, the biological events involved in the process of osseointegration resemble those of bone fracture healing at least during the initial host response, which includes hematoma formation and direct migration of mesenchymal cells through the clot matrix to the implant surface in order to initiate woven bone 
formation through the intramembranous pathway, and lamellar bone formation on the spicules of woven bone (21).

These biological events and implant success depend on implant stability. There are two main types of implant stability, the primary and secondary stability: Primary implant stability is defined as the mechanical interlocking of the implant in the bone bed without any mobility. It depends mainly on the bone's quality and quantity, and it is highly associated with successful implant integration and long-term clinical outcome (22). Adequate osteotomy preparation is key for high bone-to-implant contact (BIC), mechanical primary implant stability, and healing (23). Secondary implant stability is defined as the stability that comes through the process of osseointegration. This type of stability occurs at the process of regeneration and remodeling happing at the bone-implant interface (24), and it relies on both metabolic activities and the nature of the implant surface. Failure of osseointegration between the implant and bone can occur: during the early stages of osseointegration due to lack of intimate bone-implant contact or at later stages due to the disruption of the established contact by biological conditions such as infection or mechanical overload and fracture $(2,25)$. Failure of osseointegration devices could have serious consequences on patients' life, in terms of increased morbidity and mortality (e.g., hip replacement) as well as socioeconomical costs due to re-intervention procedures (26).

\subsection{Systematic reviews (SR)}

Access to the ever-growing medical scientific information is time-consuming and overwhelming. This problem could be addressed through systematic reviews, a type of scientific publication designed to answer very specific questions (e.g., does aspirin increase the risk of implant failure in a specific population?) by performing a systematic assessment of the scientific literature. Systematic reviews can have an enormous positive impact on global healthcare (27). For instance, 
the systematic review on the use of corticosteroids for the prevention of premature births has been reported to have saved the lives of tens of thousands of people worldwide (28). However, Systematic reviews consist of a series of labor-intensive steps that are currently performed manually: first, a search strategy is designed; second, the scientific literature is searched using various search engines; the articles found are then screened and, finally, the information is extracted and assessed for quality using a grading system based on specialized checklists. So, carrying out a systematic review is a resource-intensive and complex activity (29), which is both expensive and time-consuming (30). Indeed, nowadays, a systematic review can cost anywhere between US $\$ 30,000$ to US\$300,000 and take one to two years to be completed (30). Several tools have been developed to facilitate the process of systematic reviewing by improving the management of the systematic review process, mainly by helping to organize data extraction and team coordination (29). This can facilitate crowdsourcing and optimize resources; however, many steps of the systematic review, such as article screening, still require enormous efforts (31). This problem requires industrial-scale cost-effective ways to search and synthesize evidence. (30).

Even though systematic reviews are the "gold standard" for synthesizing primary research, they are limited when it comes to answering the complex questions faced by clinicians in daily practice, for example, “what drugs could affect osseointegration in my patient?". Answering a question such as this one is currently unfeasible because it would require over 553 systematic reviews (one for each of the 553 drug categories defined in PubMed) that could translate to an estimated 620 years of work using traditional methods (30). Moreover, in fields in which data is sparse and patchily distributed or in which there is great variability in methodology, systematic reviews are not appropriate because it focuses on finding out the state of knowledge on a particular topic (4).

\subsection{Evidence mapping review (EMR)}


An Evidence Mapping Review is defined as a systematic search of a broad field to answer complex open questions and to identify gaps in knowledge for future research needs (4) This type of review was initially developed for fields with a limited number of publications, such as environmental sciences or education, and only provides information about the distribution of articles in a particular research area (30). Accordingly, the concept of subject-wide evidence synthesis was developed to combine systematic mapping strategies with systematic reviewing of the mapped articles. This approach could, for instance, help to map the entire medical literature as a function of disease and treatments. This type of map would help answer very complex questions, such as "what mediations can be used to treat diabetes?" or, "in a patient with diabetes, what medications are best?" However, the size of the healthcare scientific literature is enormous; thus, full systemic mapping and subject-wide evidence synthesis are usually not feasible (30). Indeed, previous efforts in subject-wide evidence synthesis have been very limited and rely on extensive crowdsourcing (30).

\subsection{Machine Learning (ML) and Systematic Reviews}

Machine Learning is a large sub-field of Artificial Intelligence (AI) that gives computers the ability to learn without being explicitly programmed (32). This means creating programs that have the ability to learn and do some intelligent activities outside the notion of programming.

ML tools can be used to accelerate the systematic review process by full or semi-automation of the different steps in a systematic review (33). Previous studies have shown that human effort can be reduced by using machine learning software to prioritize large reference collections, such that most of the relevant references are identified before screening is completed (34). Also, machine learning algorithms such as Robot-Reviewer can be used to appraise the quality of the scientific literature, a critical step in any systematic review (35). 
As many as 44 different algorithms have been developed to automate screening of systematic reviews. These algorithms use natural language processing to estimate the probability of including or excluding an article (36). Some of these review tools, such as "Rayyan," train a machine learning classifier by promoting the abstracts that have more similar words to previously included abstracts (36). Others, such as the "Shiny R" application for ML article screening developed by the European Food Safety Authority (EFSA), rely on words or strings of words (37). RobotAnalyst combines text-mining and machine learning algorithms for organizing references by their content and actively prioritizing them based on a relevancy classification model trained and updated throughout the process (34).

ML has been used to perform broad/shallow systematic reviews achieving up to $98.7 \%$ sensitivity and $86 \%$ specificity; however, this requires very large training sets (i.e., up to 5,749 records) (31). Newer algorithms such as Abstrackr offers specificity that range between $0.69-0.90$, a false negative rate of $3.5-21.2 \%$, and a workload reduction of $6-67 \%$, which is promising but still not good enough to replace human screening (33). Even though ML is considered safe and ready for use in 'live' reviews (38), it still faces many issues that need to be addressed. Machine learning algorithms are often based on the inclusion and exclusion of decisions made by humans. Thus, the main limitation of all ML algorithms for systematic reviews is a large number of human decisions needed to reach reliable results (36). Usually, substantial manual screening is needed to achieve relevant results (34), and most classifiers are only able to reduce the number of abstracts requiring manual screening by about $50 \%$ (39), saving only $30 \%$ to $70 \%$ of the workload (38). Another limitation is the relatively low reliability of such classifiers (36), the naive active learning-based screening process is biased in favor of selecting similar documents (40), and the saving in workload is accompanied by a best-case-scenario loss of 5\% of relevant studies (i.e., a 95\% recall) (38). 
Therefore the use of ML is often limited to the exclusion of the most obvious articles, which constantly between $30 \%$ and $70 \%$ of the articles that need to be reviewed in the most systematic reviews (36). 


\section{Chapter 3: Osseointegration Pharmacology: A Systematic Mapping Using Artificial Intelligence}

Mohammed Mahri, ${ }^{1,2}$, Nicole Shen ${ }^{1}$, Francisco Berrizbeitia ${ }^{3}$, Rania Rodan ${ }^{1,4}$, Ammar Daer $^{1}$, Matthew Faigan ${ }^{1}$, Doaa Taqi ${ }^{1}$, Kevin Yang Wu ${ }^{1,5}$, Mothare Ahmadi ${ }^{1}$, Maxime Ducret ${ }^{1,6}$, Elham Emami ${ }^{1}$, Faleh Tamimi ${ }^{*}$

${ }^{1}$ Faculty of Dentistry, McGill University, Montreal, QC, Canada

${ }^{2}$ Department of Oral and Maxillofacial Surgery, Faculty of Dentistry, Jazan University, Jazan, Saudi Arabia

${ }^{3}$ Concordia University, Library, Montreal, QC, Canada

${ }^{4}$ Royal Medical Services, King Hussein Medical Center, Jordan

${ }^{5}$ Faculty of Medicine, Laval University, Quebec City, QC, Canada

${ }^{6}$ Université Claude Bernard Lyon 1, Faculté d'Odontologie, Lyon, France

\subsection{Abstract}

Introduction: there is growing evidence associating patient systemic conditions and medications to the success of osseointegrated medical devices such as dental implants and hip prosthesis. However, bibliographic assessment of these associations cannot be fully achieved with conventional systematic reviews due to the broad scope of the question addressed. Evidence mapping methods are better suited to such a task; however, evidence mapping can be very resource-intensive.

Artificial intelligence can be used to reduce the workload associated with systematic reviews and systematic mappings. However, the available methods are limited in their ability to reduce the workload and their sensitivity and specificity. A limiting factor is the quality of the training datasets used for machine learning. 
Hypothesis: systematic mapping of the effect of medications on bone-implant osseointegration can be successfully achieved using a machine learning (ML) algorithm trained with similar and non-similar training datasets.

Objective: the objective of this study was to develop a method for Systematic mapping of the literature using a machine learning (ML) algorithm trained with similar and non-similar training datasets and use this to identify the effect of medications on bone-implant osseointegration.

Methods: to produce high-quality training datasets for machine learning, we conducted precise search strategies to produce similar and non-similar articles using PubMed. The articles were screened manually and classified into include and excluded articles. The inclusion criteria were clinical and animal studies that assessed the effect of systemic medication on bone-implant osseointegration.

The dataset of included and excluded articles screened manually were used to train a machinelearning algorithm based on Support Vector Machines. The algorithm produced was validated against a published systematic review with a search strategy that falls within the scope of ours. Then, the trained algorithm was used to screen articles identified with a highly sensitive search strategy (543927 articles).

Results: our algorithm was able to screen half-million published articles and reduce the workload by $95 \%$ with an accuracy of $95 \%$, a False Positive Rate (TFP) of $95 \%$, a sensitivity of $93 \%$, and a specificity of $95 \%$. The number of articles retrieved and included for the final analysis was 268 articles. In these articles, we identified 31 drug families that have been studied for their effect on osseointegration. 
Conclusion: partial automation of systematic mappings can be successfully achieved with similar and non-similar training datasets classified by MeSH-terms. This method allowed us to perform a systematic mapping on the effect of medications on bone-implant osseointegration, and we identified 31 drugs that affect osseointegration.

\subsection{Introduction}

Osseointegrated devices anchored to bone, such as dental implants, orthopedic prostheses, and cochlear implants, are used to treat several conditions, including tooth and hearing loss, or joint problems. Many patients worldwide are treated with these devices, more than 24,000 total hip replacements surgeries are performed annually in Canada alone (41), and about 100,000-300,000 dental implants are and over 96,000 cochlear implant devices are placed in the United States every year (42-44). The success of these devices relies on a phenomenon called osseointegration, which is defined as an intimate contact between the surface of the implant and bone without interposed soft tissues (20). Recent studies have shown that some pharmacological agents could affect osseointegration and implant survival by interfering with the pathways that regulate bone metabolism and healing (45). This is becoming an issue since a large portion of patients treated with osseointegrated devices suffer from diseases or conditions that require them to take medications (46).

Identifying all drugs known to affect osseointegration in the literature could help make better informed clinical decisions and guide researchers towards identifying knowledge gaps related to the effect of pharmacological agents on osseointegration (4). However, complex open questions such as "what drugs affect osseointegration?" are too extensive for a conventional systematic review to address. Evidence mapping reviews were developed to address this type of questions (4). This approach consists of mapping the entire medical literature for abroad medical questions 
and visualize a thematic area to establish what the researchers know and do not know about the effects of an intervention. However, the size of the healthcare scientific literature is enormous; thus, full systemic mapping and subject-wide evidence synthesis are usually not feasible (30). Indeed, previous efforts in subject-wide evidence synthesis have been limited because they need to rely on extensive crowdsourcing (30).

Recent advances in artificial intelligence and machine learning could help accelerate the systematic review process by full or semi-automation of the different steps involved in a systematic review $(30,33)$. Indeed many different machine learning (ML) algorithms have been developed to automate screening of systematic reviews (47). These algorithms use text mining to estimate the probability of including or excluding an article based on the inclusion and exclusion decisions made by humans (36). However, most of the algorithms require very large training datasets (i.e., up to 5,749 records) (31), and they are only able to reduce the number of abstracts requiring manual screening by about $50 \%$ (39), saving only $30 \%$ to $70 \%$ of the workload (38).

Very recently, ML has also been used for fully or semi-automated evidence mapping reviews. For example, Juleen Lama et al. published an evidence mapping review on the effect of low-calorie sweeteners (LCS) on health outcomes (5). This mapping review used a semi-automated machine learning approach to tag and categorized the included articles. However, they had to screen $28 \%$ of their articles in order to train their algorithms. Also, the clinical search engine Tripdatabase.com has developed an artificial intelligence (AI) for full automation of evidence mapping (6). However, this prototype has not been validated, and it can only perform automated evidence synthesis for RCT and SR, and it cannot identify and synthesize observational or animal studies (6).

The performance of an AI for text mining depends on the quality of the training datasets and the text used for mining (48). Unfortunately, the traditional search strategies used for systematic 
reviews results in articles that are very similar, which compromises the quality of the training datasets, and the vocabulary used in the scientific literature is often inconsistent and not well controlled.

We could hypothesize that using training datasets with a controlled vocabulary and rich in nonsimilar documents could help overcome the limitations of machine learning algorithms in systematic reviews and systematic mappings.

Medical Subject Headings (MeSH) is a comprehensive controlled vocabulary for indexing journal articles in health sciences that serves as a thesaurus to facilitate searching. Very recently, PubMed has started to use a particular type of Artifical Intelligence based on "natural language understating" to generate high-quality MeSH terms (49). Indeed ML classifiers using PubMed MeSH terms allow for versatile machine learning approaches to screen the scientific literature with promising results surpassing most of the current methods (50).

The objective of this study was to provide a systematic evidence mapping of the literature to address the question, "What drugs could affect bone-implant osseointegration?". To achieve this, we developed a method to generate a ML classifier for automated article screening for systematic mappings. This classifier used MeSH terms and training datasets with similar and non-similar articles. 


\subsection{Materials and Methods}

\subsubsection{Study design}

As figure 1 shows, this study involves four main steps; manual articles screening, ML articles screening, validation of algorithm, and evidence synthesis. This evidence mapping adhered to the PRISMA-Extension for Scoping Reviews (51), and it was carried out according to the methodology of Global Evidence Mapping (GEM) (52), adding suggested components from Ballesteros, Mónica et al. (53). In this study, we used three different search strategies; two specific search strategies, one designed to retrieve similar documents, and another designed to retrieve nonsimilar documents, as well as a highly sensitive search strategy designed to retrieve any relevant documents. The articles retrieved from the specific search strategies were screened manually, whereas the articles identified with the sensitive search strategy were screened using ML. The descriptive map of the included studies involved in-depth syntheses, which assessed study design, drug name, type of study, type of implant, drug doses, route of drug administration, study measurements, and study outcomes (i.e., the effect of the drugs on osseointegration) and the study quality. 


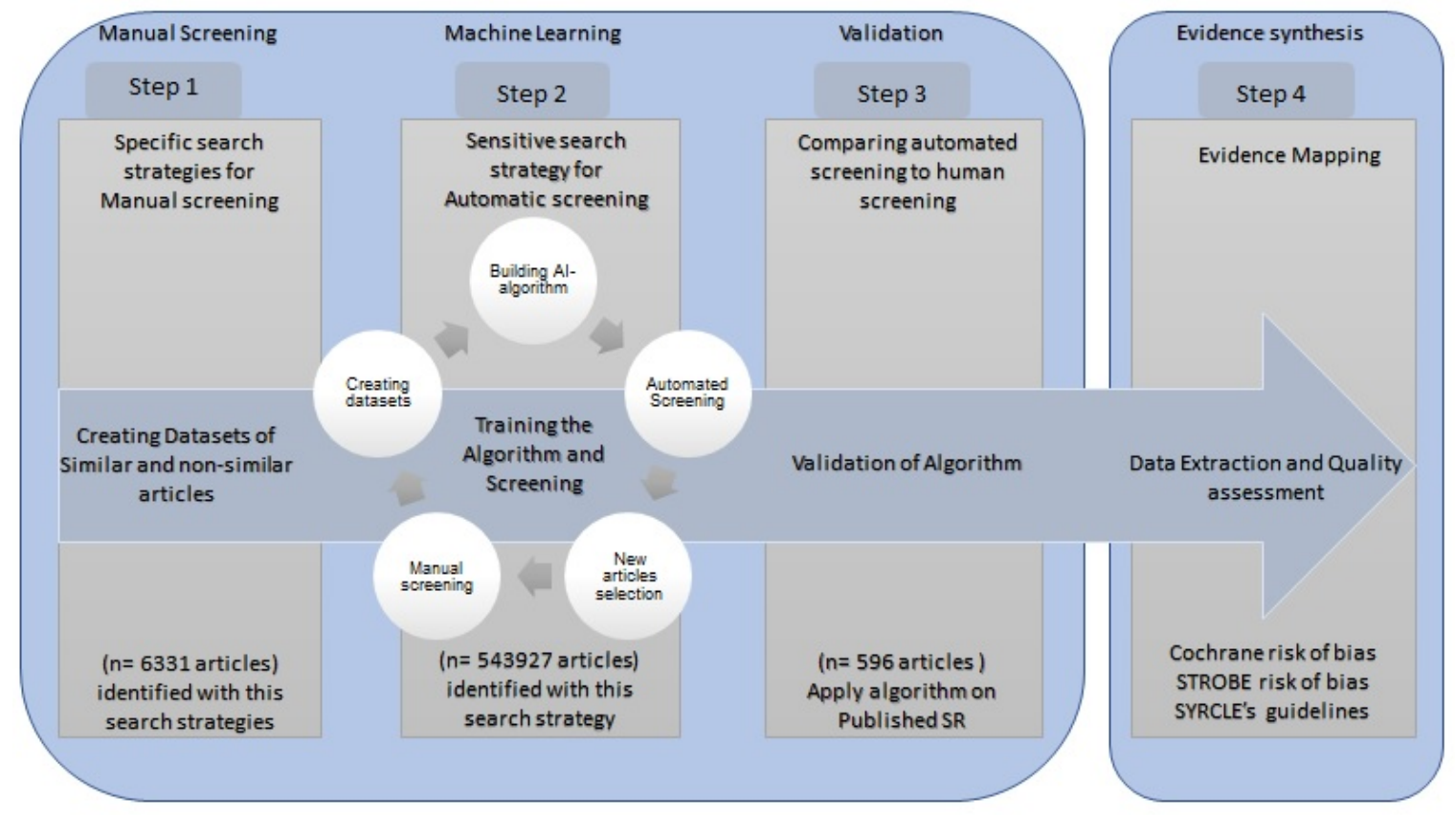

Figure 1: Workflow diagram showing the steps of our Evidence Mapping Review using Machine Learning

\subsubsection{Search strategy (step 1 and 2)}

In this evidence mapping, an electronic search of the MEDLINE databases through the PubMed interface was performed on July 1, 2018, using three different search strategies, as described in Table 1 and also complementary data is available in Appendix A:

- Search strategy A: a specific search strategy that was designed to obtain similar articles. This search strategy was very specific and focused solely on the MeSH-term "osseointegration/drug effects."

- Search strategy B: a specific search strategy that was designed to obtain non-similar articles. This search strategy included an independent search of 553 classes of drugs in PubMed ("Pharmacological actions") and combined them with the MeSH-term "Dental Implants."

- Search strategy C: a highly sensitive search strategy designed to obtain all articles related to osseointegration. This search strategy was designed to identify all relevant articles. However, 
it retrieved many irrelevant studies as well, and it could substantially increase the workload if the screening were to be done manually.

Table 1: Search strategies used in the systematic mapping

\begin{tabular}{|l|l|l|}
\hline Search Method & Pub-Med MeSH terms & $\begin{array}{l}\text { Date of } \\
\text { Search }\end{array}$ \\
\hline $\begin{array}{l}\text { A- Precise Search } \\
\text { Strategy for similar } \\
\text { articles }\end{array}$ & "Osseointegration/drug effects"[MeSH Terms] & \\
\hline $\begin{array}{l}\text { B- Precise Search } \\
\begin{array}{l}\text { Strategy for non- } \\
\text { similar articles }\end{array}\end{array}$ & $\begin{array}{l}\text { ("Dental Implants"[Mesh]) AND ("Pharmacological } \\
\text { action Category ") }\end{array}$ & \multirow{2}{*}{ July 2018} \\
\hline $\begin{array}{l}\text { C- Highly } \\
\text { Sensitive Search }\end{array}$ & $\begin{array}{l}\text { ("Dental Implantation, Endosseous"[Mesh]) OR } \\
\text { ("Dental Implants"[Mesh]) OR } \\
\text { ("Osseointegration"[Mesh]) OR ("Periprosthetic } \\
\text { Fractures"[Mesh]) OR ("Drug Implants"[Mesh]) OR } \\
\text { ("Internal Fixators"[Mesh]) OR ("Hip } \\
\text { Prosthesis"[Mesh]) OR ("Prostheses and } \\
\text { Implants"[Mesh]) OR ("Implants, Experimental"[Mesh] } \\
\text { OR "Bone Screws"[Mesh]) OR ("Prosthesis } \\
\text { Implantation"[Mesh]) }\end{array}$ & \\
\hline
\end{tabular}

\subsubsection{Eligibility criteria (step 1 and 2)}

We included articles published until July 1, 2018, assessing the effect of drugs on bone-implant osseointegration in human subjects as well as in animals. The inclusion criteria were randomized control clinical trials and observational studies on human subjects as well as animal studies assessing the effect of all known drugs on implant survival/success, or bone-implant contact. The exclusion criteria were studies on drugs applied locally, case reports, letters, comments, crosssection studies, editorials, reviews, or conference abstracts, as well as studies on cancer, metastasis, and osteonecrosis. 


\subsubsection{Screening Method (step 1 and 2)}

Screening of articles obtained with the specific search strategies A and B was done manually by two independent calibrated reviewers (MM, AD) according to our inclusion and exclusion criteria (Figure 3). Disagreements between the two reviewers were referred to a third reviewer (FT). The articles retrieved with the highly sensitive search strategy were screened automatically using a machine learning algorithm trained with the articles that were screened manually, as described below.

\subsubsection{Development of a method for automatization of data screening (step 2):}

A script was created in Python to extract the metadata from the included and excluded articles that were screened manually using specific search strategies. The metadata extracted from PubMed included title, abstract, keywords, and MeSH-terms.

The articles classified as 'included or excluded' were used to train a machine-learning algorithm using the software Waikato Environment for Knowledge Analysis (WEKA) developed at the University of Waikato, New Zealand (54). Weka is a widely used open-source machine learning platform that allows us to test, build, and compare different machine learning models (55). We used a support vector machine (SVM) algorithm due to its well-established effectiveness in text mining (56). In our preliminary work, we identified that the best results for classification were obtained by training the algorithm using the publication "MeSH terms," probably because the MeSH terms currently produced by PubMed use a natural language understanding AI that incorporates very relevant semantic value to the terms (49).

During the manual screening process, most articles were excluded, and only a small portion was included. This skewing of data resulted in an imbalance in the training dataset (i.e., a high 
proportion of irrelevant papers), which in turn impaired the performance of the ML classifier (37). To address this issue, we selectively penalized false negatives in the selection process, and we balanced the training dataset. Active prioritization and random sampling were also used to improve the performance of the classifiers (34). Clustering was also used to provide a more coherent organization than topic modeling (34).

The algorithm obtained with the training datasets described above was used for automated screening of the 543927 articles retrieved with the highly sensitive search strategy (search strategy C). The articles were screened in batches of 100,000 articles (Figure 2). After the automated screening of a batch, the articles included by the algorithm were screened manually for verification (Figure 2). The results of this manual screening were added to the training datasets, and the algorithm was updated accordingly (Figure 2). The process was repeated with subsequent batches until no more new articles could be identified by the algorithm (Figure 2).

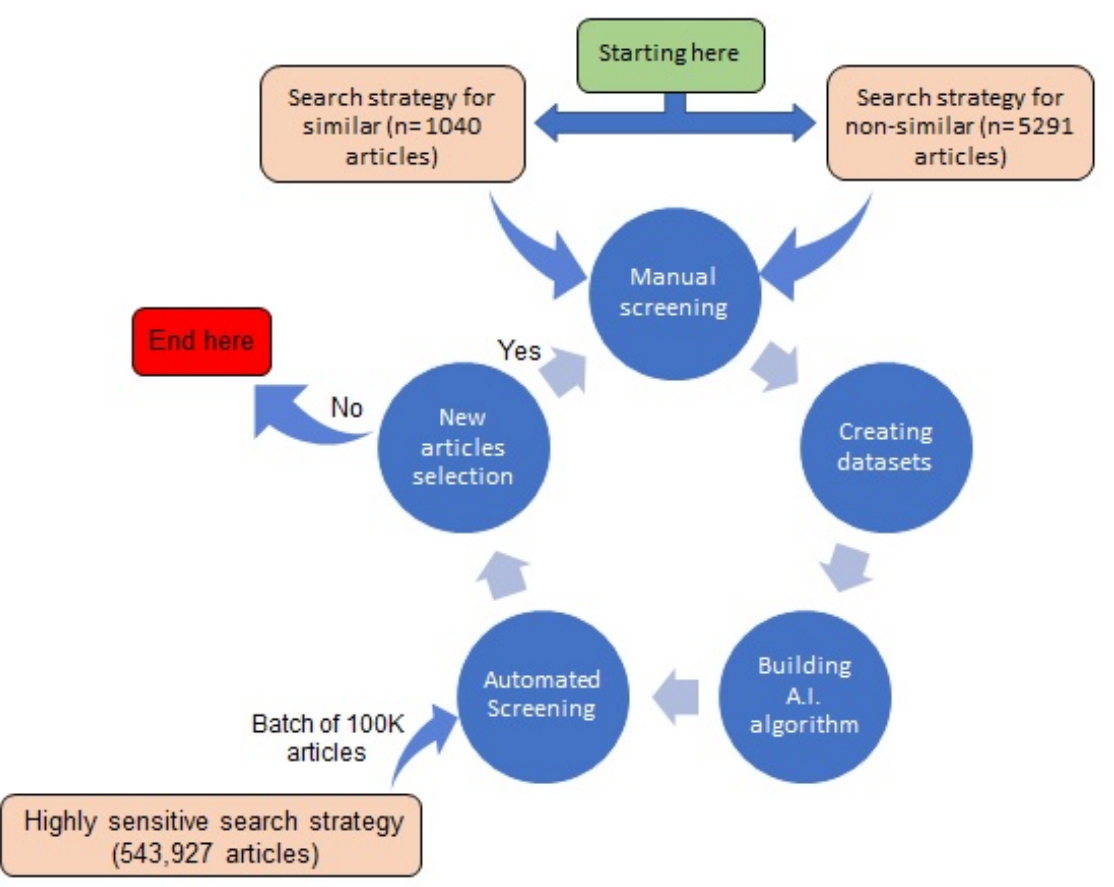

Figure 2: Workflow diagram showing the process of screening the literature in our systematic mapping. 


\subsubsection{Validation of the method for automated data screening (step 3):}

To validate the method developed for automatic screening, we tested the algorithm against an already published systematic review with a search strategy that falls within the scope of ours (3). The included and excluded articles in this previously published systematic review were kindly provided by the authors (Table 2) and used to test our algorithm and estimate its accuracy, sensitivity, and specificity.

\subsubsection{Data Extraction (step 4)}

After study selection, the following general characteristics were extracted from each included article: first author's surname, study design, drug name, type of study, mean age, gender, sample size, type of implant, drug doses, route of drug administration, follow-up time, measurements, outcome, geographical location, year published and reference; complementary data is available in Appendix B.

To identify the research questions of each study, we used the PICO framework, which specifies the four key elements; population, intervention, comparison, and outcomes (57). We only considered the articles in which the research question and all the elements of the PICO framework were provided, and a conclusion of the drug effects on bone-implant osseointegration was clearly described. The population and animal characteristics (e.g., gender, mean age, and implants location), the intervention (e.g., drug type, drug doses, route of drug administration), comparison

(such as placebo), and measurements (implant survival, bone-implant contact, implant push-out test, implant pull-out test, peri-implant bone volume, and force-torque test ) and the outcomes were extracted in details; complementary data is available in Appendix B. 
The conclusions of the included articles were divided into three categories depending on the outcome, similarly to previous studies (53). If the conclusion of the included articles showed clearly and in an indicative language without major concerns regarding the existing evidence that the drug enhanced or improved the bone-implant osseointegration, we considered the outcome as a "positive effect." If the conclusion of the included article showed clearly and in indicative language that the drug impaired or negatively influenced bone-implant osseointegration, we considered the outcome as a "negative effect." Finally, If the conclusion of the included articles showed clearly and in indicative language that the drug showed no effect, not negative or no positive effect on bone-implant osseointegration, we considered the outcome as "no effect."

\subsubsection{Quality assessment and risk of bias (step 4)}

Two reviewers assessed the methodological and reporting quality of all selected studies independently (AD, RR). Disagreements between the two reviewers were referred and discussed with a third reviewer (FT). The animal studies were assessed according to SYRCLE's guidelines (58), clinical trials were assessed using Cochrane risk of bias tool for randomized controlled trials (59), and the STROBE quality assessment tool was used for the observational studies (60).

\subsubsection{Evidence mapping presentation (step 4)}

The demographic characteristics of the included studies, methodology, measurements used to analyze osseointegration, and the main outcomes and the quality assessment were described on tables. We performed a narrative description for the included studies, including study design, type of implant, drug name, doses, and route of administration, and specific outcome. Bubble plots were used to represent the number of studies per drug, their quality, and their effect on osseointegration. The bubble charts showed the information in three dimensions: 1) the x-axis represented the effect 
of drugs on bone-implant osseointegration as "negative," "no effect," "positive"; 2) the y-axis represented level of evidence per each drug on STROBE assessment and Cochrane risk of bias for human clinical subjects and SYRCLE's guidelines for animal studies as "poor," "fair," "good"; and 3) the number of studies included for each drug was represented by the bubble size.

\subsection{Results}

\subsubsection{Study Selection}

The similar specific search strategy identified 1040 articles, the non-similar specific search strategy identified 5291 articles, and the highly sensitive search strategy identified 543927 articles. The 6331 articles identified with similar and non-similar specific search strategies were screened manually. From those articles, 250 articles were selected for full-text assessment studies, 155 were included, and 6176 were excluded. The datasets of included and excluded articles were then used to train a machine-learning algorithm. The trained algorithm was then used to screen the articles identified with the highly sensitive search strategy (543927 articles). Eventually, a total of 268 included studies were finally selected. The Flow diagram in figure 3 represents the study selection process. 


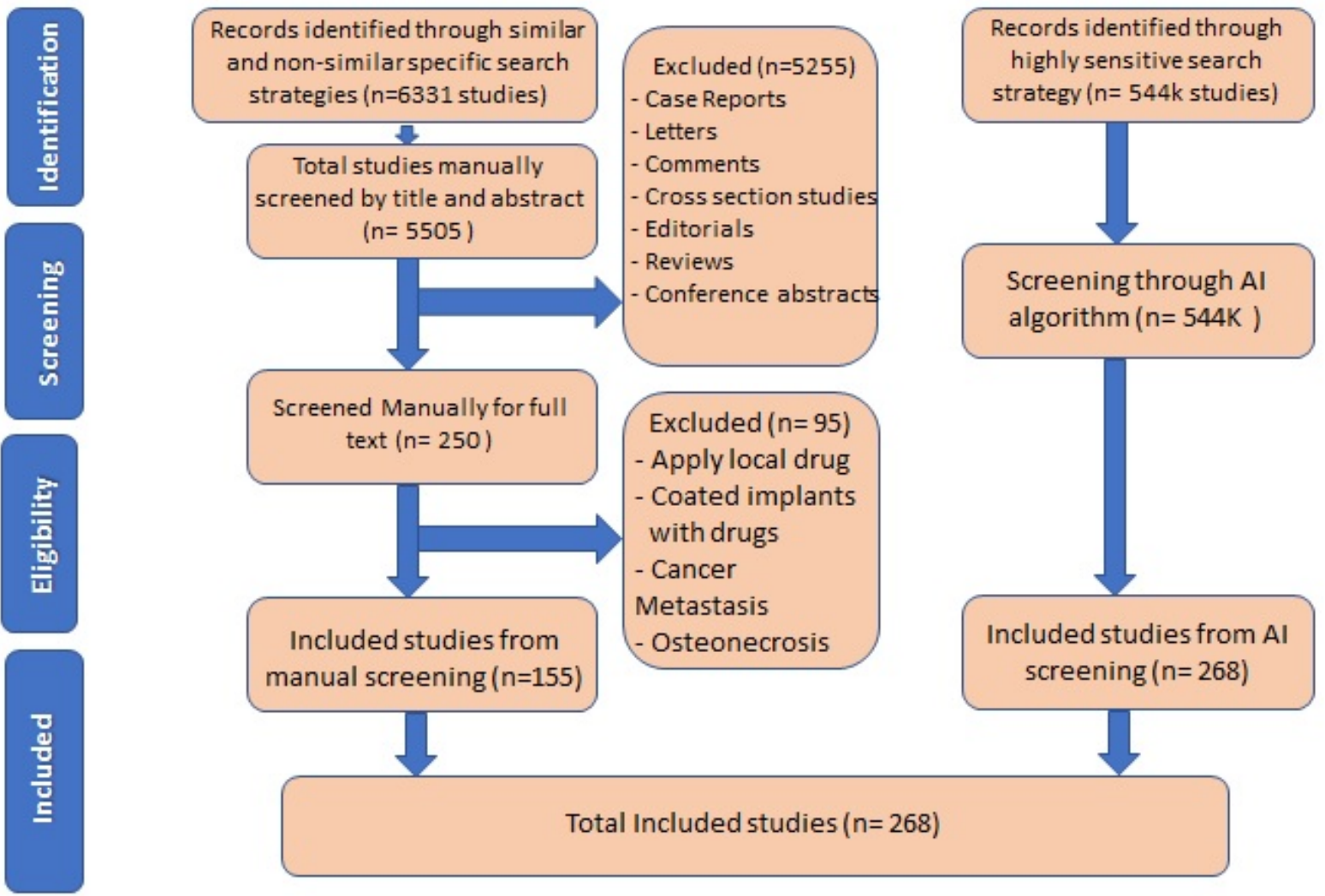

Figure 3: Flow diagram of the study selection process.

\subsubsection{Building the algorithm and improving its selection performance}

As described in Figure 4, the initial performance of the algorithm presented a low rate of true positive selection; however, after each reiteration, the size of the training datasets increased, and the algorithm performance improved. The training dataset was progressively increased until reaching a threshold beyond which the algorithm was not able to identify any new articles. This was achieved by screening 8121 articles, $1.49 \%$ of the total dataset. We were screening all articles twice in two subsequent rounds until reaching the plateau. 

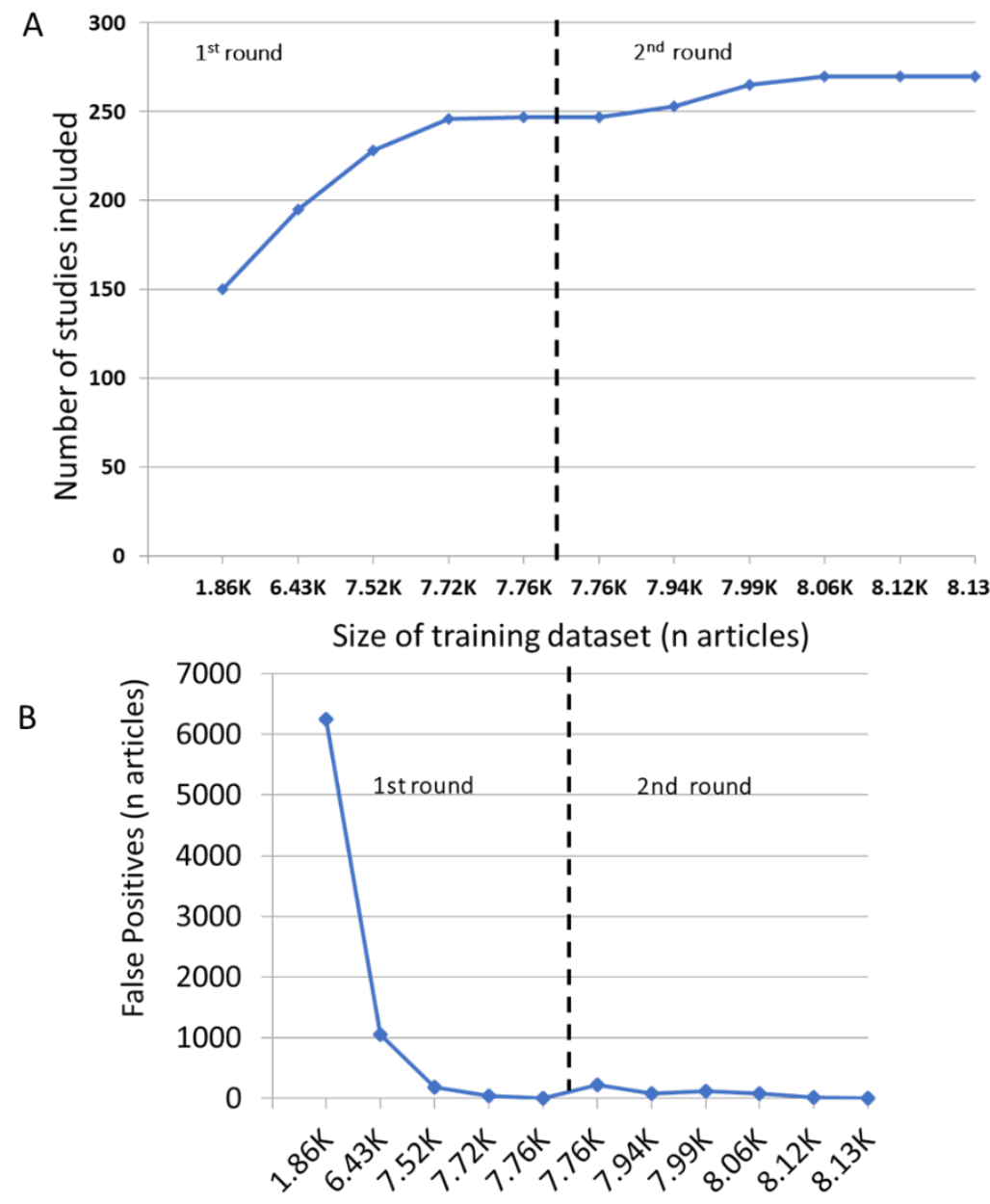

Size of training dataset ( $\mathrm{n}$ articles)

Figure 4: Performance of the algorithm as a function of the training dataset. A: Graph depicting the number of articles included as a function of the size of the training data set. As the size of the training datasets increased, the number of included articles identified by our algorithm also increased. Reaching a plateau at 268 articles with a training dataset of $8.12 \mathrm{k}$ articles, then the algorithm was ready to be applied. B: Graph depicting the number of false-positive articles as a function of the size of the training data set. The selection of false-positive articles decreased exponentially as the size of the training dataset increased. Through the second screening (Re-Run, $2^{\text {nd }}$ round) of our dataset, we were able to reduce false-positive articles from 6449 to 20 articles.

\subsubsection{Performance of the algorithm}

The initial performance of the algorithm presented a high rate of false-positive; however, after each reiteration, the performance improved until reaching a very high recall and precision, Figure

4. 


\subsubsection{Validation of the method for data screening}

With a previously published systematic review, 17/596 articles were a part of the selected articles in this published systematic review. AI was able to identify $13 / 17$ of all relevant articles with an accuracy of $95 \%$, a False Positive Rate (TFP) of 95\%, a precision of 30\%, a sensitivity of $93 \%$, and a specificity of $95 \%$. Also, the algorithm has the ability to reduce the workload up to $95 \%$, Table 2 . However, the AI correctly discarded 3/17 articles because they did not meet our inclusion criteria which is our training datasets, one article was about case reports, second was about osteoporosis and bisphosphonate-related osteonecrosis, third was about analysis of risk factors for cluster behavior, and one incorrectly discarded as a false negative.

Table 2: Validation of the algorithm

\begin{tabular}{lc}
\hline Validation of Algorithm Using a Published Systematic Review \\
\hline True positives (TP) & 13 \\
False negatives (FN) & 1 \\
True negatives (TN) & 551 \\
False Positives (FP) & 31 \\
False Positive Rate (FPR) & $95 \%$ \\
Workload reduction & $95 \%$ \\
Sensitivity & $93 \%$ \\
Specificity & $95 \%$ \\
Accuracy & $95 \%$ \\
Precision & $30 \%$ \\
\hline
\end{tabular}

We validated our algorithm against a published systematic review in which 596 articles were screened and 14 RCT and observational studies were included.

The AI screening method identified 268 articles of the 543927 articles retrieved from the highly sensitive search strategy. This includes the 155 articles retrieved from the manual screening of the articles retrieved with the specific search strategies and another 113 articles that were only 
identified using our AI screening methods, Figures 5 and 6 . Among the included studies, there were 192 animal studies and 76 human subjects' studies, Figures 10, 11, and 12. The animal and human studies assessed 31 drugs. Among these, 29 drugs were investigated in animals, and 14 drugs were studied in humans.

The quality assessment of the studies was stratified according to the drug category and type of study. RCTs on NSAID, Bupivacaine without vasoconstriction, Bisphosphonates, Parathyroid hormone replacement therapy, Vitamin D, and Thyroid hormone replacement therapy presented poor to fair quality, and the RCT on Antibiotics (amoxicillin) was the only one that showed good quality (figure 7 and also complementary data is available in Appendix E). For observational studies on Bisphosphonate, NSAID, Chemotherapy, Parathyroid hormone replacement therapy, Vitamin D, Xianlinggubao, Thyroid hormone replacement therapy, and Antibiotic (Penicillin) presented high to moderate risk of bias, studies on Antihypertensives, SSRI, Statins, and PPI presented low to moderate risk of bias, and Corticosteroid, Testosterone hormone replacement therapy, and Estrogen hormone replacement therapy presented moderate risk of bias (figure 8 and also complementary data is available in Appendix F). For animal studies, those assessing Bisphosphonate, NSAID, Chemotherapy, Immunosuppressive therapy, Sex hormone replacement therapy, Statin, Aprotinin, Thyroid hormonal replacement therapy, Parathyroid hormone replacement therapy, Nicotine, Strontium ranelate, Vitamin D, Sclerostin antibody, Oxytocin, Warfarin, Anti Diabetic, Alcohol, Antihypertensives, Antibiotics, Hyperbaric oxygen therapy (HBO), Prostaglandin EP4 receptor agonist, Cannabis, Melatonin, Lithium chloride, and Corticosteroid presented high to moderate risk of bias (figure 9 and also complementary data is available in Appendix C). Studies on Proton-Pump Inhibitor (PPI), Aprotinin, and Anti-vascular 
endothelial growth factors (VEGF) presented low to moderate risk of bias (figure 9 and also complementary data is available in Appendix C).

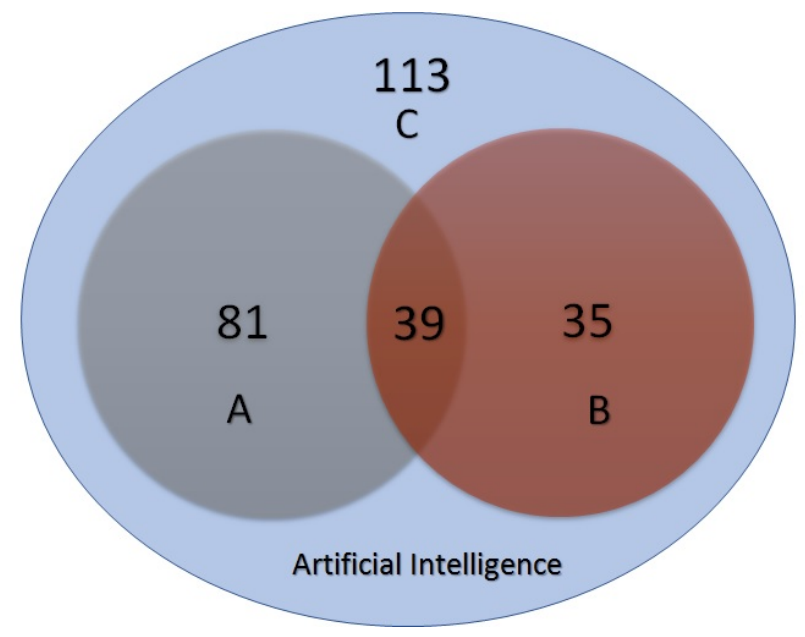

Figure 5: Venn diagram showing the number of articles identified with each screening method and search strategy. A-represents the articles screened manually from the specific search strategy for similar studies, B- represents the articles screened manually from the specific search strategy for non-similar studies, C-represents the new articles screened by AI from the highly sensitive search strategy.

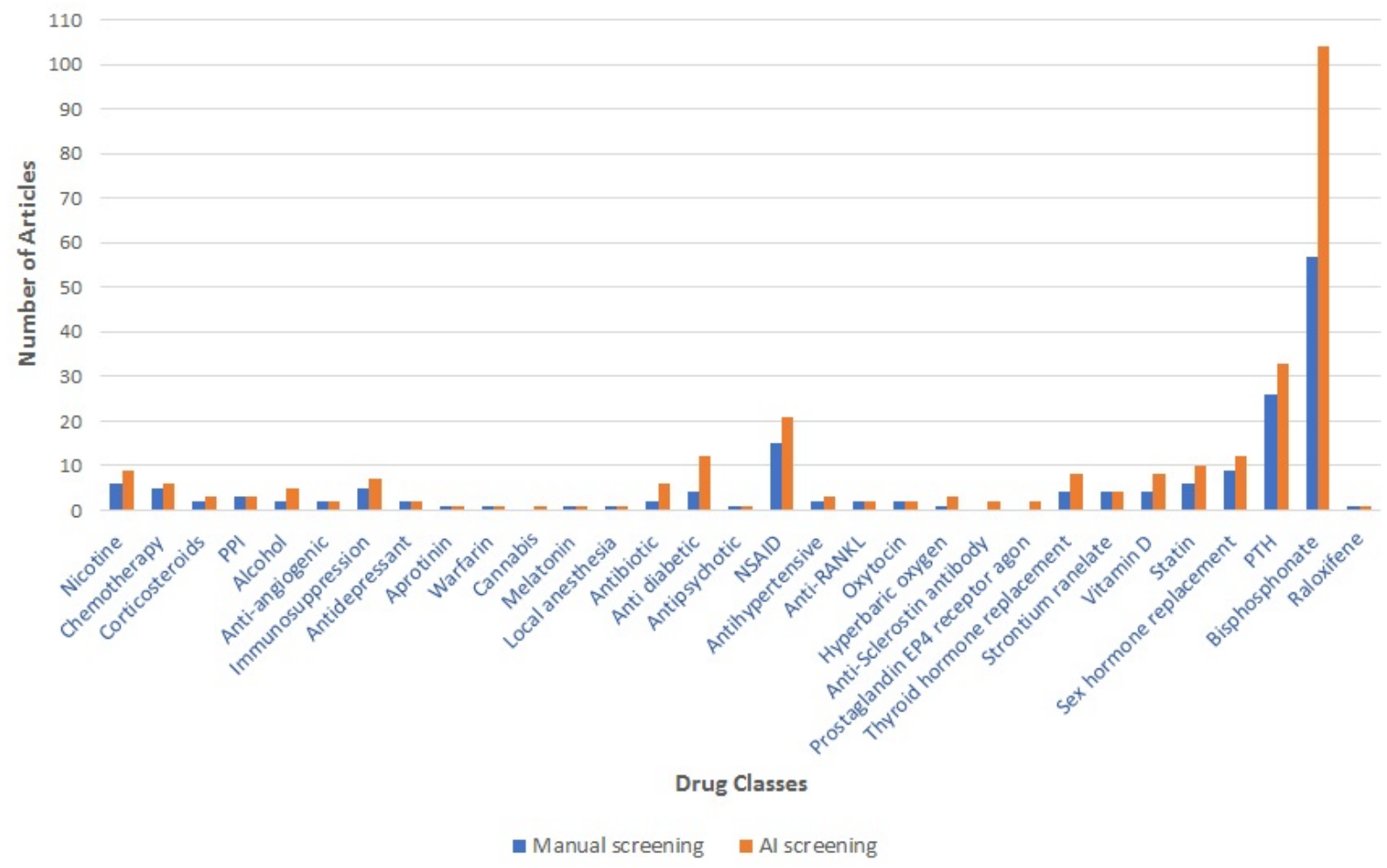

Figure 6: Number of studies included for each drug as a function of the screening methods (A.I. or manual screen). 


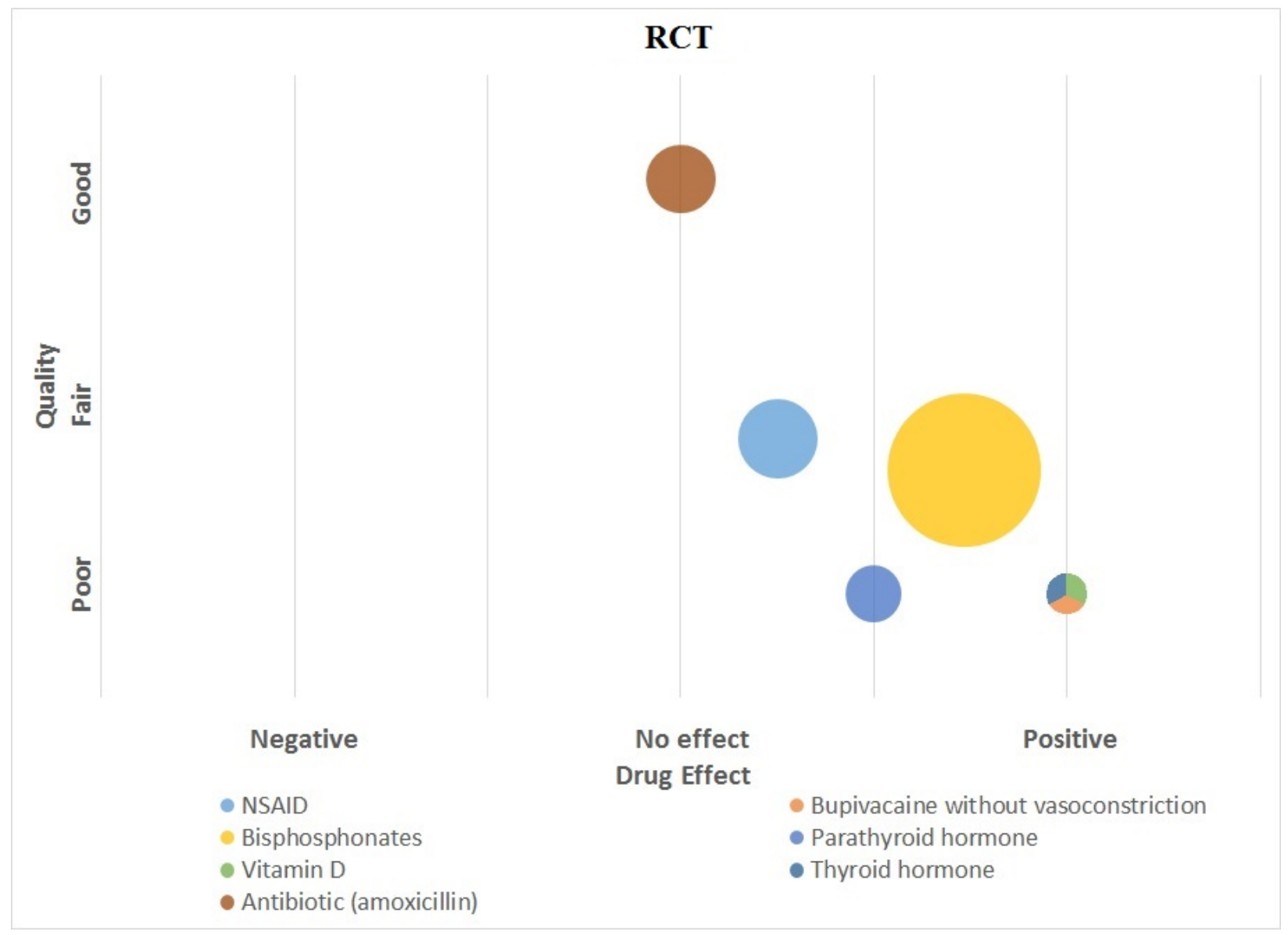

Figure 7: Bubble plot for RCT representing the number of studies per drug, the quality of the studies, and the effect of the drugs on osseointegration for each study. The $y$-axis represents the quality of the study according to the risk of bias tool. The $x$-axis notates the drug effect on osseointegration. The size of the bubble indicates the number of articles per drug. When the bubble shows more than one color it means there are two different drugs that have the same number of studies, the same quality, and the same effect on osseointegration. 


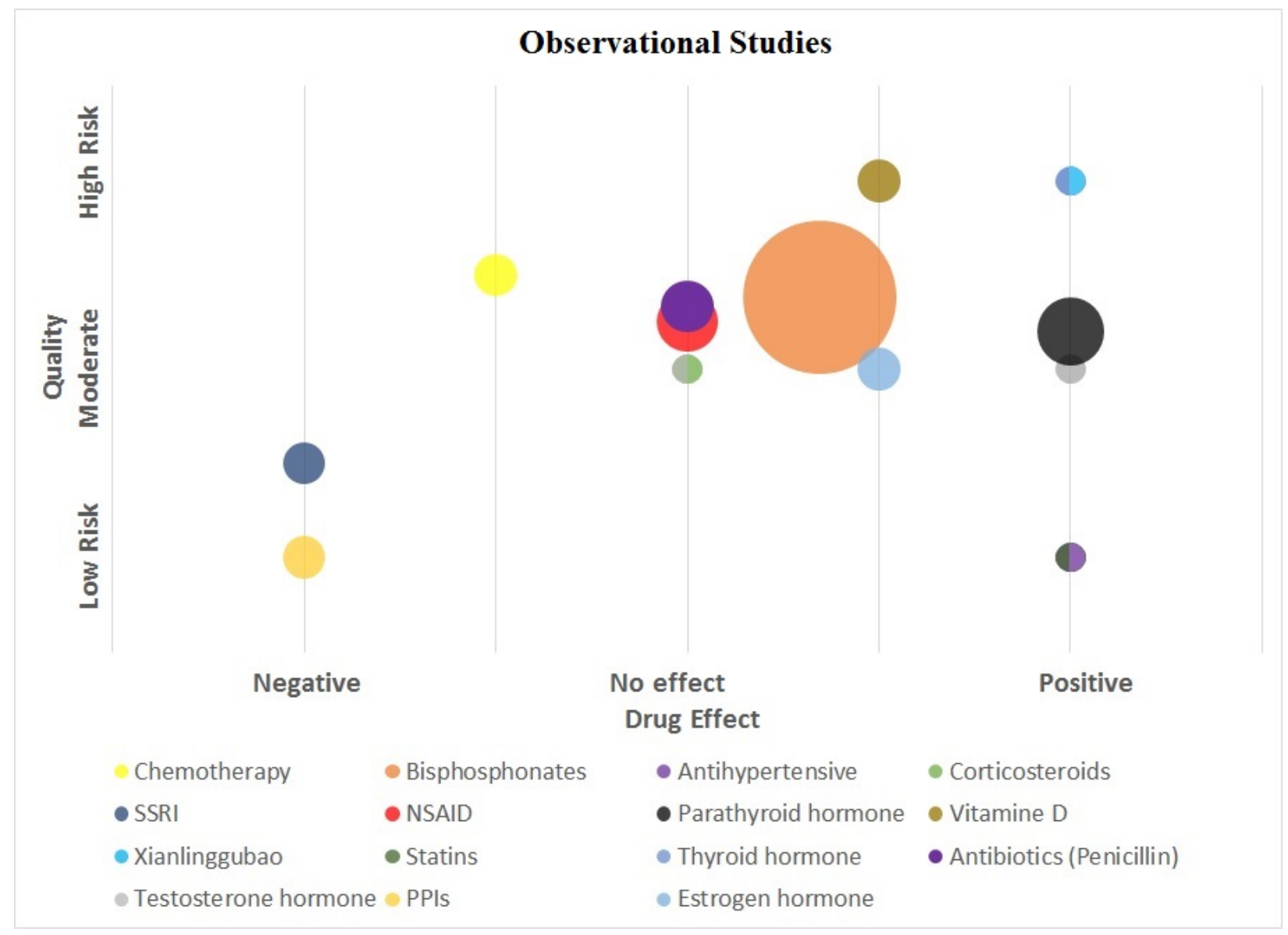

Figure 8: Bubble plot for observational studies representing the number of studies per drug, the quality of the studies, and the effect of the drugs on osseointegration for each study. The $y$-axis represents the quality of the study according to the risk of bias tool. The $x$-axis notates the drug effect on osseointegration. The size of the bubble indicates the number of articles per drug. When the bubble shows more than one color it means there are two different drugs that have the same number of studies, the same quality, and the same effect on osseointegration. 


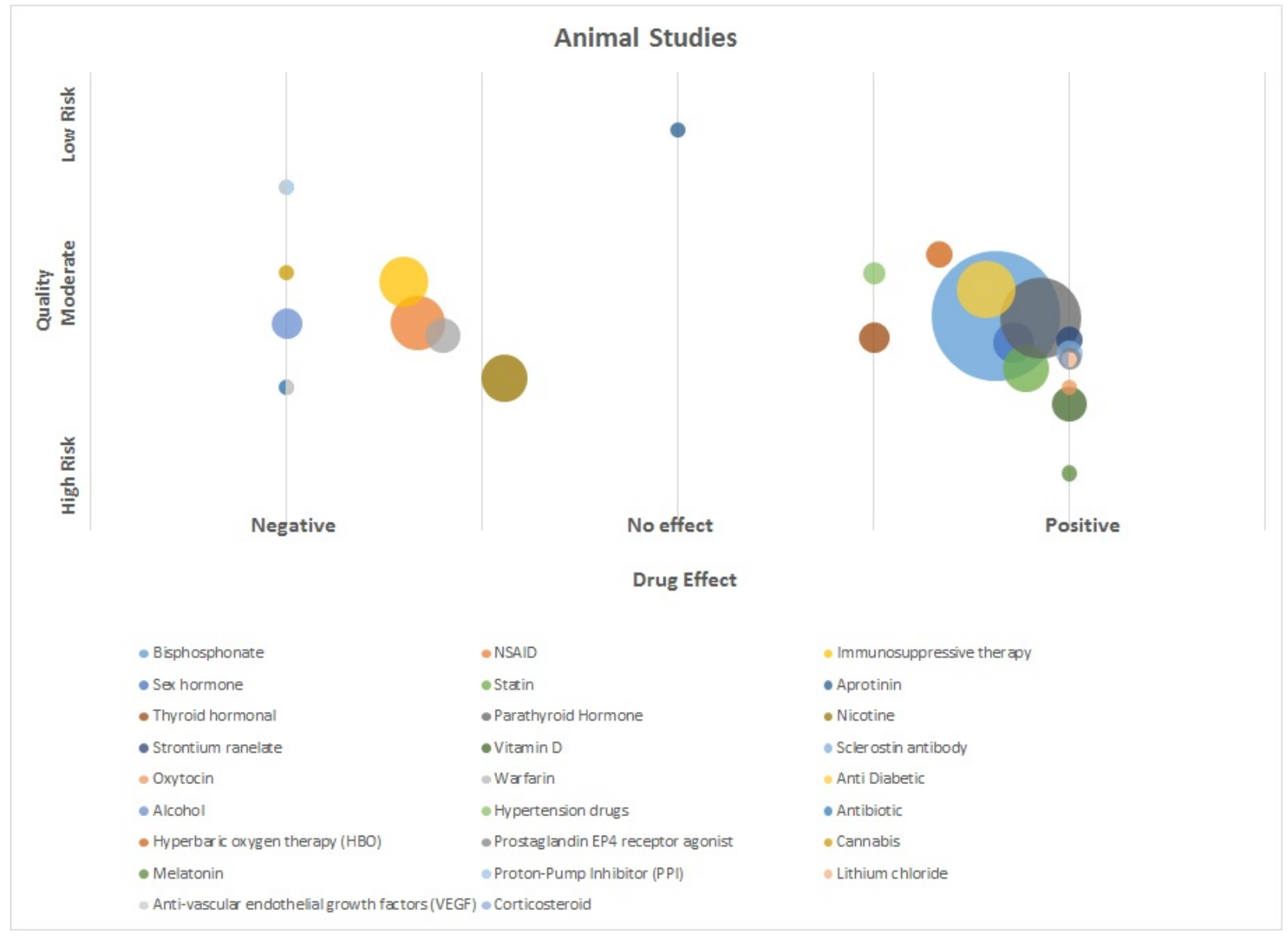

Figure 9: Bubble plot for animal studies representing the number of studies per drug, the quality of the studies, and the effect of the drugs on osseointegration for each study. The $y$-axis represents the quality of the study according to the risk of bias tool. The $x$-axis notates the drug effect on osseointegration. The size of the bubble indicates the number of articles per drug. When the bubble shows more than one color it means there are two different drugs that have the same number of studies, the same quality, and the same effect on osseointegration. 


\section{Effect of Drugs on Bone Implant Osseointegration in In vivo and Clinical Studies}

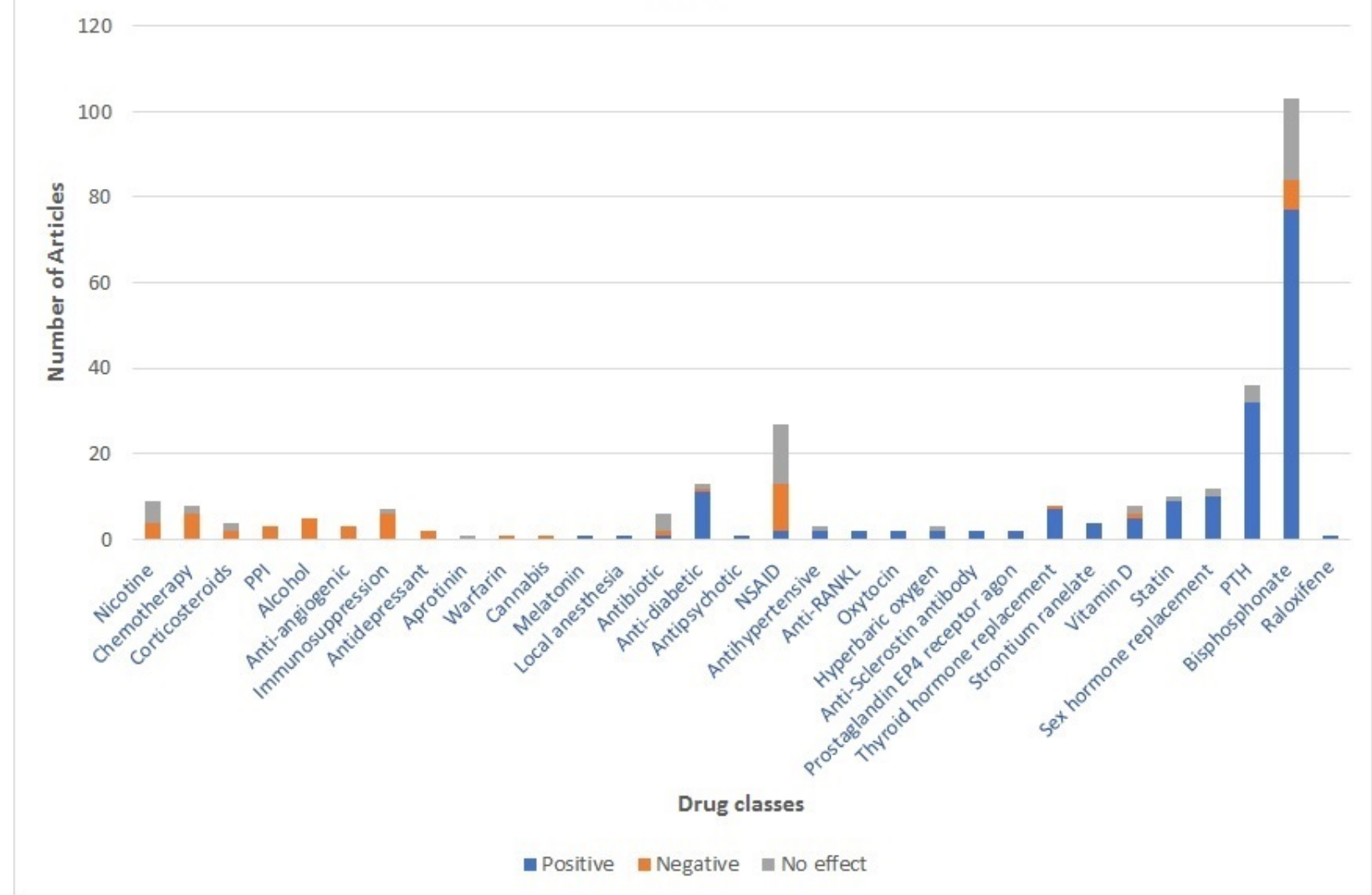

Figure 10: The effect of drugs on bone-implant osseointegration in the included in vivo and clinical studies 


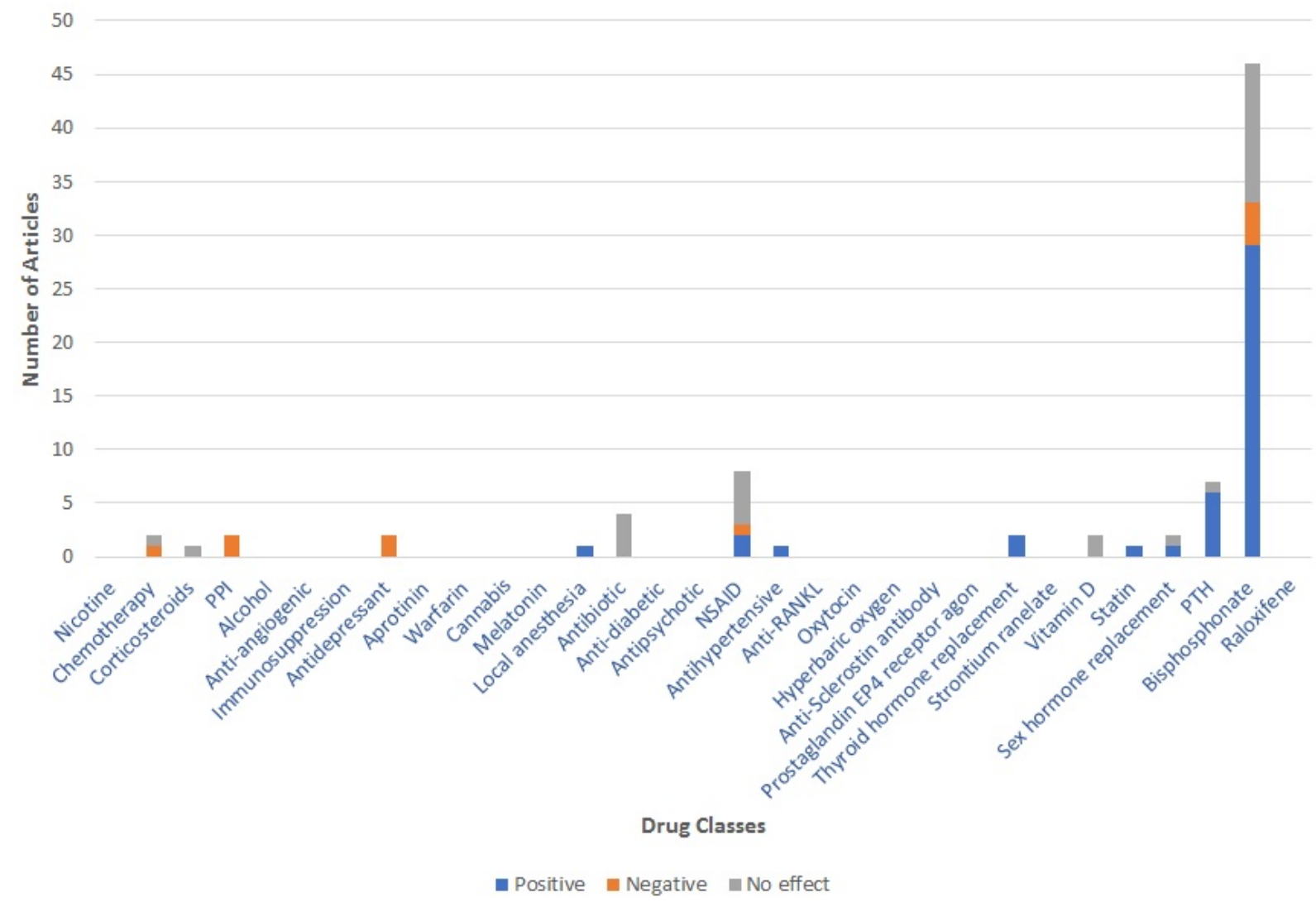

Figure 11: The effects of drugs on bone-implant osseointegration in the included clinical studies. 


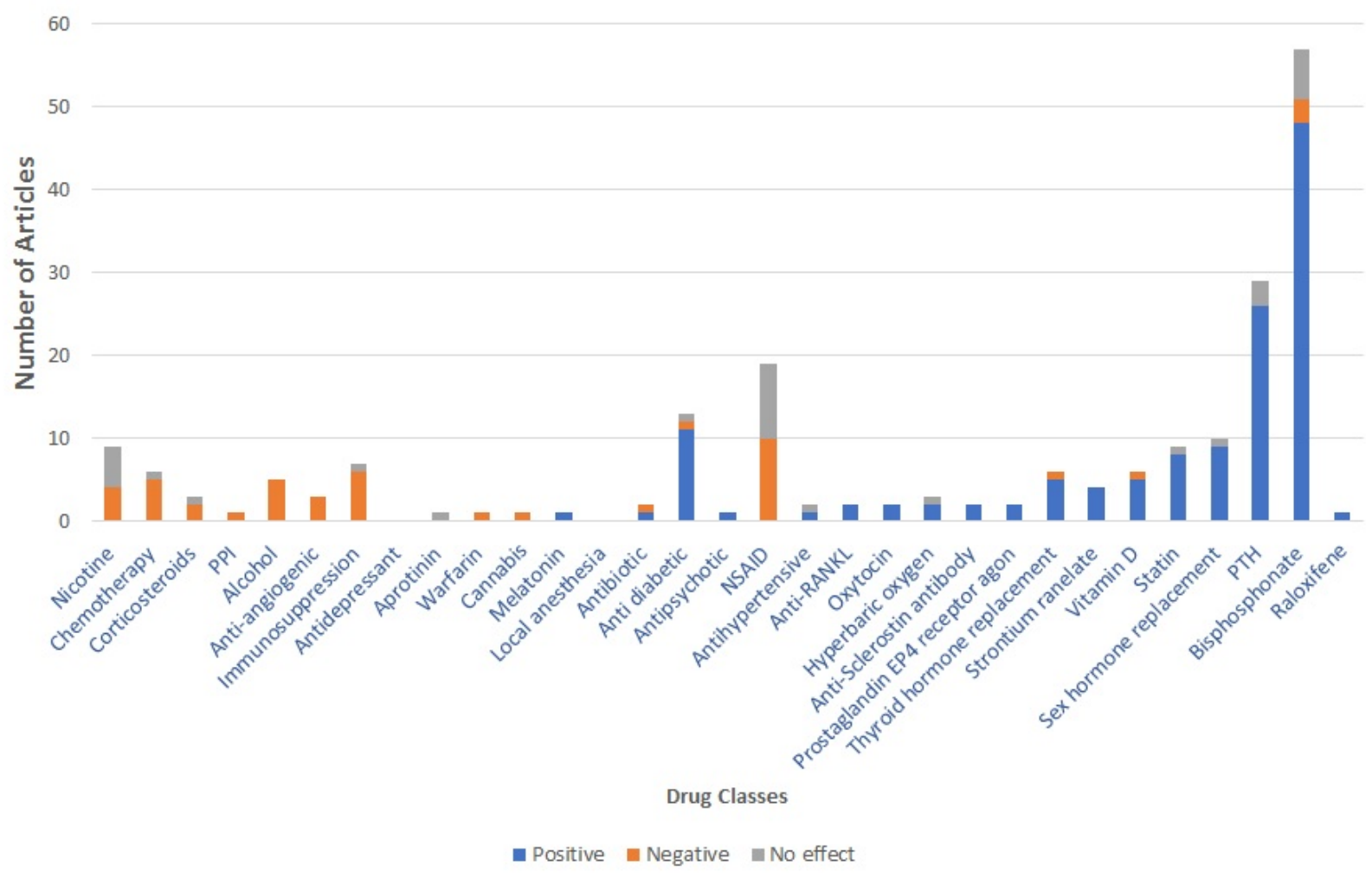

Figure 12: The Effects of drugs on bone-implant osseointegration in the included in vivo studies

Table 3 summarizes the number of articles identified per drug category as a function of the screening methods used to identify the study, the type of study, and the study outcome regarding the effect of the drug on osseointegration. Two hundred sixty-eight studies were included in this review (Table 3) and were identified by the highly sensitive search strategy using A.I. Only one hundred fifty-five of these articles were identified with specific search strategies using manual screening. Out of this, thirty-one drug categories were identified, and eight of these drugs were also used in combination with other drugs as (Table 3 and Figures 6, 10, 11, and 12).

\subsection{5 drugs effects on bone-implant osseointegration:}

Underneath were described in detail the findings on each of the drugs identified in our review.

\subsubsection{Anti-osteoporosis Drugs}




\subsection{Bisphosphonate}

Different bisphosphonate medications have been assessed for their impact on bone-implant osseointegration these include alendronate, disodium diphosphonate, zoledronic acid, risedronate, TRK-530, YM-175, pamidronate, ibandronate, clodronate, etidronate, and tiludronate. The use of unspecified doses of bisphosphonates was associated with a low risk of implant failure in four cohort studies, two of these were retrospective studies on total knee and hip arthroplasty, one was a retrospective study on total knee arthroplasty, and one was a prospective study on lumbar fusion (61-64). However, the use of unspecified doses of bisphosphonates was associated with a high risk of implant failure in one retrospective cohort study on dental implants (65). On the other hand, the use of unspecified doses of bisphosphonates had no significant effect on implant failure in six retrospective cohort studies on dental implants (66-71). Underneath, we discuss the literature on the specific types of bisphosphonates.

\subsection{Zoledronic Acid}

In human studies, use of zoledronic acid ( 4 and $5 \mathrm{mg}$ ) was associated with a low risk of implant failure in three Randomized Control Trials (two double-blinded and one open-label), two on total hip arthroplasty and one on dental implants (72-74). However, a dose of $5 \mathrm{mg}$ had no significant effect on implant failure in one prospective study on dental implants (75).

In thirteen animal studies, pre-operative and post-operative intravenous and subcutaneous administration of zoledronic acid (0.01-0.6 mg/kg/every 3-4 weeks) was found to have a positive effect on osseointegration (76-88). Five studies were on rats (four of them on ovariectomized rats), six studies on rabbits (three of them on ovariectomized rabbits), one on dogs, one on sheep, and one on mice. Five of these studies used Hydroxyapatite (HA)-coated titanium implants, four used screw titanium implants, three used nonspecific titanium implants, one used titanium rods, and one 
used cylindrical porous implant. Bone-to-implant contact, peri-implant bone volume, removal torque force test and push-out force test analyses showed that systemic administration of zoledronic acid improved BIO.

On the other hand, pre-operative and post-operative intravenous administration of zoledronic acid $(0.0075-0.1 \mathrm{mg} / \mathrm{kg} /$ every $0.5-4$ weeks $)$ was found to have a negative effect on osseointegration in four animal studies (89-92). Two of these studies were on dogs, one on rabbits, and one on sheep. Three of these studies used screw titanium implants, and one used Hydroxyapatite (HA)-coated titanium implants. Bone-to-implant contact and peri-implant bone volume analyses showed that zoledronic acid impaired BIO.

Postoperative intravenous and subcutaneous administration of zoledronic acid (0.0075-0.1 $\mathrm{mg} / \mathrm{kg} /$ every week) was found to have no effect on osseointegration in two animal studies $(93,94)$, one on ovariectomized rats and the other one on non-ovariectomized rats. One of these studies used dental titanium implants, and the other one used cylindrical titanium implants. Bone-toimplant contact, peri-implant bone volume analyses showed that zoledronic acid had no effect on BIO. Preoperative intramuscular administration of zoledronic acid $(0.01 \mathrm{mg} / \mathrm{kg} / \mathrm{twice}$ a week $)$ combined with dexamethasone $(1 \mathrm{mg} / \mathrm{kg} /$ twice a week) was found to have a negative effect on osseointegration in one study on rabbits (92). However, postoperative administration of zoledronic $\operatorname{acid}(7.5 \mu \mathrm{g} / \mathrm{kg} /$ once a week, IV) combined with dexamethasone $(1 \mathrm{mg} / \mathrm{kg}, \mathrm{IM})$ was found to have no effect on osseointegration in one study on rats (94). Moreover, postoperative administration of zoledronic acid $(7.5 \mu \mathrm{g} / \mathrm{kg} /$ once a week, IV) combined with methylprednisolone $(0.35 \mathrm{mg} / \mathrm{kg}, \mathrm{SC})$ was found to have a positive effect on osseointegration in one study on rabbits (95). 


\subsection{Alendronate}

In human studies, use of alendronate (5-35 mg/day, or $70 \mathrm{mg} /$ once a week ) was associated with low risk of implant failure in one retrospective study on total knee arthroplasty, two prospective studies on total hip arthroplasty and total knee arthroplasty, respectively, and eleven Randomized Control Trials (two double-blinded, and two single-blinded); among the RCTs, nine were on total hip arthroplasty, and two were on total knee arthroplasty (96-109). Also, the use of alendronate (70 mg/once a week ) combined with Xianlinggubao (phytoestrogen-rich natural product) (three times a day) was associated with a low risk of implant failure in one Randomized Control Trial on total hip arthroplasty (110).

However, the use of alendronate $(4,6$, or $10 \mathrm{mg} /$ day) was associated with a high risk of implant failure in two retrospective cohort studies on dental implants $(111,112)$.

The use of alendronate (10 mg/a day, or $70 \mathrm{mg} /$ week) had no significant effect on implant failure in two Randomized Control trial studies on total knee arthroplasty and two retrospective cohort studies on dental implants (113-116).

In animal studies, pre-operative and post-operative oral, intraperitoneal and subcutaneous administration of alendronate $(0.02-10 \mathrm{mg} / \mathrm{kg} / \mathrm{daily}, \quad 0.2-10 \mathrm{mg} / \mathrm{kg} / \mathrm{once}$ a week, $0.07-1$ $\mathrm{mg} / \mathrm{kg} /$ twice a week, and, $0.0025-5 \mathrm{mg} / \mathrm{kg} /$ three time a week) was found to have a positive effect on osseointegration in twenty five animal studies $(76,117-141)$. Twenty-one studies on rats (twelve of them on ovariectomized rats), two on dogs, two studies on rabbits (one of them on ovariectomized rabbits and one on non-ovariectomized rabbits), and one on pigs. Seventeen of these studies used titanium implants ( 9 screws, 3 Hydroxyapatite (HA)-coated, 4 cylindrical, one costume), two used screw non-titanium implants, one used titanium plates, one used polyethylene 
implants, one used cylindrical polymethylmethacrylate plugs, one spine pedicle screws, one used stainless-steel implants, one used Polymethylmethacrylate cement rods implants, and one did not mention the type of implants. Bone-to-implant contact, peri-implant bone volume, removal torque force test, pull-out force test, and push-out force test analyses showed that alendronate improved BIO.

On the other hand, postoperative subcutaneous administration of alendronate $(1 \mathrm{mg} / \mathrm{kg} / \mathrm{twice}$ a week) was found to have a negative effect on osseointegration in one animal study on rats (142). This study used custom made titanium implants, and it showed that alendronate impaired bone-toimplant contact.

Moreover, pre-operative and post-operative oral and subcutaneous administration of alendronate $(0.063 \mathrm{mg} / \mathrm{kg} /$ daily, $0.1 \mathrm{mg} / \mathrm{kg} / \mathrm{twice}$ a week, $2.5 \mu \mathrm{g} / \mathrm{kg} /$ three-time week, $6 \mathrm{mg} / \mathrm{kg} /$ daily or 10 $\mathrm{mg} / \mathrm{kg} /$ once a week) was found to have no effect on osseointegration in five animal studies (143148). Two of these studies were on rabbits (one of them on ovariectomized rabbits), two on nonovariectomized rats, and two on dogs (one of them on ovariectomized dogs). Four of these studies used screw-shaped titanium implants, one used titanium plates, and one used cylindrical titanium implants. Bone-to-implant contact and peri-implant bone volume analyses showed that systemic administration of alendronate did not affect on BIO.

\subsection{Disodium Diphosphonate}

In animal studies, postoperative subcutaneous administration of disodium diphosphonate (0.1-5 $\mathrm{mg} / \mathrm{kg} /$ day) was found to have a positive effect on osseointegration in one animal study on rabbits (149). This study used porous titanium fiber-mesh implants, and it showed that disodium diphosphonate improved bone-to-implant contact and peri-implant bone volume. 


\subsection{Ibandronate}

In animal studies, postoperative subcutaneous administration of ibandronate $(1.0-25 \mu \mathrm{g} / \mathrm{kg} / \mathrm{day}$ or $700 \mu \mathrm{g} / \mathrm{kg} / \mathrm{single}$ dose ) was found to have a positive effect on osseointegration in five studies on rats (one of them ovariectomized rats) (150-154). These studies used hydroxyapatite (HA)coated titanium implants, and they showed that ibandronate enhanced bone-to-implant contact and peri-implant bone volume.

\subsection{Clodronate}

In human studies, use of clodronate $(100,400$, and $1600 \mathrm{mg} / \mathrm{kg} /$ daily $)$ was associated with a low risk of implant failure in three Randomized Control Trials (two of them double-blinded), two on total knee arthroplasty and one on total hip arthroplasty (155-157).

In animal studies, postoperative subcutaneous administration of clodronate $(0.12$, and $21 \mathrm{mg} / \mathrm{kg} / 3$ times a week) was found to have a positive effect on osseointegration in one animal study on rats using titanium plates (123). This study showed that clodronate enhanced bone-to-implant contact.

\subsection{Risedronate}

In human studies, use of risedronate $(2.5$ or $35 \mathrm{mg} / \mathrm{kg} /$ daily or $35 \mathrm{mg} / \mathrm{kg} /$ once a week) was associated with a low risk of implant failure in two prospective cohort studies, one on total hip arthroplasty and another on posterior lumbar bone, as well as in two Randomized Control Trials (one of them double-blinded) on total hip arthroplasty $(99,158-160)$.

On the other hand, use of risedronate $(35 \mathrm{mg} / \mathrm{kg} /$ once a week) was not associated with implant failure in one double-blind Randomized Control Trial on total hip arthroplasty (161). Moreover, in animal studies, pre-operative and postoperative subcutaneous administration of risedronate 
$(0.1 \mathrm{mg} / \mathrm{kg} /$ once every two days) was found to have a positive effect on osseointegration in one animal study on ovariectomized rats using screw titanium implants (124). This study showed that risedronate enhanced bone-to-implant contact and push-out test analyses.

\subsection{Pamidronate}

In human studies, the use of pamidronate $(90 \mathrm{mg} / \mathrm{kg}$ ) was associated with a low risk of implant failure in one double-blind Randomized Control Trial on total hip arthroplasty (162). Moreover, in animal studies, postoperative subcutaneous, Intramuscular, and intraperitoneal administration of pamidronate $(0.4,4,40$, and $500 \mu \mathrm{g} / \mathrm{kg} / \mathrm{daily}$, and $0.6 \mathrm{mg} / \mathrm{kg} /$ three and five times a week) was found to have a positive effect on osseointegration in five animal studies (four on rats, and one on dogs). (163-167). Three of these studies used screw titanium implants, one used endotoxin-coated polyethylene particles titanium implants, and one used stainless-steel screw-shaped implants. Bone-to-implant contact, peri-implant bone volume,pull-out test, and push-out test analyses showed that pamidronate enhanced BIO.

\subsection{TRK-530 (Bisphosphonate)}

In animal studies, post-operative subcutaneous administration of TRK-530 $(1 \mathrm{mg} / \mathrm{kg} / \mathrm{every}$ other day) was found to have a positive effect on osseointegration in one animal study on rats (168). This study used Kirshner (K)-wires, and it showed that TRK-530 improved bone-to-implant contact and reduced peri-implant osteolysis.

\subsection{YM-175 (Bisphosphonate)}

In animal evidence, pre-operative and post-operative subcutaneous administration of YM-175 $(10 \mu \mathrm{g} / \mathrm{kg} /$ three times a week) was found to have a positive effect on osseointegration in one animal 
study on ovariectomized rats (169). This study used screw-form titanium implants, and it showed that YM-175 improved bone-to-implant contact and reduced peri-implant osteolysis.

\subsection{Etidronate}

In human studies, use of etidronate $(400 \mathrm{mg} / \mathrm{kg}$, a day) was not found to be a contributing factor on implant survival rate in one double-blind Randomized Control Trial on total hip arthroplasty (170).

\subsection{Parathyroid Hormone Replacement Therapy (PTH)}

Different doses of parathyroid hormone replacement therapy $(20 \mu \mathrm{g} / \mathrm{kg} /$ daily or $56.5 \mu \mathrm{g} / \mathrm{kg} / \mathrm{once}$ a week, injection) have been assessed for their impact on bone-implant osseointegration.

In human studies, use of parathyroid hormone replacement therapy (PTH) (recombinant human parathyroid hormone) had no significant effect on dental implant failure rate in one single-blinded open-label randomized controlled feasibility study (171). However, the use of PTH had a positive effect in one retrospective study on total knee arthroplasty, one Randomized Control Trial on total hip arthroplasty and four prospective studies, three of these were cohort studies on lumbar interbody fusion pedicle screws and one on total knee arthroplasty, (64, 160, 172-174).

In animal studies, pre-operative and post-operative subcutaneous administration of PTH (60 $\mu \mathrm{g} / \mathrm{kg} /$ daily, $5-60 \mu \mathrm{g} / \mathrm{kg} /$ three time a week, $10-75 \mu \mathrm{g} / \mathrm{kg} /$ five time a week, or $60 \mu \mathrm{g} / \mathrm{kg} / \mathrm{six}$ time a week) was found to have a positive effect on osseointegration in twenty six animal studies (87, 137, 164-166, 175-194). Fourteen of these studies were on rats (seven of them on ovariectomized rats), three on low protein diet rats, five on rats (two of them on ovariectomized rabbits and one 
on post-orchiectomy rabbits), three on dogs, and one on mice. Twenty-four of these studies used titanium implants (12 screws implants, 5 (HA)-coated implants, three unspecified implant designs, three cylindrical implants, one roughened surface implant), two used screw-shaped stainless-steel implants, one used cylindrical custom loading device, one used polymethylmethacrylate implants and one used cylindrical cemented titanium plates. Bone-to-implant contact, peri-implant bone volume, removal torque force test, pull-out force test and push-out force test analyses showed that systemic administration of PTH improved BIO.

On the other hand, post-operative subcutaneous administration of PTH $(2,40$ and $60 \mu \mathrm{g} / \mathrm{kg} / \mathrm{three}$ times a week) was found to have no significant effect on osseointegration in three rat studies, two of them on diabetic rats). These studies used screw titanium implants and they showed that PTH had no significant effect on bone-to-implant contact (195-197).

Moreover, two studies on rats (one on ovariectomized rats) showed that combined administration of simvastatin (5 and $25 \mathrm{mg} / \mathrm{kg}$ daily) with PTH (60 and $40 \mu \mathrm{g} / \mathrm{kg}$, three times a week) had a positive effect on bone-implant osseointegration simvastatin $(188,189)$. Also, in another study, PTH (40 $\mu \mathrm{g} / \mathrm{kg} / \mathrm{day} /$ three days a week, Sc) showed a positive effect on osseointegration on rats smoking nicotine. (191).

\subsection{Vitamin D}

In human studies, use of vitamin D (1 mg/day) was not associated with an increase in the survival rate of osseointegrated implants in two single-blinded Randomized Control Trials on total hip arthroplasty $(101,109)$.

In animal studies, pre-operative and post-operative intraperitoneal, oral and subcutaneous administration of vitamin D (calcitriol) $(0.1-60 \mu \mathrm{g} / \mathrm{kg})$ had a positive effect on bone-implant 
osseointegration in five animal studies $(131,198-201)$. Three of these studies were on ovariectomized rats, one on diabetic mice, and one on diabetic rats. Five studies used titanium implants (two screw-shaped, one unspecified design, one hydroxyapatite-coated, and one rodshaped implants). Bone-to-implant contact, bone mass, pull-out force test, and push-out force analyses showed that systemic administration of vitamin D improved BIO under osteoporotic and diabetic conditions. Also, combining this drug with insulin (3.5 IU/twice a day, SC) resulted in improved BIO in one study on diabetic rats (198). Moreover, combining this drug with bisphosphonates (3.5 IU/twice a day, SC) also resulted in improved BIO in one study on ovariectomized rats (131).

On the other hand, one study on rats showed that vitamin D deficiency has a negative impact on BIO (202). This study used cylindrical hydroxyapatite-coated titanium implants, and it showed that vitamin D deficiency impaired bone-implant contact and peri-implant bone volume.

\subsection{Anti-Sclerostin antibody}

In animal studies, post-operative subcutaneous administration of sclerostin antibody therapy (25 $\mathrm{mg} / \mathrm{kg} / \mathrm{twice}$ a week) was found to have a positive effect on osseointegration in two studies on rats $(203,204)$. One of these studies used rod-shaped titanium implants, and the other one used cylindrical titanium implants. Bone-to-implant contact, peri-implant bone volume, and pull-out force test analyses showed that sclerostin antibody therapy improved BIO and might have the ability to limit the progression of established osteolysis.

\subsection{Anti-RANKL}

In animal studies, post-operative subcutaneous administration of anti-RANKL (OPG-Fc) (8-10 $\mathrm{mg} / \mathrm{kg} /$ twice a week) was found to have a positive effect on osseointegration in two studies on rats 
$(130,205)$. One of these studies used stainless-steel screw implants, and the other one used cylindrical titanium plate plugs. Bone-to-implant contact, peri-implant bone density, and the pullout test analyses showed that anti-RANKL improved bone-implant osseointegration.

\subsection{Strontium ranelate}

In animal studies, post-operative systemic administration of strontium ranelate had a positive effect on bone-implant osseointegration in four studies on rats (one of them on ovariectomized rats). These studies used daily oral doses of $500-1000 \mathrm{mg} / \mathrm{kg} /$ day for $8-12$ weeks after implant placement. Two of these studies used hydroxyapatite-coated titanium implants, and the other two studies used titanium screw or rod-shaped implants. Bone-to-implant contact, bone volume surrounding the implants and pull-out test analysis showed that strontium ranelate improved BIO $(76,206-208)$.

\subsubsection{Analgesics}

\subsection{NSAID}

Different NSAIDs have been assessed for their impact on bone-implant osseointegration. This includes meloxicam, diclofenac sodium, aspirin, ibuprofen, celecoxib, indomethacin, naproxen, rofecoxib-A, flurbiprofen, and parecoxib.

In human studies, unspecified NSAIDs have been shown to have negative effects on the marginal bone around dental implants in one retrospective cohort study (209). However, on another retrospective cohort study, NSAID significantly increased the crestal bone levels around singletooth hydroxyapatite-coated implants (210). Underneath, we discuss the literature on specific types of NSAID drugs.

\subsection{Meloxicam}


In animal studies, post-operative subcutaneous and intramuscular administration of meloxicam $(3 \mathrm{mg} / \mathrm{kg} /$ day) had a negative effect on bone-implant osseointegration in two studies on rats (211, 212). These studies used screw-form titanium implants and showed that meloxicam impaired boneto-implant contact and bone area within the implant threads.

On the other hand, post-operative intramuscular administration of meloxicam $(0.2 \mathrm{mg} / \mathrm{kg}) \mathrm{did}$ not show significant effects on bone-implant osseointegration in one study on rats (213). This study used screw-form titanium implants, and it showed that meloxicam had no significant effect on the bone area within the threads of the implants.

\subsection{Diclofenac sodium}

In animal studies, post-operative intramuscular administration of diclofenac sodium $(1.07 \mathrm{mg} / \mathrm{kg}$ twice a day or $30 \mathrm{mg} / \mathrm{kg} /$ day) had a negative effect on bone-implant osseointegration in two studies on rats and in another one on rabbits $(213,214)$. One of these studies used cylindrical Hydroxyapatite (HA)-coated titanium implants, and the other one used screw-shaped titanium implants. The bone-to-implant contact, the bone area within the implant threads, and the pull-out test analyses showed that diclofenac sodium impaired bone-implant osseointegrations. On the other hand, post-operative oral and intramuscular administration of diclofenac sodium (2 and 5 $\mathrm{mg} / \mathrm{kg} /$ day) did not show a significant effect on bone-implant osseointegration in two other studies on rabbits $(215,216)$. These studies used cylindrical titanium implants, and cylindrical (HA)coated titanium implants. Bone-to-implant contact, bone volume and pull out test analyses showed that diclofenac sodium had no significant effect on implant osseointegration.

\subsection{Aspirin}

In animal studies, post-operative subcutaneous administration of aspirin (17 or $34 \mathrm{mg} / \mathrm{kg} / \mathrm{day}$ for 2,4 , and 8 weeks) had a negative effect on bone-implant osseointegration in one study on rabbits 
(217). This study used porous-coated chrome-cobalt implants, and it showed that aspirin impaired bone-to-implant contact and bone ingrowth.

\subsection{Ibuprofen}

In human studies, use of ibuprofen (400 mg/kg, 3 times a day or $600 \mathrm{mg} / \mathrm{kg}, 4$ times a day) was not associated with a higher risk of implant failure in one prospective cohort study on dental implants and two double-blind Randomized Control trials, one of them on total hip arthroplasty and the other one on dental implants (218-220).

In animal studies, post-operative subcutaneous administration of ibuprofen (17 or $34 \mathrm{mg} / \mathrm{kg} / \mathrm{day}$ for 2, 4, and 8 weeks) had a negative effect on bone-implant osseointegration in one study on rabbits (217). This study used porous-coated chrome-cobalt implants, and it showed that ibuprofen impaired bone-to-implant contact and bone ingrowth.

\subsection{Celecoxib}

In human studies, use of celecoxib (200 mg/ twice a day) was not associated with a higher risk of implant failure in two double-blind Randomized Control trials, one on total hip and the other one on knee arthroplasty $(221,222)$.

In animal studies, postoperative oral administration of celecoxib ( $3 \mathrm{mg} / \mathrm{kg} / \mathrm{day})$ did not show any effect on bone-implant osseointegration in one study on rabbits femora using cylindrical (HA)coated titanium implants (216). On the other hand, postoperative oral administration of celecoxib (10 or $25 \mathrm{mg} / \mathrm{kg} /$ day) had a positive effect in reducing implant debris-induced inflammation in mice. This study used titanium wear debris to assess the host inflammatory response, and the analysis of implanted titanium debris showed that celecoxib prevented implant debris-induced osteolysis (223).

\subsection{Indomethacin}


In animal studies, pre-operative and post-operative subcutaneous administration of indomethacin (1-10 $\mathrm{mg} / \mathrm{kg} /$ day) had a negative effect on bone-implant osseointegration in three animal studies, two on rabbits and one on ovariectomized rats $(124,217,224)$. These studies used porous-coated chrome-cobalt implants, cylindrical titanium implants, and screw implants, respectively. Bone-toimplant contact, bone ingrowth, and push-out test analyses showed that indomethacin impaired bone-implant osseointegration. On the other hand, pre-operative and post-operative subcutaneous and oral administration of indomethacin ( 1 and $4 \mathrm{mg} / \mathrm{kg} /$ day) did not show any effect on boneimplant osseointegration in two studies on rabbits and dogs $(225,226)$. These studies used cylindrical titanium implants, and they showed that indomethacin did not affect bone-to-implant contact and peri-implant bone density.

\subsection{Naproxen}

In animal studies, post-operative oral administration of naproxen $(110 \mathrm{mg} / \mathrm{kg} /$ day $)$ did not affect bone-implant osseointegration in one study on rabbits (227). This study used a cylindrical titanium chamber, and it showed that naproxen had no effect on bone-to-implant contact and bone ingrowth.

\subsection{Rofecoxib-A}

In animal studies, post-operative oral administration of rofecoxib-A (12.5 mg/kg/day) had no effect on bone-implant osseointegration in one study on rabbits (227). This study used cylindrical titanium chambers, and it showed that rofecoxib-A did not affect bone-to-implant contact and bone ingrowth.

\subsection{Parecoxib}

In animal studies, post-operative subcutaneous administration of parecoxib $(1.5 \mathrm{mg} / \mathrm{kg} / \mathrm{day}) \mathrm{had}$ no effect on bone-implant osseointegration in one study on rabbits (215). This study used 
cylindrical titanium implants, and it showed that parecoxib did not affect bone-to-implant contact and bone ingrowth.

\subsection{Flurbiprofen}

In human studies, use of flurbiprofen (100 mg/twice a day) in the first year of implant loading was associated with lower risk of implant failure in one double-blind Randomized Control Trial (228). This study was used to assess the effect of oral flurbiprofen on osseointegrated dental implants.

\subsection{Prostaglandin EP4 receptor agonist}

In animal studies, post-operative subcutaneous administration of prostaglandin EP4 receptor agonist (ONO-4819) (15-30 $\mu \mathrm{g} / \mathrm{kg} /$ twice a day) was found to have a positive effect on osseointegration in two studies on ovariectomized rats (229)(317). One of these studies used screw-shape hydroxyapatite/titanium composite and titanium-coated rough-surfaced implants and the other study used cylindrical hydroxyapatite-coated implants. Bone-to-implant contact, and pull-out force test analyses showed that prostaglandin EP4 receptor agonist (ONO-4819) improved $\mathrm{BIO}$, especially with rough-surface hydroxyapatite-coated titanium implants.

\subsection{Cannabinoids}

In animal studies, post-operative intermittent inhalation of marijuana ( $3 \mathrm{~g}$ of dried marijuana leaves) was found to have a negative effect on osseointegration in one study on rats (230). This study used screw-shaped titanium implants, and it showed that intermittent-marijuana impaired bone-to-implant contact and the bone area within the threads of the implants.

\subsection{Local anesthesia: Bupivacaine}


In human studies, use of bupivacaine without vasoconstrictor was associated with an increased survival rate of osseointegrated implants in one Randomized Control Trial (231).

\subsubsection{Anti-Psycholeptics Drugs}

\subsection{Melatonin}

In human studies, oral administration of melatonin had a positive effect on bone-implant osseointegration in one study of pinealectomized rats that assessed the effect of postoperative use of this drug on osseointegration of screw-form titanium implants (232). This study used a dose of $5 \mathrm{mg} / \mathrm{kg} /$ once a day for 8.5 weeks after implant placement, and it showed that oral melatonin improved bone-to-implant contact and peri-implant bone volume.

\subsection{Lithium chloride}

In animal studies, systemic administration of lithium chloride had a positive effect on boneimplant osseointegration in one study on ovariectomized rats that assessed the effect of postoperative use of this drug on osseointegration of cylindrical-shaped titanium implants (233). This study used a dose of $150 \mathrm{mg} / \mathrm{kg} / \mathrm{twice}$ a day for three months after implant placement, and it showed that $\mathrm{LiCl}$ improved bone-to-implant contact, peri-implant bone volume, and implant pushout force.

\subsubsection{Antidepressant:}

\subsection{Selective Serotonin reuptake Inhibitors (SSRIs)}

In human studies, systemic administration of Selective Serotonin Reuptake Inhibitors (SSRIs) was associated with a higher risk of implant failure in two retrospective cohort studies. Although only one of them showed significant results $(234,235)$. 


\subsubsection{Drugs Used in Addictive Disorders}

\subsection{Nicotine}

Different doses of nicotine have been assessed for their impact on bone-implant osseointegration. In animal studies, subcutaneously injection of $1.25-9 \mathrm{mg} / \mathrm{kg}$ was found to have a negative effect on osseointegration in four animal studies, while four other studies using doses either $0.37-0.93$

$\mathrm{mg} / \mathrm{kg}$ or 9,15 or $85.2 \mathrm{mg} / \mathrm{kg}$ did not show any effect, and the only study assessing the effect of smoking nicotine found that it had a negative effect on osseointegration. Also, another study, smoking nicotine combined with PTH (40 $\mu \mathrm{g} / \mathrm{kg} /$ day 3 days/week, Sc), showed a positive effect on osseointegration on rats. Moreover, in another study on rats, combined administration of nicotine with daily $10 \%$ Gay Loussac ethanol showed a negative effect on bone-to-implant osseointegration (191, 236-244).

\subsection{Alcohol}

Different doses of ethanol have been assessed for their impact on bone-implant osseointegration. In animal studies, oral administration of ethanol $(10 \%-20 \%)$ for $3-4$ weeks before implant surgery and 2-9 weeks after implant placement was found to have a negative effect on osseointegration in five studies on rats $(241,245-248)$. Three of these studies used hydroxyapatitecoated implants, and the other two used titanium screw or cylindrical titanium implants. The studies showed that ethanol impaired bone-to-implant contact and new bone formation around the HA implants. Moreover, in another study on rats combined daily administration of nicotine with 10\% Gay Lussac ethanol showed a negative effect on osseointegration (241).

\subsubsection{Systemic Hormonal Replacements Drugs}

\subsection{Sex Hormone Replacement}


Different sex hormonal replacement medications such as $17 \beta$-estradiol and dihydrotestosterone have been assessed for their impact on bone-implant osseointegration.

In human studies, use of sex hormone replacement therapy was not associated with an increased survival rate of osseointegrated implants in one retrospective cohort study (249). Underneath we discuss the literature on the specific types of sex hormone replacement drugs.

\subsection{Estradiol}

In human studies, the use of estrogen replacement therapy was associated with an increased survival rate of osseointegrated implants in one retrospective cohort study, and this association was statistically significant (250). Also, the use of alendronate $(70 \mathrm{mg} / \mathrm{kg} / \mathrm{once}$ a week ) combined with Xianlinggubao (phytoestrogen-rich natural product) (three times a day) was associated with an increased survival rate of osseointegrated implants in one Randomized Control Trial on total hip arthroplasty (110).

In animal studies, pre-operative and post-operative subcutaneous administration of $17 \beta$ estradiol (20 $\mu \mathrm{g} / \mathrm{kg} /$ daily or 3 to 4 days a week) was found to have a positive effect on osseointegration in eight studies on ovariectomized rats $(134,136,251-256)$. Five of these studies used screw-form titanium implants, two studies used titanium micro-implants, and one study used hydroxyapatitecoated screw titanium implants. Bone-to-implant contact, the bone area within the limits of implant threads, peri-implant bone density, removal torque test, and push-out force test analyses showed that $17 \beta$ estradiol improved bone-implant osseointegration. However, pre-operative and postoperative subcutaneous administration of $17 \beta$ estradiol ( $20 \mu \mathrm{g} / \mathrm{kg} / \mathrm{daily})$ was found to have no effect on osseointegration in one study on ovariectomized dogs and one study on ovariectomized rats $(169,257)$. On of these studies used cobalt-chromium porous plugs and the other used screw- 
form titanium implants and it showed that short-term, high-dose estrogen replacement hormone did not affect significantly the bone-to-implant contact, peri-implant bone ingrowth and the result of the pull-out test.

\subsection{Dihydrotestosterone}

In animal studies, pre-operative administration of dihydrotestosterone was found to have a positive effect on osseointegration in one study on rats (258). This study used cobalt-chromiummolybdenum implants, and the bone-to-implant contact and pull-out analyses showed that dihydrotestosterone improved bone-implant osseointegration.

\subsection{Raloxifene}

In animal studies, post-operative oral administration of raloxifene $(1.0 \mathrm{mg} / \mathrm{kg} /$ day $)$ was found to have a positive effect on osseointegration in one study on ovariectomized rats (132). This study used screw-shaped titanium implants, and it showed that raloxifene improved the bone-to-implant contact, the bone area within the threads of the implants, and the implant reverse torque force.

\subsection{Thyroid Hormone Replacement}

Different thyroid replacement hormone medications such as calcitonin and levothyroxine have been assessed for their impact on bone-implant osseointegration. Underneath we discuss the literature on the specific types of thyroid hormone replacement drugs.

\subsection{Calcitonin}

In human studies, use of calcitonin was associated with an increased survival rate of osseointegrated implants in two different studies $(259,260)$. This association was statistically significant in one prospective cohort study but was not significant in a Randomized Control Trial. 
In animal studies, different doses of calcitonin have been also assessed for their impact on boneimplant osseointegration in four animal studies on ovariectomized rats $(124,133,251,252)$. These studies found that subcutaneous administration of different doses of calcitonin (2 -16 IU/kg/daily or once every 2 days) had a positive effect on osseointegration. Three of these studies used screwform titanium implants, and the other one used cylindrical HA implants, and it showed that calcitonin improved bone-to-implant contact and the bone area within the threads of the implants. On the other hand, the intramuscular administration of calcitonin (2 IU/kg, daily) showed a negative effect on osseointegration in one study on rabbits (261). This study used screw-shaped titanium implants, and it showed that calcitonin impaired the initial phase of the bone healing process around the implants.

\subsection{Levothyroxine}

In animal studies, pre-operative oral administration of levothyroxine ( $0.4 \mathrm{IU}$ and $0.18 \mathrm{IU}$ ) were found to have a positive effect on osseointegration in one study on rats (262). This study used screw-form titanium implants, and it showed that levothyroxine improved bone-to-implant contact.

\subsection{Oxytocin}

In animal studies, post-operative subcutaneous administration of oxytocin $(1 \mathrm{mg} / \mathrm{kg} / \mathrm{day})$ had a positive effect on bone-implant osseointegration in one study on ovariectomized rats that assessed the effect of machined and grit-blasted rod-form titanium implants on bone-implant osseointegration. Bone-to-implant contact, peri-implant bone volume, and push-out force analyses showed that oxytocin improved BIO under osteoporotic conditions $(263,264)$.

\subsection{Corticosteroids}


Different corticosteroid drugs such as prednisolone, methylprednisolone, and glucocorticosteroid have been assessed for their impact on bone-implant osseointegration. Underneath we discuss the literature on the specific types of corticosteroid drugs.

\subsection{Methylprednisolone}

In animal studies, pre-operative and post-operative subcutaneous administration of methylprednisolone $(0.35 \mathrm{mg} / \mathrm{kg} /$ three times a week $)$ had a negative effect on bone-implant osseointegration in one study on rabbits (95). This study used screw-type titanium implants, and it showed that methylprednisolone impaired bone-implant contact and the total peri-implant bone area. However, combining this drug with zoledronic acid ( $7.5 \mu \mathrm{g} / \mathrm{kg} /$ once a week, IV) resulted in a better BIO in one study on rabbits (95).

\subsection{Prednisolone}

In animal studies, pre-operative and post-operative intramuscular administration of prednisolone $(10 \mathrm{mg} / \mathrm{kg} / \mathrm{daily})$ did show a negative effect on bone-implant osseointegration in the mandible but did not show any significant effect on bone-implant osseointegration in the tibia in the same study on rabbits (265). This study used screw-type titanium implants. Bone to implant contact, bone density, and removal torque test analyses showed that prednisolone had no significant effect on bone-implant osseointegration in the mandible, but it did have a negative effect on the tibia.

\subsection{Glucocorticosteroid}

In animal studies, the use of glucocorticosteroids (different doses from 5-60 mg) was not associated with a high risk of implant failure in one retrospective cohort study on dental implants (266).

\subsubsection{Chemotherapy}


Different Chemotherapy drugs such as cisplatin, methotrexate, doxorubicin, ifosfamide have been assessed for their impact on bone-implant osseointegration.

In human studies, chemotherapy was associated with a higher risk of implant failure in one prospective cohort study (some combination of methotrexate, cyclophosphamide, doxorubicin, ifosfamide, cisplatin, etoposide, and various other agents) (267) while no effect on another prospective cohort study (cis- or carboplatin and 5-fluorouracil in three cycles) (268). This association was statistically significant in the first study, which included 24 non-users and 30 users of chemotherapy but was not in the other study that was done on 60 non-users and 30 users of chemotherapy. Underneath we discuss the literature on specific types of chemotherapy drugs.

\subsection{Cisplatin}

In animal studies, pre-operative and post-operative systemic administration of cisplatin ( 50, 75, $150 \mathrm{mg} / \mathrm{m}^{2} /$ once a week) had a negative effect on bone-implant osseointegration in two studies on dogs and one study on rabbits (269-271). Two of these studies used porous-surface titanium implants and the other one used screw-type titanium dental implants. Bone-to-implant contact, bone ingrowth analyses, and torque force tests showed that cisplatin impaired bone-implant osseointegration.

\subsection{Methotrexate}

In animal studies, pre-operative intramuscular administration of low dose methotrexate (3 $\mathrm{mg} / \mathrm{kg} /$ once a week) had no negative effect on bone-implant osseointegration in one study on rabbits (272). This study used screw-shaped titanium implants, and it showed that methotrexate did not impair bone-to-implant contact and the total peri-implant bone area.

\subsection{Doxorubicin}


In animal studies, pre-operative and post-operative systemic administration of doxorubicin (20 $\mathrm{mg} / \mathrm{m}^{2} /$ once a week) had a negative effect on bone-implant osseointegration in one study on dogs (271). This study used porous-surface titanium implants. Bone-to-implant contact, bone ingrowth analyses, and torque force tests showed that doxorubicin impaired bone-implant osseointegration.

\subsection{Ifosfamide}

In animal studies, pre-operative and post-operative systemic administration of ifosfamide (300 $\mathrm{mg} / \mathrm{m}^{2} /$ once a week) had a negative effect on bone-implant osseointegration in one study on dogs (271). This study used porous-surface titanium implants. Bone-to-implant contact, bone ingrowth, and torque force analyses showed that ifosfamide impaired bone-implant osseointegration.

\subsubsection{Anti-Angiogenic}

Different anti-angiogenic medications such as TNP-470, anti-VEGF, and ranibizumab have been assessed for their impact on bone-implant osseointegration.

\subsection{TNP-470}

In animal studies, post-operative subcutaneous administration of TNP-470 (10 mg/kg/three days a week) was found to have a negative effect on osseointegration in one study on rabbits (273). This study used screw-shaped titanium implants, and it showed that TNP-470 impaired bone-to-implant contact and new bone formation around the implants.

\subsection{Anti-vascular endothelial growth factor (Anti-VEGF)}

In animal studies, post-operative intraperitoneal administration of anti-VEGF (4 $\mu \mathrm{g} / \mathrm{kg}) \mathrm{was}$ found to have a negative effect on osseointegration in one study on rats (274). This study used 
cylindrical titanium implants, and it showed that anti-VEGF impaired bone-to-implant contact and peri-implant bone formation.

\subsection{Ranibizumab}

In animal studies, post-operative intraperitoneal administration of ranibizumab $(15 \mu \mathrm{g} / \mathrm{kg}) \mathrm{was}$ found to have a negative effect on osseointegration in one study on rats (274). This study used cylindrical titanium implants, and it showed that ranibizumab impaired bone-to-implant contact and peri-implant bone formation.

\subsubsection{Antibiotic}

Different antibiotics such as amoxicillin and doxycycline have been assessed for their impact on bone-implant osseointegration.

In human studies, pre-operative administration of antibiotics prior to implant placement had no significant effect on implant failure in 3 randomized controlled clinical trials (275-277) and one retrospective cohort study (278).

In animal studies, one study on rats showed that amoxicillin had a negative effect on osseointegration when used at a pre-operative dose of $40 \mathrm{mg} / \mathrm{kg}$ and a post-operative dose of 10 $\mathrm{mg} / \mathrm{kg}$ at day 3, 5, and 7 (279). On the other hand, postoperative oral administration of doxycycline $(16.67 \mathrm{mg} / \mathrm{kg})$ showed a positive effect on the bone-to-implant contact in diabetic rats (280).

\subsubsection{Anti-Diabetic}


Three drugs commonly used for diabetes, such as insulin, aminoguanidine, and metformin have been assessed for their impact on bone-implant osseointegration. Underneath we discuss the literature on the specific types of anti-diabetic drugs.

\subsection{Insulin}

In animal studies, different doses of insulin have been assessed for their impact on bone-implant osseointegration. Insulin doses of 2-17 IU/day were found to have a positive effect on osseointegration in seven different studies on diabetic rats $(198,281-286)$. Three of these studies

used screw-form implants, two used cylindrical implants, one used the rod-shaped implants, and one used dental titanium implants. These studies showed that insulin improved bone-to-implant contact and the bone area within the limits of the implant threads. On the other hand, one study on diabetic rabbits using dose 20 IU/day did not show any significant effect (287). This study used unthreaded titanium implants, and it showed that insulin did not affect the bone-implant contact during the removal torque test. Also, combining insulin with vitamin D (12 $\mu \mathrm{g} / \mathrm{kg} /$ daily, gavage) resulted in improved BIO in one study on diabetic rats (198).

\subsection{Metformin}

In animal studies, different doses of metformin have been assessed for their impact on boneimplant osseointegration in three studies on rats. Short term use of oral metformin (40 and 100 $\mathrm{mg} / \mathrm{kg} / \mathrm{daily}$ ) was found to have a positive effect on osseointegration in two of these studies (288, 289), while long term use of oral metformin ( $40 \mathrm{mg} / \mathrm{kg} / \mathrm{daily})$ showed a negative effect on osseointegration in the third study (289). All three studies used screw-form titanium implants. The studies on short term use of oral metformin showed improve in bone-to-implant contact and peri- 
implant bone area, while the long term used of oral metformin impaired bone-to-implant contact, and peri-implant bone area.

\subsection{Aminoguanidine}

In animal studies, different doses of aminoguanidine have been assessed for their impact on boneimplant osseointegration in two studies on rats. Intraperitoneally administration of aminoguanidine $(10-132.2 \mathrm{mg} / \mathrm{kg} / \mathrm{daily})$ was found to have a positive effect on osseointegration in both studies $(280,290)$. One study used screw-form titanium implants, and the other used cylindrical titanium implants. These studies showed that aminoguanidine improved bone-to-implant contact, bone marrow to implant contact, and the results of the counter-torque test.

\subsubsection{Cardiovascular System Drugs}

\subsection{Antihypertensive}

In human studies, systemic administration of antihypertensive medications was associated with an increase in the survival rate of osseointegrated implants in one retrospective cohort study (291). Also, different hypertension drugs such as propranolol and nifedipine have been assessed in vivo for their impact on bone-implant osseointegration.

\subsection{Propranolol}

In animal studies, post-operative subcutaneous administration of propranolol ( $5 \mathrm{mg} / \mathrm{kg} / \mathrm{daily})$ was found to have a positive effect on osseointegration in one study on rats (292). This study used cylindrical titanium implants, and it showed that propranolol improved bone-to-implant contact.

\subsection{Nifedipine}

In animal studies, post-operative subcutaneous administration of nifedipine (50 mg/kg/daily) in combination with the immunosuppressive drug CsA (10 mg/kg/daily) was found to have no 
significant effect on osseointegration in one study on rabbits (293). This study used screw-shaped titanium implants, and it showed that the administration of nifedipine in combination with the immunosuppression drug for a short period of time had no significant effects on peri-implant bone density.

\subsection{Statins}

In human studies, use of statins was significantly associated with an increased survival rate of osseointegrated implants at 5 years in a retrospective cohort study on total hip arthroplasty (294).

In animal studies, post-operative subcutaneous, intraperitoneal, and oral administration of simvastatin (3-10 or $25-50 \mathrm{mg} / \mathrm{kg}$ ) was found to have a positive effect on osseointegration in eight animal studies $(295)(188,189,296-300)$. Three of these on ovariectomized rats, two on nonovariectomized rats, one on low protein diet rats, one on dogs, and one on rabbits. Seven of these studies used titanium implants ( 2 screw-shaped, 2 unspecified implant design, 2 hydroxyapatitecoated, 1 cylindrical-shaped), and one used grit-blasted implants. Bone-to-implant contact, the bone area within the limits of implant threads, peri-implant bone quality, and bone density, and push-out test analyses showed that simvastatin enhanced bone-implant osseointegration. Moreover, a study on ovariectomized rats and another one on rats showed that combined administration of simvastatin ( 5 and $25 \mathrm{mg} / \mathrm{kg} /$ daily) with parathyroid hormone replacement therapy (60 and $40 \mu \mathrm{g} / \mathrm{kg} /$ three times a week) had a positive effect on bone-implant osseointegration $(188,189)$. On the other hand, postoperative oral administration of different doses of simvastatin $(5,10$, or $50 \mathrm{mg} / \mathrm{kg})$ was found to have no effect on osseointegration in one study on rats (301). This study used HA-coated stainless-steel implants in which bone-to-implant contact and peri-implant bone density analysis showed that simvastatin had no effect on bone-implant osseointegration. 


\subsubsection{Blood Drugs}

\subsection{Anti-Hemorrhagic: Aprotinin}

In animal studies, post-operative intravenous administration of aprotinin (7,200 KIU) was found to have no effect on osseointegration in one study on rats (302). This study used steel Kirschnerwires. Bone-to-implant contact and push-out force analyses showed that systemic administration of aprotinin had no effect on BIO.

\subsection{Anti-Thrombotic: Warfarin}

In animal studies, post-operative oral administration of warfarin $(5 \mathrm{mg} / \mathrm{kg})$ was found to have a negative effect on osseointegration in one study on goats (303). This study used cylindrical hydroxyapatite-coated cobalt-chromium-molybdenum alloy implants. Bone-to-implant contact and push-out force analyses showed that systemic administration of warfarin impaired BIO. However, hydroxyapatite-coated reverse the negative effect and improve BIO.

\subsubsection{Immunosuppression}

Different immunosuppressive medications such as cyclosporin A and FK-506 have been assessed for their impact on bone-implant osseointegration.

\subsection{Cyclosporin A}

In animal studies, pre-operative and post-operative subcutaneous administration of cyclosporin A (10 mg/kg/daily) was found to have a negative effect on osseointegration in five studies on rabbits (304-308). Four of these studies used screw-shaped titanium implants, and one used cylindrical titanium dental implants. Bone-to-implant contact, the bone area within the limits of the implant threads, peri-implant bone quality and density, and removal torque test analyses 
showed that cyclosporin A impaired bone-implant osseointegration. On the other hand, postoperative intraperitoneal administration of cyclosporin A ( $2 \mathrm{mg} / \mathrm{kg})$ was found to have no effect on osseointegration in one study on rats (309). This study used a threaded titanium cylindrical chamber. Bone-to-implant contact and peri-implant bone area analyses showed that a low dose of cyclosporin A had no effect on bone-implant osseointegration. Moreover, Post-operative subcutaneous administration of cyclosporin A (10 mg/kg, daily) in combination with nifedipine $(50 \mathrm{mg} / \mathrm{kg}$, daily) and antihypertension medications were found to have no effect on osseointegration in one study on rabbits (293).

\subsection{FK-506}

In animal studies, pre-operative and post-operative subcutaneous administration of FK-506 (1 $\mathrm{mg} / \mathrm{kg}$ ) was found to have a negative effect on osseointegration in one study on rats (310). This study used sandblasted titanium implants, and it showed that FK-506 impaired bone-implant contact and peri-implant bone formation.

\subsubsection{Anti-Gastric:}

\subsection{Proton Pump Inhibitors (PPI)}

In human studies, systemic administration of Proton Pump Inhibitors (PPIs) was associated with a higher risk of implant failure in two retrospective cohort studies $(311,312)$.

In animal studies, post-operative intraperitoneal administration of Proton Pump Inhibitors (PPIs) $(5 \mathrm{mg} / \mathrm{kg} /$ daily) was found to have a negative effect on osseointegration in one study on rats. This study used titanium implants, and it showed that Proton Pump Inhibitors (PPIs) impaired boneimplant contact and peri-implant bone formation (313). 


\subsubsection{Hyperbaric oxygen (HBO)}

In animal studies, post-operative systemic administration of HBO treatment (10 sessions, 2.0-2.5 ATM of pure oxygen, 90 minutes/day) was found to have a positive effect on early healing of osseointegration in two studies on diabetic rabbits and diabetic rats $(314,315)$. One of these studies used screw dental implants, and the other used screw-shaped titanium implants, and they showed that HBO improved bone-implant osseointegration under diabetic conditions. On the other hand, one study on rats showed that of HBO treatment (10 sessions, 2.80 ATM of pure oxygen, 120 minutes/twice a day) had no effect on BIO in irradiated rats (316). This study used a screw-shaped titanium implant. Bone-to-implant contacts and removal torque test analyses showed that 10 sessions of $\mathrm{HBO}$ treatment had no effect on $\mathrm{BIO}$ in irradiated rats.

\subsubsection{Synthesis of results}

The qualitative synthesis summary of the collected data is shown in three critical analyses: RCT studies, observational studies, and animal studies. 
Table 3: Number of articles identified per drug category as a function of screening method used to identify the study, the type of study, and the study outcome regarding the effect of the drug on osseointegration.

\begin{tabular}{|c|c|c|c|c|c|c|c|c|}
\hline \multirow[t]{3}{*}{ Drug classes identified } & \multicolumn{8}{|c|}{ Number of studies identified per drug } \\
\hline & \multicolumn{2}{|c|}{ Screening method } & \multicolumn{6}{|c|}{ Study design and outcome } \\
\hline & $\begin{array}{l}\text { Manual screening } \\
\text { of specific search } \\
\text { strategies }\end{array}$ & $\begin{array}{l}\text { AI screening of } \\
\text { highly sensitive } \\
\text { search strategy }\end{array}$ & $+\mathrm{ve}$ & -ve & NS & $+\mathrm{ve}$ & -ve & NS \\
\hline Nicotine $(236-242)(243,244)$ & 6 & 9 & 0 & 0 & 0 & 0 & 4 & 5 \\
\hline Nicotine + PTH (191) & 1 & 1 & 0 & 0 & 0 & 1 & 0 & 0 \\
\hline Nicotine + alcohol (241) & 1 & 1 & 0 & 0 & 0 & 0 & 1 & 0 \\
\hline Antibiotic (275-280) & 2 & 6 & 0 & 0 & 4 & 1 & 1 & 0 \\
\hline NSAID $(124,209-228)$ & 15 & 21 & 2 & 1 & 5 & 0 & 10 & 9 \\
\hline Melatonin (232) & 1 & 1 & 0 & 0 & 0 & 1 & 0 & 0 \\
\hline Bisphosphonate (61-147, 149-170) & 57 & 104 & 29 & 4 & 13 & 48 & 3 & 6 \\
\hline Raloxifene (132) & 1 & 1 & 0 & 0 & 0 & 1 & 0 & 0 \\
\hline Chemotherapy (267-272) & 5 & 6 & 0 & 1 & 1 & 0 & 5 & 1 \\
\hline Corticosteroids $(95,265,266)$ & 2 & 3 & 0 & 0 & 1 & 0 & 2 & 1 \\
\hline Antihypertensive (291-293) & 2 & 3 & 1 & 0 & 0 & 1 & 0 & 1 \\
\hline Local anesthesia (231) & 1 & 1 & 1 & 0 & 0 & 0 & 0 & 0 \\
\hline Thyroid hormone replacement $(124,133,251,252,259-262)$ & 4 & 8 & 2 & 0 & 0 & 5 & 1 & 0 \\
\hline Sex hormone replacement $(134,136,169,249-258)$ & 9 & 12 & 1 & 0 & 1 & 9 & 0 & 1 \\
\hline Sex hormone replacement + Bisphosphonate (110) & 0 & 1 & 0 & 0 & 0 & 1 & 0 & 0 \\
\hline Anti-RANKL $(130,205)$ & 2 & 2 & 0 & 0 & 0 & 2 & 0 & 0 \\
\hline Anti-angiogenic $(273,274)$ & 2 & 2 & 0 & 0 & 0 & 0 & 3 & 0 \\
\hline Immunosuppression (304-310) & 5 & 7 & 0 & 0 & 0 & 0 & 6 & 1 \\
\hline Immunosuppression + nifedipine (293) & 0 & 1 & 0 & 0 & 0 & 0 & 0 & 1 \\
\hline Statin $(188,189,294-301)$ & 6 & 10 & 1 & 0 & 0 & 8 & 0 & 1 \\
\hline Statin + PTH $(188,189)$ & 2 & 2 & 0 & 0 & 0 & 2 & 0 & 0 \\
\hline Warfarin (303) & 1 & 1 & 0 & 0 & 0 & 0 & 1 & 0 \\
\hline Anti-Sclerostin antibody $(203,204)$ & 0 & 2 & 0 & 0 & 0 & 2 & 0 & 0 \\
\hline Prostaglandin EP4 receptor agonist (229)(317) & 0 & 2 & 0 & 0 & 0 & 2 & 0 & 0 \\
\hline Cannabis (230) & 0 & 1 & 0 & 0 & 0 & 0 & 1 & 0 \\
\hline
\end{tabular}

NS: a study showing no significant differences between control and drug-treated group; -ve: negative; +ve: positive 


\subsubsection{Discussion}

This study achieved two key objectives, it provided a new way of performing systematic evidence mappings using AI, and it provided a comprehensive systematic mapping of the medications known to affect osseointegration. The results of this study highlighted the importance of using AI in data screening for evidence mapping reviews. Using machine learning, we were able to screen automatically 543927 articles by only having to screen manually $1.49 \%$ of the total dataset. This allowed us to retrieve 268 relevant articles and reduced the workload of the evidence mapping by 95\% while achieving high sensitivity, specificity, and accuracy. As a result of this, we were able to identify a total of 31 drug categories known to affect osseointegration.

The literature on the use of AI for systematic mapping is scarce, and only two groups have done this. A study from Lam, J. et al., on the effect of low-calorie sweeteners (LCS) on health outcomes (5), and the tool of Tripdatabase.com for fully automated mapping (6). Our method required a lower percentage of manual article screening than Lam, J. et al. (1.49\% vs. $28 \%$ ), and even though Tripdatabase does not require manual screening, our method was able to detect far more relevant articles. The clinical search engine Tripdatabase.com includes an artificial intelligence (AI) for full automation of evidence mapping that does not require any manual screening by the user (6). However, this prototype can only perform automated evidence synthesis for RCT and SR, and it can't identify and synthesize observational or animal studies (6). In order to compare our systematic mapping with the performance of the Tripdatabase.com, on November 18, 2019, we executed a search for the term "osseointegration" on the evidence map tool of Tripdatabase.com. The search on the Tripdatabase.com was only able to detect 2 RCTs assessing osseointegration pharmacology. This is way below than 26 RCTs detected with our method. Also, within the limits of our knowledge, unlike the studies of Lam, J. et al., and the Tripdatabase.com tool for evidence 
mapping review, our algorithm for systematic mapping is the first that has been validated against published systematic reviews performed by humans $(5,6)$.

Our algorithm was validated against 2 already published systematic reviews (Chappuis et al.) (Aghaloo et al.) with search strategies that falls within the scope of ours (3) (318). We validated our algorithm only against the RCTs and observational clinical studies included by Chappuis et al., because in our review we excluded cross-section, case-series and case reports. Therefore, we only focused on 14 of the 17 articles included in their review for our validation. We used our algorithm to screen the 596 articles identified by the search strategy of their published systematic review, and our AI was able to identify 13 of the 14 articles included by the authors that met our inclusion criteria. This indicated that our AI perhaps could have missed up to $7 \%$ of relevant clinical studies. Nevertheless, our review included 76 more clinical studies (five-folds) compared to Chappuis et al. article (3) including 28 RCTs compared to 2 articles identified by Chappuis et al., and 48 observational studies compared to 12 articles identified by Chappuis et al. (3). Also, we were able to identify 14 drug classes assessed in clinical studies compared to 5 drug classes identified by Chappuis et al. article (3). Upon validation with the systematic review of Aghaloo et al. (318), our AI was able to identify 14 of the 15 articles retrieved by Aghaloo et al that fit our inclusion criteria reaching a sensitivity of $93 \%$.

The thirty-one drug classes identified by our systematic mapping are known to affect different metabolic pathways involved in the bone healing processes. For instance, Warfarin, NSAID, and Aspirin are known to impair hemostasis, and they were found to have a negative effect on osseointegration. Cannabis, NSAID, Aspirin, Corticosteroids, Antibiotics, Alcohol, Metformin, and Immunosuppressants affect the inflammation. Chemotherapy, Nicotine, Alcohol, Corticosteroids, Cannabis, Hyperbaric oxygen, Aprotinin, Melatonin, Parathyroid hormone 
replacement, and Anti-VEGF affect angiogenesis and proliferation. And, the following drugs are known to affect remodeling: Chemotherapy, Corticosteroids, Antibiotics, Prostaglandin EP4 receptor agonist, Anti-Sclerostin antibody, Statin, PPI, Lithium chloride, SSRIs, Vitamin D, Oxytocin, Anti-RANKL, Estradiol, Dihydrotestosterone, Thyroid hormone replacement, Parathyroid hormone replacement, Insulin, Melatonin, NSAID, Antihypertensive, Bisphosphonate, Raloxifene, Strontium ranelate, and Glucocorticoids (Table 4 ). These observations confirm our hypothesis stating that drugs affecting the pathways of bone healing have an effect on osseointegration (61-316).

Table 4: The stages of osseointegration that could be affected by the drugs identified in our review (61-316).

\begin{tabular}{|c|c|}
\hline Stages of osseointegration & Drugs that could affect each stage \\
\hline Hemostasis and Thrombosis & Warfarin, NSAID (Aspirin), and SSRIs \\
\hline Inflammation & $\begin{array}{l}\text { Cannabis, Immunosuppression, Corticosteroids, Antibiotics, Alcohol, Anti- } \\
\text { diabetic, NSAID, and SSRIs. }\end{array}$ \\
\hline Proliferation & $\begin{array}{l}\text { Chemotherapy, Nicotine, Alcohol, Corticosteroids, Cannabis, Hyperbaric oxygen, } \\
\text { Aprotinin, Melatonin, Anti-angiogenic, PTH, and Antibiotics. }\end{array}$ \\
\hline Remodeling & $\begin{array}{l}\text { Chemotherapy, Corticosteroids, Antibiotics, Prostaglandin EP4 receptor agonist, } \\
\text { Anti-Sclerostin antibody, Statin, PPI, Lithium chloride, SSRIs, Vit D, Oxytocin, } \\
\text { Anti-RANKL, Estradiol, Dihydrotestosterone, Thyroid hormone replacement, } \\
\text { Strontium ranelate, Bisphosphonate Antihypertensive, Glucocorticoids, Anti- } \\
\text { diabetic, PTH, Raloxifene, and Melatonin. }\end{array}$ \\
\hline
\end{tabular}

\section{Differences between orthopaedic and Craniofacial osseointegration}

Craniofacial bone and skeletal bone have different embryological origins and metabolism. Thus, drugs and osseointegrated implants could behave differently in these two types of bone. Among the 12 drugs and drug categories assessed for their effect on implant osseointegration in both craniofacial and skeletal bones, most were found to have similar effects on both types of bone. This included Zoledronic Acid, Alendronate, Ibuprofen, $17 \beta$ estradiol, Alcohol, AntiHypertensive, and PTH (Table 5, and Figure 13). However, Diclofenac sodium, Prednisolone, Amoxicillin and Chemotherapy had a negative effect on osseointegration of orthopedic implants 
$(213,214,265,267)$, but did not show a significant effect on craniofacial implants $(215,216,265$, 268) (275-279). On the other hand, metformin was found to have a positive effect on orthopedic implants (288), while having a negative effect on craniofacial implants, (Table 5, and Figure 13) (289).

\section{Craniofacial implants;}

Few drugs were assessed only in craniofacial bone but not in skeletal bones. These include SSRI, PPI, Glucocorticosteroids, Non-specific NSAID, Parecoxib, Flurbiprofen, and Bupivacaine without vasoconstrictor (Table 5, and Figure 13). On the other hand, a large number of drugs were assessed on implants placed on skeletal bones but not in craniofacial bones. This included: Nicotine, Lithium chloride, Strontium ranelate, Celecoxib, Meloxicam, Aspirin, Naproxen, Celecoxib, Rofecoxib-a, Indomethacin, Melatonin, Disodium Diphosphonate, Ibandronate,

Clodronate, Risedronate, Pamidronate, Etidronate, Bisphosphonate (TRK-530), Bisphosphonate (YM-175), Calcitriol (Vitamin D), OPG-Fc, Raloxifene, Methylprednisolone, Calcitonin, Levothyroxine, Dihydrotestosterone, Xianlinggubao, Statins, Cisplatin, Methotrexate, Doxorubicin, Ifosfamide, Insulin, Aminoguanidine, Anti-RANKL, Anti-angiogenic (TNP-470), Anti-VEGF, Ranibizumab, Cyclosporin A, FK-506, Oxytocin, Aprotinin, Hyperbaric oxygen therapy (HBO), Warfarin, Sclerostin antibody, Prostaglandin EP4 receptor agonist, and Cannabis (Table 5 and Figure 13).

Future research should be performed to assess the effect of these drugs on both craniofacial and skeletal bones.

Table 5: The list of the drugs that were tested in each type of bone.

\begin{tabular}{|l|l|}
\hline Type of bone & \multicolumn{1}{|c|}{ Drugs that could affect each type of bone } \\
\hline Orthopaedic & Nicotine, Lithium chloride, Strontium ranelate, Celecoxib, Meloxicam, Aspirin, \\
& Naproxen, Celecoxib, Rofecoxib-a, Indomethacin, Melatonin, Disodium \\
& Diphosphonate, Ibandronate, Clodronate, Risedronate, Pamidronate, Etidronate, \\
& Bisphosphonate (TRK-530), Bisphosphonate (YM-175), Calcitriol (Vitamin D), \\
& OPG-Fc, Raloxifene, Methylprednisolone, Calcitonin, Levothyroxine, \\
\hline
\end{tabular}




\begin{tabular}{|l|l|}
\hline & $\begin{array}{l}\text { Dihydrotestosterone, Xianlinggubao, Statins, Cisplatin, Methotrexate, } \\
\text { Doxorubicin, Ifosfamide, Insulin, Aminoguanidine, Anti-RANKL, Anti- } \\
\text { angiogenic (TNP-470), Anti-VEGF, Ranibizumab, Cyclosporin A, FK-506, } \\
\text { Oxytocin, Aprotinin, Hyperbaric oxygen therapy (HBO), Warfarin, Sclerostin } \\
\text { antibody, Prostaglandin EP4 receptor agonist, and Cannabis }\end{array}$ \\
\hline Craniofacial & $\begin{array}{l}\text { SSRI, PPI, Glucocorticosteroids, Non-specific NSAID, Parecoxib, Flurbiprofen, } \\
\text { and Bupivacaine without vasoconstrictor. }\end{array}$ \\
\hline $\begin{array}{l}\text { Orthopaedic and } \\
\text { Craniofacial }\end{array}$ & $\begin{array}{l}\text { Zoledronic Acid, Alendronate, Ibuprofen, 17ß estradiol, Alcohol, Anti- } \\
\text { Hypertensive, PTH, Diclofenac sodium, Prednisolone, Amoxicillin and } \\
\text { Chemotherapy, and Metformin. }\end{array}$ \\
\hline
\end{tabular}

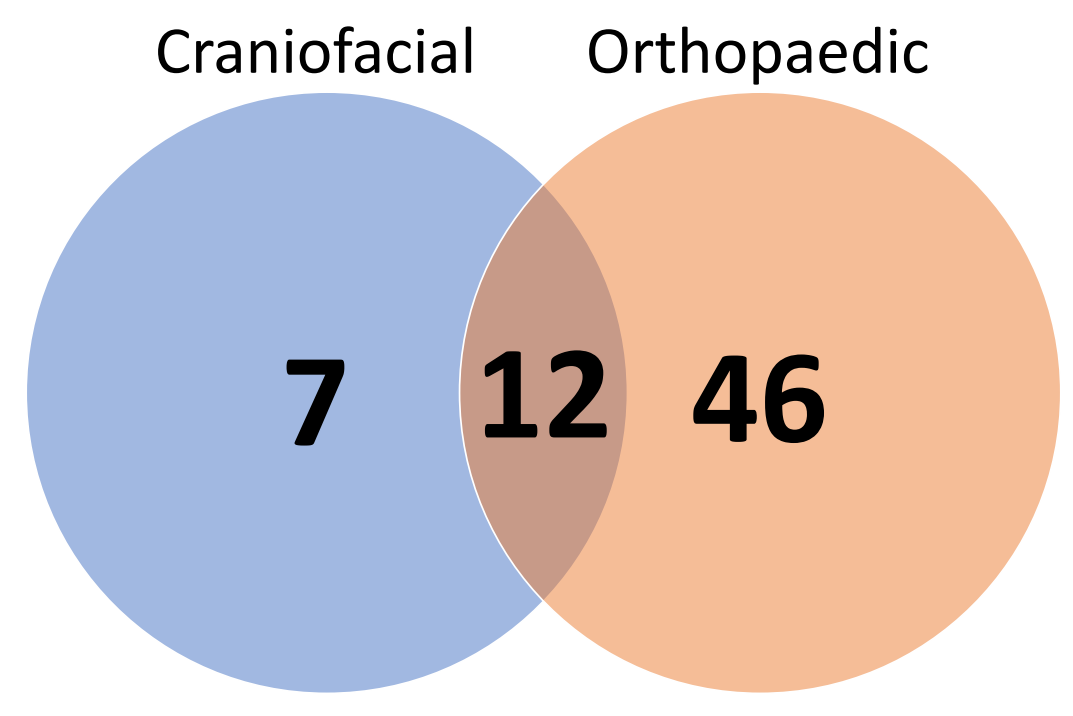

Figure 13: Venn diagram showing the number of drugs that were tested in each type of bone.

\subsubsection{Limitations, Strength and future work}

The main limitation of this study is that we searched only the Pubmed database because of its unique high-quality MeSH-terms, and thus we may have lost some publications found in other databases. Also, the Pubmed database has a delay in publishing the MeSH-terms of each article, thus some recently published studies might have been missed by our search method. Nevertheless, focusing on the Pubmed database, and the use of MeSH-terms allowed us to achieve excellent results. Another limitation of our algorithm was that 5\% of the articles included were falsepositives, and 7\% were false-negatives; thus, manual screening is still mandatory to identify such 
articles. Therefore, new methods are required to reduce manual screening of false-positive articles and to reduce the false-negative rate.

Also, our results in this thesis, guide researchers towards identifying the research gaps related to the effect of pharmacological agents on osseointegration and could help suggest future clinical studies on the effect of pharmacological drugs on implant osseointegration.

\subsubsection{Conclusions}

MeSH-term classifier trained with a dataset that includes non-similar studies only requires manual screening of $1.49 \%$ of the original search of an evidence mapping review. This approach could make complex systematic reviews or evidence mapping reviews increasingly time-efficient and allows us to answer a complex question such as, "What drugs could affect bone-implant osseointegration?". Our evidence mapping on this specific subject revealed that drugs known to affect the metabolic activities involved in the process of osseointegration could indeed affect osseointegration.

\subsubsection{Acknowledgments}

We thank Mr. Martin Morris for assisting in building the search strategy. Also, We thank Jazan University, College of Dentistry, and the Saudi Arabian Cultural Bureau in Ottawa for their financial support. 


\section{References;}

1. Albrektsson T, Brånemark P-I, Hansson H-A, Lindström J. Osseointegrated titanium implants: requirements for ensuring a long-lasting, direct bone-to-implant anchorage in man. Acta Orthop Scand. 1981;52(2):155-70.

2. Esposito M, Hirsch JM, Lekholm U, Thomsen P. Biological factors contributing to failures of osseointegrated oral implants,(II). Etiopathogenesis. Eur J Oral Sci. 1998;106(3):721-64.

3. Chappuis V, Avila-Ortiz G, Araújo MG, Monje A. Medication-related dental implant failure: Systematic review and meta-analysis. Clin Oral Implant Res. 2018;29:55-68.

4. Miake-Lye IM, Hempel S, Shanman R, Shekelle PG. What is an evidence map? A systematic review of published evidence maps and their definitions, methods, and products. Syst Rev. 2016;5(1):28.

5. Lam J, Howard BE, Thayer K, Shah RR. Low-calorie sweeteners and health outcomes: A demonstration of rapid evidence mapping (rEM). Environ Int. 2019;123:451-8.

6. Brassey J, Price C, Edwards J, Zlabinger M, Bampoulidis A, Hanbury A. Developing a fully automated evidence synthesis tool for identifying, assessing and collating the evidence. BMJ Evid Based Med. 2019:bmjebm-2018-111126.

7. Lian JB, Stein GS, van Wijnen AJ, Stein JL, Hassan MQ, Gaur T, et al. MicroRNA control of bone formation and homeostasis. Nat Rev Endocrinol. Nat Rev Endocrinol. 2012;8:212.

8. Anthony BA, Link DC. Regulation of hematopoietic stem cells by bone marrow stromal cells. Trends in immunology. Trends Immunol. 2014;35(1):32-7.

9. Maas MC. Bones and Teeth, Histology of. In: Perrin WF, Würsig B, Thewissen JGM, editors. Encyclopedia of Marine Mammals (Second Edition). London: Academic Press; 2009. p. 124-9.

10. Kini U, Nandeesh BN. Physiology of Bone Formation, Remodeling, and Metabolism. In: Fogelman I, Gnanasegaran G, van der Wall H, editors. Radionuclide and Hybrid Bone Imaging. Berlin, Heidelberg: Springer Berlin Heidelberg; 2012. p. 29-57.

11. Sommerfeldt D, Rubin C. Biology of bone and how it orchestrates the form and function of the skeleton. European Spine Journal. 2001;10(2):S86-S95.

12. Ortega N, Behonick DJ, Werb Z. Matrix remodeling during endochondral ossification. Trends in cell biology. 2004;14(2):86-93.

13. Katsimbri P. The biology of normal bone remodelling. Eur J Cancer Care (Engl). 2017;26(6).

14. Giannoudis PV, Einhorn TA, Marsh D. Fracture healing: the diamond concept. Injury. 2007;38:S3-

S6.

15. Marsell R, Einhorn TA. The biology of fracture healing. Injury. 2011;42(6):551-5.

16. Kalfas IH. Principles of bone healing. Neurosurg Focus. 2001;10(4):1-4.

17. Taipale J, Keski-Oja J. Growth factors in the extracellular matrix. FASEB J. 1997;11(1):51-9.

18. Terheyden H, Lang NP, Bierbaum S, Stadlinger B. Osseointegration--communication of cells. Clin Oral Implants Res. 2012;23(10):1127-35.

19. Raggatt $\mathrm{L}$, Partridge NC. Cellular and molecular mechanisms of bone remodeling. J Biol Chem. 2010;285(33):25103-8.

20. Vaidya P, Mahale S, Kale S, Patil A, Sciences M. Osseointegration-a review. IOSR Journal. 2017;16(1):45-8.

21. Mavrogenis A, Dimitriou R, Parvizi J, Babis G. Biology of implant osseointegration. J Musculoskelet Neuronal Interact. 2009;9(2):61-71.

22. Javed F, Ahmed HB, Crespi R, Romanos GE. Role of primary stability for successful osseointegration of dental implants: Factors of influence and evaluation. Interv Med Appl Sci. 2013;5(4):162-7. 
23. Branemark PI, Hansson BO, Adell R, Breine U, Lindstrom J, Hallen O, et al. Osseointegrated implants in the treatment of the edentulous jaw. Experience from a 10-year period. Scand J Plast Reconstr Surg Hand Surg Suppl. 1977;16:1-132.

24. Raghavendra S, Wood MC, Taylor T, Implants M. Early wound healing around endosseous implants: a review of the literature. Int J Oral Maxillofac Implants. 2005;20(3): p425-431.

25. Esposito M, Hirsch JM, Lekholm U, Thomsen P. Biological factors contributing to failures of osseointegrated oral implants,(I). Success criteria and epidemiology. Eur. J. Oral Sci. 1998;106(1):527-51.

26. Schep N, Heintjes R, Martens E, van Dortmont L, Van Vugt AB. Retrospective analysis of factors influencing the operative result after percutaneous osteosynthesis of intracapsular femoral neck fractures. Injury. 2004;35(10):1003-9.

27. Gopalakrishnan S, Ganeshkumar P. Systematic reviews and meta-analysis: understanding the best evidence in primary healthcare. J Family Med Prim Care. 2013;2(1): 9-14.

28. Crowley P, Chalmers I, Keirse MJ. The effects of corticosteroid administration before preterm delivery: an overview of the evidence from controlled trials. Br J Obstet Gynaecol. 1990;97(1):11-25.

29. Kohl C, McIntosh EJ, Unger S, Haddaway NR, Kecke S, Schiemann J. Online tools supporting the conduct and reporting of systematic reviews and systematic maps: a case study on CADIMA and review of existing tools. Environ Evid. 2018;7(1):8.

30. Sutherland WJ, Wordley CFR. A fresh approach to evidence synthesis. Nature. 2018;558(7710):364-6.

31. Bannach-Brown A, Przybyla P, Thomas J, Rice ASC, Ananiadou S, Liao J. Machine learning algorithms for systematic review: reducing workload in a preclinical review of animal studies and reducing human screening error. Syst Rev. 2019;8(1):23.

32. Samuel AL. Some Studies in Machine Learning Using the Game of Checkers. II-Recent Progress. In: Levy DNL, editor. Computer Games I. New York, NY: Springer New York; 1988. p. 366-400.

33. Gates A, Johnson C, Hartling L. Technology-assisted title and abstract screening for systematic reviews: a retrospective evaluation of the Abstrackr machine learning tool. Syst Rev. 2018;7(1):45.

34. Przybyła P, Brockmeier AJ, Kontonatsios G, Le Pogam MA, McNaught J, von Elm E, et al. Prioritising references for systematic reviews with RobotAnalyst: A user study. Res Synth Methods. 2018;9(3):470-88.

35. Marshall IJ, Kuiper J, Wallace BC. RobotReviewer: evaluation of a system for automatically assessing bias in clinical trials. J Am Med Inform Assoc. 2016;23(1):193-201.

36. Waddington $\mathrm{H}$, Masset $\mathrm{E}$, Jimenez $\mathrm{E}$. What have we learned after ten years of systematic reviews in international development? : Taylor \& Francis; J Dev Effect. 2018;10(1)

37. Jaspers $S$, De Troyer E, Aerts MJESP. Machine learning techniques for the automation of literature reviews and systematic reviews in EFSA. EFSA. 2018;15(6):1427E.

38. O'Mara-Eves A, Thomas J, McNaught J, Miwa M, Ananiadou S. Using text mining for study identification in systematic reviews: a systematic review of current approaches. Syst Rev. 2015;4:5. 39. Tsafnat G, Glasziou P, Karystianis G, Coiera E. Automated screening of research studies for systematic reviews using study characteristics. Syst Rev. 2018;7(1):64.

40. Singh G, Thomas J, Shawe-Taylor J. Improving active learning in systematic reviews. 2018.

41. Petis $S$, Howard JL, Lanting BL, Vasarhelyi EM. Surgical approach in primary total hip arthroplasty: anatomy, technique and clinical outcomes. Can J Surg. 2015;58(2):128-39.

42. American Dental Association. Dental Implants. 2015, February 12

43. Gaviria L, Salcido JP, Guda T, Ong JL. Current trends in dental implants. J Korean Assoc Oral Maxillofac Surg. 2014;40(2):50-60.

44. Carlson ML, O'Connell BP, Lohse CM, Driscoll CL, Sweeney AD. Survey of the American Neurotology Society on Cochlear Implantation: Part 2, Surgical and Device-Related Practice Patterns. Otol Neurotol. 2018;39(1):e20-e7. 
45. Wu X, Tamimi F. Pharmacological Risk Assessment for Dental Implants. In: Emami E, Feine J, editors. Mandibular Implant Prostheses: Guidelines for Edentulous Geriatric Populations. Cham: Springer International Publishing; 2018. p. 37-65.

46. Szumita RP, Szumita PM. S214: Hemostasis: A Clinical Review of Pathophysiology, Pharmacotherapy, and Perioperative Management. J. Oral Maxillofac. Surg.. 2007;65(9):88-9.

47. Tsafnat G, Glasziou P, Choong MK, Dunn A, Galgani F, Coiera E. Systematic review automation technologies. Syst Rev. 2014;3(1):74.

48. Berndt DJ, McCart JA, Finch DK, Luther SLJAToMIS. A case study of data quality in text mining clinical progress notes. ACM Trans. Manage. Inf. Syst. 2015;6(1):1-21.

49. Friedman C, Rindflesch TC, Corn M. Natural language processing: state of the art and prospects for significant progress, a workshop sponsored by the National Library of Medicine. J Biomed Inform. 2013;46(5):765-73.

50. Yu Z, Bernstam E, Cohen T, Wallace BC, Johnson TR. Improving the utility of MeSH ${ }^{\circledR}$ terms using the TopicalMeSH representation. J Biomed Inform. 2016;61:77-86.

51. Tricco AC, Lillie E, Zarin W, O'Brien KK, Colquhoun H, Levac D, et al. PRISMA extension for scoping reviews (PRISMA-ScR): checklist and explanation. Ann. Intern. Med. 2018;169(7):467-73.

52. Bragge $P$, Clavisi O, Turner T, Tavender E, Collie A, Gruen RL. The global evidence mapping initiative: scoping research in broad topic areas. BMC Med Res Methodol. 2011;11(1):92.

53. Ballesteros M, Montero N, López-Pousa A, Urrútia G, Solà I, Rada G, et al. Evidence mapping based on systematic reviews of therapeutic interventions for gastrointestinal stromal tumors (GIST). BMC Med Res Methodol. 2017;17(1):135.

54. Eibe Frank MAH, and lan H. Witten. The WEKA Workbench. Online Appendix for "Data Mining: Practical Machine Learning Tools and Techniques", Morgan Kaufmann, Fourth Edition, 2016.

55. Witten IH, Frank E, Hall MA, Pal CJ. Data Mining: Practical machine learning tools and techniques: Morgan Kaufmann; 2016.

56. Huang C-L, Chen M-C, Wang C-J. Credit scoring with a data mining approach based on support vector machines. Expert Syst Appl. 2007;33(4):847-56.

57. Schünemann HJ, Oxman AD, Higgins JP, Vist GE, Glasziou P, Guyatt G. Chapter 5: Defining the review question and developing criteria for including studies. In: Julian PT H. and Sally G., eds. Cochrane Handbook for Systematic Reviews of Interventions version 5.1.0. Great Britain. 2008;5(0): 84-90.

58. Hooijmans CR, Rovers MM, de Vries RB, Leenaars $M$, Ritskes-Hoitinga $M$, Langendam MW. SYRCLE's risk of bias tool for animal studies. BMC Med Res Methodol. 2014;14:43.

59. Zeng X, Zhang Y, Kwong JS, Zhang C, Li S, Sun F, et al. The methodological quality assessment tools for preclinical and clinical studies, systematic review and meta-analysis, and clinical practice guideline: a systematic review. J Evid Based Med. 2015;8(1):2-10.

60. von Elm E, Altman DG, Egger M, Pocock SJ, Gotzsche PC, Vandenbroucke JP. The Strengthening the Reporting of Observational Studies in Epidemiology (STROBE) Statement: guidelines for reporting observational studies. Int J Surg. 2014;12(12):1495-9.

61. Prieto-Alhambra D, Javaid MK, Judge A, Murray D, Carr A, Cooper C, et al. Association between bisphosphonate use and implant survival after primary total arthroplasty of the knee or hip: population based retrospective cohort study. BMJ (Clinical research ed). 2011;343:d7222.

62. Fu S-H, Wang C-Y, Yang R-S, Wu F-L, Hsiao F-Y. Bisphosphonate use and the risk of undergoing total knee arthroplasty in osteoporotic patients with osteoarthritis: a nationwide cohort study in taiwan. J Bone Joint Surg Am.. 2017;99(11):938-46.

63. Prieto-Alhambra D, Lalmohamed A, Abrahamsen B, Arden NK, de Boer A, Vestergaard P, et al. Oral bisphosphonate use and total knee/hip implant survival: validation of results in an external population-based cohort. Arthritis Rheumatol. 2014;66(11):3233-40. 
64. Cho PG, Ji GY, Shin DA, Ha Y, Kim K. An effect comparison of teriparatide and bisphosphonate on posterior lumbar interbody fusion in patients with osteoporosis: a prospective cohort study and preliminary data. Eur Spine J. 2017;26(3):691-7.

65. Yip JK, Borrell LN, Cho SC, Francisco H, Tarnow DP. Association between oral bisphosphonate use and dental implant failure among middle-aged women. J Clin Periodontol. 2012;39(4):408-14.

66. Memon S, Weltman RL, Katancik JA. Oral bisphosphonates: early endosseous dental implant success and crestal bone changes. A retrospective study. Int J Oral Maxillofac Implants. 2012;27(5):121622.

67. Grant BT, Amenedo C, Freeman K, Kraut RA. Outcomes of placing dental implants in patients taking oral bisphosphonates: a review of 115 cases. J Oral Maxillofac Surg. 2008;66(2):223-30.

68. Mozzati M, Arata V, Giacomello M, Del Fabbro M, Gallesio G, Mortellaro C, et al. Failure risk estimates after dental implants placement associated with plasma rich in growth factor-Endoret in osteoporotic women under bisphosphonate therapy. J Craniofac Surg. 2015;26(3):749-55.

69. Bell BM, Bell RE. Oral bisphosphonates and dental implants: a retrospective study. J Oral Maxillofac Surg. 2008;66(5):1022-4.

70. Famili P, Quigley S, Mosher T. Survival of dental implants among post-menopausal female dental school patients taking oral bisphosphonates: a retrospective study. Compend Contin Educ Dent. 2011;32(6):E106-9.

71. Zahid TM, Wang BY, Cohen RE. Influence of bisphosphonates on alveolar bone loss around osseointegrated implants. J Oral Implantol. 2011;37(3):335-46.

72. Scott DF, Woltz JN, Smith RR. Effect of zoledronic acid on reducing femoral bone mineral density loss following total hip arthroplasty: preliminary results of a prospective randomized trial. J Arthroplasty. 2013;28(4):671-5.

73. Friedl G, Radl R, Stihsen C, Rehak P, Aigner R, Windhager R. The effect of a single infusion of zoledronic acid on early implant migration in total hip arthroplasty: a randomized, double-blind, controlled trial. J Bone Joint Surg Am.. 2009;91(2):274-81.

74. Huang TW, Wang CJ, Shih HN, Chang Y, Huang KC, Peng KT, et al. Bone turnover and periprosthetic bone loss after cementless total hip arthroplasty can be restored by zoledronic acid: a prospective, randomized, open-label, controlled trial. BMC musculoskeletal disorders. 2017;18(1):209.

75. Siebert T, Jurkovic R, Statelova D, Strecha J. Immediate Implant Placement in a Patient With Osteoporosis Undergoing Bisphosphonate Therapy: 1-Year Preliminary Prospective Study. J Oral Implantol. 2015;41 Spec No:360-5.

76. Chen B, Li Y, Yang X, Xu H, Xie D. Zoledronic acid enhances bone-implant osseointegration more than alendronate and strontium ranelate in ovariectomized rats. Osteoporos Int. 2013;24(7):2115-21.

77. Yaman F, Agacayak S, Atilgan S, Benlidayi E, Ucan MC, Erol B, et al. Effects of systemic zoledronic Acid administration on osseointegration of hydroxyapatite-coated and resorbable blast material surface implants in rabbit models. Int J Oral Maxillofac Implants. 2012;27(6):1443-7.

78. Li JP, Li P, Hu J, Dong W, Liao NN, Qi MC, et al. Early healing of hydroxyapatite-coated implants in grafted bone of zoledronic acid-treated osteoporotic rabbits. J Periodontol. 2014;85(2):308-16.

79. Dikicier E, Karacayli U, Dikicier S, Gunaydin Y. Effect of systemic administered zoledronic acid on osseointegration of a titanium implant in ovariectomized rats. J Craniomaxillofac Surg. 2014;42(7):110611.

80. Dikicier S, Dikicier E, Karacayli U, Erguder B. Radiodensitometric study for evaluation of bone mineral density around dental implants after zoledronic acid treatment in ovariectomized rats. Med Oral Patol Oral Cir Bucal. 2017;22(3):e377-e82.

81. Bobyn JD, Hacking SA, Krygier JJ, Harvey EJ, Little DG, Tanzer M. Zoledronic acid causes enhancement of bone growth into porous implants. J Bone Joint Surg Br. 2005;87(3):416-20. 
82. Qi M, Hu J, Li J, Li J, Dong W, Feng X, et al. Effect of zoledronate acid treatment on osseointegration and fixation of implants in autologous iliac bone grafts in ovariectomized rabbits. Bone. 2012;50(1):119-27.

83. Dundar S, Yaman F, Gecor O, Cakmak O, Kirtay M, Yildirim TT, et al. Effects of local and systemic zoledronic acid application on titanium implant osseointegration: an experimental study conducted on two surface types. J Craniofac Surg. 2017;28(4):935-8.

84. Ayan M, Dolanmaz D, Mihmanli A, Ayan A, Kurkcu M. The effect of systemically administrated zoledronic acid on the osseointegration of dental implants. Oral Dis 2012;18(8):802-8.

85. Blazsek J, Dobo Nagy C, Blazsek I, Varga R, Vecsei B, Fejerdy P, et al. Aminobisphosphonate stimulates bone regeneration and enforces consolidation of titanium implant into a new rat caudal vertebrae model. Pathol Oncol Res. 2009;15(4):567-77.

86. Goodship AE, Blunn GW, Green J, Coathup MJ. Prevention of strain-related osteopenia in aseptic loosening of hip prostheses using perioperative bisphosphonate. J Orthop Res. 2008;26(5):693-703.

87. Li YF, Li XD, Bao CY, Chen QM, Zhang H, Hu J. Promotion of peri-implant bone healing by systemically administered parathyroid hormone (1-34) and zoledronic acid adsorbed onto the implant surface. Osteoporos Int : 2013;24(3):1063-71.

88. Wu FQ, Ye J, Wu LG. [Inhibitory effect of zoledronate sodium on periprosthetic osteolysis induced by polyethylene particles]. Zhongguo Gu Shang. 2015;28(10):936-9.

89. Spence G, Phillips S, Campion C, Brooks R, Rushton N. Bone formation in a carbonatesubstituted hydroxyapatite implant is inhibited by zoledronate: the importance of bioresorption to osteoconduction. J Bone Joint Surg Br. 2008;90(12):1635-40.

90. Huja SS, Kaya B, Mo X, D'Atri AM, Fernandez SA. Effect of zoledronic acid on bone healing subsequent to mini-implant insertion. Angle Orthod. 2011;81(3):363-9.

91. Huja SS, Mason A, Fenell CE, Mo X, Hueni S, D'Atri AM, et al. Effects of short-term zoledronic acid treatment on bone remodeling and healing at surgical sites in the maxilla and mandible of aged dogs. J Oral Maxillofac Surg. 2011;69(2):418-27.

92. Kim I, Ki H, Lee W, Kim H, Park JB. The effect of systemically administered bisphosphonates on bony healing after tooth extraction and osseointegration of dental implants in the rabbit maxilla. Int J Oral Maxillofac Implants. 2013;28(5):1194-200.

93. Yildiz A, Esen E, Kurkcu M, Damlar I, Daglioglu K, Akova T. Effect of zoledronic acid on osseointegration of titanium implants: an experimental study in an ovariectomized rabbit model. J Oral Maxillofac Surg. 2010;68(3):515-23.

94. de Oliveira MA, Asahi DA, Silveira CA, Lima LAP, Glick M, Gallottini MJCoir. The effects of zoledronic acid and dexamethasone on osseointegration of endosseous implants: histological and histomorphometrical evaluation in rats. Clin Oral Implants Res. 2015;26(4):e17-e21.

95. Carvas JS, Pereira RM, Caparbo VF, Fuller P, Silveira CA, Lima LA, et al. A single dose of zoledronic acid reverses the deleterious effects of glucocorticoids on titanium implant osseointegration. Osteoporos Int. 2010;21(10):1723-9.

96. Lee J, Lee C, Choi C. QCT bone mineral density responses to 1 year of oral bisphosphonate after total knee replacement for knee osteoarthritis. Osteoporos Int. 2013;24(1):287-92.

97. Hennigs T, Arabmotlagh M, Schwarz A, Zichner L. [Dose-dependent prevention of early periprosthetic bone loss by alendronate]. Z Orthop Ihre Grenzgeb. 2002;140(1):42-7.

98. Lee JK, Choi $\mathrm{CH}$, Kang CN. Quantitative computed tomography assessment of bone mineral density after 2 years' oral bisphosphonate treatment in postmenopausal osteoarthritis patients who underwent total knee arthroplasty. J Int Med Res. 2013;41(3):878-88.

99. Kinov P, Tivchev P, Doukova P, Leithner A. Effect of risedronate on bone metabolism after total hip arthroplasty: a prospective randomised study. Acta orthopaedica Belgica. 2006;72(1):44-50. 
100. Jaroma AV, Soininvaara TA, Kroger H. Effect of one-year post-operative alendronate treatment on periprosthetic bone after total knee arthroplasty. A seven-year randomised controlled trial of 26 patients. Bone Joint J. 2015;97-b(3):337-45.

101. Iwamoto N, Inaba Y, Kobayashi N, Ishida T, Yukizawa Y, Saito TJ. A comparison of the effects of alendronate and alfacalcidol on bone mineral density around the femoral implant and in the lumbar spine after total hip arthroplasty. J Bone Joint Surg Am.. 2011;93(13):1203-9.

102. Tapaninen T, Venesmaa P, Jurvelin J, Miettinen H, Kröger HJSJoS. Alendronate reduces periprosthetic bone loss after uncemented primary total hip arthroplasty-a 5-year follow-up of 16 patients. Scand J Surg. 2010;99(1):32-7.

103. Nishioka T, Yagi S, Mitsuhashi T, Miyamoto M, Tamura T, Kobayashi T, et al. Alendronate inhibits periprosthetic bone loss around uncemented femoral components. J Bone Miner Metab. 2007;25(3):179-83.

104. Moroni A, Faldini C, Hoang-Kim A, Pegreffi F, Giannini SJJ. Alendronate improves screw fixation in osteoporotic bone. J Bone Joint Surg Am.. 2007;89(1):96-101.

105. Wang CJ, Wang JW, Weng LH, Hsu CC, Huang CC, Chen HS. The effect of alendronate on bone mineral density in the distal part of the femur and proximal part of the tibia after total knee arthroplasty. J Bone Joint Surg Am. 2003;85-a(11):2121-6.

106. Soininvaara TA, Jurvelin JS, Miettinen HJ, Suomalainen OT, Alhava EM, Kroger PJ. Effect of alendronate on periprosthetic bone loss after total knee arthroplasty: a one-year, randomized, controlled trial of 19 patients. Calcif Tissue Int. 2002;71(6):472-7.

107. Arabmotlagh M, Pilz M, Warzecha J, Rauschmann MJJoOR. Changes of femoral periprosthetic bone mineral density 6 years after treatment with alendronate following total hip arthroplasty. J Orthop Res. 2009;27(2):183-8.

108. Kobayashi N, Inaba Y, Uchiyama M, Ike H, Kubota S, Saito T. Teriparatide Versus Alendronate for the Preservation of Bone Mineral Density After Total Hip Arthroplasty - A randomized Controlled Trial. J Arthroplasty. 2016;31(1):333-8.

109. Yukizawa Y, Inaba Y, Kobayashi N, Choe H, Kubota S, Saito T. Efficacy of Alendronate for the Prevention of Bone Loss in Calcar Region Following Total Hip Arthroplasty. J Arthroplasty. 2017;32(7):2176-80.

110. Ji W-P, Wang X-L, Ma M-Q, Lan J, Li H. Traumatology. Prevention of early bone loss around the prosthesis by administration of anti-osteoporotic agents and influences of collared and non-collared femoral stem prostheses on early periprosthetic bone loss. Eur J Orthop Surg Traumatol.

2013;23(5):565-71.

111. Kasai T, Pogrel MA, Hossaini M. The prognosis for dental implants placed in patients taking oral bisphosphonates. J Calif Dent Assoc. 2009;37(1):39-42.

112. Martin DC, O'Ryan FS, Indresano AT, Bogdanos P, Wang B, Hui RL, et al. Characteristics of implant failures in patients with a history of oral bisphosphonate therapy. J Oral Maxillofac Surg. 2010;68(3):508-14.

113. Hansson U, Toksvig-Larsen S, Ryd L, Aspenberg PJAo. Once-weekly oral medication with alendronate does not prevent migration of knee prostheses: A double-blind randomized RSA study. Acta Orthop. 2009;80(1):41-5.

114. Wang C-J, Wang J-W, Ko J-y, Weng L-H, Huang C-C. Three-year changes in bone mineral density around the knee after a six-month course of oral alendronate following total knee arthroplasty: a prospective, randomized study. J Bone Joint Surg Am.. 2006;88(2):267-72.

115. Fugazzotto PA, Lightfoot WS, Jaffin R, Kumar A. Implant placement with or without simultaneous tooth extraction in patients taking oral bisphosphonates: postoperative healing, early follow-up, and the incidence of complications in two private practices. J Periodontol. 2007;78(9):1664-9. 
116. Koka S, Babu NM, Norell A. Survival of dental implants in post-menopausal bisphosphonate users. J Prosthodont Res. 2010;54(3):108-11.

117. Verzola MH, Frizzera F, de Oliveira GJ, Pereira RM, Rodrigues-Filho UP, Nonaka KO, et al. Effects of the long-term administration of alendronate on the mechanical properties of the basal bone and on osseointegration. Clin Oral Implants Res. 2015;26(12):1466-75.

118. Kim JH, Park YB, Li Z, Shim JS, Moon HS, Jung HS, et al. Effect of alendronate on healing of extraction sockets and healing around implants. Oral Dis. 2011;17(7):705-11.

119. Narai S, Nagahata S. Effects of alendronate on the removal torque of implants in rats with induced osteoporosis. Int J Oral Maxillofac Implants. 2003;18(2):218-23.

120. Oliveira Dd, Hassumi JS, GOMES-FERREIRA PHdS, POLO TOB, Ferreira GR, Faverani LP, et al. Short term sodium alendronate administration improves the peri-implant bone quality in osteoporotic animals. J Appl Oral Sci. 2017;25(1):42-52.

121. Viera-Negrón YE, Ruan W-h, Winger JN, Hou X, Sharawy MM, Borke JL. Effect of ovariectomy and alendronate on implant osseointegration in rat maxillary bone. J Oral Implantol. 2008;34(2):76-82.

122. Jensen TB, Bechtold JE, Chen X, Soballe K. Systemic alendronate treatment improves fixation of press-fit implants: a canine study using nonloaded implants. J Orthop Res. 2007;25(6):772-8.

123. Åstrand J, Aspenberg P. Reduction of instability-induced bone resorption using bisphosphonates: high doses are needed in rats. Acta Orthop Scand. 2002;73(1):24-30.

124. Cankaya D, Tabak Y, Ozturk AM, Gunay MC. Perioperative alendronate, risedronate, calcitonin and indomethacin treatment alters femoral stem fixation and periprosthetic bone mineral density in ovariectomized rats. J Orthop Sci. 2015;20(4):728-33.

125. Xue Q, Li H, Zou X, Dalstra M, Lind M, Christensen FB, et al. Alendronate treatment improves bone-pedicle screw interface fixation in posterior lateral spine fusion: an experimental study in a porcine model. Int Orthop. 2010;34(3):447-51.

126. Conte Neto N, de Andrade CR, Spolidorio LC, Planeta CdS, Cruz FC, de Souza Bastos A, et al. Effects of chronic stress and alendronate therapy on the osseointegration of titanium implants. Clin Implant Dent Relat Res. 2014;16(5):762-71.

127. Hazzaa HH, Amin G, Abo Hager EA, El Shiekh MA. Influence of alendronate administration regimen on the final outcome of implant osseointegration in an osteoporotic model. J Int Acad Periodontol. 2014;16(1):19-30.

128. Li CY, Zhou YM, Wang L, Li YQ, Fu L, Gong L. [Effect of alendronate sodium on torque-out testing on implant-bone interfaces in estrogen-deficient rabbits with alendronate systemic administration]. Hua Xi Kou Qiang Yi Xue Za Zhi. 2011;29(3):233-6.

129. Søballe K, Chen X, B Jensen T, Kidder L, E Bechtold JJAo. Alendronate treatment in the revision setting, with and without controlled implant motion: an experimental study in dogs. Acta Orthop. 2007;78(6):800-7.

130. Bernhardsson $M$, Sandberg $O$, Aspenberg P. Anti-RANKL treatment improves screw fixation in cancellous bone in rats. Injury. 2015;46(6):990-5.

131. Nakamura Y, Hayashi K, Abu-Ali S, Naito M, Fotovati A. Effect of preoperative combined treatment with alendronate and calcitriol on fixation of hydroxyapatite-coated implants in ovariectomized rats. J Bone Joint Surg Am. 2008;90(4):824-32.

132. Ramalho-Ferreira G, Faverani L, Prado F, Garcia Jr I, Okamoto R. Raloxifene enhances periimplant bone healing in osteoporotic rats. Int J Oral Maxillofac Surg. 2015;44(6):798-805.

133. Chen BL, Xie DH, Zheng ZM, Lu W, Ning CY, Li YQ, et al. Comparison of the effects of alendronate sodium and calcitonin on bone-prosthesis osseointegration in osteoporotic rats. Osteoporos Int 2011;22(1):265-70. 
134. Giro G, Coelho PG, Pereira RMR, Jorgetti V, Marcantonio Jr E, Orrico SR. The effect of oestrogen and alendronate therapies on postmenopausal bone loss around osseointegrated titanium implants. Clin Oral Implants Res. 2011;22(3):259-64.

135. Giro G, Sakakura CE, Gonçalves D, Pereira RM, Marcantonio E, Orrico SR. Effect of 17 $\beta$-Estradiol and Alendronate on the Removal Torque of Osseointegrated Titanium Implants in Ovariectomized Rats. J Periodontol. 2007;78(7):1316-21.

136. Giro G, Gonçalves D, Sakakura CE, Pereira RM, Marcantonio JE, Orrico SR. Influence of estrogen deficiency and its treatment with alendronate and estrogen on bone density around osseointegrated implants: radiographic study in female rats. Oral Med Oral Pathol Oral Radiol Endod. 2008;105(2):162-7. 137. Skripitz R, Johansson HR, Ulrich SD, Werner A, Aspenberg P. Effect of alendronate and intermittent parathyroid hormone on implant fixation in ovariectomized rats. J Orthop Sci. 2009;14(2):138-43.

138. Bragdon CR, Doherty AM, Jasty $M$, Rubash $\mathrm{H}$, Harris WH. Effect of oral alendronate on net bone ingrowth into canine cementless total hips. J Arthroplasty. 2005;20(2):258-63.

139. Thadani PJ, Waxman B, Sladek E, Barmada R, Gonzalez MH. Inhibition of particulate debrisinduced osteolysis by alendronate in a rat model. Orthopedics. 2002;25(1):59-63.

140. Millett PJ, Allen MJ, Bostrom MP. Effects of alendronate on particle-induced osteolysis in a rat model. J Bone Joint Surg Am. 2002;84(2):236-49.

141. Miyaji T, Nakase T, Azuma Y, Shimizu N, Uchiyama Y, Yoshikawa H. Alendronate inhibits bone resorption at the bone-screw interface. Clin Orthop Relat Res. 2005(430):195-201.

142. Oh KC, Hwang W, Park YB, Lee JH, Moon HS, Kim JH. Effects of Alendronate on Bone Remodeling Around Osseointegrated Implants in Rats. Implant Dent. 2017;26(1):46-53.

143. Oh K, Moon H, Lee J, Park Y, Kim JH. Effects of alendronate on the peri-implant bone in rats. Oral Dis. 2015;21(2):248-56.

144. Tsetsenekou E, Papadopoulos T, Kalyvas D, Papaioannou N, Tangl S, Watzek G. The influence of alendronate on osseointegration of nanotreated dental implants in New Zealand rabbits. Clin Oral Implants Res. 2012;23(6):659-66.

145. Chacon GE, Stine EA, Larsen PE, Beck FM, McGlumphy EA. Effect of alendronate on endosseous implant integration: an in vivo study in rabbits. J Oral Maxillofac Surg. 2006;64(7):1005-9.

146. Frenkel SR, Jaffe WL, Valle CD, Jazrawi L, Maurer S, Baitner A, et al. The effect of alendronate (Fosamax ${ }^{\mathrm{TM}}$ ) and implant surface on bone integration and remodeling in a canine model. J Biomed Mater Res. 2001;58(6):645-50.

147. Astrand J, Aspenberg P. Alendronate did not inhibit instability-induced bone resorption. A study in rats. Acta Orthop Scand. 1999;70(1):67-70.

148. Wang X, Shanbhag AS, Rubash HE, Agrawal CM. Short-term effects of bisphosphonates on the biomechanical properties of canine bone. J Biomed Mater Res. 1999;44(4):456-60.

149. Kitsugi T, Yamamuro T, Nakamura T, Oka M. Influence of disodium (1-hydroxythylidene) diphosphonate on bone ingrowth into porous, titanium fiber-mesh implants. J Arthroplasty. 1995;10(2):245-53.

150. Eberhardt C, Habermann B, Muller S, Schwarz M, Bauss F, Kurth AH. The bisphosphonate ibandronate accelerates osseointegration of hydroxyapatite-coated cementless implants in an animal model. J Orthop Sci. 2007;12(1):61-6.

151. Kurth AH, Eberhardt C, Muller S, Steinacker M, Schwarz M, Bauss F. The bisphosphonate ibandronate improves implant integration in osteopenic ovariectomized rats. Bone. 2005;37(2):204-10.

152. Eberhardt C, Schwarz M, Kurth AH. High dosage treatment of nitrogen-containing bisphosphonate ibandronate is required for osseointegration of cementless metal implants. J Orthop Sci. 2005;10(6):622-6. 
153. Eberhardt C, Stumpf U, Brankamp J, Schwarz M, Kurth AH. Osseointegration of cementless implants with different bisphosphonate regimens. Clin Orthop Relat Res. 2006;447:195-200.

154. Skoglund B, Holmertz J, Aspenberg P. Systemic and local ibandronate enhance screw fixation. J Orthop Res. 2004;22(5):1108-13.

155. Hilding M, Aspenberg P. Postoperative clodronate decreases prosthetic migration: 4-year follow-up of a randomized radiostereometric study of 50 total knee patients. Acta Orthop. 2006;77(6):912-6.

156. Hilding M, Ryd L, Toksvig-Larsen S, Aspenberg P. Clodronate prevents prosthetic migration: a randomized radiostereometric study of 50 total knee patients. Acta Orthop Scand. 2000;71(6):553-7.

157. Trevisan C, Ortolani S, Romano P, Isaia G, Agnese L, Dallari D, et al. Decreased periprosthetic bone loss in patients treated with clodronate: a 1-year randomized controlled study. Calcif Tissue Int. 2010;86(6):436-46.

158. Skoldenberg OG, Salemyr MO, Boden HS, AhI TE, Adolphson PY. The effect of weekly risedronate on periprosthetic bone resorption following total hip arthroplasty: a randomized, double-blind, placebocontrolled trial. J Bone Joint Surg Am. 2011;93(20):1857-64.

159. Yamasaki S, Masuhara K, Yamaguchi K, Nakai T, Fuji T, Seino Y. Risedronate reduces postoperative bone resorption after cementless total hip arthroplasty. Osteoporos Int. 2007;18(7):100915.

160. Ohtori S, Inoue G, Orita S, Yamauchi K, Eguchi Y, Ochiai N, et al. Comparison of teriparatide and bisphosphonate treatment to reduce pedicle screw loosening after lumbar spinal fusion surgery in postmenopausal women with osteoporosis from a bone quality perspective. Spine (Phila Pa 1976) . 2013;38(8):E487-E92.

161. Muren O, Akbarian E, Salemyr M, Bodén H, Eisler T, Stark A, et al. No effect of risedronate on femoral periprosthetic bone loss following total hip arthroplasty. A 4-year follow-up of 61 patients in a double-blind, randomized placebo-controlled trial. Acta orthopaedica. 2015;86(5):569-74.

162. Wilkinson JM, Stockley I, Peel NF, Hamer AJ, Elson RA, Barrington NA, et al. Effect of pamidronate in preventing local bone loss after total hip arthroplasty: a randomized, double-blind, controlled trial. J Bone Miner Res. 2001;16(3):556-64.

163. Xing Z, Hasty KA, Smith RA. Administration of pamidronate alters bone-titanium attachment in the presence of endotoxin-coated polyethylene particles. J Biomed Mater Res B Appl Biomater. 2007;83(2):354-8.

164. Dayer R, Brennan TC, Rizzoli R, Ammann P. PTH improves titanium implant fixation more than pamidronate or renutrition in osteopenic rats chronically fed a low protein diet. Osteoporos Int. 2010;21(6):957-67.

165. Dayer R, Badoud I, Rizzoli R, Ammann P. Defective implant osseointegration under protein undernutrition: prevention by PTH or pamidronate. J Bone Miner Res. 2007;22(10):1526-33.

166. Johansson HR, Skripitz R, Aspenberg PJ. Bisphosphonates can block the deterioration in implant fixation after withdrawal of intermittent doses of parathyroid hormone. J Bone Joint Surg Br. 2008;90(3):400-4.

167. Shibutani T, Inuduka A, Horiki I, Luan Q, Iwayama Y. Bisphosphonate inhibits alveolar bone resorption in experimentally-induced peri-implantitis in dogs. Clin Oral Implants Res. 2001;12(2):109-14. 168. Iwase M, Kim KJ, Kobayashi Y, Itoh M, Itoh T. A novel bisphosphonate inhibits inflammatory bone resorption in a rat osteolysis model with continuous infusion of polyethylene particles. J Orthop Res. 2002;20(3):499-505.

169. Tokugawa Y, Shirota T, Ohno K, Yamaguchi A. Effects of bisphosphonate on bone reaction after placement of titanium implants in tibiae of ovariectomized rats. Int J Oral Maxillofac Implants.

2003;18(1):66-74. 
170. Fokter SK, Komadina R, Repše-Fokter A. Effect of etidronate in preventing periprosthetic bone loss following cemented hip arthroplasty: a randomized, double blind, controlled trial. Wien Klin Wochenschr. 2006;118(2):23-8.

171. Kuchler U, Luvizuto ER, TangI S, Watzek G, Gruber R. Short-term teriparatide delivery and osseointegration: a clinical feasibility study. J Dent Res. 2011;90(8):1001-6.

172. Kaneko T, Otani T, Kono N, Mochizuki Y, Mori T, Nango N, et al. Weekly injection of teriparatide for bone ingrowth after cementless total knee arthroplasty. J Orthop Surg (Hong Kong). 2016;24(1):1621.

173. Inoue G, Ueno M, Nakazawa T, Imura T, Saito W, Uchida K, et al. Teriparatide increases the insertional torque of pedicle screws during fusion surgery in patients with postmenopausal osteoporosis. J Neurosurg Spine. 2014;21(3):425-31.

174. Suzuki T, Sukezaki F, Shibuki T, Toyoshima Y, Nagai T, Inagaki K. Teriparatide administration increases periprosthetic bone mineral density after total knee arthroplasty: a prospective study. J Arthroplasty. 2018;33(1):79-85.

175. Shirota T, Tashiro M, Ohno K, Yamaguchi A. Effect of intermittent parathyroid hormone (1-34) treatment on the bone response after placement of titanium implants into the tibia of ovariectomized rats. J Oral Maxillofac Surg. 2003;61(4):471-80.

176. Corsini MS, Faraco FN, Castro AA, Onuma T, Sendyk WR, Shibli JA. Effect of systemic intermittent administration of human parathyroid hormone ( $\mathrm{rhPTH}[1-34])$ on the resistance to reverse torque in rabbit tibiae. J Oral Implantol. 2008;34(6):298-302.

177. Daugaard H, Elmengaard B, Andreassen T, Bechtold J, Lamberg A, Soballe K. Parathyroid hormone treatment increases fixation of orthopedic implants with gap healing: a biomechanical and histomorphometric canine study of porous coated titanium alloy implants in cancellous bone. Calcif Tissue Int. 2011;88(4):294-303.

178. Almagro MI, Roman-Blas JA, Bellido M, Castaneda S, Cortez R, Herrero-Beaumont G. PTH [1-34] enhances bone response around titanium implants in a rabbit model of osteoporosis. Clin Oral Implants Res. 2013;24(9):1027-34.

179. Gabet Y, Muller R, Levy J, Dimarchi R, Chorev M, Bab I, et al. Parathyroid hormone 1-34 enhances titanium implant anchorage in low-density trabecular bone: a correlative micro-computed tomographic and biomechanical analysis. Bone. 2006;39(2):276-82.

180. Mair B, Tangl S, Feierfeil J, Skiba D, Watzek G, Gruber R. Age-related efficacy of parathyroid hormone on osseointegration in the rat. Clin Oral Implants Res. 2009;20(4):400-5.

181. Daugaard H, Elmengaard B, Andreassen TT, Lamberg A, Bechtold JE, Soballe K. Systemic intermittent parathyroid hormone treatment improves osseointegration of press-fit inserted implants in cancellous bone. Acta orthopaedica. 2012;83(4):411-9.

182. Daugaard H, Elmengaard B, Andreassen T, Baas J, Bechtold JE, Soballe K. The combined effect of parathyroid hormone and bone graft on implant fixation. J Bone Joint Surg Br. 2011;93(1):131-9.

183. Tao Z-S, Zhou W-S, Qiang Z, Tu K-k, Huang Z-L, Xu H-M, et al. Intermittent administration of human parathyroid hormone (1-34) increases fixation of strontium-doped hydroxyapatite coating titanium implants via electrochemical deposition in ovariectomized rat femur. J Biomater Appl. 2016;30(7):952-60.

184. Fahlgren A, Yang X, Ciani C, Ryan JA, Kelly N, Ko FC, et al. The effects of PTH, loading and surgical insult on cancellous bone at the bone-implant interface in the rabbit. Bone. 2013;52(2):718-24.

185. Heo HA, Park SH, Jeon YS, Pyo SW. Enhancing Effect of Intermittent Parathyroid Hormone Administration on Bone Formation After Titanium Implant Placement in an Ovariectomized Rat Maxilla. Implant Dent. 2016;25(2):227-31. 
186. Yang X, Ricciardi BF, Dvorzhinskiy A, Brial C, Lane Z, Bhimani S, et al. Intermittent Parathyroid Hormone Enhances Cancellous Osseointegration of a Novel Murine Tibial Implant. J Bone Joint Surg Am. 2015;97(13):1074-83.

187. Skripitz R, Aspenberg P. Implant fixation enhanced by intermittent treatment with parathyroid hormone. J Bone Joint Surg Br. 2001;83(3):437-40.

188. Tao ZS, Zhou WS, Tu KK, Huang ZL, Zhou Q, Sun T, et al. The effects of combined human parathyroid hormone (1-34) and simvastatin treatment on osseous integration of hydroxyapatite-coated titanium implants in the femur of ovariectomized rats. Injury. 2015;46(11):2164-9.

189. Tao ZS, Zhou WS, Bai BL, Cui W, Lv YX, Yu XB, et al. The effects of combined human parathyroid hormone (1-34) and simvastatin treatment on the interface of hydroxyapatite-coated titanium rods implanted into osteopenic rats femurs. J Mater Sci Mater Med. 2016;27(3):43.

190. Oki Y, Doi K, Makihara Y, Kobatake R, Kubo T, Tsuga K. Effects of continual intermittent administration of parathyroid hormone on implant stability in the presence of osteoporosis: an in vivo study using resonance frequency analysis in a rabbit model. J Appl Oral Sci: revista FOB. 2017;25(5):498505.

191. Lima LL, Cesar Neto JB, Cayana EG, Nociti FH, Jr., Sallum EA, Casati MZ. Parathyroid hormone (134) compensates the negative effect of smoking around implants. Clin Oral Implants Res. 2013;24(9):1055-9.

192. Ohkawa Y, Tokunaga K, Endo N. Intermittent administration of human parathyroid hormone (134) increases new bone formation on the interface of hydroxyapatitecoated titanium rods implanted into ovariectomized rat femora. J Orthop Sci. 2008;13(6):533-42.

193. Skripitz R, Aspenberg P. Parathyroid hormone (1-34) increases attachment of PMMA cement to bone. J Orthop Sci. 2001;6(6):540-4.

194. Aspenberg P, Wermelin K, Tengwall P, Fahlgren A. Additive effects of PTH and bisphosphonates on the bone healing response to metaphyseal implants in rats. Acta orthopaedica. 2008;79(1):111-5. 195. Rybaczek T, Tangl S, Dobsak T, Gruber R, Kuchler U. The Effect of Parathyroid Hormone on Osseointegration in Insulin-Treated Diabetic Rats. Implant Dent. 2015;24(4):392-6.

196. dos Santos RA, Ferreira MS, Mafra CE, Holzhausen M, de Lima LA, Mendes P, et al. Synthetic parathyroid hormone may augment bone volume in autogenous grafts: a study in rats. J Periodontol. 2016;87(1):66-73.

197. Kuchler U, Spilka T, Baron K, Tangl S, Watzek G, Gruber R. Intermittent parathyroid hormone fails to stimulate osseointegration in diabetic rats. Clin Oral Implants Res. 2011;22(5):518-23.

198. Wu YY, Yu T, Yang XY, Li F, Ma L, Yang Y, et al. Vitamin D3 and insulin combined treatment promotes titanium implant osseointegration in diabetes mellitus rats. Bone. 2013;52(1):1-8.

199. Dvorak G, Fugl A, Watzek G, Tangl S, Pokorny P, Gruber R. Impact of dietary vitamin D on osseointegration in the ovariectomized rat. Clin Oral Implants Res. 2012;23(11):1308-13.

200. Xiong Y, Zhang Y, Guo Y, Yuan Y, Guo Q, Gong P, et al. 1alpha,25-Dihydroxyvitamin D3 increases implant osseointegration in diabetic mice partly through FoxO1 inactivation in osteoblasts. Biochem Biophys Res Commun. 2017;494(3-4):626-33.

201. Zhou C, Li Y, Wang X, Shui X, Hu J. 1,25Dihydroxy vitamin D(3) improves titanium implant osseointegration in osteoporotic rats. Oral Surg Oral Med Oral Pathol Oral Radiol. 2012;114(5 Suppl):S174-8.

202. Kelly J, Lin A, Wang CJ, Park S, Nishimura I. Vitamin D and bone physiology: demonstration of vitamin D deficiency in an implant osseointegration rat model. J Prosthodont. 2009;18(6):473-8.

203. Liu S, Virdi AS, Sena K, Sumner DR. Sclerostin antibody prevents particle-induced implant loosening by stimulating bone formation and inhibiting bone resorption in a rat model. Arthritis Rheum. 2012;64(12):4012-20. 
204. Virdi AS, Liu M, Sena K, Maletich J, McNulty M, Ke HZ, et al. Sclerostin antibody increases bone volume and enhances implant fixation in a rat model. J Bone Joint Surg Am. 2012;94(18):1670-80.

205. Aspenberg P, Agholme F, Magnusson P, Fahlgren A. Targeting RANKL for reduction of bone loss around unstable implants: OPG-Fc compared to alendronate in a model for mechanically induced loosening. Bone. 2011;48(2):225-30.

206. Li Y, Feng G, Gao Y, Luo E, Liu X, Hu J. Strontium ranelate treatment enhances hydroxyapatitecoated titanium screws fixation in osteoporotic rats. J Orthop Res. 2010;28(5):578-82.

207. Maimoun L, Brennan TC, Badoud I, Dubois-Ferriere V, Rizzoli R, Ammann P. Strontium ranelate improves implant osseointegration. Bone. 2010;46(5):1436-41.

208. Li Y, Li X, Song G, Chen K, Yin G, Hu J. Effects of strontium ranelate on osseointegration of titanium implant in osteoporotic rats. Clin Oral Implants Res. 2012;23(9):1038-44.

209. Winnett B, Tenenbaum HC, Ganss B, Jokstad A. Perioperative use of non-steroidal antiinflammatory drugs might impair dental implant osseointegration. Clin Oral Implants Res. 2016;27(2):e1e7.

210. Urdaneta RA, Daher S, Lery J, Emanuel K, Chuang SK. Factors associated with crestal bone gain on single-tooth locking-taper implants: the effect of nonsteroidal anti-inflammatory drugs. Int J Oral Maxillofac Implants. 2011;26(5):1063-78.

211. Ribeiro FV, Nociti FH, Jr., Sallum EA, Casati MZ. Effect of aluminum oxide-blasted implant surface on the bone healing around implants in rats submitted to continuous administration of selective cyclooxygenase-2 inhibitors. Int J Oral Maxillofac Implants. 2009;24(2):226-33.

212. Ribeiro FV, Cesar-Neto JB, Nociti FH, Sallum EA, Sallum AW, De Toledo S, et al. Selective cyclooxygenase-2 inhibitor may impair bone healing around titanium implants in rats. J Periodontol. 2006;77(10):1731-5.

213. Pablos AB, Ramalho SA, Konig B, Jr., Furuse C, de Araujo VC, Cury PR. Effect of meloxicam and diclofenac sodium on peri-implant bone healing in rats. J Periodontol. 2008;79(2):300-6.

214. Jacobsson SA, Djerf K, Ivarsson I, Wahlstrom O. Effect of diclofenac on fixation of hydroxyapatite-coated implants. An experimental study. J Bone Joint Surg Br. 1994;76(5):831-3. 215. Cai WX, Ma L, Zheng LW, Kruse-Gujer A, Stubinger S, Lang NP, et al. Influence of non-steroidal anti-inflammatory drugs (NSAIDs) on osseointegration of dental implants in rabbit calvaria. Clin Oral Implants Res. 2015;26(4):478-83.

216. Salduz A, Dikici F, Kilicoglu OI, Balci HI, Akgul T, Kurkcu M, et al. Effects of NSAIDs and hydroxyapatite coating on osseointegration. J Orthop Surg (Hong Kong). 2017;25(1):2309499016684410.

217. Trancik T, Mills W, Vinson N. The effect of indomethacin, aspirin, and ibuprofen on bone ingrowth into a porous-coated implant. Clin Orthop Relat Res. 1989(249):113-21.

218. Alissa R, Sakka S, Oliver R, Horner K, Esposito M, Worthington HV, et al. Influence of ibuprofen on bone healing around dental implants: a randomised double-blind placebo-controlled clinical study. Eur J Oral Implantol. 2009;2(3):185-99.

219. Persson PE, Nilsson OS, Berggren AM. Do non-steroidal anti-inflammatory drugs cause endoprosthetic loosening? A 10-year follow-up of a randomized trial on ibuprofen for prevention of heterotopic ossification after hip arthroplasty. Acta orthopaedica. 2005;76(6):735-40.

220. Sakka S, Hanouneh SI. Investigation of the effect of ibuprofen on the healing of osseointegrated oral implants. J Investig Clin Dent. 2013;4(2):113-9.

221. Lionberger DR, Noble PC. Celecoxib does not affect osteointegration of cementless total hip stems. J Arthroplasty. 2005;20(7 Suppl 3):115-22.

222. Meunier A, Aspenberg P, Good L. Celecoxib does not appear to affect prosthesis fixation in total knee replacement: A randomized study using radiostereometry in 50 patients. Acta orthopaedica. 2009;80(1):46-50. 
223. Zhang X, Morham SG, Langenbach R, Young DA, Xing L, Boyce BF, et al. Evidence for a direct role of cyclo-oxygenase 2 in implant wear debris-induced osteolysis. J Bone Miner Res. 2001;16(4):660-70.

224. Keller JC, Trancik TM, Young FA, St Mary E. Effects of indomethacin on bone ingrowth. J Orthop Res. 1989;7(1):28-34.

225. Sennerby L, Kalebo $P$, Thomsen $P$, Albrektsson T. Influence of indomethacin on the regeneration of cortical bone within titanium implants in rabbits. Biomaterials. 1993;14(2):156-8.

226. Cook SD, Barrack RL, Dalton JE, Thomas KA, Brown TD. Effects of indomethacin on biologic fixation of porous-coated titanium implants. J Arthroplasty. 1995;10(3):351-8.

227. Goodman S, Ma T, Trindade M, Ikenoue T, Matsuura I, Wong N, et al. COX-2 selective NSAID decreases bone ingrowth in vivo. J Orthop Res. 2002;20(6):1164-9.

228. Jeffcoat MK, Reddy MS, Wang IC, Meuninghoff LA, Farmer JB, Koth DL. The effect of systemic flurbiprofen on bone supporting dental implants. J Am Dent Assoc. 1995;126(3):305-11.

229. Hayashi K, Fotovati A, Abu Ali S, Nakamura Y, Inagaki M, Naito M. Effect of a prostaglandin EP4 receptor agonist on early fixation of hydroxyapatite/titanium composite- and titanium-coated roughsurfaced implants in ovariectomized rats. J Biomed Mater Res A. 2010;92(3):1202-9.

230. Nogueira-Filho Gda R, Cadide T, Rosa BT, Neiva TG, Tunes R, Peruzzo D, et al. Cannabis sativa smoke inhalation decreases bone filling around titanium implants: a histomorphometric study in rats. Implant Dent. 2008;17(4):461-70.

231. Duka M, Lazic Z, Stamatovic N, Tatic Z, Bubalo M, Veljovic M. Clinical parameters of the local anesthetic effects of bupivacaine applied with and without a vasoconstrictor in oral implantology. Vojnosanit Pregl. 2007;64(9):611-5.

232. Palin LP, Polo TOB, Batista FRS, Gomes-Ferreira PHS, Garcia Junior IR, Rossi AC, et al. Daily melatonin administration improves osseointegration in pinealectomized rats. J Appl Oral Sci: revista FOB. 2018;26:e20170470.

233. Jin Y, Xu L, Hu X, Liao S, Pathak JL, Liu J. Lithium chloride enhances bone regeneration and implant osseointegration in osteoporotic conditions. J Bone Miner Metab. 2017;35(5):497-503.

234. Wu X, Al-Abedalla K, Rastikerdar E, Abi Nader S, Daniel NG, Nicolau B, et al. Selective serotonin reuptake inhibitors and the risk of osseointegrated implant failure: a cohort study. J Dent Res. 2014;93(11):1054-61.

235. Chrcanovic BR, Kisch J, Albrektsson T, Wennerberg A. Is the intake of selective serotonin reuptake inhibitors associated with an increased risk of dental implant failure? International J Oral Maxillofac Surg. 2017;46(6):782-8.

236. Balatsouka D, Gotfredsen $\mathrm{K}$, Lindh $\mathrm{CH}$, Berglundh T. The impact of nicotine on bone healing and osseointegration. Clin Oral Implants Res. 2005;16(3):268-76.

237. Linden MSS, Bittencourt ME, Carli JP, Miyagaki DC, Santos PLD, Paranhos LR, et al. The effects of subcutaneous injection of nicotine on osseointegration of machined and anodized implants in rabbits. Acta cirurgica brasileira. 2018;33(1):31-9.

238. Berley J, Yamano S, Sukotjo C. The effect of systemic nicotine on osseointegration of titanium implants in the rat femur. J Oral Implantol. 2010;36(3):185-93.

239. Yamano S, Berley JA, Kuo WP, Gallucci GO, Weber HP, Sukotjo C. Effects of nicotine on gene expression and osseointegration in rats. Clin Oral Implants Res. 2010;21(12):1353-9.

240. Cesar-Neto JB, Duarte PM, Sallum EA, Barbieri D, Moreno H, Jr., Nociti FH, Jr. A comparative study on the effect of nicotine administration and cigarette smoke inhalation on bone healing around titanium implants. J Periodontol. 2003;74(10):1454-9.

241. Soares EV, Favaro WJ, Cagnon VH, Bertran CA, Camilli JA. Effects of alcohol and nicotine on the mechanical resistance of bone and bone neoformation around hydroxyapatite implants. J Bone Miner Metab. 2010;28(1):101-7. 
242. Balatsouka D, Gotfredsen K, Lindh CH, Berglundh T. The impact of nicotine on osseointegration. An experimental study in the femur and tibia of rabbits. Clin Oral Implants Res. 2005;16(4):389-95.

243. Stefani CM, Nogueira F, Sallum EA, de TS, Sallum AW, Nociti FH, Jr. Influence of nicotine administration on different implant surfaces: a histometric study in rabbits. J Periodontol. 2002;73(2):206-12.

244. Gotfredsen K, Lindh CH, Berglundh T. Does longstanding nicotine exposure impair bone healing and osseointegration? An experimental study in rabbits. J Biomed Mater Res B Appl Biomater. 2009;91(2):918-23.

245. Bombonato-Prado KF, Brentegani LG, Thomazini JA, Lachat JJ, Carvalho TL. Alcohol intake and osseointegration around implants: a histometric and scanning electron microscopy study. Implant Dent. 2004;13(3):238-44.

246. de Deco CP, da Silva Marchini AM, Barbara MA, de Vasconcellos LM, da Rocha RF, Marchini L. Negative effects of alcohol intake and estrogen deficiency combination on osseointegration in a rat model. J Oral Implantol. 2011;37(6):633-9.

247. Koo S, Konig B, Jr., Mizusaki Cl, Allegrini S, Jr., Yoshimoto M, Carbonari MJ. Effects of alcohol consumption on osseointegration of titanium implants in rabbits. Implant Dent. 2004;13(3):232-7.

248. Lima CC, Silva TD, Santos L, Nakagaki WR, Loyola YC, Resck MC, et al. Effects of ethanol on the osteogenesis around porous hydroxyapatite implants. Braz J Biol. 2011;71(1):115-9.

249. Minsk L, Polson AM. Dental implant outcomes in postmenopausal women undergoing hormone replacement. Compend Contin Educ Dent. 1998;19(9):859-62, 64; quiz 66.

250. August M, Chung K, Chang Y, Glowacki J. Influence of estrogen status on endosseous implant osseointegration. J Oral Maxillofac Surg. 2001;59(11):1285-9; discussion 90-1.

251. Nociti FH, Jr., Sallum AW, Sallum EA, Duarte PM. Effect of estrogen replacement and calcitonin therapies on bone around titanium implants placed in ovariectomized rats: a histometric study. Int J Oral Maxillofac Implants. 2002;17(6):786-92.

252. Duarte PM, Cesar-Neto JB, Sallum AW, Sallum EA, Nociti FH, Jr. Effect of estrogen and calcitonin therapies on bone density in a lateral area adjacent to implants placed in the tibiae of ovariectomized rats. J Periodontol. 2003;74(11):1618-24.

253. Duarte PM, de Vasconcelos Gurgel BC, Sallum AW, Filho GR, Sallum EA, Nociti FH, Jr. Alendronate therapy may be effective in the prevention of bone loss around titanium implants inserted in estrogen-deficient rats. J Periodontol. 2005;76(1):107-14.

254. Qi MC, Zhou XQ, Hu J, Du ZJ, Yang JH, Liu M, et al. Oestrogen replacement therapy promotes bone healing around dental implants in osteoporotic rats. International J Oral Maxillofac Surg. 2004;33(3):279-85.

255. Li Y, Gao Y, Song G, Liu X, Hu J. Additive effects of estrogen replacement therapy and bisphosphonates on osseointegration of hydroxyapatite-coated titanium screws in ovariectomized rats. Oral Surg Oral Med Oral Pathol Oral Radiol Endod. 2010;109(5):700-5.

256. Giro G, Sakakura CE, Goncalves D, Pereira RM, Marcantonio E, Jr., Orrico SR. Effect of 17betaestradiol and alendronate on the removal torque of osseointegrated titanium implants in ovariectomized rats. J Periodontol. 2007;78(7):1316-21.

257. Shih LY, Shih HN, Chen TH. The effects of sex and estrogen therapy on bone ingrowth into porous coated implant. J Orthop Res. 2003;21(6):1033-40.

258. Maus UM, Luhmann M, Ohnsorge JA, Andereya S, Schmidt H, Zombory G, et al. [Dihydrotestosterone improves the osseointegration of cobalt-chromium implants]. Z Orthop Unfall. 2013;151(1):25-30.

259. Peichl P, Marteau R, Griesmacher A, Kumpan W, Schedl R, Prosquil E, et al. Salmon calcitonin nasal spray treatment for postmenopausal women after hip fracture with total hip arthroplasty. J Bone Miner Metab. 2005;23(3):243-52. 
260. Arnala IO. Salmon calcitonin (Miacalcic ns $200 \mathrm{IU}$ ) in prevention of bone loss after hip replacement. Scand J Surg. 2012;101(4):249-54.

261. Nociti FH, Jr., Sallum EA, Toledo S, Newman HN, Sallum AW. Effect of calcitonin on bone healing following titanium implant insertion. J Oral Sci. 1999;41(2):77-80.

262. Feitosa Dda S, Bezerra Bde B, Ambrosano GM, Nociti FH, Casati MZ, Sallum EA, et al. Thyroid hormones may influence cortical bone healing around titanium implants: a histometric study in rats. J Periodontol. 2008;79(5):881-7.

263. Wang M, Lan L, Li T, Li J, Li Y. The effect of oxytocin on osseointegration of titanium implant in ovariectomized rats. Connect Tissue Res. 2016;57(3):220-5.

264. Maiquan W, Liwei P, Yunfeng L. [Efficacy of systemic administration of oxytocin on implant osseointegration in osteoporotic rats]. Hua Xi Kou Qiang Yi Xue Za Zhi. 2016;34(4):332-5.

265. Fujimoto T, Niimi A, Sawai T, Ueda M. Effects of steroid-induced osteoporosis on osseointegration of titanium implants. Int J Oral Maxillofac Implants. 1998;13(2):183-9.

266. Petsinis V, Kamperos G, Alexandridi F, Alexandridis K. The impact of glucocorticosteroids administered for systemic diseases on the osseointegration and survival of dental implants placed without bone grafting-A retrospective study in 31 patients. J Craniomaxillofac Surg. 2017;45(8):1197200.

267. Avedian RS, Goldsby RE, Kramer MJ, O'Donnell RJ. Effect of chemotherapy on initial compressive osseointegration of tumor endoprostheses. Clin Orthop Relat Res. 2007;459:48-53.

268. Kovacs AF. Influence of chemotherapy on endosteal implant survival and success in oral cancer patients. International J Oral Maxillofac Surg. 2001;30(2):144-7.

269. Young DR, Shih LY, Rock MG, Frassica FJ, Virolainen P, Chao EY. Effect of cisplatin chemotherapy on extracortical tissue formation in canine diaphyseal segmental replacement. J Orthop Res. 1997;15(5):773-80.

270. Al-Mahalawy H, Marei HF, Abuohashish H, Alhawaj H, Alrefaee M, Al-Jandan B. Effects of cisplatin chemotherapy on the osseointegration of titanium implants. J Craniomaxillofac Surg. 2016;44(4):337-46.

271. Virolainen P, Inoue N, Nagao M, Frassica FJ, Chao EY. The effect of multidrug chemotherapy on bone graft augmented prosthesis fixation. J Orthop Res. 2005;23(4):795-801.

272. Carvas JB, Pereira RM, Bonfa E, Silveira CA, Lima LL, Caparbo Vde F, et al. No deleterious effect of low dose methotrexate on titanium implant osseointegration in a rabbit model. Clinics (Sao Paulo). 2011;66(6):1055-9.

273. Mair B, Fuerst G, Kubitzky P, Tangl S, Bergmeister H, Losert U, et al. The anti-angiogenic substance TNP-470 impairs peri-implant bone formation: a pilot study in the rabbit metaphysis model. Clin Oral Implants Res. 2007;18(3):370-5.

274. Al Subaie AE, Eimar H, Abdallah MN, Durand R, Feine J, Tamimi F, et al. Anti-VEGFs hinder bone healing and implant osseointegration in rat tibiae. J Clin Periodontol. 2015;42(7):688-96.

275. El-Kholey KE. Efficacy of two antibiotic regimens in the reduction of early dental implant failure: a pilot study. Int J Oral Maxillofac Surg. 2014;43(4):487-90.

276. Esposito M, Cannizzaro G, Bozzoli P, Checchi L, Ferri V, Landriani S, et al. Effectiveness of prophylactic antibiotics at placement of dental implants: a pragmatic multicentre placebo-controlled randomised clinical trial. Eur J Oral Implantol. 2010;3(2):135-43.

277. Caiazzo A, Casavecchia P, Barone A, Brugnami F. A pilot study to determine the effectiveness of different amoxicillin regimens in implant surgery. J Oral Implantol. 2011;37(6):691-6.

278. Kashsni H, Dahlin C, Alse'n B. Influence of different prophylactic antibiotic regimens on implant survival rate: a retrospective clinical study. Clin Implant Dent Relat Res. 2005;7(1):32-5. 
279. Giro G, In J, Witek L, Granato R, Marin C, Coelho PG, et al. Amoxicillin administrations and its influence on bone repair around osseointegrated implants. J Oral Maxillofac Surg. 2014;72(2):305. e1-. e5.

280. Kopman JA, Kim DM, Rahman SS, Arandia JA, Karimbux NY, Fiorellini JP. Modulating the effects of diabetes on osseointegration with aminoguanidine and doxycycline. J Periodontol. 2005;76(4):614-20. 281. Fiorellini JP, Nevins ML, Norkin A, Weber HP, Karimbux NY. The effect of insulin therapy on osseointegration in a diabetic rat model. Clin Oral Implants Res. 1999;10(5):362-8.

282. Siqueira JT, Cavalher-Machado SC, Arana-Chavez VE, Sannomiya P. Bone formation around titanium implants in the rat tibia: role of insulin. Implant Dent. 2003;12(3):242-51.

283. McCracken MS, Aponte-Wesson R, Chavali R, Lemons JE. Bone associated with implants in diabetic and insulin-treated rats. Clin Oral Implants Res. 2006;17(5):495-500.

284. de Molon RS, Morais-Camilo JA, Verzola MH, Faeda RS, Pepato MT, Marcantonio E, Jr. Impact of diabetes mellitus and metabolic control on bone healing around osseointegrated implants: removal torque and histomorphometric analysis in rats. Clin Oral Implants Res. 2013;24(7):831-7.

285. Kwon PT, Rahman SS, Kim DM, Kopman JA, Karimbux NY, Fiorellini JP. Maintenance of osseointegration utilizing insulin therapy in a diabetic rat model. J Periodontol. 2005;76(4):621-6.

286. de Morais JA, Trindade-Suedam IK, Pepato MT, Marcantonio E, Jr., Wenzel A, Scaf G. Effect of diabetes mellitus and insulin therapy on bone density around osseointegrated dental implants: a digital subtraction radiography study in rats. Clin Oral Implants Res. 2009;20(8):796-801.

287. Margonar R, Sakakura CE, Holzhausen M, Pepato MT, Alba jR, Marcantonio jE. The influence of diabetes mellitus and insulin therapy on biomechanical retention around dental implants: a study in rabbits. Implant Dent. 2003;12(4):333-9.

288. Serrao CR, Bastos MF, Cruz DF, de Souza Malta F, Vallim PC, Duarte PM. Role of Metformin in Reversing the Negative Impact of Hyperglycemia on Bone Healing Around Implants Inserted in Type 2 Diabetic Rats. Int J Oral Maxillofac Implants. 2017;32(3):547-54.

289. Inouye KA, Bisch FC, Elsalanty ME, Zakhary I, Khashaba RM, Borke JL. Effect of metformin on periimplant wound healing in a rat model of type 2 diabetes. Implant Dent. 2014;23(3):319-27.

290. Guimaraes RP, de Oliveira PA, Oliveira AM. Effects of induced diabetes and the administration of aminoguanidine in the biomechanical retention of implants: a study in rats. J Periodontal Res. 2011;46(6):691-6.

291. Wu X, Al-Abedalla K, Eimar H, Arekunnath Madathil S, Abi-Nader S, Daniel NG, et al. Antihypertensive Medications and the Survival Rate of Osseointegrated Dental Implants: A Cohort Study. Clin Implant Dent Relat Res. 2016;18(6):1171-82.

292. Al-Subaie AE, Laurenti M, Abdallah MN, Tamimi I, Yaghoubi F, Eimar H, et al. Propranolol enhances bone healing and implant osseointegration in rats tibiae. J Clin Periodontol. 2016;43(12):116070.

293. Duarte PM, Nogueira Filho GR, Sallum EA, Sallum AW, Nociti Junior FH. Short-term immunosuppressive therapy does not affect the density of the pre-existing bone around titanium implants placed in rabbits. Pesqui Odontol Bras. 2003;17(4):362-6.

294. Lubbeke A, Garavaglia G, Rothman KJ, Bonvin A, Roussos C, Miozzari H, et al. Statins may reduce femoral osteolysis in patients with total Hip arthroplasty. J Orthop Res. 2013;31(5):814-20.

295. Ayukawa Y, Okamura A, Koyano K. Simvastatin promotes osteogenesis around titanium implants. Clin Oral Implants Res. 2004;15(3):346-50.

296. Basarir K, Erdemli B, Can A, Erdemli E, Zeyrek T. Osseointegration in arthroplasty: can simvastatin promote bone response to implants? Int Orthop. 2009;33(3):855-9.

297. Yin H, Li J, Yu X, Fu Z. Effects of simvastatin on osseointegration in a canine total hip arthroplasty model: an experimental study. J Arthroplasty. 2011;26(8):1534-9. 
298. Du Z, Chen J, Yan F, Xiao Y. Effects of Simvastatin on bone healing around titanium implants in osteoporotic rats. Clin Oral Implants Res. 2009;20(2):145-50.

299. Du Z, Chen J, Yan F, Doan N, Ivanovski S, Xiao Y. Serum bone formation marker correlation with improved osseointegration in osteoporotic rats treated with simvastatin. Clin Oral Implants Res.

2013;24(4):422-7.

300. Ayukawa Y, Ogino Y, Moriyama Y, Atsuta I, Jinno Y, Kihara M, et al. Simvastatin enhances bone formation around titanium implants in rat tibiae. J Oral Rehabil. 2010;37(2):123-30.

301. Ma B, Clarke SA, Brooks RA, Rushton N. The effect of simvastatin on bone formation and ceramic resorption in a peri-implant defect model. Acta biomaterialia. 2008;4(1):149-55.

302. Faensen B, Hain C, Hohne J, Schwabe P, Haas N, Schmidmaier G, et al. Aprotinin application has no negative effect on osseous implant integration: a biomechanical and histomorphometric investigation in a rat model. Arch Orthop Trauma Surg. 2009;129(1):51-6.

303. Callahan BC, Lisecki EJ, Banks RE, Dalton JE, Cook SD, Wolff JD. The effect of warfarin on the attachment of bone to hydroxyapatite-coated and uncoated porous implants. J Bone Joint Surg Am. 1995;77(2):225-30.

304. Sakakura CE, Margonar R, Sartori R, Morais JA, Marcantonio E, Jr. The influence of cyclosporin a on mechanical retention of dental implants previously integrated to the bone: a study in rabbits. J Periodontol. 2006;77(12):2059-62.

305. Sakakura CE, Marcantonio E, Jr., Wenzel A, Scaf G. Influence of cyclosporin A on quality of bone around integrated dental implants: a radiographic study in rabbits. Clin Oral Implants Res.

2007;18(1):34-9.

306. Duarte PM, Nogueira Filho GR, Sallum EA, de Toledo S, Sallum AW, Nociti Junior FH. The effect of an immunosuppressive therapy and its withdrawal on bone healing around titanium implants. A histometric study in rabbits. J Periodontol. 2001;72(10):1391-7.

307. El Hadary AA, Yassin HH, Mekhemer ST, Holmes JC, Grootveld M. Evaluation of the effect of ozonated plant oils on the quality of osseointegration of dental implants under the influence of Cyclosporin A an in vivo study. J Oral Implantol. 2011;37(2):247-57.

308. Sakakura CE, Margonar R, Holzhausen M, Nociti FH, Jr., Alba RC, Jr., Marcantonio E, Jr. Influence of cyclosporin A therapy on bone healing around titanium implants: a histometric and biomechanic study in rabbits. J Periodontol. 2003;74(7):976-81.

309. Ekelund A, Aspenberg P, Nilsson O. No effect of immunosuppression with cyclosporin A detected on bone ingrowth into cancellous allo- and xenografts in the rat. Acta Orthop Scand. 1999;70(5):491-6.

310. Zheng X, Mo A, Wang Y, Guo Y, Wu Y, Yuan Q. Effect of FK-506 (tacrolimus) therapy on bone healing of titanium implants: a histometric and biomechanical study in mice. Eur J Oral Sci. 2017;125(1):28-33.

311. Wu X, Al-Abedalla K, Abi-Nader S, Daniel NG, Nicolau B, Tamimi F. Proton Pump Inhibitors and the Risk of Osseointegrated Dental Implant Failure: A Cohort Study. Clin Implant Dent Relat Res. 2017;19(2):222-32.

312. Chrcanovic BR, Kisch J, Albrektsson T, Wennerberg A. Intake of Proton Pump Inhibitors Is Associated with an Increased Risk of Dental Implant Failure. Int J Oral Maxillofac Implants. 2017;32(5):1097-102.

313. Al Subaie A, Emami E, Tamimi I, Laurenti M, Eimar H, Abdallah MN, et al. Systemic administration of omeprazole interferes with bone healing and implant osseointegration: an in vivo study on rat tibiae. J Clin Periodontol. 2016;43(2):193-203.

314. Altug HA, Tatli U, Coskun AT, Erdogan O, Ozkan A, Sencimen M, et al. Effects of hyperbaric oxygen treatment on implant osseointegration in experimental diabetes mellitus. J Appl Oral Sci: revista FOB. 2018;26:e20180083. 
315. Oliveira PA, Oliveira AM, Pablos AB, Costa FO, Silva GA, Santos JN, et al. Influence of hyperbaric oxygen therapy on peri-implant bone healing in rats with alloxan-induced diabetes. J Clin Periodontol. 2012;39(9):879-86.

316. Nyberg J, Hertzman S, Svensson B, Johansson CB. Osseointegration of implants in irradiated bone with and without hyperbaric oxygen treatment: an experimental study in rat Tibiae. Int J Oral Maxillofac Implants. 2013;28(3):739-46.

317. Hayashi, K., et al., Prostaglandin EP4 receptor agonist augments fixation of hydroxyapatitecoated implants in a rat model of osteoporosis. J Bone Joint Surg Br. 2005. 87(8): p. 1150-6.

318. Aghaloo T, Pi-Anfruns J, Moshaverinia A, Sim D, Grogan T, Hadaya D. The Effects of Systemic Diseases and Medications on Implant Osseointegration: A Systematic Review. Int J Oral Maxillofac Implants. 2019;34:s35-s49.

\section{Appendices}

\section{Appendix A: Search Strategies}

Table 6: Search Strategies used for the systematic mapping

\begin{tabular}{|l|l|}
\hline $\begin{array}{l}\text { Type } \\
\text { of } \\
\text { search }\end{array}$ & Mesh terms and keywords \\
\hline A. Specific search strategy for similar articles \\
\hline & "Osseointegration/drug effects"[MeSH Terms] \\
\hline \multicolumn{2}{|l|}{ B. Specific search strategy for non-similar articles } \\
\hline & $\begin{array}{l}\text { ("Dental Implants"[Mesh]) AND ("14-alpha Demethylase Inhibitors" OR ("5- } \\
\text { alpha+Reductase+Inhibitors") OR ("5-Lipoxygenase-Activating+Protein+Inhibitors") OR }\end{array}$ \\
\hline
\end{tabular}




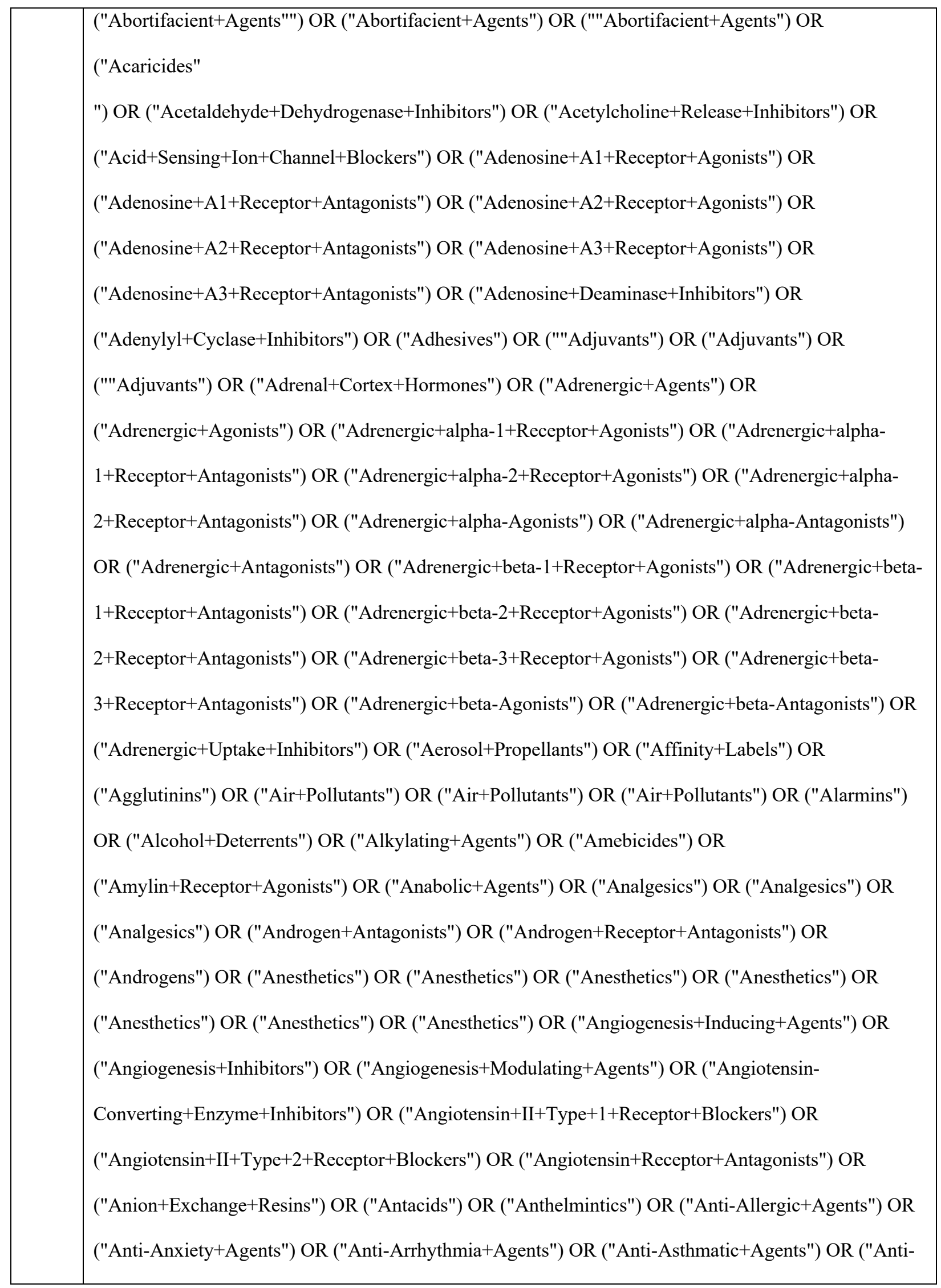




\begin{tabular}{|c|}
\hline 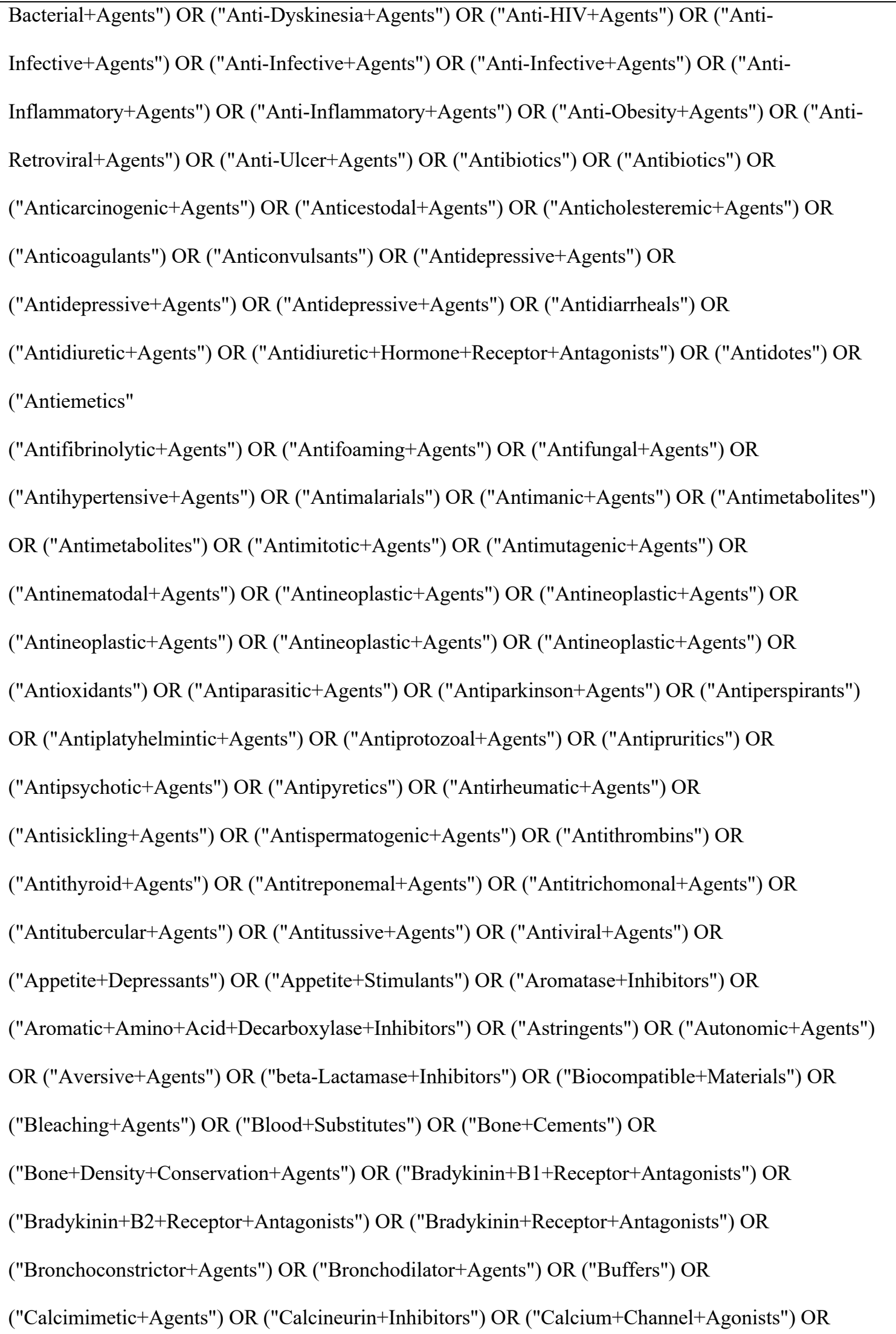 \\
\hline
\end{tabular}




\begin{tabular}{|c|}
\hline 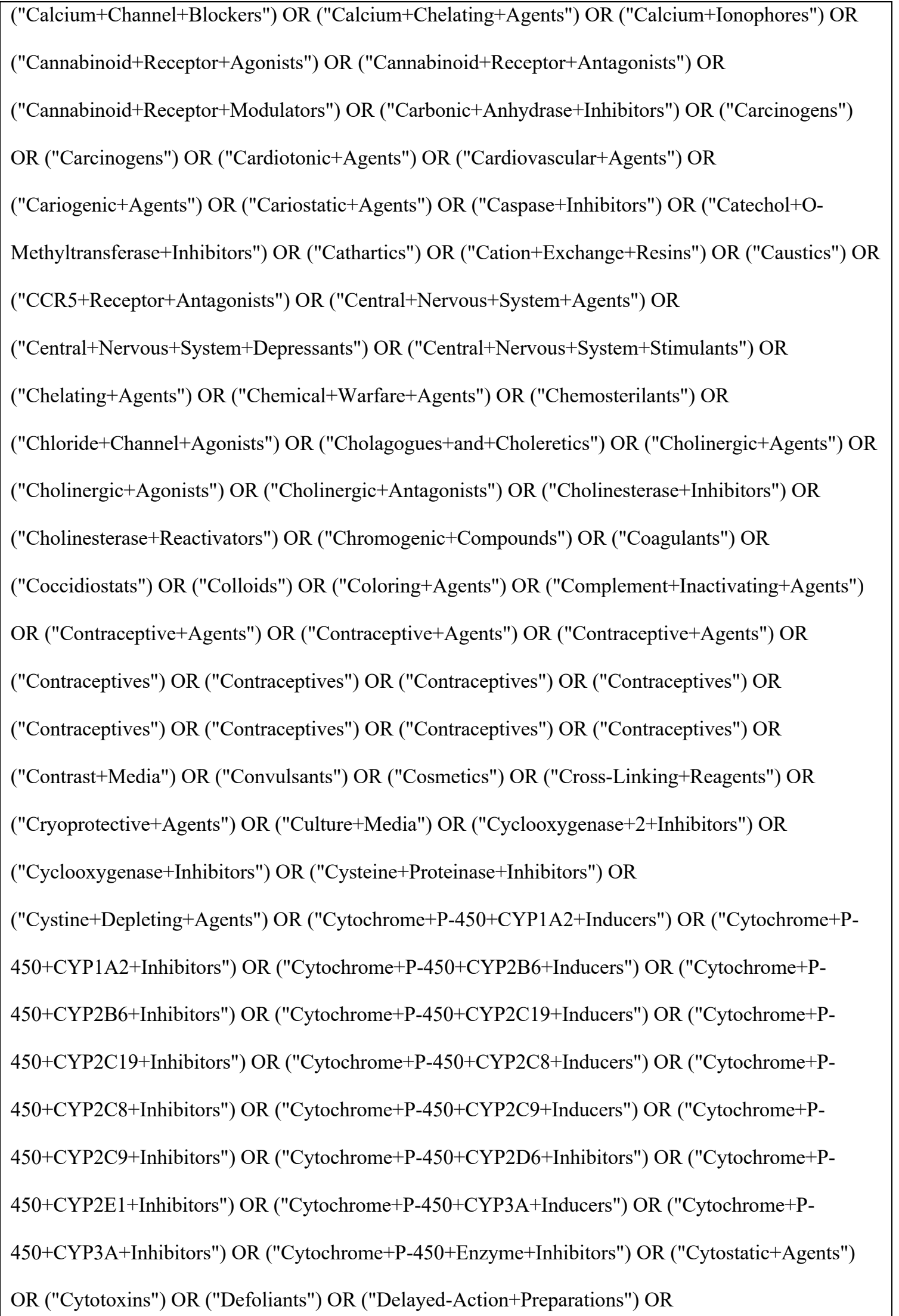 \\
\hline
\end{tabular}




\begin{tabular}{|c|}
\hline 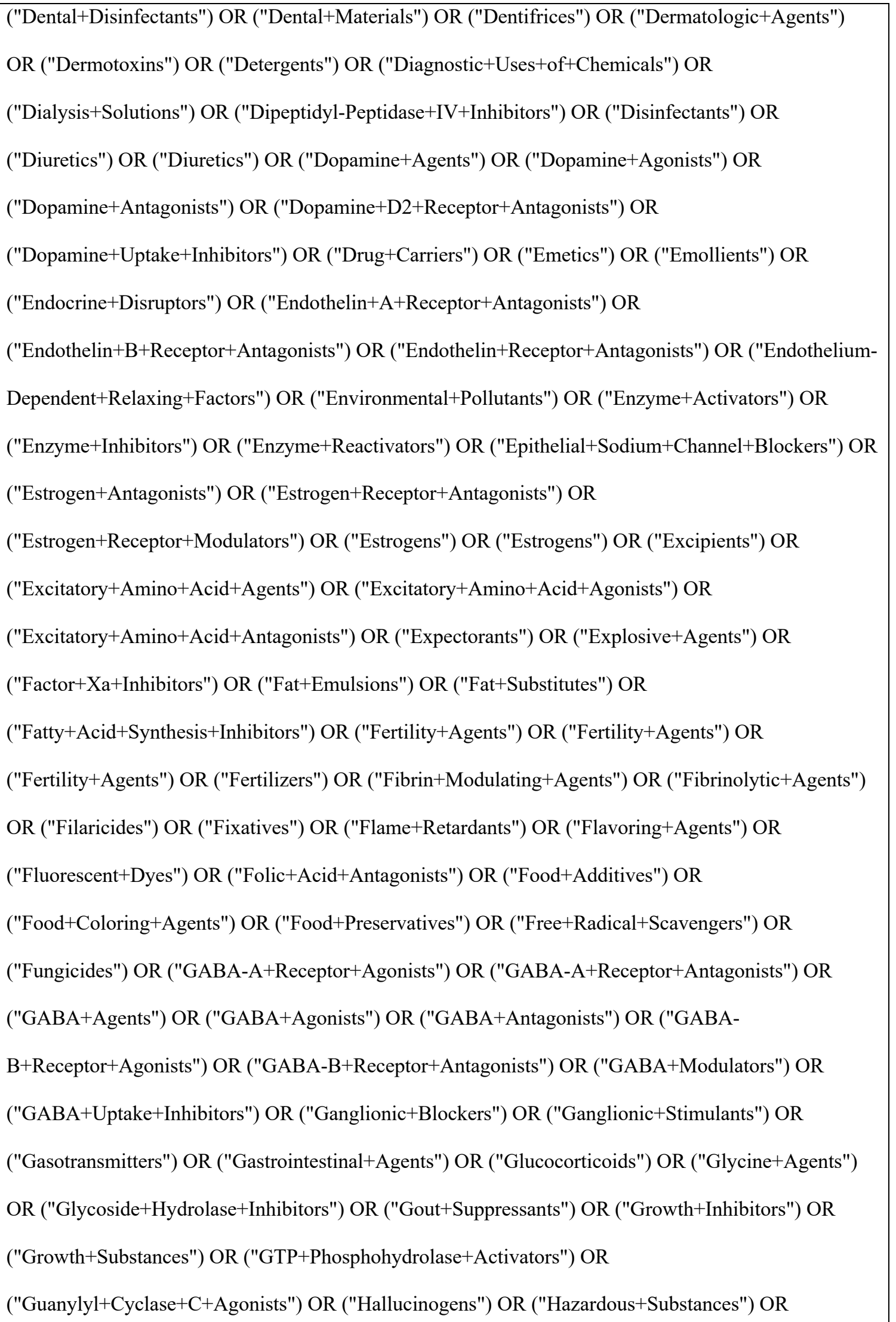 \\
\hline
\end{tabular}




\begin{tabular}{|c|}
\hline 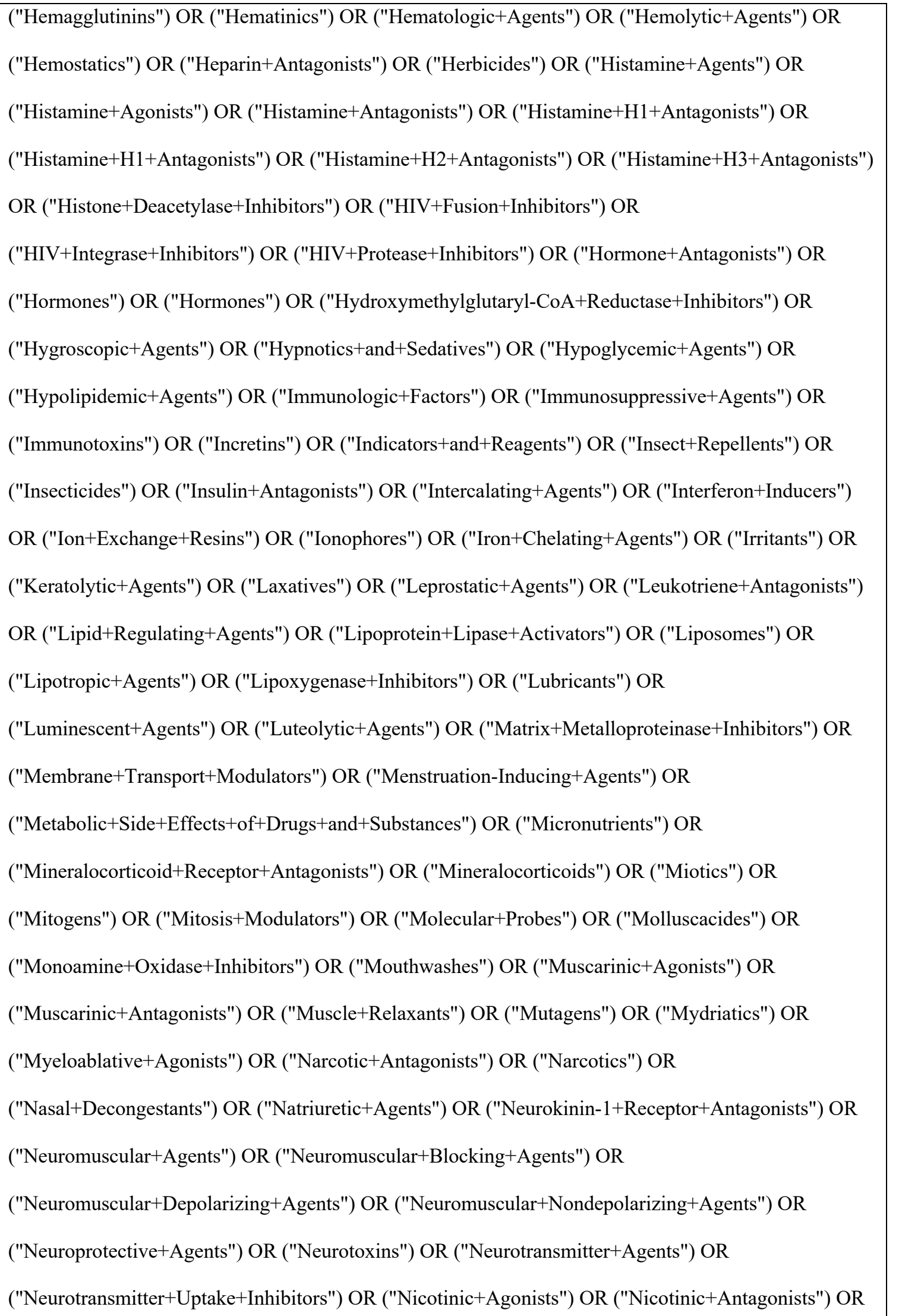 \\
\hline
\end{tabular}




\begin{tabular}{|c|}
\hline 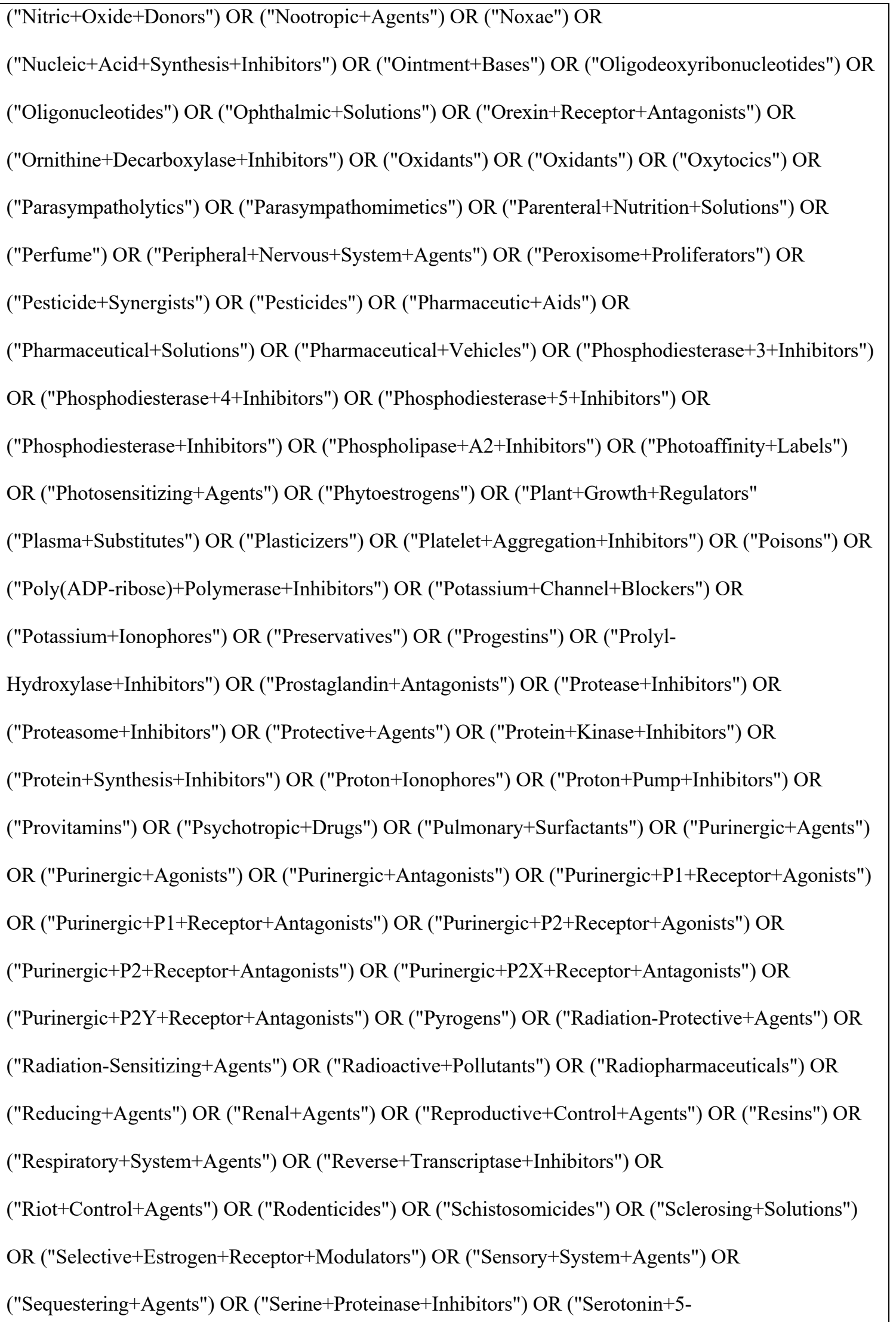 \\
\hline
\end{tabular}




\begin{tabular}{|c|c|}
\hline & 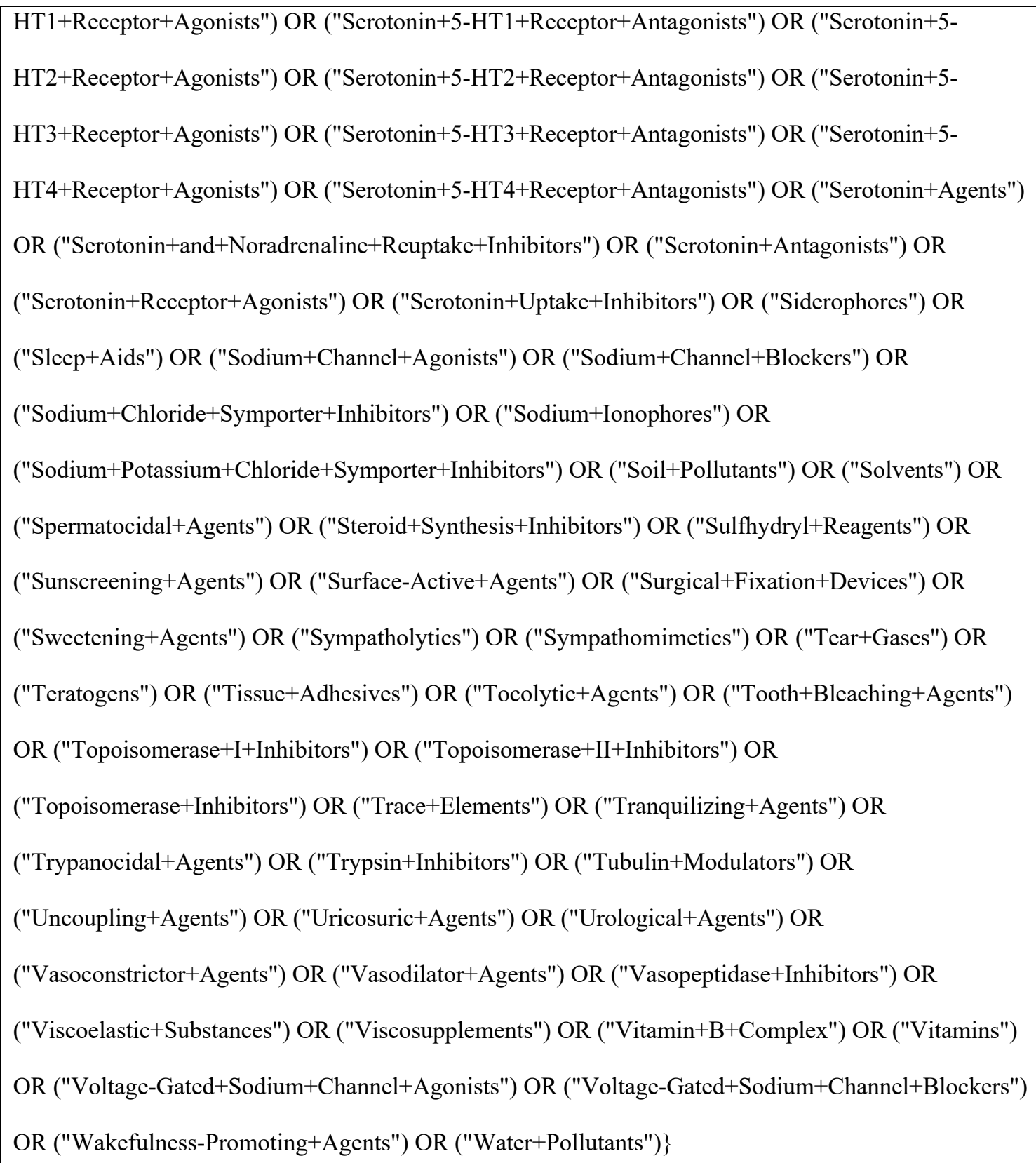 \\
\hline \multicolumn{2}{|c|}{ C. Senstivie Search strategy } \\
\hline & $\begin{array}{l}\text { ("Dental Implantation, Endosseous"[Mesh] OR ("Dental Implants"[Mesh]) OR } \\
\text { "Osseointegration"[Mesh]) OR "Periprosthetic Fractures"[Mesh] OR "Drug Implants"[Mesh] OR } \\
\text { "Internal Fixators"[Mesh] OR "Hip Prosthesis"[Mesh] OR "Prostheses and Implants"[Mesh] OR } \\
\text { "Implants, Experimental"[Mesh] OR "Bone Screws"[Mesh] OR "Prosthesis Implantation"[Mesh] }\end{array}$ \\
\hline
\end{tabular}




\section{Appendix B: Studies Characteristics}

Table 7: Included studies characteristics.

\begin{tabular}{|c|c|c|c|c|c|c|c|c|}
\hline Year & $\begin{array}{l}\text { First } \\
\text { Author }\end{array}$ & $\begin{array}{l}\text { Type } \\
\text { of } \\
\text { Study }\end{array}$ & Drug & $\begin{array}{l}\text { Drug } \\
\text { route }\end{array}$ & Drug Dose & $\begin{array}{l}\text { Sample } \\
\text { Size }\end{array}$ & Outcome & Location \\
\hline 2003 & $\begin{array}{l}\text { Shirota } \\
\text { T. et al. }\end{array}$ & $\mathrm{a}$ & $\begin{array}{l}\text { Parathyroid } \\
\text { hormone }\end{array}$ & SC & $30 \mu \mathrm{g} / \mathrm{kg}$ & 72 rats & bic & Japan \\
\hline 2018 & $\begin{array}{l}\text { Palin } \\
\text { L.P. et } \\
\text { al. }\end{array}$ & $a$ & Melatonin & Oral & $5 \mathrm{mg} / \mathrm{kg}$ & 18 rats & bic & Brazil \\
\hline 2015 & $\begin{array}{l}\text { Cai } \\
\text { W.X. et } \\
\text { al. }\end{array}$ & $a$ & $\begin{array}{l}\text { Diclofenac } \\
\text { Parecoxib }\end{array}$ & $\begin{array}{l}\text { Oral } \\
\text { SC }\end{array}$ & $\begin{array}{l}2 \mathrm{mg} / \mathrm{kg} \\
1.5 \mathrm{mg} / \mathrm{kg}\end{array}$ & 18 rabbits & bic & China \\
\hline 2011 & $\begin{array}{l}\text { Aspenb } \\
\text { erg } P . \\
\text { et al }\end{array}$ & a & $\begin{array}{l}\text { Alendronate } \\
\text { OPG-Fc }\end{array}$ & $\mathrm{SC}$ & $\begin{array}{l}20 \mu \mathrm{g} / \mathrm{kg} \\
200 \mu \mathrm{g} / \mathrm{kg} \\
10 \mathrm{mg} / \mathrm{kg}\end{array}$ & 56 rats & bic & Sweden \\
\hline 2012 & $\begin{array}{l}\text { Yaman } \\
\text { F. et al. }\end{array}$ & $a$ & Zoledronic acid & IV & $0.1 \mathrm{mg} / \mathrm{kg}$ & 28 rabbits & bic & Turkey \\
\hline 2007 & $\begin{array}{l}\text { Avedian } \\
\text { R.S. et } \\
\text { al. }\end{array}$ & $\mathrm{pr}$ & $\begin{array}{l}\text { Combination of } \\
\text { methotrexate, } \\
\text { cyclophosphami } \\
\text { de, doxorubicin, } \\
\text { ifosfamide, } \\
\text { cisplatin, } \\
\text { etoposide, and } \\
\text { various other } \\
\text { agents }\end{array}$ & NR & NR & 54 patients & is & USA \\
\hline 2015 & $\begin{array}{l}\text { Rybacze } \\
\text { k T. et } \\
\text { al. }\end{array}$ & ex & $\begin{array}{l}\text { Insulin } \\
\text { Parathyroid } \\
\text { hormone } \\
\end{array}$ & $\begin{array}{l}\text { SC } \\
" 1\end{array}$ & $\begin{array}{l}100 \mathrm{IU} / \mathrm{mL} \\
60 \mathrm{mg} / \mathrm{kg} .\end{array}$ & 40 rats & bic & Austria \\
\hline 2009 & $\begin{array}{l}\text { Kasai T. } \\
\text { et al. }\end{array}$ & RE & Alendronate & Oral & NR & $\begin{array}{l}51 \\
\text { patients, } \\
11 \text { with bis } \\
\text { and } 40 \\
\text { non-bis }\end{array}$ & is & USA \\
\hline 2005 & $\begin{array}{l}\text { Balatso } \\
\text { uka D. } \\
\text { et al. }\end{array}$ & ex & Nicotine & SC & $3 \mathrm{mg} / \mathrm{kg}$ & 16 rabbits & bic & Denmark \\
\hline 2008 & $\begin{array}{l}\text { Pablos } \\
\text { A.B. et } \\
\text { al. }\end{array}$ & ex & $\begin{array}{l}\text { Diclofenac } \\
\text { sodium and } \\
\text { Meloxicam }\end{array}$ & IM & $\begin{array}{l}\text { Diclofenac } \\
\text { sodium } \\
1.07 \\
\mathrm{mg} / \mathrm{kg} . \\
\text { Meloxicam } \\
0.2 \mathrm{mg} / \mathrm{kg} .\end{array}$ & 30 rats & bic & Brazil \\
\hline 2014 & $\begin{array}{l}\text { Li J.P. } \\
\text { et al. }\end{array}$ & ex & Zoledronic acid & SC & $0.1 \mathrm{mg} / \mathrm{kg}$ & 46 rats & bic & China \\
\hline
\end{tabular}




\begin{tabular}{|c|c|c|c|c|c|c|c|c|}
\hline 2001 & $\begin{array}{l}\text { Kovacs } \\
\text { A.F. et } \\
\text { al }\end{array}$ & re & $\begin{array}{l}\text { cis- or } \\
\text { carboplatin and } \\
\text { 5-fluorouracil }\end{array}$ & IV & $\begin{array}{l}\text { Carboplati } \\
\mathrm{n} 300 \\
\mathrm{mg} / \mathrm{m} 2 \text { and } \\
\text { Cisplatin } \\
100 \\
\mathrm{mg} / \mathrm{m} 2) \\
\text { and for } \\
\text { both of } 5- \\
\text { fluorouraci } \\
\text { I }(1 \mathrm{~g} / \mathrm{m} 2)\end{array}$ & 30 patients & is & Germany \\
\hline 2010 & $\begin{array}{l}\text { Li Y. et } \\
\text { al. }\end{array}$ & ex & $\begin{array}{l}\text { Strontium } \\
\text { Ranelate }\end{array}$ & Oral & $\begin{array}{l}200 \mathrm{and} \\
400 \mathrm{mg} / \mathrm{kg}\end{array}$ & 40 rats & bic & China \\
\hline 2005 & $\begin{array}{l}\text { Duarte } \\
\text { P.M. et } \\
\text { al. }\end{array}$ & ex & $\begin{array}{l}\text { Alendronate } \\
\text { and } 17 \beta \\
\text { estradiol }\end{array}$ & SC & $\begin{array}{l}\text { Alendronat } \\
\text { e } 5 \mathrm{mg} / \mathrm{kg} \\
\text { and } 17 \beta \\
\text { estradiol } \\
20 \mu \mathrm{g} / \mathrm{kg}\end{array}$ & 87 rats & bic & Brazil \\
\hline 2015 & $\begin{array}{l}\text { Bernhar } \\
\text { dsson } \\
\text { M. et } \\
\text { al. }\end{array}$ & ex & $\begin{array}{l}\text { OPG-Fc and } \\
\text { Alendronate }\end{array}$ & SC & $\begin{array}{l}\text { OPG-Fc } 8 \\
\mathrm{mg} / \mathrm{kg} \text { and } \\
\text { Alendronat } \\
\text { e } 20,200 \\
\mu \mathrm{g} / \mathrm{kg}\end{array}$ & 42 rats & bic & Sweden \\
\hline 1999 & $\begin{array}{l}\text { FH Jr } \\
\text { N. et al. }\end{array}$ & ex & Calcitonin & IM & $\begin{array}{l}2 \mathrm{UI} / \mathrm{kg} \\
\text { single daily } \\
\text { doses }\end{array}$ & 30 rabbits & bic & Brazil \\
\hline 1999 & $\begin{array}{l}\text { Fiorellin } \\
\text { i J.P. et } \\
\text { al. }\end{array}$ & ex & Insulin & IM & $\mathrm{nr}$ & 10 rats & bic & USA \\
\hline 2017 & $\begin{array}{l}\text { Petsinis } \\
\text { V. et al. }\end{array}$ & re & $\begin{array}{l}\text { Glucocorticoste } \\
\text { roid } \\
\text { (prednisolone } \\
\text { or } \\
\text { methylprednisol } \\
\text { one) }\end{array}$ & $\begin{array}{l}\text { Inhalati } \\
\text { on or } \\
\text { local }\end{array}$ & $\begin{array}{l}5 \text { and } 60 \\
\mathrm{mg} \text { of } \\
\text { prednisolo } \\
\text { ne }\end{array}$ & 31 patients & is & Greece \\
\hline 2011 & $\begin{array}{l}\text { Prieto- } \\
\text { Alhamb } \\
\text { ra D. et } \\
\text { al. }\end{array}$ & re & $\begin{array}{l}\text { Alendronate, } \\
\text { Etidronate, } \\
\text { Ibandronate, } \\
\text { and Risedronate }\end{array}$ & $\begin{array}{l}\text { Oral, } \\
\text { IV, or } \\
\text { Local }\end{array}$ & $\mathrm{nr}$ & $\begin{array}{l}41995 \\
\text { patients }\end{array}$ & is & UK \\
\hline 2015 & $\begin{array}{l}\text { Verzola } \\
\text { M.H. et } \\
\text { al. }\end{array}$ & ex & Alendronate & SC & $1 \mathrm{mg} / \mathrm{kg}$ & 160 rats & bic & Brazil \\
\hline 2002 & $\begin{array}{l}\text { Goodm } \\
\text { an S. et } \\
\text { al. }\end{array}$ & ex & $\begin{array}{l}\text { Naproxen and } \\
\text { Rofecoxib }\end{array}$ & Oral & $\begin{array}{l}110 \mathrm{mg} / \mathrm{kg} \\
\text { Naproxen } \\
\text { and } 12.5 \\
\mathrm{mg} / \mathrm{kg} \\
\text { Rofecoxib }\end{array}$ & 8 rabbits & bic & USA \\
\hline 2007 & $\begin{array}{l}\text { Mair B. } \\
\text { et al. }\end{array}$ & ex & TNP-470 & SC & 10 mg/kg & 12 rabbits & bic & Austria \\
\hline 2012 & $\begin{array}{l}\text { Memon } \\
\text { S. et al. }\end{array}$ & re & $\begin{array}{l}\text { Alendronate, } \\
\text { lbandronate, } \\
\text { and Risedronate }\end{array}$ & oral & $\mathrm{nr}$ & $\begin{array}{l}200 \\
\text { patients }\end{array}$ & is & USA \\
\hline
\end{tabular}




\begin{tabular}{|c|c|c|c|c|c|c|c|c|}
\hline 2005 & $\begin{array}{l}\text { Lionber } \\
\text { ger } \\
\text { D.R. } \\
\text { and P.C. } \\
\text { Noble } \\
\end{array}$ & rct & Celecoxib & Oral & $200 \mathrm{mg} / \mathrm{kg}$ & 54 patients & is & USA \\
\hline 2009 & $\begin{array}{l}\text { Ribeiro } \\
\text { F.V. et } \\
\text { al. }\end{array}$ & ex & Meloxicam & SC & $3 \mathrm{mg} / \mathrm{kg}$ & 30 rats & bic & Brazil \\
\hline 2008 & $\begin{array}{l}\text { Grant } \\
\text { B.T. et } \\
\text { al. }\end{array}$ & re & $\begin{array}{l}\text { Alendronate, } \\
\text { lbandronate, } \\
\text { and Risedronate }\end{array}$ & Oral & $\mathrm{nr}$ & $\begin{array}{l}458 \\
\text { participant } \\
\text { s }\end{array}$ & is & USA \\
\hline 2008 & $\begin{array}{l}\text { Nakam } \\
\text { ura Y. }\end{array}$ & ex & $\begin{array}{l}\text { Alendronate } \\
\text { and calcitriol }\end{array}$ & SC & $\begin{array}{l}0.1 \mathrm{mg} / \mathrm{kg} \\
\text { alendronat } \\
\text { e and } 0.1 \\
\mathrm{mg} / \mathrm{kg} \\
\text { calcitriol }\end{array}$ & 64 rats & bic & Japan \\
\hline 2015 & $\begin{array}{l}\text { Siebert } \\
\text { T. et al. }\end{array}$ & $\mathrm{pr}$ & Zoledronic acid & IV & $5 \mathrm{mg} / \mathrm{kg}$ & 24 patient & is & Slovakia \\
\hline 2008 & $\begin{array}{l}\text { Corsini } \\
\text { M.S. et } \\
\text { al. }\end{array}$ & ex & PTH & SC & $6 \mu \mathrm{g} / \mathrm{kg}$ & 20 rabbits & bic & Brazil \\
\hline 2007 & $\begin{array}{l}\text { Fugazzo } \\
\text { tto P.A. } \\
\text { et al. }\end{array}$ & re & $\begin{array}{l}\text { Alendronate, } \\
\text { and Risedronate }\end{array}$ & Oral & $\begin{array}{l}35 \mathrm{mg} / \mathrm{kg} \\
\text { Alendronat } \\
\text { e and } 70 \\
\mathrm{mg} / \mathrm{kg} \\
\text { Risedronat } \\
\mathrm{e}\end{array}$ & 61 patient & is & USA \\
\hline 2007 & $\begin{array}{l}\text { Duka } \\
\text { M. et } \\
\text { al. }\end{array}$ & rct & $\begin{array}{l}\text { Bupivacaine } \\
\text { with/without a } \\
\text { vasoconstrictor }\end{array}$ & $\begin{array}{l}\text { Local } \\
\text { anesth } \\
\text { esia }\end{array}$ & $\begin{array}{l}3.5 \mathrm{~cm} 3 \text { of } \\
0.5 \% \\
\text { bupivacain } \\
\text { e with a } \\
\text { vasoconstr } \\
\text { ictor } \\
\text { ( } \\
\text { adrenalin, } \\
1: 200000)\end{array}$ & 30 patients & is & Serbia \\
\hline 2013 & $\begin{array}{l}\text { Kim I. } \\
\text { et al. }\end{array}$ & ex & $\begin{array}{l}\text { Zoledronic acid } \\
\text { and } \\
\text { Dexamethasone }\end{array}$ & $\begin{array}{l}\text { IV ZA } \\
\text { and } \\
\text { IM } \\
\text { Dexam } \\
\text { ethaso } \\
\text { ne }\end{array}$ & $\begin{array}{l}0.01 \mathrm{mg} / \mathrm{kg} \\
\mathrm{ZA} \text { and } \\
1 \mathrm{mg} / \mathrm{kg} \\
\text { Dexameth } \\
\text { asone }\end{array}$ & 24 rabbits & bic & $\begin{array}{l}\text { South } \\
\text { Korea }\end{array}$ \\
\hline 2014 & $\begin{array}{l}\text { Dikicier } \\
\text { E. et al. }\end{array}$ & ex & Zoledronic acid & IV & $0.04 \mathrm{mg} / \mathrm{kg}$ & 36 rats & bic & Turkey \\
\hline 2015 & $\begin{array}{l}\text { Ramalh } \\
\text { o- } \\
\text { Ferreira } \\
\text { G. et al. }\end{array}$ & ex & $\begin{array}{l}\text { Alendronate } \\
\text { and Raloxifene }\end{array}$ & Oral & $\begin{array}{l}0.1 \mathrm{mg} / \mathrm{kg} \\
\text { Alendronat } \\
\text { e and ral } \\
1.0 \mathrm{mg} / \mathrm{kg} \\
\text { Raloxifene }\end{array}$ & 72 rats & bic & Brazil \\
\hline 2011 & $\begin{array}{l}\text { Daugaa } \\
\text { rd H. et } \\
\text { al }\end{array}$ & ex & PTH & SC & $5 \mu \mathrm{g} / \mathrm{kg}$ & 20 canines & bic & Denmark \\
\hline
\end{tabular}




\begin{tabular}{|c|c|c|c|c|c|c|c|c|}
\hline 2010 & $\begin{array}{l}\text { Maimo } \\
\text { un L. et } \\
\text { al }\end{array}$ & ex & $\begin{array}{l}\text { Strontium } \\
\text { ranelate }\end{array}$ & Oral & $625 \mathrm{mg} / \mathrm{kg}$ & 30 rats & bic & $\begin{array}{l}\text { Switzerla } \\
\text { nd }\end{array}$ \\
\hline 2017 & $\begin{array}{l}\text { Zheng } \\
\text { X. et al. }\end{array}$ & ex & $\begin{array}{l}\text { (FK-506) } \\
\text { tacrolimus }\end{array}$ & SC & $1 \mathrm{mg} / \mathrm{kg}$ & 32 mice & bic & China \\
\hline 2013 & $\begin{array}{l}\text { Almagr } \\
\text { o M.I. } \\
\text { et al. }\end{array}$ & ex & PTH & SC & $10 \mu \mathrm{g} / \mathrm{kg}$ & 38 rabbits & bic & Spain \\
\hline 2016 & $\begin{array}{l}\text { Wu X. } \\
\text { et al. }\end{array}$ & re & $\begin{array}{l}\text { Hypertensive } \\
\text { drugs }\end{array}$ & NR & $\mathrm{nr}$ & $\begin{array}{l}728 \\
\text { patients }\end{array}$ & is & Canada \\
\hline 2010 & $\begin{array}{l}\text { Yildiz } \\
\text { A. et al. }\end{array}$ & ex & Zoledronic acid & IV & $0.1 \mathrm{mg} / \mathrm{kg}$ & 36 rabbits & bic & Turkey \\
\hline 2010 & $\begin{array}{l}\text { Koka S. } \\
\text { et al. }\end{array}$ & re & Alendronate & Oral & $70 \mathrm{mg} / \mathrm{kg}$ & $\begin{array}{l}137 \\
\text { patients }\end{array}$ & is & USA \\
\hline 2005 & $\begin{array}{l}\text { Kopma } \\
n \text { J.A. } \\
\text { et al. }\end{array}$ & ex & $\begin{array}{l}\text { Aminoguanidine } \\
\text { and Doxycycline }\end{array}$ & SC & $\begin{array}{l}7.35 \\
\mathrm{mmol} / \mathrm{kg} \\
\text { Aminogua } \\
\text { nidine and } \\
16.67 \\
\mathrm{mg} / \mathrm{kg} \\
\text { Doxycyclin } \\
\text { e } \\
\end{array}$ & 32 rats & bic & USA \\
\hline 1994 & $\begin{array}{l}\text { Jacobss } \\
\text { on S.A. } \\
\text { et al. }\end{array}$ & ex & Diclofenac & IM & $\begin{array}{l}30 \mathrm{mg} / \mathrm{kg} \\
\text { diclo }\end{array}$ & 10 rabbits & bic & Sweden \\
\hline 2014 & Giro G. & ex & Amoxicillin & Oral & $40 \mathrm{mg} / \mathrm{kg}$ & 35 rats & bic & Brazil \\
\hline 2006 & $\begin{array}{l}\text { Gabet } \\
\text { Y. }\end{array}$ & ex & PTH & SC & $\begin{array}{l}5,25 \text { and } \\
75 \mu \mathrm{g} / \mathrm{kg}\end{array}$ & 37 rats & bic & Israel \\
\hline 2010 & $\begin{array}{l}\text { Soares } \\
\text { E.V. et } \\
\text { al. }\end{array}$ & ex & $\begin{array}{l}\text { Nicotine and } \\
\text { Alcohol }\end{array}$ & SC & $\begin{array}{l}\text { Diluted } \\
10 \% \\
\text { ethanol } \\
\text { and } 0.125 \\
\mathrm{mg} / 100 \mathrm{~g} \\
\text { Nicotine } \\
\end{array}$ & 20 rats & bic & Brazil \\
\hline 2004 & $\begin{array}{l}\text { Bombo } \\
\text { nato- } \\
\text { Prado } \\
\text { K.F. et } \\
\text { al. } \\
\end{array}$ & ex & Alcohol & Oral & $\begin{array}{l}10^{\circ}, 15^{\circ}, \\
20^{\circ}, 25^{\circ}, \\
\text { and } 30^{\circ} \mathrm{GL} \\
\text { Brandy }\end{array}$ & 112 rats & bic & Brazil \\
\hline 2012 & $\begin{array}{l}\text { Yip J.K. } \\
\text { et al }\end{array}$ & re & $\begin{array}{l}\text { Alendronate, } \\
\text { lbandronate, } \\
\text { and } \\
\text { Risedronate, } \\
\text { Tiludronate, and } \\
\text { Etidronate }\end{array}$ & Oral & $\mathrm{nr}$ & $\begin{array}{l}337 \\
\text { patients }\end{array}$ & is & USA \\
\hline 2011 & $\begin{array}{l}\text { Kim } \\
\text { J.H. et } \\
\text { al. }\end{array}$ & ex & Alendronate & SC & $5 \mathrm{mg} \mathrm{kg}$ & 24 rats & bic & $\begin{array}{l}\text { South } \\
\text { Korea }\end{array}$ \\
\hline 2010 & $\begin{array}{l}\text { Carvas } \\
\text { J.S. et } \\
\text { al. }\end{array}$ & ex & $\begin{array}{l}\text { Methylprednisol } \\
\text { one and } \\
\text { Zoledronic acid }\end{array}$ & $\begin{array}{l}\text { SC and } \\
\text { IV }\end{array}$ & $\begin{array}{l}0.35 \mathrm{mg} / \mathrm{kg} \\
\text { Methylpre } \\
\text { dnisolone } \\
\text { and } 0.1\end{array}$ & 18 rabbits & bic & Brazil \\
\hline
\end{tabular}




\begin{tabular}{|c|c|c|c|c|c|c|c|c|}
\hline & & & & & $\begin{array}{l}\mathrm{mg} / \mathrm{kg} \\
\text { Zoledronic } \\
\text { acid }\end{array}$ & & & \\
\hline 2017 & $\begin{array}{l}\text { Dikicier } \\
\text { S. et al }\end{array}$ & ex & Zoledronic acid & IV & $\begin{array}{l}0.04 \mathrm{mg} \\
/ \mathrm{kg}\end{array}$ & 36 rats & bic & Turkey \\
\hline 2003 & $\begin{array}{l}\text { Narai } \\
\text { S. and } \\
\text { S. } \\
\text { Nagaha } \\
\text { ta }\end{array}$ & ex & Alendronate & SC & $70 \mu \mathrm{g} / \mathrm{kg}$ & 25 rats & bic & Japan \\
\hline 2005 & $\begin{array}{l}\text { Bobyn } \\
\text { J.D. et } \\
\text { al. }\end{array}$ & ex & Zoledronic acid & IV & $0.1 \mathrm{mg} / \mathrm{kg}$ & 7 dogs & bic & Canada \\
\hline 2017 & $\begin{array}{l}\text { Oliveira } \\
\text { D. et al. }\end{array}$ & ex & Alendronate & Oral & $0.1 \mathrm{mg} / \mathrm{kg}$ & 42 rat & bic & Brasil \\
\hline 2006 & $\begin{array}{l}\text { Ribeiro } \\
\text { F.V. et } \\
\text { al. }\end{array}$ & ex & Meloxicam & SC & $3 \mathrm{mg} / \mathrm{kg}$ & 31 rat & bic & Brazil \\
\hline 1995 & $\begin{array}{l}\text { Kitsugi } \\
\text { T. et al. }\end{array}$ & ex & $\begin{array}{l}\text { Disodium } \\
\text { Diphosphonate }\end{array}$ & SC & $\begin{array}{l}5.0,2.5 \\
1.0, \text { and } \\
0.1 \mathrm{mg} / \mathrm{kg}\end{array}$ & 30 rabbit & bic & Japan \\
\hline 2013 & $\begin{array}{l}\text { Chen } \\
\text { B. et al. }\end{array}$ & ex & $\begin{array}{l}\text { Zoledronic acid, } \\
\text { Alendronate, } \\
\text { and Strontium } \\
\text { ranelate. }\end{array}$ & $\begin{array}{l}\text { Oral, } \\
\text { and IV }\end{array}$ & $\begin{array}{l}0.1 \mathrm{mg} / \mathrm{kg} \\
\text { Zoledronic } \\
\text { acid, } 500 \\
\mathrm{mg} / \mathrm{kg} \\
\text { Strontium } \\
\text { ranelate, } \\
\text { and } 7 \\
\mathrm{mg} / \mathrm{kg} \\
\text { Alendronat } \\
\text { e }\end{array}$ & 60 rat & bic & China \\
\hline 2009 & $\begin{array}{l}\text { Alissa } \\
\text { R. et al. }\end{array}$ & rct & Ibuprofen & Oral & $600 \mathrm{mg} / \mathrm{kg}$ & 61 patients & is & UK \\
\hline 2012 & $\begin{array}{l}\text { Qi M. } \\
\text { et al. }\end{array}$ & ex & $\begin{array}{l}\text { Zoledronate } \\
\text { acid }\end{array}$ & SC & $0.1 \mathrm{mg} / \mathrm{kg}$ & 56 rabbit & bic & China \\
\hline 2015 & $\begin{array}{l}\text { Virdi } \\
\text { A.S. et } \\
\text { al. } \\
\end{array}$ & ex & $\begin{array}{l}\text { Sclerostin } \\
\text { Antibody }\end{array}$ & SC & $25 \mathrm{mg} / \mathrm{kg}$ & 161 rats & bic & USA \\
\hline 1998 & $\begin{array}{l}\text { Minsk } \\
\text { L. and } \\
\text { A.M. } \\
\text { Polson }\end{array}$ & re & $\begin{array}{l}\text { Hormonal } \\
\text { replacement } \\
\text { therapy }\end{array}$ & NR & $\mathrm{nr}$ & $\begin{array}{l}380 \\
\text { women }\end{array}$ & is & USA \\
\hline 2009 & $\begin{array}{l}\text { Faense } \\
\mathrm{n} \text { B. et } \\
\text { al. }\end{array}$ & ex & Aprotinin & IV & $7,200 \mathrm{KIU}$ & 40 rat & bic & Germany \\
\hline 1999 & $\begin{array}{l}\text { Ekelund } \\
\text { A. et al. }\end{array}$ & ex & Cyclosporin A & $\begin{array}{l}\text { Intrape } \\
\text { ritonea } \\
\text { I }\end{array}$ & $2 \mathrm{mg} / \mathrm{kg}$ & 24 rat & bic & Sweden \\
\hline 2016 & $\begin{array}{l}\text { Wang } \\
\text { M. et } \\
\text { al. }\end{array}$ & ex & Oxytocin & SC & $1 \mathrm{mg} / \mathrm{kg}$ & 20 rat & bic & China \\
\hline
\end{tabular}




\begin{tabular}{|c|c|c|c|c|c|c|c|c|}
\hline 2012 & $\begin{array}{l}\text { Dvorak } \\
\text { G. et al. }\end{array}$ & ex & Vitamine D & Oral & $2400 \mathrm{IU} / \mathrm{kg}$ & 50 rat & bic & Austria \\
\hline 2003 & $\begin{array}{l}\text { Shih } \\
\text { L.Y. et } \\
\text { al. }\end{array}$ & ex & $\begin{array}{l}\text { Estrogen } \\
\text { therapy }\end{array}$ & SC & $20 \mu \mathrm{g} / \mathrm{kg}$ & 32 dog & bic & Tuiwun \\
\hline 2018 & $\begin{array}{l}\text { Linden } \\
\text { M.S.S. } \\
\text { et al. }\end{array}$ & ex & Nicotine & SC & $3 \mathrm{mg} / \mathrm{kg}$ & 22 rabbit & bic & Brazil \\
\hline 2010 & $\begin{array}{l}\text { Berley } \\
\text { J. et al. }\end{array}$ & ex & Nicotine & SC & $6 \mathrm{mg} / \mathrm{kg}$ & 30 rat & bic & USA \\
\hline 2006 & $\begin{array}{l}\text { Eberhar } \\
\text { dt C. et } \\
\text { al. }\end{array}$ & ex & Ibandronate & SC & $\begin{array}{l}1.0,2.5, \text { or } \\
5.0 \mu \mathrm{g} / \mathrm{kg}\end{array}$ & 88 rats & bic & Germany \\
\hline 2009 & $\begin{array}{l}\text { Mair B. } \\
\text { et al. }\end{array}$ & ex & PTH & SC & $60 \mu \mathrm{g} / \mathrm{kg}$ & 40 rats & bic & Austria \\
\hline 2008 & $\begin{array}{l}\text { Viera- } \\
\text { Negron } \\
\text { Y.E. et } \\
\text { al. }\end{array}$ & ex & ald & subcut & $\begin{array}{l}5 \mathrm{mg} / \mathrm{kg} \\
\text { ALD } 3 \\
\text { times a } \\
\text { week. }\end{array}$ & $\begin{array}{l}32 \text { rat in } 4 \\
\text { groups: } \\
\text { ALD-OVX } \\
n=8, \\
O V X=8 \text {, } \\
A L D=8 \text { and } \\
\text { control }=8\end{array}$ & bic & USA \\
\hline 2015 & Oh K.C. & ex & Alendronate & SC & $1.0 \mathrm{mg} / \mathrm{kg}$ & 36 rats & bic & $\begin{array}{l}\text { South } \\
\text { Korea }\end{array}$ \\
\hline 2017 & $\begin{array}{l}\text { Wu X. } \\
\text { et al. }\end{array}$ & re & PPI & NR & $\mathrm{nr}$ & $\begin{array}{l}799 \\
\text { patients }\end{array}$ & is & Canada \\
\hline 2018 & $\begin{array}{l}\text { Yang } \\
\text { Q. and } \\
\text { F.L. Li. } \\
\text { Et al. }\end{array}$ & ex & Aspirin & NR & $\begin{array}{l}2.06,4.11 \\
8.21 \mathrm{mg} / \mathrm{kg}\end{array}$ & 60 rats & bic & $\mathrm{nr}$ \\
\hline 2010 & $\begin{array}{l}\text { Dayer } \\
\text { R. }\end{array}$ & ex & $\begin{array}{l}\text { PTH or } \\
\text { Pamidronate }\end{array}$ & SC & $\begin{array}{l}40 \mu \mathrm{\mu g} / \mathrm{kg} \\
\text { PTH } 0.6 \\
\mathrm{mg} / \mathrm{kg} \\
\text { Pamidrona } \\
\text { te }\end{array}$ & 41 rats & bic & $\begin{array}{l}\text { Switzerla } \\
\text { nd }\end{array}$ \\
\hline 2017 & $\begin{array}{l}\text { Dundar } \\
\text { S. et al }\end{array}$ & ex & Zoledronic Acid & NR & $\begin{array}{l}0.1 \text { and } 2 \\
\mathrm{mg} / \mathrm{kg}\end{array}$ & 12 rabbits & bic & Turkey \\
\hline 2005 & $\begin{array}{l}\text { Kurth } \\
\text { A.H. et } \\
\text { al }\end{array}$ & ex & Ibandronate & SC & $\begin{array}{l}1.0 \text { or } 25 \\
\mu \mathrm{g} / \mathrm{kg}\end{array}$ & 84 rats & bic & Germany \\
\hline 1997 & $\begin{array}{l}\text { Young } \\
\text { D.R. et } \\
\text { al. }\end{array}$ & ex & Cisplatin & IV & $75 \mathrm{mg} / \mathrm{m} 2$ & 24 dogs & bic & USA \\
\hline 2004 & $\begin{array}{l}\text { Qi M.C. } \\
\text { et al. }\end{array}$ & ex & Benzyl estradiol & SC & $20 \mu \mathrm{g} / \mathrm{kg}$ & 60 rats & bic & China \\
\hline 2017 & $\begin{array}{l}\text { Xiong } \\
\text { Y. }\end{array}$ & ex & Vitamine D & $\begin{array}{l}\text { Intrape } \\
\text { ritonea } \\
\text { I }\end{array}$ & $5 \mu \mathrm{g} / \mathrm{kg}$ & 40 mice & bic & China \\
\hline 2012 & $\begin{array}{l}\text { Li Y. et } \\
\text { al. }\end{array}$ & ex & $\begin{array}{l}\text { Strontium } \\
\text { ranelate }\end{array}$ & Oral & $625 \mathrm{mg} / \mathrm{kg}$ & 20 rats & bic & China \\
\hline
\end{tabular}




\begin{tabular}{|c|c|c|c|c|c|c|c|c|}
\hline 2004 & $\begin{array}{l}\text { Ayukaw } \\
\text { a Y. et } \\
\text { al. }\end{array}$ & ex & Simvastatin & $\begin{array}{l}\text { Intrape } \\
\text { ritonea } \\
\text { I }\end{array}$ & $10 \mathrm{mg} / \mathrm{kg}$ & 10 rats & bic & Japan \\
\hline 2016 & $\begin{array}{l}\text { dos } \\
\text { Santos } \\
\text { R.A. et } \\
\text { al. } \\
\end{array}$ & ex & PTH & SC & $\begin{array}{l}2 \text { or } 40 \\
\mu g / k g\end{array}$ & 50 rats & bic & Brazil \\
\hline 2011 & $\begin{array}{l}\text { Carvas } \\
\text { J.B. et } \\
\text { al. }\end{array}$ & ex & Methotrexate & IM & $3 \mathrm{mg} / \mathrm{kg}$ & $\begin{array}{l}\text { Four } \\
\text { groups of } \\
6-8 \text { rabbits } \\
\text { each }\end{array}$ & bic & Brazil \\
\hline 2008 & $\begin{array}{l}\text { Feitosa } \\
\text { Dda S. } \\
\text { et al. }\end{array}$ & ex & $\begin{array}{l}\text { Thyroid } \\
\text { hormonre }\end{array}$ & Oral & $\begin{array}{l}800 \mu \mathrm{g} \\
\text { sodium I- } \\
\text { thyroxine } \\
\text { and } 180 \mu \mathrm{g} \\
\text { sodium } \\
\text { triiodothyr } \\
\text { onine/1 L }\end{array}$ & 42 rats & bic & Brazil \\
\hline 2012 & $\begin{array}{l}\text { Daugaa } \\
\text { rd H. et } \\
\text { al. }\end{array}$ & ex & PTH & SC & $5 \mu \mathrm{g} / \mathrm{kg}$ & 20 dogs & bic & Denmark \\
\hline 2016 & $\begin{array}{l}\text { Maiqua } \\
\mathrm{n} \text { W. et } \\
\text { al. }\end{array}$ & ex & Oxytocin & SC & $1 \mathrm{mg} / \mathrm{kg}$ & 20 rats & bic & China \\
\hline 2005 & $\begin{array}{l}\text { Eberhar } \\
\text { dt C. et } \\
\text { al. }\end{array}$ & ex & Ibandronate & SC & $\begin{array}{l}1 \text { or } 25 \\
\mu \mathrm{g} / \mathrm{kg}\end{array}$ & 52 rats & bic & Germany \\
\hline 2012 & $\begin{array}{l}\text { Ayan } \\
\text { M. et } \\
\text { al. }\end{array}$ & ex & Zoledronic acid & SC & $0.1 \mathrm{mg} / \mathrm{kg}$ & 12 rabbits & bic & Turkey \\
\hline 2012 & $\begin{array}{l}\text { Tsetsen } \\
\text { ekou E. } \\
\text { et al. }\end{array}$ & ex & Alendronate & Oral & $10 \mathrm{mg} / \mathrm{kg}$ & 32 rabbit & bic & Austria \\
\hline 2017 & $\begin{array}{l}\text { Serrao } \\
\text { C.R. et } \\
\text { al. } \\
\end{array}$ & ex & Metformin & $\begin{array}{l}\text { Intrape } \\
\text { ritonea } \\
1\end{array}$ & $40 \mathrm{mg} / \mathrm{kg}$ & 30 rats & bic & Brazil \\
\hline 1993 & $\begin{array}{l}\text { Senner } \\
\text { by L. et } \\
\text { al. }\end{array}$ & ex & Indomethacin & SC & $\begin{array}{l}1 \text { or } 4 \\
\mathrm{mg} / \mathrm{kg}\end{array}$ & 6 rabbits & bic & Sweden \\
\hline 2015 & $\begin{array}{l}\text { Mozzati } \\
\text { M. }\end{array}$ & re & $\begin{array}{l}\text { Alendronate, } \\
\text { Risedronate, } \\
\text { and } \\
\text { Ibandronate }\end{array}$ & Oral & $\mathrm{nr}$ & $\begin{array}{l}235 \\
\text { patients }\end{array}$ & is & Italy \\
\hline 2006 & $\begin{array}{l}\text { Chacon } \\
\text { G.E. et } \\
\text { al. }\end{array}$ & ex & Alendronate & Oral & $10 \mathrm{mg} / \mathrm{kg}$ & 20 rabbits & bic & USA \\
\hline 2011 & $\begin{array}{l}\text { Daugaa } \\
\text { rd H. et } \\
\text { al. }\end{array}$ & ex & PTH & SC & $5 \mu \mathrm{g} / \mathrm{kg} /$ & 20 dogs & bic & Denmark \\
\hline 2001 & $\begin{array}{l}\text { Frenkel } \\
\text { S.R. et } \\
\text { al. } \\
\end{array}$ & ex & Alendronate & SC & $2.5 \mu \mathrm{g} / \mathrm{kg}$ & 16 dogs & bic & USA \\
\hline
\end{tabular}




\begin{tabular}{|c|c|c|c|c|c|c|c|c|}
\hline 2011 & $\begin{array}{l}\text { Skolden } \\
\text { berg } \\
\text { O.G. et } \\
\text { al. }\end{array}$ & rct & Risedronate & Oral & $35 \mathrm{mg} / \mathrm{kg}$ & 73 patient & is & Sweden \\
\hline 2006 & $\begin{array}{l}\text { Sakakur } \\
\text { a C.E. } \\
\text { et al. }\end{array}$ & ex & Cyclosporin A & SC & $10 \mathrm{mg} / \mathrm{kg}$ & 18 rabbit & bic & Brazil \\
\hline 2010 & $\begin{array}{l}\text { Li Y. et } \\
\text { al. }\end{array}$ & ex & $17 \beta$-estradiol & SC & $20 \mu \mathrm{g} / \mathrm{kg}$ & 20 rats & bic & China \\
\hline 2014 & $\begin{array}{l}\text { Wu X. } \\
\text { et al. }\end{array}$ & re & SSRI & NR & $\mathrm{nr}$ & $\begin{array}{l}490 \\
\text { patients }\end{array}$ & is & Canada \\
\hline 1996 & $\begin{array}{l}\text { Werner } \\
\text { S.B. et } \\
\text { al. }\end{array}$ & ex & Dexamethasone & $\begin{array}{l}\text { Intrape } \\
\text { ritonea } \\
\text { I }\end{array}$ & $120 \mu \mathrm{g} / \mathrm{kg}$ & 9 rats & bic & $\begin{array}{l}\text { Argentin } \\
a\end{array}$ \\
\hline 2010 & $\begin{array}{l}\text { Martin } \\
\text { D.C. et } \\
\text { al. }\end{array}$ & re & $\begin{array}{l}\text { Alendronate, } \\
\text { Risedronate, } \\
\text { and } \\
\text { lbandronate }\end{array}$ & Oral & $\begin{array}{l}10 \text { or } 4 \text { to } \\
6 \\
\mathrm{mg} / \mathrm{kgAlen} \\
\text { dronate }\end{array}$ & 16 patients & is & USA \\
\hline 2010 & $\begin{array}{l}\text { Yamano } \\
\text { S. et al. }\end{array}$ & ex & Nicotine & SC & $6 \mathrm{mg} / \mathrm{kg}$ & 44 rats & bic & USA \\
\hline 2009 & $\begin{array}{l}\text { Basarir } \\
\text { K. et al. }\end{array}$ & ex & Simvastatin & SC & $50 \mathrm{mg} / \mathrm{kg}$ & 20 rabbits & bic & Turkey \\
\hline 2006 & $\begin{array}{l}\text { Eberhar } \\
\text { dt C. et } \\
\text { al. }\end{array}$ & ex & Ibandronate & SC & $25 \mu \mathrm{g} / \mathrm{kg}$ & 55 rats & bic & Germany \\
\hline 2005 & $\begin{array}{l}\text { Sakakur } \\
\text { a CE. et } \\
\text { al. }\end{array}$ & ex & Cyclosporin A & SCe & $10 \mathrm{mg} / \mathrm{kg}$ & 18 rabbits & bic & Brazil \\
\hline 2016 & $\begin{array}{l}\text { Tao ZS. } \\
\text { et al. }\end{array}$ & ex & PTH & SC & $60 \mathrm{mg} / \mathrm{kg}$ & 50 rats & bic & $\begin{array}{l}\text { Zhejiang, } \\
\text { china }\end{array}$ \\
\hline 2017 & $\begin{array}{l}\text { Salduz } \\
\text { A. et al. }\end{array}$ & ex & $\begin{array}{l}\text { Celecoxib and } \\
\text { Diclofenac }\end{array}$ & $\begin{array}{l}\text { Diclofe } \\
\text { nac } \\
\text { IMly } \\
\text { and } \\
\text { Celecox } \\
\text { ib oral } \\
\end{array}$ & $\begin{array}{l}5 \mathrm{mg} / \mathrm{kg} \\
\text { Diclofenac } \\
\mathrm{Na} \text { and } 3 \\
\mathrm{mg} / \mathrm{kg} \\
\text { Celecoxib }\end{array}$ & 40 rabbits & bic & Turkey \\
\hline 2008 & $\begin{array}{l}\text { Bell } \\
\text { BM. et } \\
\text { al. }\end{array}$ & re & $\begin{array}{l}\text { Alendronate, Ris } \\
\text { edronate, or } \\
\text { lbandronate. }\end{array}$ & Oral & $\mathrm{nr}$ & 42 patients & is & USA \\
\hline 2003 & $\begin{array}{l}\text { Cesar- } \\
\text { Neto } \\
\text { JB. et } \\
\text { al. }\end{array}$ & ex & Nicotine & $\begin{array}{l}\text { Inhalati } \\
\text { on or } \\
\text { SC }\end{array}$ & $3 \mathrm{mg} / \mathrm{kg}$ & 45 rats & bic & Brazil \\
\hline 2008 & $\begin{array}{l}\text { Spence } \\
\text { G. et al. }\end{array}$ & ex & Zoledronic acid & IV & $0.05 \mathrm{mg} / \mathrm{kg}$ & 12 sheep & bic & England \\
\hline 1995 & $\begin{array}{l}\text { Jeffcoat } \\
\text { MK, et } \\
\text { al. }\end{array}$ & rct & Flurbiprofen & IV & $\begin{array}{l}50 \text { or } 100 \\
\mathrm{mg} / \mathrm{kg}\end{array}$ & 29 patients & bic & USA \\
\hline 1995 & $\begin{array}{l}\text { Cook } \\
\text { SD, et } \\
\text { al. }\end{array}$ & ex & Indomethacin & Oral & $1 \mathrm{mg} / \mathrm{kg}$ & 26 dogs & bic & USA \\
\hline
\end{tabular}




\begin{tabular}{|c|c|c|c|c|c|c|c|c|}
\hline 2012 & $\begin{array}{l}\text { Fahlgre } \\
\text { n A., et } \\
\text { al. }\end{array}$ & ex & PTH & SC & $20 \mu \mathrm{g} / \mathrm{kg}$ & 104 rabbits & bic & Sweden \\
\hline 2016 & $\begin{array}{l}\text { Bastos } \\
\text { MF., et } \\
\text { al. }\end{array}$ & ex & Metformin & Oral & $40 \mathrm{mg} / \mathrm{kg}$ & 20 rats & bic & Brazil \\
\hline 2016 & $\begin{array}{l}\text { Heo } \\
\text { HA., et } \\
\text { al. }\end{array}$ & ex & PTH & SC & $30 \mathrm{mg} / \mathrm{kg}$ & 27 rats & bic & $\begin{array}{l}\text { South } \\
\text { Korea }\end{array}$ \\
\hline 2013 & $\begin{array}{l}\text { de } \\
\text { Oliveira } \\
\text { MA., et } \\
\text { al. }\end{array}$ & ex & $\begin{array}{l}\text { Zoledronic acid } \\
\text { and } \\
\text { Dexamethasone }\end{array}$ & SC & $\begin{array}{l}7.5 \mu \mathrm{g} / \mathrm{kg} \\
\text { Zoledronic } \\
\text { acid and } \\
1 \mathrm{mg} / \mathrm{kg} \\
\text { Dexameth } \\
\text { asone }\end{array}$ & 27 rats & bic & Brazil \\
\hline 2010 & $\begin{array}{l}\text { Yin H., } \\
\text { et al. }\end{array}$ & ex & Simvastatin & SC & $\begin{array}{l}3.0 \text { or } 6.0 \\
\mathrm{mg} / \mathrm{kg}\end{array}$ & 15 dogs & bic & China \\
\hline 2012 & Sakka S & $\mathrm{pr}$ & ibuprofen & NR & $600 \mathrm{mg} / \mathrm{kg}$ & 28 patients & bic & $\begin{array}{l}\text { Saudi } \\
\text { Arabia }\end{array}$ \\
\hline 2007 & $\begin{array}{l}\text { Jensen } \\
\text { TB }\end{array}$ & ex & Alendronate & Oral & $0.5 \mathrm{mg} / \mathrm{kg}$ & 16 dogs & bic & Denmark \\
\hline 2011 & $\begin{array}{l}\text { Famili } \\
\text { P., et al. }\end{array}$ & re & $\begin{array}{l}\text { Bisphosphonate } \\
\text { s }\end{array}$ & Oral & $\mathrm{nr}$ & $\begin{array}{l}211 \\
\text { women }\end{array}$ & bic & USA \\
\hline 2015 & $\begin{array}{l}\text { Yang X., } \\
\text { et al. }\end{array}$ & ex & PTH & SC & $40 \mu \mathrm{g} / \mathrm{kg}$ & 90 mice & bic & USA \\
\hline 2007 & $\begin{array}{l}\text { Dayer } \\
\text { R., et al. }\end{array}$ & ex & $\begin{array}{l}\text { PTH or } \\
\text { Pamidronate }\end{array}$ & SC & $\begin{array}{l}40 \mu \mathrm{g} / \mathrm{kg} \\
\text { PTH or } 0.6 \\
\mathrm{mg} / \mathrm{kg} \\
\text { Pamidrona } \\
\text { te }\end{array}$ & 49 rats & bic & $\begin{array}{l}\text { Switzerla } \\
\text { nd }\end{array}$ \\
\hline 2008 & Du Z & ex & Simvastatin & Oral & $5 \mathrm{mg} / \mathrm{kg}$ & 54 rats & bic & China \\
\hline 2001 & $\begin{array}{l}\text { Skripitz } \\
\text { R., et al. }\end{array}$ & ex & PTH & SC & $60 \mu \mathrm{g} / \mathrm{kg}$ & 28 rats & bic & Sweden \\
\hline 2015 & $\begin{array}{l}\text { Xue Y., } \\
\text { et al. }\end{array}$ & ex & PTH & SC & $40 \mu \mathrm{g} / \mathrm{kg}$ & 8 dogs & bic & China \\
\hline 2016 & $\begin{array}{l}\text { Al- } \\
\text { Subaie } \\
\text { AE., et } \\
\text { al. }\end{array}$ & ex & Propranolol & SC & $5 \mathrm{mg} / \mathrm{kg}$ & 24 rats & bic & Canada \\
\hline 2011 & $\begin{array}{l}\text { Kuchler } \\
\text { U., et } \\
\text { al. }\end{array}$ & ex & PTH & SC & $60 \mu \mathrm{g} / \mathrm{kg}$ & 40 rats & bic & Austria \\
\hline 2011 & $\begin{array}{l}\text { Kuchler } \\
\text { U., et al }\end{array}$ & rct & PTH & SC & $20 \mu \mathrm{g} / \mathrm{kg}$ & 24 patients & bic & Austria \\
\hline 2014 & $\begin{array}{l}\text { Winnet } \\
\text { t B., et } \\
\text { al. }\end{array}$ & re & $\begin{array}{l}\text { NSAID } \\
\text { (ibuprofen and } \\
\text { ASA), Non- } \\
\text { NSAID } \\
\text { (Ketorolac, } \\
\text { Vioxx, Celebrex, } \\
\text { Diflunisal, } \\
\text { Meloxicam, }\end{array}$ & NR & $\mathrm{nr}$ & $\begin{array}{l}168 \\
\text { patients }\end{array}$ & is & Canada \\
\hline
\end{tabular}




\begin{tabular}{|c|c|c|c|c|c|c|c|c|}
\hline & & & $\begin{array}{l}\text { Acetaminophen, } \\
\text { and Naproxen }\end{array}$ & & & & & \\
\hline 2015 & $\begin{array}{l}\text { Cho } \\
\text { PG., et } \\
\text { al. }\end{array}$ & $\mathrm{pr}$ & $\begin{array}{l}\text { PTH or } \\
\text { Alendronate }\end{array}$ & $\begin{array}{l}\text { PTH } \\
\text { SC and } \\
\text { Alendr } \\
\text { onate } \\
\text { oral }\end{array}$ & $\begin{array}{l}20 \mu \mathrm{g} / \mathrm{kg} \\
\text { PTH or } \\
91.37 \\
\mathrm{mg} / \mathrm{kg} / \mathrm{we} \\
\text { ek } \\
\text { Alendronat } \\
\text { e }\end{array}$ & 47 patients & Is & $\begin{array}{l}\text { South } \\
\text { Korea }\end{array}$ \\
\hline 2016 & $\begin{array}{l}\text { Al } \\
\text { Subaie } \\
\text { A }\end{array}$ & ex & PPI & $\begin{array}{l}\text { Intrape } \\
\text { ritonea } \\
\text { I }\end{array}$ & $5 \mathrm{mg} / \mathrm{kg}$ & 24 rats & bic & Canada \\
\hline 1995 & $\begin{array}{l}\text { Callaha } \\
\text { n BC., } \\
\text { et al. }\end{array}$ & ex & warfarin & oral & $\begin{array}{l}0,5, \text { and } \\
7.5 \mathrm{mg} / \mathrm{kg}\end{array}$ & 18 goats & bic & USA \\
\hline 2011 & $\begin{array}{l}\text { Zahid } \\
\text { TM., et } \\
\text { al. }\end{array}$ & re & $\begin{array}{l}\text { Bisphosphonate } \\
\text { s }\end{array}$ & NR & $\begin{array}{l}5,35, \text { or } 70 \\
\mathrm{mg} / \mathrm{kg}\end{array}$ & $\begin{array}{l}362 \\
\text { patients }\end{array}$ & is & USA \\
\hline 2002 & $\begin{array}{l}\text { Nociti } \\
\text { FH., et } \\
\text { al. }\end{array}$ & ex & $\begin{array}{l}\text { Calcitonin and } \\
\text { Estradiol }\end{array}$ & SC & $\begin{array}{l}16 \mathrm{IU} / \mathrm{Kg} \\
\text { Calcitonin } \\
\text { or } 20 \\
\mu \mathrm{g} / \mathrm{Kg} 17 \beta \\
\text { estradiol }\end{array}$ & 58 rats & bic & Brazil \\
\hline 2018 & $\begin{array}{l}\text { Altug } \\
\text { HA., et } \\
\text { al. }\end{array}$ & ex & $\begin{array}{l}\text { Hyperbaric } \\
\text { oxygen }\end{array}$ & $\begin{array}{l}\text { Inhalati } \\
\text { on }\end{array}$ & $\begin{array}{l}10 \text { sessions } \\
\text { of HBO } \\
\text { treatment } \\
\text { (each } \\
\text { session } \\
\text { lasted } 90 \\
\text { minutes } \\
\text { with } \\
\text { exposure } \\
\text { to } 2.5 \text { ATM } \\
\text { of pure } \\
\text { oxygen) }\end{array}$ & 32 rabbits & bic & Turkey \\
\hline 2010 & $\begin{array}{l}\text { Chen } \\
\text { BL., et } \\
\text { al. }\end{array}$ & ex & $\begin{array}{l}\text { Alendronate } \\
\text { and Calcitonin }\end{array}$ & $\begin{array}{l}\text { Alendr } \\
\text { onate } \\
\text { oral,Cal } \\
\text { citonin } \\
\text { SC } \\
\end{array}$ & $\begin{array}{l}7 \mathrm{mg} / \mathrm{kg} \\
\text { Alendronat } \\
\text { e and } 5 \\
\mathrm{IU} / \mathrm{kg} \\
\text { Calcitonin } \\
\end{array}$ & 40 rats & bic & China \\
\hline 2015 & $\begin{array}{l}\text { Tao ZS., } \\
\text { et al. }\end{array}$ & ex & $\begin{array}{l}\text { PTH or } \\
\text { Simvastatin }\end{array}$ & NR & $\begin{array}{l}\text { PTH } 60 \\
\mu \mathrm{g} / \mathrm{kg} \text { and } \\
5 \mathrm{mg} / \mathrm{kg} \\
\text { Simvastati } \\
\mathrm{n}\end{array}$ & 50 rats & bic & China \\
\hline 2001 & $\begin{array}{l}\text { Duarte } \\
\text { PM., et } \\
\text { al. }\end{array}$ & ex & $\begin{array}{l}\text { Cyclosporin A } \\
\text { and nifedipine }\end{array}$ & SC & $\begin{array}{l}10 \mathrm{mg} / \mathrm{kg} \\
\text { Cyclospori } \\
\mathrm{n} \mathrm{A} \text { and } 0.5 \\
\mathrm{mg} / \mathrm{kg} \\
\text { Nifedipine }\end{array}$ & 28 rabbits & bic & Brazil \\
\hline 2017 & $\begin{array}{l}\text { Oki Y., } \\
\text { et al. }\end{array}$ & ex & PTH & SC & $40 \mu \mathrm{g} / \mathrm{kg}$ & 15 rabbits & bic & Japan \\
\hline
\end{tabular}




\begin{tabular}{|c|c|c|c|c|c|c|c|c|}
\hline 2004 & $\begin{array}{l}\text { Skoglun } \\
\text { d B.,et } \\
\text { al }\end{array}$ & ex & Ibandronate & $\begin{array}{l}\text { Subcut } \\
\text { or } \\
\text { locally } \\
\text { applied }\end{array}$ & $3 \mu \mathrm{g} / \mathrm{kg}$ & 76 rats & bic & Sweden \\
\hline 2012 & $\begin{array}{l}\text { Lima } \\
\text { LL., et } \\
\text { al. }\end{array}$ & ex & $\begin{array}{l}\text { PTH and } \\
\text { Nicotine }\end{array}$ & $\begin{array}{l}\text { SC and } \\
\text { inhalati } \\
\text { on }\end{array}$ & $40 \mu \mathrm{g} / \mathrm{Kg}$ & 48 rats & bic & Brazil \\
\hline 2011 & $\begin{array}{l}\text { Giro G., } \\
\text { et al. }\end{array}$ & ex & $\begin{array}{l}\text { Alendronate } \\
\text { and estrogen }\end{array}$ & NR & $\begin{array}{l}\text { Alendronat } \\
\text { e } 50 \mu \mathrm{g} / \mathrm{Kg} \\
\text { or } 17 \mathrm{~b} \text { - } \\
\text { estradiol } \\
20 \mu \mathrm{g} / \mathrm{Kg}\end{array}$ & 66 rats & bic & Brazil \\
\hline 2003 & $\begin{array}{l}\text { Siqueira } \\
\text { JT. et al. }\end{array}$ & ex & Insulin & SC & $2 \mathrm{IU}$ & 43 rats & bic & Brazil \\
\hline 2017 & $\begin{array}{l}\text { Oh KC., } \\
\text { et al. }\end{array}$ & ex & Alendronate & SC & $1.0 \mathrm{mg} / \mathrm{kg}$ & 36 rats & bic & $\begin{array}{l}\text { South } \\
\text { Korea }\end{array}$ \\
\hline 2007 & $\begin{array}{l}\text { Giro G., } \\
\text { et al. }\end{array}$ & ex & $\begin{array}{l}\text { Alendronate } \\
\text { and 17B } \\
\text { Estradiol }\end{array}$ & SC & $\begin{array}{l}20 \mathrm{mg} / \mathrm{kg} \\
17 \mathrm{~b}- \\
\text { estradiol } \\
\text { and } 50- \\
\mu \mathrm{g} / \mathrm{Kg} \\
\text { Alendronat } \\
\mathrm{e}\end{array}$ & 58 rats & bic & Brazil \\
\hline 2016 & $\begin{array}{l}\text { Al- } \\
\text { Mahala } \\
\text { wy H., } \\
\text { et al. }\end{array}$ & ex & Cisplatin & $\begin{array}{l}\text { Intrape } \\
\text { ritonea } \\
\text { I }\end{array}$ & $2.5 \mathrm{mg} / \mathrm{kg}$ & 16 rabbits & bic & $\begin{array}{l}\text { Saudi } \\
\text { Arabia }\end{array}$ \\
\hline 2017 & $\begin{array}{l}\text { Jin Y. et } \\
\text { al. }\end{array}$ & ex & Lithium chloride & Oral & $150 \mathrm{mg} / \mathrm{kg}$ & 27 rats & bic & China \\
\hline 2015 & $\begin{array}{l}\text { Al } \\
\text { Subaie } \\
\text { AE., et } \\
\text { al. }\end{array}$ & ex & $\begin{array}{l}\text { Ranibizumab, } \\
\text { anti-vascular } \\
\text { endothelial } \\
\text { growth factors } \\
\text { (VEGF) }\end{array}$ & $\begin{array}{l}\text { Intrape } \\
\text { ritonea } \\
\text { I }\end{array}$ & $\begin{array}{l}15 \mu \mathrm{g} / \mathrm{Kg} \\
\text { Ranibizum } \\
\text { ab or } 4 \\
\mu \mathrm{g} / \mathrm{Kg} \\
\text { anti-VEGF }\end{array}$ & 36 rats & bic & Canada \\
\hline 2016 & $\begin{array}{l}\text { Tao ZS., } \\
\text { et al. }\end{array}$ & ex & $\begin{array}{l}\text { PTH or } \\
\text { Simvastatin }\end{array}$ & NR & $\begin{array}{l}40 \mu \mathrm{g} / \mathrm{Kg} \\
\mathrm{PTH} \text { or } 25 \\
\mathrm{mg} / \mathrm{kg} \\
\text { Simvastati } \\
\mathrm{n}\end{array}$ & 40 rats & bic & China \\
\hline 2008 & $\begin{array}{l}\text { Giro G., } \\
\text { et al. }\end{array}$ & ex & $\begin{array}{l}\text { Estrogen, and } \\
\text { Alendronate }\end{array}$ & SC & $\begin{array}{l}\text { 17B- } \\
\text { estradiol } \\
20 \mu \mathrm{g} / \mathrm{Kg} \\
\text { or } 50 \\
\mu \mathrm{g} / \mathrm{Kg} \\
\text { Alendronat } \\
\mathrm{e}\end{array}$ & 66 rats & bic & Brazil \\
\hline 2012 & $\begin{array}{l}\text { Zhou C., } \\
\text { et al. }\end{array}$ & ex & Vitamin D & Oral & $0.1 \mu \mathrm{g} / \mathrm{Kg}$ & 20 rats & $\begin{array}{l}\text { Push-out } \\
\text { force,bic }\end{array}$ & China \\
\hline 2013 & $\begin{array}{l}\text { Li YF., } \\
\text { et al. }\end{array}$ & ex & $\begin{array}{l}\text { PTH and local } \\
\text { Zoledronic acid }\end{array}$ & SC & $60 \mu \mathrm{g} / \mathrm{kg}$ & 50 rats & bic & China \\
\hline 2005 & $\begin{array}{l}\text { von } \\
\text { Knoch }\end{array}$ & ex & Zoledronic acid & SC & $\begin{array}{l}\text { Single } \\
\text { injection }\end{array}$ & 28 mice & bic & Germany \\
\hline
\end{tabular}




\begin{tabular}{|c|c|c|c|c|c|c|c|c|}
\hline & $\begin{array}{l}\text { M., et } \\
\text { al. }\end{array}$ & & & & $\begin{array}{l}\text { dose of } 25 \\
\mu \mathrm{g} / \mathrm{kg}\end{array}$ & & & \\
\hline 2002 & $\begin{array}{l}\text { Astrand } \\
\text { J. et al., }\end{array}$ & ex & $\begin{array}{l}\text { Alendronate or } \\
\text { Clodronate }\end{array}$ & SC & $\begin{array}{l}3.8,21, \\
205 \mu \mathrm{g} / \mathrm{kg} \\
\text { Alendronat } \\
\text { e or } 0.12 \text {, } \\
21 \mathrm{mg} / \mathrm{kg} \\
\text { Clodronate }\end{array}$ & 111 rats & bic, & Sweden \\
\hline 2005 & $\begin{array}{l}\text { Eberhar } \\
\text { dt C., et } \\
\text { al. }\end{array}$ & ex & Ibandronate & SC & $\begin{array}{l}1,5 \text { and } 25 \\
\mu \mathrm{g} / \mathrm{kg}\end{array}$ & 69 rats & bic & Germany \\
\hline 1989 & Trancik & ex & $\begin{array}{l}\text { Indomethacin, } \\
\text { aspirin, and } \\
\text { ibuprofen }\end{array}$ & SC & $\begin{array}{l}\text { Indometha } \\
\text { cin } 2 \\
\mathrm{mg} / \mathrm{kg} \\
\text { aspirin } 17 \\
\mathrm{mg} / \mathrm{kg} \\
\text { Ibuprofen } \\
17 \mathrm{mg} / \mathrm{kg}\end{array}$ & 120 rabbits & bic & USA \\
\hline 2014 & $\begin{array}{l}\text { Hazzaa } \\
\text { HH., et } \\
\text { al. }\end{array}$ & ex & Alendronate & Oral & $10 \mathrm{mg} / \mathrm{kg}$ & 34 rabbits & bic & Egypt \\
\hline 2013 & $\begin{array}{l}\text { Maus } \\
\text { UM., et } \\
\text { al. }\end{array}$ & ex & $\begin{array}{l}\text { Dihydrotestoste } \\
\text { rone }\end{array}$ & NR & $1 \mathrm{mg} / \mathrm{kg}$ & 20 & bic & Germany \\
\hline 2017 & Fu SH & re & $\begin{array}{l}\text { Alendronate, } \\
\text { Ibandronate, } \\
\text { and Zoledronate }\end{array}$ & NR & $\mathrm{nr}$ & $\begin{array}{l}140067 \\
\text { patients }\end{array}$ & is & Taiwan \\
\hline 2017 & $\begin{array}{l}\text { Yukizaw } \\
\text { a Y., et } \\
\text { al. }\end{array}$ & $\mathrm{rct}$ & $\begin{array}{l}\text { Alendronate or } \\
\text { Vitamin D }\end{array}$ & Oral & $\begin{array}{l}5 \mathrm{mg} / \mathrm{kg} \\
\text { Alendronat } \\
\text { e and } \\
\text { Vitamin D } \\
1 \mathrm{\mu g} / \mathrm{kg}\end{array}$ & $\begin{array}{l}60 \\
\text { patients }\end{array}$ & is & Japan \\
\hline 2015 & $\begin{array}{l}\text { Cankay } \\
\text { a D. et } \\
\text { al. }\end{array}$ & ex & $\begin{array}{l}\text { Alendronate, } \\
\text { Risedronate, } \\
\text { Calcitonin, } \\
\text { indomethacin }\end{array}$ & SC & $\begin{array}{l}0.2 \mathrm{mg} / \mathrm{kg} \\
\text { Alendronat } \\
\mathrm{e}, 0.1 \\
\mathrm{mg} / \mathrm{kg} \\
\text { Risedronat } \\
\mathrm{e}, 2 \mathrm{IU} / \mathrm{kg} \\
\text { salmon } \\
\text { Calcitonin, } \\
\text { and } 4 \\
\mathrm{mg} / \mathrm{kg} \\
\text { Indometha } \\
\text { cin }\end{array}$ & 30 rats & $\begin{array}{l}\text { bic, } \\
\text { push-out } \\
\text { strength }\end{array}$ & Turkey \\
\hline 2015 & $\begin{array}{l}\text { Jaroma } \\
\text { AV., et } \\
\text { al. }\end{array}$ & rct & Alendronate & Oral & $10 \mathrm{mg} / \mathrm{kg}$ & 26 patients & is & Finland \\
\hline 2014 & $\begin{array}{l}\text { Prieto- } \\
\text { alhamb } \\
\text { ra D., et } \\
\text { al. }\end{array}$ & re & $\begin{array}{l}\text { Oral } \\
\text { bisphosphonate }\end{array}$ & Oral & $\mathrm{nr}$ & $\begin{array}{l}80342 \\
\text { patient }\end{array}$ & $\begin{array}{l}\text { Effect of } \\
\text { oral } \\
\text { bisphosp } \\
\text { honates } \\
\text { on total }\end{array}$ & $\begin{array}{l}\text { Netherla } \\
\text { nds }\end{array}$ \\
\hline
\end{tabular}




\begin{tabular}{|c|c|c|c|c|c|c|c|c|}
\hline & & & & & & & $\begin{array}{l}\text { knee and } \\
\text { hip } \\
\text { implant } \\
\text { survival. }\end{array}$ & \\
\hline 2014 & $\begin{array}{l}\text { Inoue } \\
\text { G., et } \\
\text { al. }\end{array}$ & $\mathrm{pr}$ & PTH & SC & $\begin{array}{l}20 \text { or } 56.5 \\
\mu \mathrm{g} / \mathrm{kg}\end{array}$ & 29 women & $\begin{array}{l}\text { bic, } \\
\text { torque } \\
\text { force }\end{array}$ & Japan \\
\hline 2010 & $\begin{array}{l}\text { Xue Q., } \\
\text { et al. }\end{array}$ & ex & Alendronate & Oral & $10 \mathrm{mg} / \mathrm{kg}$ & 22 pigs & $\begin{array}{l}\text { Bic, } \\
\text { torque } \\
\text { force }\end{array}$ & Denmark \\
\hline 2013 & $\begin{array}{l}\text { Nyberg } \\
\text { J., et al. }\end{array}$ & ex & $\begin{array}{l}\text { Hyperbaric } \\
\text { oxygen }\end{array}$ & $\begin{array}{l}\text { Inhalati } \\
\text { on }\end{array}$ & $\begin{array}{l}75-\mathrm{L} \\
\text { pressure } \\
\text { chamber } \\
\text { (Göteborgs } \\
\text { Dykeritekn } \\
\text { ik) and } \\
\text { subjected } \\
\text { to pure } \\
\text { oxygen at } \\
2.80 \mathrm{kPa} \\
\text { absolute } \\
\text { pressure } \\
\text { for } 2 \text { hours } \\
\text { two times } \\
\text { daily }\end{array}$ & 16 rats & $\begin{array}{l}\text { bic, } \\
\text { removal } \\
\text { torque } \\
\text { tests }\end{array}$ & Sweden \\
\hline 2014 & $\begin{array}{l}\text { Conte } \\
\text { neto N., } \\
\text { et al }\end{array}$ & ex & Alendronate & Oral & $1 \mathrm{mg} / \mathrm{kg}$ & 48 rats & $\begin{array}{l}\text { Bic, } \\
\text { removal } \\
\text { torque } \\
\text { tests }\end{array}$ & Brazil \\
\hline 2013 & $\begin{array}{l}\text { Ji WP., } \\
\text { et al. }\end{array}$ & $\mathrm{pr}$ & $\begin{array}{l}\text { Alendronate } \\
\text { and } \\
\text { Xianlinggubao }\end{array}$ & Oral & $\begin{array}{l}70 \mathrm{mg} / \mathrm{day} \\
\text { Alendronat } \\
\text { e and } \\
\text { three } \\
\text { capsules } \\
\text { Xianlinggu } \\
\text { bao }\end{array}$ & 80 patients & is & China \\
\hline 2013 & $\begin{array}{l}\text { Ohtori } \\
\text { S., et al. }\end{array}$ & $\mathrm{pr}$ & $\begin{array}{l}\text { PTH or } \\
\text { Risedronate }\end{array}$ & $\begin{array}{l}\text { SC } \\
\text { PTH, } \\
\text { Oral } \\
\text { Risedro } \\
\text { nate }\end{array}$ & $\begin{array}{l}20 \mu \mathrm{g} / \mathrm{kg} \\
\text { PTH or } 2.5 \\
\mathrm{mg} \\
\text { Risdronate }\end{array}$ & 62 women & is & Japan \\
\hline 2012 & $\begin{array}{l}\text { Arnala } \\
\text { IO., et } \\
\text { al. }\end{array}$ & rct & $\begin{array}{l}\text { Calcitonin ( } \\
\text { thyroid } \\
\text { hormone } \\
\text { replacement) }\end{array}$ & $\begin{array}{l}\text { Nasal } \\
\text { spray }\end{array}$ & $200 \mathrm{IU}$ & 60 patients & is & Finland \\
\hline 2012 & $\begin{array}{l}\text { Liu S., } \\
\text { et al. }\end{array}$ & ex & $\begin{array}{l}\text { Sclerostin } \\
\text { antibody }\end{array}$ & SC & $25 \mathrm{mg} / \mathrm{kg}$ & 36 rats & $\begin{array}{l}\text { bic, pull- } \\
\text { out test }\end{array}$ & USA \\
\hline 2013 & $\begin{array}{l}\text { Scott } \\
\text { DF., et } \\
\text { al. }\end{array}$ & rct & Zoledronic acid & IV & $5 \mathrm{mg} / \mathrm{kg}$ & 51 patient & is & USA \\
\hline
\end{tabular}




\begin{tabular}{|c|c|c|c|c|c|c|c|c|}
\hline 2013 & $\begin{array}{l}\text { Lübbek } \\
\text { e A., et } \\
\text { al. }\end{array}$ & $\mathrm{pr}$ & Statins & Oral & $\mathrm{nr}$ & $\begin{array}{l}735 \\
\text { patient }\end{array}$ & is & USA \\
\hline 2012 & $\begin{array}{l}\text { Virdi } \\
\text { AS., et } \\
\text { al. }\end{array}$ & ex & $\begin{array}{l}\text { Sclerostin } \\
\text { antibody }\end{array}$ & SC & $25 \mathrm{mg} / \mathrm{kg}$ & 90 rats & $\begin{array}{l}\text { bic, pull- } \\
\text { out test }\end{array}$ & USA \\
\hline 2012 & $\begin{array}{l}\text { Oliveira } \\
\text { PA., et } \\
\text { al. }\end{array}$ & ex & $\begin{array}{l}\text { Hyperbaric } \\
\text { oxygen }\end{array}$ & $\begin{array}{l}\text { Inhalati } \\
\text { on }\end{array}$ & $\begin{array}{l}10 \text { sessions } \\
\text { Pure } \\
\text { oxygen at } \\
2.0 \\
\text { atmospher } \\
\text { ic } \\
\text { absolute } \\
\text { pressure } \\
\text { (ATA) was } \\
\text { applied for } \\
90 \text { min. } \\
\text { per day for } \\
10 \text { days }\end{array}$ & 48 rats & bic & Brazil \\
\hline 2013 & $\begin{array}{l}\text { Du Z., } \\
\text { et al. }\end{array}$ & ex & Simvastatin & Oral & $5 \mathrm{mg} / \mathrm{kg}$ & 54 rats & bic & Australia \\
\hline 2011 & $\begin{array}{l}\text { Li CY., } \\
\text { et al. }\end{array}$ & ex & Alendronate & $\begin{array}{l}\text { Intrape } \\
\text { ritonea } \\
\text { l }\end{array}$ & $\mathrm{nr}$ & 27 rabbits & $\begin{array}{l}\text { Bic, } \\
\text { torque- } \\
\text { out force }\end{array}$ & China \\
\hline 2011 & $\begin{array}{l}\text { Iwamot } \\
\text { o N., et } \\
\text { al. }\end{array}$ & $\mathrm{pr}$ & $\begin{array}{l}\text { Alendronate or } \\
\text { Vitamin D }\end{array}$ & Oral & $\begin{array}{l}5 \mathrm{mg} / \mathrm{kg} \\
\text { Alendronat } \\
\text { e or } 1 \\
\mu \mathrm{g} / \mathrm{kg} \\
\text { Vitamin D }\end{array}$ & $\begin{array}{l}60 \\
\text { patients }\end{array}$ & is & Japan \\
\hline 2011 & $\begin{array}{l}\text { Guimar } \\
\text { ães RP., } \\
\text { et al. }\end{array}$ & ex & Aminoguanidine & $\begin{array}{l}\text { intrape } \\
\text { ritonea } \\
\text { I }\end{array}$ & $\begin{array}{l}10-20 \\
\mathrm{mg} / \mathrm{kg}\end{array}$ & 36 rats & $\begin{array}{l}\text { Bic and } \\
\text { Biomech } \\
\text { anical } \\
\text { torque } \\
\text { force }\end{array}$ & Brazil \\
\hline 2011 & $\begin{array}{l}\text { De deco } \\
\text { CP., et } \\
\text { al. }\end{array}$ & ex & Alcohol & Oral & $\begin{array}{l}20 \% \\
\text { ethanol } \\
\text { solution }\end{array}$ & 96 rats & Bic & Brazil \\
\hline 2011 & $\begin{array}{l}\text { Huja } \\
\text { SS., et } \\
\text { al. } \\
\end{array}$ & ex & Zoledronic acid & IV & $0.1 \mathrm{mg} / \mathrm{kg}$ & 12 dogs & Bic & USA \\
\hline 2011 & $\begin{array}{l}\text { Huja } \\
\text { SS., et } \\
\text { al. }\end{array}$ & ex & Zoledronic acid & IV & $0.1 \mathrm{mg} / \mathrm{kg}$ & 4 dogs & Bic & USA \\
\hline 2010 & $\begin{array}{l}\text { Tapanin } \\
\text { en TS., } \\
\text { et al. }\end{array}$ & $\mathrm{pr}$ & Alendronate & Oral & $10 \mathrm{mg} / \mathrm{kg}$ & 16 patients & is & Finland \\
\hline 2010 & $\begin{array}{l}\text { Ayukaw } \\
\text { a Y., et } \\
\text { al. }\end{array}$ & ex & Simvastatin & $\begin{array}{l}\text { Intrape } \\
\text { ritonea } \\
\text { I }\end{array}$ & $\begin{array}{l}0.125,1,5 \text {, } \\
\text { or } 10 \\
\mathrm{mg} / \mathrm{kg}\end{array}$ & 60 rats & Bic & Japan \\
\hline 2009 & $\begin{array}{l}\text { Kelly J., } \\
\text { et al. }\end{array}$ & ex & Vitamin D & $\mathrm{NR}$ & $\mathrm{nr}$ & 28 rats & $\begin{array}{l}\text { Bic and } \\
\text { push-in } \\
\text { test }\end{array}$ & USA \\
\hline
\end{tabular}




\begin{tabular}{|c|c|c|c|c|c|c|c|c|}
\hline 2009 & $\begin{array}{l}\text { Skripitz } \\
\text { R., et al }\end{array}$ & ex & $\begin{array}{l}\text { Alendronate } \\
\text { and } \\
\text { intermittent } \\
\text { PTH }\end{array}$ & SC & $\begin{array}{l}\text { PTH } 60 \\
\mu \mathrm{g} / \mathrm{kg} \text { or } \\
200 \mu \mathrm{g} / \mathrm{kg} \\
\text { Alendronat } \\
\mathrm{e}\end{array}$ & 36 rats & Bic & Sweden \\
\hline 2010 & $\begin{array}{l}\text { Hayashi } \\
\text { K., et al. }\end{array}$ & ex & $\begin{array}{l}\text { Prostaglandin } \\
\text { EP4 receptor } \\
\text { agonist (ONO- } \\
\text { 4819) }\end{array}$ & SC & $30 \mu \mathrm{g} / \mathrm{kg}$ & 26 rats & $\begin{array}{l}\text { Bic and } \\
\text { push-out } \\
\text { test }\end{array}$ & Japan \\
\hline 2009 & $\begin{array}{l}\text { Hansso } \\
\mathrm{n} \mathrm{U.,} \mathrm{et} \\
\text { al. }\end{array}$ & rct & Alendronate & Oral & $70 \mathrm{mg} / \mathrm{kg}$ & 60 patients & is & Sweden \\
\hline 2009 & $\begin{array}{l}\text { Blazsek } \\
\text { J., et al. }\end{array}$ & ex & $\begin{array}{l}\text { Aminobisphosp } \\
\text { honate } \\
\text { (Zoledronate) }\end{array}$ & $\begin{array}{l}\text { Intrape } \\
\text { ritonea } \\
\text { I }\end{array}$ & $0.6 \mathrm{mg} / \mathrm{kg}$ & 10 rats & Bic & Hungary \\
\hline 2009 & $\begin{array}{l}\text { Meunie } \\
\text { r A.et } \\
\text { al. }\end{array}$ & rct & Celecoxib & Oral & $200 \mathrm{mg} / \mathrm{kg}$ & 50 patients & is & Sweden \\
\hline 2009 & $\begin{array}{l}\text { Friedl } \\
\text { G., et } \\
\text { al. }\end{array}$ & rct & Zoledronic acid & IV & $4 \mathrm{mg} / \mathrm{kg}$ & 50 patients & is & Austria \\
\hline 2008 & $\begin{array}{l}\text { Chen } \\
\text { M., et } \\
\text { al. }\end{array}$ & ex & Alendronate & Oral & $\begin{array}{l}10(-4) \text { or } \\
10(-5) \\
\mathrm{mol} / \mathrm{L} \\
\text { Alendronat } \\
\mathrm{e}\end{array}$ & 36 rats & Bic & China \\
\hline 2008 & $\begin{array}{l}\text { Ohkawa } \\
\text {, Y., et } \\
\text { al. }\end{array}$ & ex & PTH & $N R$ & $30 \mu \mathrm{g} / \mathrm{kg}$ & 81 rats & $\begin{array}{l}\text { Bic and } \\
\text { push-out } \\
\text { tset }\end{array}$ & Japan \\
\hline 2008 & $\begin{array}{l}\text { Nogueir } \\
\text { a-Filho } \\
\text { Gda, R., } \\
\text { et al. }\end{array}$ & ex & Cannabis sativa & $\begin{array}{l}\text { Inhalati } \\
\text { on }\end{array}$ & $8 \mathrm{~min} / \mathrm{day}$ & 30 rats & Bic & Brazil \\
\hline 2008 & $\begin{array}{l}\text { Johanss } \\
\text { on HR., } \\
\text { et al. }\end{array}$ & ex & $\begin{array}{l}\text { PTH and } \\
\text { Pamidronate }\end{array}$ & SC & $\begin{array}{l}60 \mu \mathrm{g} / \mathrm{kg} \\
\text { PTH and } \\
500 \mu \mathrm{g} / \mathrm{kg} \\
\text { Pamidrona } \\
\text { te }\end{array}$ & 138 rats & $\begin{array}{l}\text { Bic and } \\
\text { pull-out } \\
\text { test }\end{array}$ & Sweden \\
\hline 2008 & $\begin{array}{l}\text { Aspenb } \\
\text { erg P., } \\
\text { et al. }\end{array}$ & ex & $\begin{array}{l}\text { PTH and ocal } \\
\text { Pamidronate }\end{array}$ & NR & $\mathrm{nr}$ & 48 rats & $\begin{array}{l}\text { Bic and } \\
\text { pull-out } \\
\text { test }\end{array}$ & Sweden \\
\hline 2007 & $\begin{array}{l}\text { Søballe } \\
\text { K., et al. }\end{array}$ & ex & Alendronate & Oral & $0.5 \mathrm{mg} / \mathrm{kg}$ & 16 dogs & $\begin{array}{l}\text { Bic and } \\
\text { push-out } \\
\text { tests }\end{array}$ & USA \\
\hline 2008 & $\begin{array}{l}\text { Goodsh } \\
\text { ip AE., } \\
\text { et al. }\end{array}$ & ex & Zoledronate & IV & $10 \mu \mathrm{g} / \mathrm{kg}$ & 12 Sheep & Bic & $\begin{array}{l}\text { Switzerla } \\
\text { nd }\end{array}$ \\
\hline 2008 & $\begin{array}{l}\text { Ma B., } \\
\text { et al. }\end{array}$ & ex & Simvastatin & $\begin{array}{l}\text { Oral } \\
\text { and } \\
\text { Local } \\
\text { applica } \\
\text { tion } \\
\end{array}$ & $\begin{array}{l}5,10 \text { or } 50 \\
\mathrm{mg} / \mathrm{kg}\end{array}$ & 162 rats & $\begin{array}{l}\text { Bic and } \\
\text { push out } \\
\text { tests }\end{array}$ & UK \\
\hline
\end{tabular}




\begin{tabular}{|c|c|c|c|c|c|c|c|c|}
\hline 2007 & $\begin{array}{l}\text { Yamasa } \\
\text { ki S., et } \\
\text { al. }\end{array}$ & $\mathrm{pr}$ & Risedronate & Oral & $2.5 \mathrm{mg} / \mathrm{kg}$ & 43 patients & is & Japan \\
\hline 2007 & $\begin{array}{l}\text { Nishiok } \\
\text { a T., et } \\
\text { al. }\end{array}$ & $\mathrm{pr}$ & Alendronate & Oral & $5 \mathrm{mg} /$ day & 17 patients & is & Japan \\
\hline 2006 & $\begin{array}{l}\text { Xing Z., } \\
\text { et al. }\end{array}$ & ex & Pamidronate & $\begin{array}{l}\text { intrape } \\
\text { ritonea } \\
\text { | }\end{array}$ & $\begin{array}{l}0-40 \\
\mu \mathrm{g} / \mathrm{kg}\end{array}$ & 25 rats & Bic & USA \\
\hline 2006 & $\begin{array}{l}\text { Hilding, } \\
\text { M., et } \\
\text { al. }\end{array}$ & rct & Coldronate & Oral & $1.16 \mathrm{~g} / \mathrm{kg}$ & 50 patients & is & Sweden \\
\hline 2007 & $\begin{array}{l}\text { Moroni, } \\
\text { A., et } \\
\text { al., }\end{array}$ & $\mathrm{pr}$ & Alendronate & Oral & $70 \mathrm{mg} / \mathrm{kg}$ & 16 patients & is & Italy \\
\hline 2006 & $\begin{array}{l}\text { McCrac } \\
\text { ken, } \\
\text { M.S., et } \\
\text { al., }\end{array}$ & ex & Insulin & SC & $\begin{array}{l}\text { Insulin } \\
\text { pellet }\end{array}$ & 152 rats, & Bic & USA \\
\hline 2006 & $\begin{array}{l}\text { Fokter, } \\
\text { S. K., et } \\
\text { al., }\end{array}$ & rct & Etidronate & Oral & $400 \mathrm{mg} / \mathrm{kg}$ & 31 patients & is & Slovenia \\
\hline 2006 & $\begin{array}{l}\text { Kinov, } \\
\text { P., et } \\
\text { al., } \\
\end{array}$ & $\mathrm{pr}$ & Risedronate & Oral & $35 \mathrm{mg} / \mathrm{kg}$ & 24 patients & is & Bulgaria \\
\hline 2005 & $\begin{array}{l}\text { Persson } \\
\text { P. E., et } \\
\text { al., }\end{array}$ & $\mathrm{pr}$ & NSAID & $\begin{array}{l}\text { Ibuprof } \\
\text { en }\end{array}$ & $400 \mathrm{mg} / \mathrm{kg}$ & 96 patients & is & Sweden \\
\hline 2005 & $\begin{array}{l}\text { Wise, L. } \\
\text { M., et } \\
\text { al., }\end{array}$ & ex & Zoledronate & SC & $\begin{array}{l}2 \text { or } 10 \\
\mu \mathrm{g} / \mathrm{kg}\end{array}$ & 30 dogs & bic & Canada \\
\hline 2005 & $\begin{array}{l}\text { Balatso } \\
\text { uka, D., } \\
\text { et al }\end{array}$ & ex & Nicotine & SC & $3 \mu \mathrm{g} / \mathrm{kg}$ & 16 rabbits & $\begin{array}{l}\text { Bic and } \\
\text { removal } \\
\text { torque } \\
\text { test }\end{array}$ & Sweden \\
\hline 2005 & $\begin{array}{l}\text { Hayashi } \\
\text {, K., et } \\
\text { al., }\end{array}$ & ex & $\begin{array}{l}\text { Prostaglandin } \\
\text { EP4 receptor } \\
\text { agonist (ONO- } \\
4819 \text { ) }\end{array}$ & subcut & $15 \mu \mathrm{g} / \mathrm{kg}$ & 84 rats & $\begin{array}{l}\text { Bic and } \\
\text { push-out } \\
\text { test }\end{array}$ & Japan \\
\hline 2005 & $\begin{array}{l}\text { Virolain } \\
\text { en, P., } \\
\text { et al., }\end{array}$ & ex & $\begin{array}{l}\text { Doxorubicin, } \\
\text { Cisplatin, and } \\
\text { Ifosfamide }\end{array}$ & IV & $\begin{array}{l}20 \mathrm{mg} / \mathrm{m} 2 \\
\text { doxorubici } \\
\mathrm{n}, 50 \\
\mathrm{mg} / \mathrm{m}^{\prime} \\
\text { cisplatin, } \\
\text { and } 300 \\
\mathrm{mg} / \mathrm{m}^{\prime} \text { of } \\
\text { ifosfamide }\end{array}$ & 8 dogs & $\begin{array}{l}\text { Bic and } \\
\text { removal } \\
\text { torque } \\
\text { test }\end{array}$ & USA \\
\hline 2006 & $\begin{array}{l}\text { Hossein } \\
\text { K., et al. }\end{array}$ & re & $\begin{array}{l}\text { Phenoxymethyl } \\
\text { penicillin }\end{array}$ & Oral & $2 \mathrm{~g}$ & $\begin{array}{l}868 \\
\text { patients }\end{array}$ & is & Sweden \\
\hline 2004 & $\begin{array}{l}\text { Peichl } \\
\text { P., et al. }\end{array}$ & $\mathrm{pr}$ & Calcitonin & $\begin{array}{l}\text { Nasal } \\
\text { spray }\end{array}$ & $200 \mathrm{IU}$ & 75 women & is & Austria \\
\hline
\end{tabular}




\begin{tabular}{|c|c|c|c|c|c|c|c|c|}
\hline 2004 & $\begin{array}{l}\text { Miyaji } \\
\text { T., et al. }\end{array}$ & ex & Alendronate & SC & $350 \mu \mathrm{g} / \mathrm{kg}$ & 18 rats & Bic & Japan \\
\hline 2004 & $\begin{array}{l}\text { Koo S., } \\
\text { et al. }\end{array}$ & ex & Alcohol & Oral & $\begin{array}{l}\text { Brandy } \\
\text { with } 20 \% \\
\text { ethanol }\end{array}$ & 9 rabbits & Bic & Brazil \\
\hline 2003 & $\begin{array}{l}\text { Margon } \\
\text { ar R., } \\
\text { et al. }\end{array}$ & ex & Insulin & SC & 10 U/day & 27 rabbits & $\begin{array}{l}\text { Bic and } \\
\text { removal } \\
\text { torque } \\
\text { test }\end{array}$ & Brazil \\
\hline 2003 & $\begin{array}{l}\text { Nehme } \\
\text { A., et } \\
\text { al. }\end{array}$ & rct & Alendronate & Oral & 10 mg/kg & 38 patients & Bic & France \\
\hline 2003 & $\begin{array}{l}\text { Duarte } \\
\text { P. M. et } \\
\text { al. }\end{array}$ & ex & $\begin{array}{l}17 \text { beta } \\
\text { estradiol and } \\
\text { Calcitonin }\end{array}$ & SC & $\begin{array}{l}20 \mu \mathrm{g} / \mathrm{kg} \\
\text { of } 17 \mathrm{beta} \\
\text { estradiol } \\
\text { or } 16 \mathrm{IU} / \mathrm{kg} \\
\text { of } \\
\text { Calcitonin }\end{array}$ & 58 rats & Bic & Brazil \\
\hline 2003 & $\begin{array}{l}\text { Wang } \\
\text { C. J., et } \\
\text { al. }\end{array}$ & rct & Alendronate & Oral & $10 \mathrm{mg} / \mathrm{kg}$ & 96 patient & is & Taiwan \\
\hline 2003 & $\begin{array}{l}\text { Zou X., } \\
\text { et al. }\end{array}$ & ex & Alendronate & Oral & $10 \mathrm{mg} / \mathrm{kg}$ & 18 pigs & Bic & Denmark \\
\hline 2003 & $\begin{array}{l}\text { Tokuga } \\
\text { wa Y., } \\
\text { et al }\end{array}$ & ex & $\begin{array}{l}\text { Bisphosphonate } \\
\text { (YM-175) and } \\
\text { 17beta-estradiol } \\
\text { pellet }\end{array}$ & SC & $10 \mu \mathrm{g} / \mathrm{kg}$ & 72 rats & Bic & Japan \\
\hline 2002 & $\begin{array}{l}\text { Soininv } \\
\text { aara T. } \\
\text { A., et } \\
\text { al. } \\
\end{array}$ & rct & Alendronate & Oral & $10 \mathrm{mg} / \mathrm{kg}$ & 19 patients & is & Finland \\
\hline 2002 & $\begin{array}{l}\text { Iwase } \\
\text { M., et } \\
\text { al. }\end{array}$ & ex & $\begin{array}{l}\text { Bisphosphonate } \\
\text { (TRK-530) }\end{array}$ & $\mathrm{SC}$ & $1 \mathrm{mg} / \mathrm{kg}$ & 40 rats & Bic & Japan \\
\hline 2002 & $\begin{array}{l}\text { Hennigs } \\
\text { T., et al. }\end{array}$ & rct & Alendronate & NR & 10 mg/kg & 66 patients & Bic & Germany \\
\hline 2002 & $\begin{array}{l}\text { Stefani } \\
\text { C. M., } \\
\text { et al. }\end{array}$ & ex & Nicotine & SC & $\begin{array}{l}0.37,0.57, \\
\text { and } 0.93 \\
\mathrm{mg} / \mathrm{kg}\end{array}$ & 32 rabbits & Bic & Brazil \\
\hline 2002 & $\begin{array}{l}\text { Millett } \\
\text { P. J., et } \\
\text { al. }\end{array}$ & ex & Alendronate & SC & $0.01 \mathrm{mg} / \mathrm{kg}$ & 72 rats & Bic & USA \\
\hline 2002 & $\begin{array}{l}\text { Thadani } \\
\text { P. J., et } \\
\text { al. }\end{array}$ & ex & Alendronate & SC & $70 \mu \mathrm{g} / \mathrm{kg}$ & 24 rats & Bic & USA \\
\hline 2001 & $\begin{array}{l}\text { Skripitz } \\
\text { R., et al. }\end{array}$ & ex & PTH & SC & $60 \mu \mathrm{g} / \mathrm{kg}$ & 20 rats & Bic & Sweden \\
\hline 2001 & $\begin{array}{l}\text { Skripitz } \\
\text { R., et al. }\end{array}$ & ex & PTH & SC & $60 \mu \mathrm{g} / \mathrm{kg}$ & 38 rats & $\begin{array}{l}\text { Bic and } \\
\text { pull-out } \\
\text { test }\end{array}$ & Sweden \\
\hline
\end{tabular}




\begin{tabular}{|c|c|c|c|c|c|c|c|c|}
\hline 2001 & $\begin{array}{l}\text { August } \\
\text { M., et } \\
\text { al. }\end{array}$ & re & $\begin{array}{l}\text { estrogen } \\
\text { replacement } \\
\text { therapy }\end{array}$ & NR & $\mathrm{nr}$ & $\begin{array}{l}526 \\
\text { patients }\end{array}$ & is & USA \\
\hline 2001 & $\begin{array}{l}\text { Zhang } \\
\text { X., et al. }\end{array}$ & ex & Celecoxib & Oral & $\begin{array}{l}10 \text { or } 25 \\
\mathrm{mg} / \mathrm{kg}\end{array}$ & 12 mice & Bic & USA \\
\hline 2001 & $\begin{array}{l}\text { Wilkins } \\
\text { on J. } \\
\text { M. }\end{array}$ & rct & Pamidronate & IV & $90 \mathrm{mg} / \mathrm{kg}$ & 47 patients & is & UK \\
\hline 2000 & $\begin{array}{l}\text { Hilding } \\
\text { M., et } \\
\text { al. }\end{array}$ & rct & Clodronate & Oral & $400 \mathrm{mg} / \mathrm{kg}$ & 50 patient & is & Sweden \\
\hline 1999 & $\begin{array}{l}\text { Wang } \\
X \text {. } \\
\end{array}$ & ex & Alendronate & Oral & $6 \mathrm{mg} / \mathrm{kg}$ & 16 dogs & Bic & USA \\
\hline 1999 & $\begin{array}{l}\text { Astrand } \\
\text { J, et al. }\end{array}$ & ex & Alendronate & SC & $\begin{array}{c}0.063 \\
\mathrm{mg} / \mathrm{kg} \\
\end{array}$ & 48 rats & Bic & Sweden \\
\hline 1998 & $\begin{array}{l}\text { Fujimot } \\
\text { o T., et } \\
\text { al. }\end{array}$ & ex & Prednisolone & IM & $10 \mathrm{mg} / \mathrm{kg}$ & 12 rabbits & $\begin{array}{l}\text { Bic and } \\
\text { removal } \\
\text { torque } \\
\text { test }\end{array}$ & Japan \\
\hline 1989 & $\begin{array}{l}\text { Keller } \\
\text { J. C., et } \\
\text { al. }\end{array}$ & ex & $\begin{array}{l}\text { NSAID } \\
\text { (Indomethacin) }\end{array}$ & SC & $10 \mathrm{mg} / \mathrm{kg}$ & 30 rabbits & Bic & USA \\
\hline 2018 & $\begin{array}{l}\text { Suzuki } \\
\text { T., et al. }\end{array}$ & $\mathrm{pr}$ & PTH & SC & $56.5 \mu \mathrm{g} / \mathrm{wk}$ & 34 patients & is & Japan \\
\hline 2017 & $\begin{array}{l}\text { Huang } \\
\text { T. W., } \\
\text { et al. }\end{array}$ & $\mathrm{pr}$ & Zoledronic acid & IV & $5 \mathrm{mg} / \mathrm{kg}$ & 60 patients & is & Taiwan \\
\hline 2016 & $\begin{array}{l}\text { Kaneko } \\
\text { T., et al. }\end{array}$ & $\mathrm{pr}$ & PTH & SC & $\mathrm{nr}$ & 40 patients & Bic & Japan \\
\hline 2015 & $\begin{array}{l}\text { Wu F. } \\
\text { Q., et } \\
\text { al. }\end{array}$ & ex & $\begin{array}{l}\text { Zoledronic } \\
\text { sodium }\end{array}$ & SC & $0.1 \mathrm{mg} / \mathrm{kg}$ & 30 rats & Bic & China \\
\hline 2016 & $\begin{array}{l}\text { Kobaya } \\
\text { shi N., } \\
\text { et al. }\end{array}$ & rct & $\begin{array}{l}\text { Teriparatide or } \\
\text { Aldondrenate }\end{array}$ & $\begin{array}{l}\text { SC } \\
\text { of PTH } \\
\text { and } \\
\text { Oral of } \\
\text { Alendr } \\
\text { onate } \\
\end{array}$ & $\begin{array}{l}20 \mu \mathrm{g} / \mathrm{kg} \\
\mathrm{PTH} \text { or } 35 \\
\mathrm{mg} / \mathrm{kg} \\
\text { Alendronat } \\
\mathrm{e}\end{array}$ & 48 patients & is & Japan \\
\hline 2015 & $\begin{array}{l}\text { Muren } \\
\text { O., et } \\
\text { al. }\end{array}$ & rct & Risedronate & Oral & $35 \mathrm{mg} / \mathrm{kg}$ & 61 patients & is & Sweden \\
\hline 2014 & $\begin{array}{l}\text { Inouye } \\
\text { K. A. S., } \\
\text { et al. }\end{array}$ & ex & Metformin & Oral & $100 \mathrm{mg} / \mathrm{kg}$ & 36 rats & Bic & USA \\
\hline 2014 & $\begin{array}{l}\text { El- } \\
\text { Kholey } \\
\text { K. E., et } \\
\text { al. }\end{array}$ & rct & $\begin{array}{l}\text { antibiotic } \\
\text { (Amoxicillin) }\end{array}$ & Oral & $1 \mathrm{~g}$ & $\begin{array}{l}\text { 80; no } A B, \\
\text { single } \\
\text { dose, or } 3 \\
\text { days }\end{array}$ & is & $\begin{array}{l}\text { Saudi } \\
\text { Arabia }\end{array}$ \\
\hline 2013 & $\begin{array}{l}\text { Lee J. } \\
\text { K., et al. }\end{array}$ & $\mathrm{pr}$ & Aldendronate & Oral & $70 \mathrm{mg} / \mathrm{kg}$ & $\begin{array}{l}61 \\
\text { Patients } \\
\end{array}$ & is & $\begin{array}{l}\text { South } \\
\text { Korea }\end{array}$ \\
\hline
\end{tabular}




\begin{tabular}{|c|c|c|c|c|c|c|c|c|}
\hline 2013 & $\begin{array}{l}\text { Wu Y. } \\
\text { Y., et al. }\end{array}$ & ex & $\begin{array}{l}\text { vitamin D and } \\
\text { insulin }\end{array}$ & Oral & $\begin{array}{l}12 \mu \mathrm{g} / \mathrm{kg} \\
\text { of } \\
\text { vitamine D } \\
\text { and } \\
5.5 \mathrm{UI} \text { at } \\
20: 00 \\
\text { hours and } \\
3.5 \mathrm{Ul} \text { at } \\
8: 00 \\
\text { hours) of } \\
\text { insulin }\end{array}$ & 30 rats & $\begin{array}{l}\text { Bic and } \\
\text { push-out } \\
\text { test }\end{array}$ & China \\
\hline 2012 & $\begin{array}{l}\text { de } \\
\text { Molon } \\
\text { R. S.,et } \\
\text { al. }\end{array}$ & ex & Insulin & SC & $100 \mathrm{U} / \mathrm{ml}$ & 80 rats & $\begin{array}{l}\text { Bic and } \\
\text { removal } \\
\text { torque } \\
\text { test }\end{array}$ & Brazil \\
\hline 2012 & $\begin{array}{l}\text { Lee J. } \\
\text { K., et al. }\end{array}$ & re & Aldendronate & Oral & 70 mg/kg & 82 patients & is & $\begin{array}{l}\text { South } \\
\text { Korea }\end{array}$ \\
\hline 2011 & $\begin{array}{l}\text { Lima C. } \\
\text { C., et al. }\end{array}$ & ex & Alcohol & Oral & $\begin{array}{l}5 \% \text { and } \\
15 \% \\
\text { ethanol }\end{array}$ & 15 rats & Bic & Brazil \\
\hline 2010 & $\begin{array}{l}\text { Esposit } \\
\text { o M., } \\
\text { et al. }\end{array}$ & rct & $\begin{array}{l}\text { Antibiotics } \\
\text { (Amoxicillin) }\end{array}$ & Oral & $2 \mathrm{~g} / \mathrm{kg}$ & $\begin{array}{l}506 \\
\text { patients }\end{array}$ & is & UK \\
\hline 2011 & $\begin{array}{l}\text { Caiazzo } \\
\text { A., et } \\
\text { al. } \\
\end{array}$ & rct & $\begin{array}{l}\text { Antibiotics } \\
\text { (Amoxicillin) }\end{array}$ & Oral & $\begin{array}{l}1 \text { or } 2 \\
\mathrm{~g} / \mathrm{kg}\end{array}$ & $\begin{array}{l}100 \\
\text { patients }\end{array}$ & is & Italy \\
\hline 2011 & $\begin{array}{l}\text { El } \\
\text { Hadary } \\
\text { A. A., } \\
\text { et al. }\end{array}$ & ex & $\begin{array}{l}\text { Cyclosporin A } \\
\text { and ozonated } \\
\text { plant }\end{array}$ & $\begin{array}{l}\text { SC } \\
\text { Cyclosp } \\
\text { orin A } \\
\text { and } \\
\text { topical } \\
\text { ozonat } \\
\text { ed } \\
\text { plant }\end{array}$ & $10 \mathrm{mg} / \mathrm{kg}$ & 20 rabbits & Bic & Egypt \\
\hline 2010 & $\begin{array}{l}\text { Trevisa } \\
\text { n C., et } \\
\text { al. }\end{array}$ & rct & Clodronate & $\mathrm{IM}$ & $100 \mathrm{mg}$ & $\begin{array}{l}104 \\
\text { patients }\end{array}$ & is & Italy \\
\hline 2009 & $\begin{array}{l}\text { Gotfred } \\
\text { sen K., } \\
\text { et al }\end{array}$ & ex & Nicotine & SC & $6 \mu \mathrm{g} / \mathrm{kg}$ & 20 rabbits & $\begin{array}{l}\text { Bic and } \\
\text { removal } \\
\text { torque } \\
\text { test }\end{array}$ & Sweden \\
\hline 2009 & $\begin{array}{l}\text { De } \\
\text { Morais } \\
\text { J. A. N. } \\
\text { D., et } \\
\text { al. } \\
\end{array}$ & ex & Insulin & SC & $100 \mathrm{U} / \mathrm{ml}$ & 40 rats & Bic & Brazil \\
\hline 2008 & $\begin{array}{l}\text { Arabmo } \\
\text { tlagh } \\
\text { M., et } \\
\text { al. } \\
\end{array}$ & $\mathrm{pr}$ & Alendronate & NR & $\mathrm{nr}$ & 49 patients & is & Germany \\
\hline
\end{tabular}




\begin{tabular}{|c|c|c|c|c|c|c|c|c|}
\hline 2006 & $\begin{array}{l}\text { Wang } \\
\text { C. J., et } \\
\text { al. }\end{array}$ & rct & Alendronate & Oral & $10 \mathrm{mg}$ & 60 patients & is & Taiwan \\
\hline 2005 & $\begin{array}{l}\text { Bragdo } \\
\text { n C. R., } \\
\text { et al. }\end{array}$ & ex & Alendronate & Oral & $5 \mathrm{mg}$ & 12 dogs & Bic & USA \\
\hline 2005 & $\begin{array}{l}\text { Kwon } \\
\text { P. T., et } \\
\text { al. }\end{array}$ & ex & Insulin & NR & $\mathrm{nr}$ & 32 rats & Bic & USA \\
\hline 2003 & $\begin{array}{l}\text { Duarte } \\
\text { P. M., } \\
\text { et al. }\end{array}$ & ex & $\begin{array}{l}\text { Cyclosporin } \\
\text { A plus } \\
\text { nifedipine }\end{array}$ & SC & $\begin{array}{l}\text { CsA (10 } \\
\mathrm{mg} / \mathrm{kg}) \\
\text { plus } \\
\text { nifedipine } \\
(50 \mathrm{mg} / \mathrm{kg})\end{array}$ & 28 rabbits & Bic & Brazil \\
\hline 2003 & $\begin{array}{l}\text { Sakakur } \\
\text { a C. E., } \\
\text { et al. }\end{array}$ & ex & Cyclosporin A & SC & $10 \mathrm{mg} / \mathrm{kg}$ & 18 rabbits & $\begin{array}{l}\text { Bic and } \\
\text { removal } \\
\text { torque } \\
\text { test }\end{array}$ & Brazil \\
\hline 2001 & $\begin{array}{l}\text { Shibuta } \\
\text { ni T., et } \\
\text { al. }\end{array}$ & ex & Pamidronate & IM & $\begin{array}{l}0.6 \mathrm{mg} / \mathrm{kg} \\
\text { every }\end{array}$ & 10 dogs & Bic & Japan \\
\hline 2017 & $\begin{array}{l}\text { Chrcan } \\
\text { ovic } \\
\text { B.R. }\end{array}$ & re & SSRI & NR & $\mathrm{nr}$ & $\begin{array}{l}300 \\
\text { patients }\end{array}$ & is & Sweden \\
\hline 2011 & $\begin{array}{l}\text { Urdane } \\
\text { ta et al., }\end{array}$ & re & NSAID & NR & $\begin{array}{l}\text { Aspirin } 81 \text {, } \\
162.2 \text {, and } \\
325 \\
\text { Ibuprofen } \\
400,600 \\
\text { or } 800- \\
1600 \\
\text { Rofecoxib } \\
25 \mathrm{mg} \\
\text { Diclofenac } \\
150 \mathrm{mg} \\
\text { Celecoxib } \\
200 \mathrm{mg} \\
\text { Nabumeto } \\
\text { ne } 500 \mathrm{mg} \\
\text { Naproxen } \\
375 \mathrm{mg} \\
\text { Etodolac } \\
400 \mathrm{mg}\end{array}$ & 81 patients & is & USA \\
\hline 2017 & $\begin{array}{l}\text { Chrcan } \\
\text { ovic } \\
\text { BR., et } \\
\text { al }\end{array}$ & re & PPI & NR & $\mathrm{nr}$ & $\begin{array}{l}999 \\
\text { patients }\end{array}$ & $\mathrm{nr}$ & Sweden \\
\hline
\end{tabular}


Appendix C: Quality assessment of animal studies

Table 8: SYRCLE's guidelines assessments for included articles of animal studies

\begin{tabular}{|c|c|c|c|c|c|c|c|c|c|c|c|}
\hline \multirow[t]{2}{*}{ Author } & \multicolumn{3}{|c|}{ Selection bias } & \multicolumn{2}{|c|}{ Performance bias } & \multicolumn{2}{|c|}{ Detection bias } & \multirow{2}{*}{$\begin{array}{l}\text { Attrition } \\
\text { bias }\end{array}$} & \multirow{2}{*}{$\begin{array}{c}\text { Reporting } \\
\text { bias }\end{array}$} & \multirow{2}{*}{$\begin{array}{l}\text { Other } \\
\text { Other } \\
\text { source } \\
\text { s of } \\
\text { bias }\end{array}$} & \multirow{2}{*}{$\begin{array}{c}\text { Qualit } \\
y\end{array}$} \\
\hline & $\begin{array}{l}\text { Sequence } \\
\text { generation }\end{array}$ & $\begin{array}{l}\text { Baseline } \\
\text { characteristi } \\
\text { cs }\end{array}$ & $\begin{array}{l}\text { Allocation } \\
\text { concealment }\end{array}$ & $\begin{array}{l}\text { Random } \\
\text { housing }\end{array}$ & Blinding & $\begin{array}{l}\text { Random } \\
\text { outcome } \\
\text { assessmen } \\
\mathrm{t}\end{array}$ & Blinding & & & & \\
\hline $\begin{array}{l}\text { Toshiaki } \\
\text { Kitsugi }\end{array}$ & no & yes & no & no & no & no & no & yes & no & no & -0.6 \\
\hline $\begin{array}{l}\text { Lars } \\
\text { Sennerb } \\
\text { y }\end{array}$ & no & no & no & no & no & no & no & no & no & no & -1 \\
\hline $\begin{array}{l}\text { David } \\
\text { R. } \\
\text { Young, }\end{array}$ & no & no & no & no & no & no & no & yes & no & yes & -0.6 \\
\hline $\begin{array}{l}\text { Anders } \\
\text { Ekelund }\end{array}$ & unclear & no & no & no & yes & yes & yes & unclear & no & no & -0.2 \\
\hline $\begin{array}{l}\text { Sally R. } \\
\text { Frenkel }\end{array}$ & no & unclear & no & no & no & no & yes & yes & yes & no & -0.3 \\
\hline $\begin{array}{l}\text { Satoru } \\
\text { Narai }\end{array}$ & no & no & no & no & no & no & no & no & no & no & -1 \\
\hline $\begin{array}{l}\text { Lih- } \\
\text { Yuann } \\
\text { Shih }\end{array}$ & unclear & yes & no & no & no & yes & no & yes & no & no & -0.3 \\
\hline $\begin{array}{l}\text { Yasunor } \\
\text { i } \\
\text { Ayukaw } \\
\text { a }\end{array}$ & no & no & no & no & no & no & no & no & no & no & -1 \\
\hline $\begin{array}{l}\text { M.- } \\
\text { C. Qi }\end{array}$ & unclear & yes & no & yes & no & yes & no & no & no & no & -0.3 \\
\hline $\begin{array}{l}\text { J. D. } \\
\text { Bobyn, }\end{array}$ & no & no & no & no & no & no & yes & no & yes & no & -0.6 \\
\hline $\begin{array}{l}\text { A.H.A. } \\
\text { Kurtha, }\end{array}$ & unclear & yes & no & no & no & no & no & no & no & no & -0.7 \\
\hline $\begin{array}{l}\text { Christia } \\
\mathrm{n} \\
\text { Eberhar } \\
\mathrm{dt}\end{array}$ & unclear & yes & no & yes & no & no & no & yes & no & no & -0.3 \\
\hline $\begin{array}{l}\text { Christia } \\
\mathrm{n}\end{array}$ & unclear & yes & no & yes & no & no & no & yes & no & no & -0.3 \\
\hline
\end{tabular}




\begin{tabular}{|c|c|c|c|c|c|c|c|c|c|c|c|}
\hline $\begin{array}{l}\text { Eberhar } \\
\text { dt, }\end{array}$ & & & & & & & & & & & \\
\hline $\begin{array}{l}\text { Guiller } \\
\text { mo E. } \\
\text { Chacon }\end{array}$ & unclear & yes & no & yes & no & no & yes & yes & yes & no & 0.1 \\
\hline $\begin{array}{l}\text { Fernand } \\
\text { a V. } \\
\text { Ribeiro }\end{array}$ & unclear & yes & yes & yes & yes & yes & yes & no & yes & no & 0.5 \\
\hline $\begin{array}{l}\text { Celso E. } \\
\text { Sakakur } \\
\text { a }\end{array}$ & unclear & yes & no & yes & no & yes & no & yes & yes & no & 0.1 \\
\hline $\begin{array}{l}\text { Christia } \\
\mathrm{n} \\
\text { Eberhar } \\
\text { dt1 }\end{array}$ & unclear & yes & no & yes & no & no & no & unclear & no & no & -0.4 \\
\hline $\begin{array}{l}\text { Kerem } \\
\text { Başarır }\end{array}$ & no & no & no & no & no & no & no & yes & no & no & -0.8 \\
\hline $\begin{array}{l}\text { B. } \\
\text { Faensen }\end{array}$ & unclear & yes & no & unclear & yes & yes & yes & yes & no & no & 0.2 \\
\hline $\begin{array}{l}\text { Daniela } \\
\text { da Silva } \\
\text { Feitosa }\end{array}$ & unclear & yes & no & no & no & yes & no & no & no & no & -0.5 \\
\hline $\begin{array}{l}\text { Yeritxa } \\
\text { E. } \\
\text { Viera- } \\
\text { Negro'n }\end{array}$ & no & yes & yes & no & yes & yes & yes & no & yes & yes & 0.4 \\
\hline $\begin{array}{l}\text { Birgit } \\
\text { Mair }\end{array}$ & unclear & no & no & no & no & yes & no & no & no & no & -0.7 \\
\hline $\begin{array}{l}\text { R. } \\
\text { Dayer }\end{array}$ & no & yes & no & no & no & no & no & no & no & no & -0.8 \\
\hline $\begin{array}{l}\text { Yunfeng } \\
\mathrm{Li}\end{array}$ & no & yes & no & no & no & no & no & no & no & no & -0.8 \\
\hline $\begin{array}{l}\text { Joel } \\
\text { Berley }\end{array}$ & no & no & no & no & no & no & no & no & no & no & -1 \\
\hline $\begin{array}{l}\text { Seiichi } \\
\text { Yamano }\end{array}$ & no & no & no & no & no & no & yes & no & no & no & -0.8 \\
\hline $\begin{array}{l}\text { H. } \\
\text { Daugaar } \\
\text { d }\end{array}$ & unclear & no & no & no & no & yes & yes & no & no & no & -0.5 \\
\hline $\begin{array}{l}\text { Efstathi } \\
\text { a } \\
\text { Tsetsene } \\
\text { kou }\end{array}$ & unclear & yes & no & no & no & no & yes & no & no & no & -0.5 \\
\hline
\end{tabular}




\begin{tabular}{|c|c|c|c|c|c|c|c|c|c|c|c|}
\hline $\begin{array}{l}\text { Janaina } \\
\text { Badin } \\
\text { Carvas }\end{array}$ & no & no & no & no & no & no & yes & yes & no & no & -0.6 \\
\hline $\begin{array}{l}\text { Mengch } \\
\text { un Qi }\end{array}$ & no & yes & no & yes & no & yes & no & no & no & no & -0.4 \\
\hline $\begin{array}{l}\text { Yunfeng } \\
\mathrm{Li}\end{array}$ & unclear & yes & no & yes & no & no & yes & yes & no & no & -0.1 \\
\hline $\begin{array}{l}\text { Gabriell } \\
\text { a Dvora } \\
k\end{array}$ & unclear & yes & no & no & no & no & no & no & no & no & -0.7 \\
\hline $\begin{array}{l}\text { M Aya } \\
n\end{array}$ & unclear & yes & no & yes & no & no & no & yes & no & no & -0.3 \\
\hline $\begin{array}{l}\text { Henrik } \\
\text { Daugaar } \\
\text { d, }\end{array}$ & unclear & yes & no & yes & yes & yes & yes & yes & yes & $\begin{array}{l}\text { unclea } \\
\mathrm{r}\end{array}$ & 0.6 \\
\hline B. Chen & unclear & yes & no & no & no & yes & yes & yes & yes & no & 0.1 \\
\hline $\mathrm{KC} \mathrm{Oh}$ & no & no & no & no & no & no & no & yes & no & no & -0.8 \\
\hline $\begin{array}{l}\text { Amarjit } \\
\text { S. Virdi }\end{array}$ & unclear & yes & no & no & no & no & yes & yes & no & no & -0.3 \\
\hline $\begin{array}{l}\text { Rodrigo } \\
\text { A. B. }\end{array}$ & unclear & yes & no & no & no & no & no & yes & no & no & -0.5 \\
\hline $\begin{array}{l}\text { Maiqua } \\
n \text { Wang }\end{array}$ & unclear & yes & no & no & no & no & no & no & no & no & -0.7 \\
\hline $\begin{array}{l}\text { Danila } \\
\text { de } \\
\text { OLIVEI } \\
\text { RA }\end{array}$ & no & yes & no & no & no & no & no & no & no & no & -0.8 \\
\hline $\begin{array}{l}\text { Serkan } \\
\text { Dundar }\end{array}$ & unclear & yes & no & no & no & no & no & no & no & no & -0.7 \\
\hline $\begin{array}{l}\text { Yi } \\
\text { Xiong }\end{array}$ & no & no & no & no & no & no & no & no & no & no & -1 \\
\hline $\begin{array}{l}\text { Maria } \\
\text { Salete } \\
\text { Sandini } \\
\text { Linden }\end{array}$ & unclear & yes & no & no & no & no & no & no & no & no & -0.7 \\
\hline $\begin{array}{l}\text { Stephen } \\
\text { D. Cook }\end{array}$ & unclear & yes & no & no & no & no & no & yes & no & no & -0.5 \\
\hline $\begin{array}{l}\text { BERT } \\
\text { C. } \\
\text { CALLA } \\
\text { HAN. }\end{array}$ & unclear & yes & no & no & no & no & no & no & no & no & -0.7 \\
\hline $\begin{array}{l}\text { R. } \\
\text { Skripitz }\end{array}$ & unclear & yes & no & no & yes & no & yes & yes & no & no & -0.1 \\
\hline
\end{tabular}




\begin{tabular}{|c|c|c|c|c|c|c|c|c|c|c|c|}
\hline $\begin{array}{l}\text { Poliana } \\
\text { M. } \\
\text { Duarte }\end{array}$ & unclear & yes & no & no & no & no & no & no & no & no & -0.7 \\
\hline $\begin{array}{l}\text { Jörgen } \\
\text { Åstrand }\end{array}$ & no & no & no & no & yes & no & yes & yes & no & no & -0.4 \\
\hline $\begin{array}{l}\text { Bjorn } \\
\text { Skoglun } \\
\text { d }\end{array}$ & yes & yes & yes & no & yes & no & yes & yes & yes & no & 0.4 \\
\hline $\begin{array}{l}\text { Marius } \\
\text { von } \\
\text { Knoch }\end{array}$ & no & yes & no & no & no & no & no & yes & no & no & -0.6 \\
\hline $\begin{array}{l}\text { Celso } \\
\text { Eduardo } \\
\text { Sakakur } \\
\text { a }\end{array}$ & unclear & yes & no & no & yes & yes & yes & yes & no & no & 0.1 \\
\hline $\begin{array}{l}\text { Thomas } \\
\text { B. } \\
\text { Jensen }\end{array}$ & unclear & yes & no & no & yes & no & yes & yes & no & no & -0.1 \\
\hline $\begin{array}{l}\text { Romain } \\
\text { Dayer }\end{array}$ & no & yes & no & no & no & no & no & no & no & no & -0.8 \\
\hline $\begin{array}{l}\text { Gabriela } \\
\text { Giro }\end{array}$ & unclear & yes & no & no & no & no & no & no & no & no & -0.7 \\
\hline $\begin{array}{l}\text { Iwase, } \\
\text { M., et } \\
\text { al., }\end{array}$ & unclear & yes & no & unclear & yes & unclear & yes & no & unclear & $\begin{array}{l}\text { unclea } \\
\mathrm{r}\end{array}$ & 0.1 \\
\hline $\begin{array}{l}\text { Millett, } \\
\text { P. J., et } \\
\text { al., }\end{array}$ & yes & yes & no & no & yes & unclear & yes & yes & unclear & $\begin{array}{l}\text { unclea } \\
\mathrm{r}\end{array}$ & 0.3 \\
\hline $\begin{array}{l}\text { Inouye, } \\
\text { K. A., et } \\
\text { al., }\end{array}$ & no & yes & no & unclear & unclear & no & no & unclear & yes & no & -0.3 \\
\hline $\begin{array}{l}\text { Wu, Y. } \\
\text { Y., et } \\
\text { al., }\end{array}$ & no & yes & no & no & no & no & no & unclear & unclear & no & -0.6 \\
\hline $\begin{array}{l}\text { El } \\
\text { Hadary, } \\
\text { A.A., et } \\
\text { al., }\end{array}$ & yes & yes & no & yes & no & unclear & no & no & unclear & no & -0.2 \\
\hline $\begin{array}{l}\text { Kwon, } \\
\text { P. T., et } \\
\text { al., }\end{array}$ & no & yes & no & no & no & no & no & unclear & no & no & -0.7 \\
\hline $\begin{array}{l}\text { Shibuta } \\
\text { ni, T., et } \\
\text { al., }\end{array}$ & no & yes & no & no & no & no & no & no & unclear & no & -0.7 \\
\hline
\end{tabular}




\begin{tabular}{|c|c|c|c|c|c|c|c|c|c|c|c|}
\hline $\begin{array}{l}\text { José T. } \\
\text { Siqueira }\end{array}$ & no & yes & no & no & no & no & no & no & no & no & -0.8 \\
\hline $\begin{array}{l}\text { Sakakur } \\
\text { a, C. E., } \\
\text { et al., }\end{array}$ & unclear & yes & yes & yes & no & no & no & yes & yes & no & 0.1 \\
\hline $\begin{array}{l}\text { Zhang, } \\
\text { X., et } \\
\text { al., }\end{array}$ & no & yes & yes & no & no & no & no & yes & yes & no & -0.2 \\
\hline $\begin{array}{l}\text { Lima, C. } \\
\text { C., et al. }\end{array}$ & unclear & yes & yes & yes & no & no & no & no & yes & no & -0.1 \\
\hline $\begin{array}{l}\text { de } \\
\text { Molon, } \\
\text { R.S., et } \\
\text { al., }\end{array}$ & unclear & yes & yes & yes & no & no & no & yes & yes & no & 0.1 \\
\hline $\begin{array}{l}\text { Keller, } \\
\text { J. C., et } \\
\text { al. }\end{array}$ & no & yes & no & no & no & no & no & no & yes & no & -0.6 \\
\hline $\begin{array}{l}\text { Stefani, } \\
\text { C. M., } \\
\text { et al }\end{array}$ & unclear & yes & yes & yes & no & yes & no & no & yes & no & 0.1 \\
\hline $\begin{array}{l}\text { Duarte, } \\
\text { P. M., et } \\
\text { al., }\end{array}$ & no & yes & no & yes & no & no & no & no & no & no & -0.6 \\
\hline $\begin{array}{l}\text { Skripitz, } \\
\text { R., et } \\
\text { al., }\end{array}$ & unclear & yes & no & no & no & yes & yes & no & no & no & -0.3 \\
\hline $\begin{array}{l}\text { Deniz } \\
\text { Cankaya } \\
1\end{array}$ & unclear & yes & no & no & no & no & no & no & no & no & -0.7 \\
\hline $\begin{array}{l}\text { Nicolau } \\
\text { Conte } \\
\text { Neto }\end{array}$ & unclear & yes & no & no & no & no & yes & no & no & no & -0.5 \\
\hline $\begin{array}{l}\text { Shuo } \\
\text { Liu }\end{array}$ & no & no & no & no & no & no & no & no & no & no & -1 \\
\hline $\begin{array}{l}\text { Amarjit } \\
\text { S. Virdi }\end{array}$ & unclear & yes & no & no & no & no & no & yed & yes & no & -0.4 \\
\hline $\begin{array}{l}\text { Oliveira } \\
\text { PAD }\end{array}$ & unclear & yes & no & no & no & no & yes & yes & no & no & -0.3 \\
\hline $\begin{array}{l}\text { Zhibin } \\
\mathrm{Du}\end{array}$ & unclear & yes & no & no & no & no & no & no & no & no & -0.7 \\
\hline $\begin{array}{l}\text { Guimara } \\
\text { es RP }\end{array}$ & unclear & yes & no & no & no & no & no & no & no & no & -0.7 \\
\hline $\begin{array}{l}\text { Sarande } \\
\text { ep S. } \\
\text { Huja }\end{array}$ & no & no & no & no & no & no & yes & yes & no & no & -0.6 \\
\hline
\end{tabular}




\begin{tabular}{|c|c|c|c|c|c|c|c|c|c|c|c|}
\hline $\begin{array}{l}\text { Sarande } \\
\text { ep S. } \\
\text { Huja }\end{array}$ & no & yes & no & no & no & no & yes & yes & no & no & -0.4 \\
\hline $\begin{array}{l}\text { Y. } \\
\text { AYUK } \\
\text { AWA }\end{array}$ & no & no & no & no & no & no & no & no & no & no & -1 \\
\hline $\begin{array}{l}\text { James } \\
\text { Kelly }\end{array}$ & no & yes & no & no & no & no & no & no & no & no & -0.8 \\
\hline $\begin{array}{l}\text { Qingyun } \\
\text { Xue }\end{array}$ & unclear & yes & no & no & no & yes & yes & yes & no & no & -0.1 \\
\hline $\begin{array}{l}\mathrm{K} . \\
\text { Hayashi }\end{array}$ & no & yes & no & no & no & no & no & no & no & no & -0.8 \\
\hline $\begin{array}{l}\text { József } \\
\text { Blazsek }\end{array}$ & no & yes & no & no & no & no & no & no & no & no & -0.8 \\
\hline $\begin{array}{l}\text { Getulio } \\
\text { da R. } \\
\text { Nogueir } \\
\text { a-Filho }\end{array}$ & unclear & yes & no & no & no & no & yes & yes & no & no & -0.3 \\
\hline $\begin{array}{l}\text { H. R. } \\
\text { Johanss } \\
\text { on }\end{array}$ & unclear & yes & no & no & yes & yes & yes & yes & no & no & 0.1 \\
\hline $\begin{array}{l}\text { Per } \\
\text { Aspenbe } \\
\text { rg }\end{array}$ & yes & yes & no & no & yes & no & yes & yes & no & no & 0 \\
\hline $\begin{array}{l}\text { Kjeld } \\
\text { Søballe }\end{array}$ & no & yes & no & no & no & yes & yes & yes & no & no & -0.2 \\
\hline $\begin{array}{l}\text { Allen E. } \\
\text { Goodshi } \\
\mathrm{p}\end{array}$ & unclear & yes & no & no & no & no & yes & no & no & no & -0.5 \\
\hline $\begin{array}{l}\text { Bingkui } \\
\mathrm{Ma}\end{array}$ & unclear & yes & no & no & no & no & no & yes & no & no & -0.5 \\
\hline $\begin{array}{l}\text { Zhiqing } \\
\text { Xing }\end{array}$ & unclear & yes & no & no & no & no & no & yes & no & no & -0.5 \\
\hline $\begin{array}{l}\text { L. M. } \\
\text { Wise }\end{array}$ & no & yes & no & no & yes & no & yes & no & no & no & -0.4 \\
\hline $\begin{array}{l}\text { Dimitra } \\
\text { Balatsou } \\
\text { ka }\end{array}$ & no & yes & no & no & no & no & no & no & no & no & -0.8 \\
\hline $\begin{array}{l}\text { K. } \\
\text { Hayashi }\end{array}$ & yes & yes & no & no & yes & no & no & no & no & no & -0.4 \\
\hline $\begin{array}{l}\text { Samuel } \\
\text { Koo }\end{array}$ & no & yes & no & no & no & no & no & no & no & no & -0.8 \\
\hline
\end{tabular}




\begin{tabular}{|c|c|c|c|c|c|c|c|c|c|c|c|}
\hline $\begin{array}{l}\text { Poliana } \\
\text { Mendes } \\
\text { Duarte }\end{array}$ & unclear & yes & no & no & no & no & no & yes & no & no & -0.5 \\
\hline $\begin{array}{l}\text { THOM } \\
\text { AS TR } \\
\text { ANCI }\end{array}$ & no & no & no & no & no & no & no & no & no & no & -1 \\
\hline $\begin{array}{l}\text { SVEN- } \\
\text { ARNE } \\
\text { JACOB } \\
\text { SSON, }\end{array}$ & yes & yes & no & no & no & no & no & yes & no & no & -0.4 \\
\hline $\begin{array}{l}\text { Fiorellin } \\
\text { i JP, }\end{array}$ & no & no & no & no & no & no & no & yes & no & no & -0.8 \\
\hline $\begin{array}{l}\text { Stuart } \\
\text { Goodma } \\
n\end{array}$ & no & yes & no & no & no & no & yes & no & no & no & -0.6 \\
\hline $\begin{array}{l}\text { Tatsuo } \\
\text { Shirota }\end{array}$ & unclear & yes & no & no & no & no & no & no & no & no & -0.7 \\
\hline $\begin{array}{l}\text { Karina } \\
\text { Fittipald } \\
\text { i } \\
\text { Bombon } \\
\text { ato- } \\
\text { Prado }\end{array}$ & no & yes & no & no & no & no & yes & no & no & no & -0.6 \\
\hline $\begin{array}{l}\text { Poliana } \\
\text { Mendes } \\
\text { Duarte, }\end{array}$ & unclear & yes & no & no & no & no & yes & yes & no & no & -0.3 \\
\hline $\begin{array}{l}\text { Jeffrey } \\
\text { A }\end{array}$ & unclear & no & no & no & no & yes & yes & yes & no & no & -0.3 \\
\hline $\begin{array}{l}\text { Dimitra } \\
\text { Balatsou } \\
\text { ka }\end{array}$ & unclear & yes & no & no & no & no & no & no & no & no & -0.7 \\
\hline $\begin{array}{l}\text { Yankel } \\
\text { Gabet }\end{array}$ & unclear & yes & no & no & no & no & no & yes & no & no & -0.5 \\
\hline $\begin{array}{l}\text { Birgit } \\
\text { Mair }\end{array}$ & unclear & yes & no & no & no & no & no & yes & no & no & -0.5 \\
\hline $\begin{array}{l}\text { Alethe'i } \\
\text { a B. } \\
\text { Pablos }\end{array}$ & unclear & yes & no & no & no & no & yes & no & no & no & -0.5 \\
\hline $\begin{array}{l}\text { By } \\
\text { Yoshina } \\
\text { ri } \\
\text { Nakamu } \\
\text { ra }\end{array}$ & no & yes & no & no & no & no & no & no & no & no & -0.8 \\
\hline $\begin{array}{l}\text { Marcelo } \\
\text { Soeiro } \\
\text { Corsini }\end{array}$ & unclear & yes & no & no & no & no & no & no & no & no & -0.7 \\
\hline
\end{tabular}




\begin{tabular}{|c|c|c|c|c|c|c|c|c|c|c|c|}
\hline $\begin{array}{l}\text { Fernand } \\
\text { a Vieira } \\
\text { Ribeiro }\end{array}$ & unclear & yes & no & no & no & no & yes & no & no & no & -0.5 \\
\hline $\begin{array}{l}\text { Evelise } \\
\text { V. }\end{array}$ & no & no & no & no & no & no & no & yes & no & no & -0.8 \\
\hline $\begin{array}{l}\text { J. S. B. } \\
\text { Carvas }\end{array}$ & no & yes & no & no & no & no & no & no & no & no & -0.8 \\
\hline $\begin{array}{l}\text { Yunfeng } \\
\mathrm{Li} \text {, }\end{array}$ & unclear & yes & no & no & no & no & no & yes & no & no & -0.5 \\
\hline $\begin{array}{l}\text { Laurent } \\
\text { Maïmou } \\
\text { n }\end{array}$ & no & no & no & no & no & no & no & no & no & no & -1 \\
\hline $\begin{array}{l}\text { Alper } \\
\text { Yildiz }\end{array}$ & unclear & yes & no & no & no & yes & no & yes & no & no & -0.3 \\
\hline $\begin{array}{l}\text { Per } \\
\text { Aspenbe } \\
\text { rg }\end{array}$ & unclear & no & no & no & yes & no & yes & yes & no & no & -0.3 \\
\hline $\begin{array}{l}\text { Henrik } \\
\text { Daugaar } \\
\text { d }\end{array}$ & unclear & yes & no & no & no & yes & yes & yes & no & no & -0.1 \\
\hline J-H Kim & no & yes & no & no & no & no & no & yes & no & no & -0.6 \\
\hline $\begin{array}{l}\text { M. } \\
\text { Isabel } \\
\text { Almagr } \\
\mathrm{o}\end{array}$ & no & yes & no & no & no & yes & no & no & no & no & $\begin{array}{l}-0.6 \\
\end{array}$ \\
\hline $\begin{array}{l}\text { Ferhan } \\
\text { Yaman }\end{array}$ & unclear & yes & no & no & no & no & no & no & no & no & -0.7 \\
\hline $\begin{array}{l}\text { Jian- } \\
\text { Ping Li }\end{array}$ & no & yes & no & no & no & no & no & yes & no & no & -0.6 \\
\hline $\begin{array}{l}\text { InSoo } \\
\text { Kim }\end{array}$ & no & yes & no & no & no & no & no & yes & no & no & -0.6 \\
\hline $\begin{array}{l}\text { Gabriela } \\
\text { Giro }\end{array}$ & unclear & yes & no & no & no & no & no & no & no & no & -0.7 \\
\hline $\begin{array}{l}\text { Emre } \\
\text { Dikicier }\end{array}$ & unclear & yes & no & no & no & no & no & yes & no & no & -0.5 \\
\hline $\begin{array}{l}\text { Wei Xin } \\
\text { Cai }\end{array}$ & unclear & yes & no & no & no & no & no & yes & no & no & -0.5 \\
\hline $\begin{array}{l}\text { Mario } \\
\text { Henriqu } \\
\text { e A. }\end{array}$ & unclear & yes & no & no & no & no & yes & yes & no & no & -0.3 \\
\hline $\begin{array}{l}\text { Magnus } \\
\text { Bernhar } \\
\text { dsson }\end{array}$ & unclear & yes & no & no & no & no & yes & yes & no & no & -0.3 \\
\hline
\end{tabular}




\begin{tabular}{|c|c|c|c|c|c|c|c|c|c|c|c|}
\hline $\begin{array}{l}\text { G. } \\
\text { Ramalh } \\
\text { o- } \\
\text { Ferreira }\end{array}$ & no & yes & no & no & no & no & no & no & no & no & -0.8 \\
\hline $\begin{array}{l}\text { Tina } \\
\text { Rybacze } \\
\text { k }\end{array}$ & unclear & no & no & no & no & no & no & no & no & no & -0.9 \\
\hline $\begin{array}{l}\text { Zheng } \\
X \text {, }\end{array}$ & unclear & yes & no & no & no & no & no & yes & no & no & -0.5 \\
\hline $\begin{array}{l}\text { Sibel } \\
\text { Dikicier }\end{array}$ & unclear & yes & no & no & no & no & no & yes & no & no & -0.5 \\
\hline $\begin{array}{l}\text { Letícia } \\
\text { Pitol } \\
\text { PALIN }\end{array}$ & no & no & no & no & no & no & no & no & no & no & -1 \\
\hline $\begin{array}{l}\text { João B. } \\
\text { César- } \\
\text { Neto }\end{array}$ & unclear & yes & no & no & no & no & no & yes & no & no & -0.5 \\
\hline $\begin{array}{l}\text { Gabriela } \\
\text { Giro }\end{array}$ & unclear & yes & no & no & no & no & no & no & no & no & -0.7 \\
\hline $\begin{array}{l}\text { G. } \\
\text { Spence }\end{array}$ & no & no & no & no & no & no & yes & no & no & no & -1 \\
\hline $\begin{array}{l}\text { Zhibin } \\
\mathrm{Du}\end{array}$ & yes & yes & no & no & no & no & no & no & no & no & -0.6 \\
\hline $\begin{array}{l}\text { B.-L. } \\
\text { Chen }\end{array}$ & unclear & yes & no & no & no & no & no & no & no & no & -0.7 \\
\hline $\begin{array}{l}\text { Gabriela } \\
\text { Giro }\end{array}$ & no & yes & no & no & no & no & no & no & no & no & -0.8 \\
\hline $\begin{array}{l}\text { Ulrike } \\
\text { Kuchler }\end{array}$ & unclear & yes & no & no & no & no & no & no & no & no & -0.7 \\
\hline Han Yin & unclear & yes & no & no & no & no & no & yes & no & no & -0.5 \\
\hline $\begin{array}{l}\text { Anna } \\
\text { Fahlgre } \\
n\end{array}$ & no & no & no & no & no & no & yes & no & yes & no & -0.77 \\
\hline $\begin{array}{l}\text { Liana } \\
\text { Linhares } \\
\text { Lima }\end{array}$ & unclear & yes & no & no & no & no & yes & yes & no & no & -0.44 \\
\hline $\begin{array}{l}\text { Chenche } \\
\text { n Zhou }\end{array}$ & unclear & yes & no & no & no & no & no & no & no & no & -0.7 \\
\hline $\begin{array}{l}\text { Y.F. Li } \\
\&\end{array}$ & unclear & yes & no & no & no & no & no & yes & no & no & -0.5 \\
\hline $\begin{array}{l}\text { Marcio } \\
\text { A. de } \\
\text { Oliveira }\end{array}$ & unclear & yes & no & no & no & yes & yes & yes & no & no & -0.22 \\
\hline
\end{tabular}




\begin{tabular}{|c|c|c|c|c|c|c|c|c|c|c|c|}
\hline $\begin{array}{l}\text { Al } \\
\text { Subaie } \\
\text { A }\end{array}$ & unclear & yes & no & yes & yes & no & yes & yes & no & no & 0 \\
\hline $\begin{array}{l}\text { Xu } \\
\text { Yang }\end{array}$ & no & yes & no & no & yes & no & yes & yes & no & no & -0.33 \\
\hline $\begin{array}{l}\text { Zhou- } \\
\text { Shan } \\
\text { Tao }\end{array}$ & unclear & yes & no & no & no & YES & no & yes & no & no & -0.3 \\
\hline $\begin{array}{l}\text { Zhou- } \\
\text { Shan } \\
\text { Tao }\end{array}$ & no & yes & no & no & yes & no & yes & yes & no & no & -0.33 \\
\hline $\begin{array}{l}\text { Hyun-A } \\
\text { Heo }\end{array}$ & no & yes & no & no & no & no & no & no & no & no & -0.8 \\
\hline $\begin{array}{l}\text { Al } \\
\text { Subaie } \\
\text { A }\end{array}$ & yes & yes & no & no & yes & no & yes & yes & no & no & 0 \\
\hline $\begin{array}{l}\text { Zhou- } \\
\text { Shan } \\
\text { Tao }\end{array}$ & unclear & yes & no & no & no & yes & no & yes & no & no & -0.3 \\
\hline $\begin{array}{l}\text { Haytha } \\
\text { m Al- } \\
\text { Mahala } \\
\text { wy }\end{array}$ & unclear & yes & no & no & no & no & no & yes & no & no & -0.5 \\
\hline $\begin{array}{l}\text { Marta } \\
\text { Ferreira } \\
\text { Bastos }\end{array}$ & unclear & yes & no & no & no & no & yes & yes & no & no & -0.3 \\
\hline $\begin{array}{l}\text { Al- } \\
\text { Subaie } \\
\text { AE }\end{array}$ & yes & yes & no & no & yes & no & yes & yes & no & no & 0 \\
\hline $\begin{array}{l}\text { Yifan } \\
\text { Jin }\end{array}$ & yes & yes & no & no & no & no & no & no & no & no & -0.6 \\
\hline $\begin{array}{l}\text { Kyung } \\
\text { Chul Oh }\end{array}$ & no & yes & no & no & no & no & no & yes & no & no & -0.6 \\
\hline $\begin{array}{l}\text { Ahmet } \\
\text { Salduz }\end{array}$ & yes & yes & no & no & no & no & no & yes & no & no & -0.4 \\
\hline $\begin{array}{l}\text { Yoshifu } \\
\text { mi OK }\end{array}$ & no & yes & no & no & no & no & no & no & no & no & -0.8 \\
\hline $\begin{array}{l}\text { Hasan } \\
\text { Ayberk } \\
\text { ALTUG }\end{array}$ & yes & yes & no & no & no & no & yes & yes & no & no & -0.2 \\
\hline $\begin{array}{l}\text { Thadani, } \\
\text { P. J., et } \\
\text { al., }\end{array}$ & no & no & no & no & no & no & no & no & no & no & -1 \\
\hline
\end{tabular}




\begin{tabular}{|c|c|c|c|c|c|c|c|c|c|c|c|}
\hline $\begin{array}{l}\text { Skripitz, } \\
\text { R., et } \\
\text { al., }\end{array}$ & unclear & yes & yes & no & no & yes & no & yes & yes & no & 0.1 \\
\hline $\begin{array}{l}\text { Wang, } \\
\text { X., et } \\
\text { al., }\end{array}$ & unclear & yes & yes & no & no & yes & no & no & no & no & -0.3 \\
\hline $\begin{array}{l}\text { Gotfreds } \\
\text { en, K., } \\
\text { et al., }\end{array}$ & no & yes & no & no & no & no & no & no & no & no & -0.8 \\
\hline $\begin{array}{l}\text { de } \\
\text { Morais, } \\
\text { J. A., et } \\
\text { al., }\end{array}$ & unclear & yes & yes & no & no & no & yes & yes & no & no & -0.1 \\
\hline $\begin{array}{l}\text { Bragdon } \\
\text { C. R., } \\
\text { et al., }\end{array}$ & no & yes & no & no & no & no & no & yes & no & no & -0.6 \\
\hline $\begin{array}{l}\text { Caroline } \\
\text { Ribeiro } \\
\text { Serrão } \\
\text { et al. }\end{array}$ & unclear & yes & yes & no & no & no & yes & yes & yes & yes & 0.3 \\
\hline $\begin{array}{l}\text { Astrand, } \\
\text { J., et al., }\end{array}$ & no & yes & no & no & no & no & no & no & yes & no & -0.6 \\
\hline $\begin{array}{l}\text { Fujimot } \\
\text { o et al }\end{array}$ & no & yes & no & no & no & no & no & no & yes & no & -0.6 \\
\hline $\begin{array}{l}\text { F. H. } \\
\text { Nociti } \\
\text { Jr., et al. }\end{array}$ & unclear & yes & no & no & no & no & no & no & yes & no & -0.5 \\
\hline $\begin{array}{l}\text { Werner } \\
\text { SB1, et } \\
\text { al. }\end{array}$ & no & yes & no & no & no & no & no & no & yes & no & -0.6 \\
\hline $\begin{array}{l}\text { Nociti } \\
\text { FH Jr, et } \\
\text { al. }\end{array}$ & no & yes & no & no & no & no & no & no & yes & no & -0.6 \\
\hline $\begin{array}{l}\text { Hazzaa } \\
\text { HH,Ami } \\
\text { n et al. }\end{array}$ & unclear & yes & no & no & no & no & no & yes & yes & no & -0.3 \\
\hline $\begin{array}{l}\text { Nyberg } \\
\text { J,Hertz } \\
\text { m et al. }\end{array}$ & no & yes & no & no & no & no & yes & yes & yes & no & -0.2 \\
\hline $\begin{array}{l}\text { de Deco } \\
\text { CP,da et } \\
\text { al. }\end{array}$ & no & yes & no & no & no & no & no & yes & yes & no & -0.4 \\
\hline $\begin{array}{l}\text { Ohkawa } \\
\text { Y,Toku } \\
\text { naga et } \\
\text { al. }\end{array}$ & no & yes & no & no & no & no & no & no & yes & no & -0.6 \\
\hline
\end{tabular}




\begin{tabular}{|c|c|c|c|c|c|c|c|c|c|c|c|}
\hline $\begin{array}{l}\text { McCrac } \\
\text { ken MS, } \\
\text { et al. }\end{array}$ & no & yes & no & no & no & no & no & yes & yes & no & -0.4 \\
\hline $\begin{array}{l}\text { Virolain } \\
\text { en P,et } \\
\text { al. }\end{array}$ & no & yes & no & no & no & no & no & yes & yes & no & -0.4 \\
\hline $\begin{array}{l}\text { Miyaji T } \\
\text { et al., }\end{array}$ & no & yes & no & no & no & no & no & yes & yes & no & -0.4 \\
\hline $\begin{array}{l}\text { Margon } \\
\text { ar R, et } \\
\text { al,. }\end{array}$ & unclear & yes & no & no & no & no & no & no & yes & no & -0.5 \\
\hline $\begin{array}{l}\text { Zou } \\
\text { X,Xue } \\
\text { Q, et al, }\end{array}$ & unclear & yes & no & no & no & yes & yes & no & yes & no & -0.1 \\
\hline $\begin{array}{l}\text { Tokuga } \\
\text { wa Y,et } \\
\text { al, }\end{array}$ & unclear & yes & no & no & no & no & no & no & yes & no & -0.5 \\
\hline $\begin{array}{l}\text { Skripitz } \\
\mathrm{R} 1 \text {, } \\
\text { Aspenbe } \\
\text { rg P. }\end{array}$ & unclear & yes & no & no & no & yes & yes & yes & yes & no & 0.1 \\
\hline
\end{tabular}




\section{Appendix D: Quality assessment of RCTs}

Table 8: Cochrane risk of bias assessments for included articles of randomized controlled trials RCTs

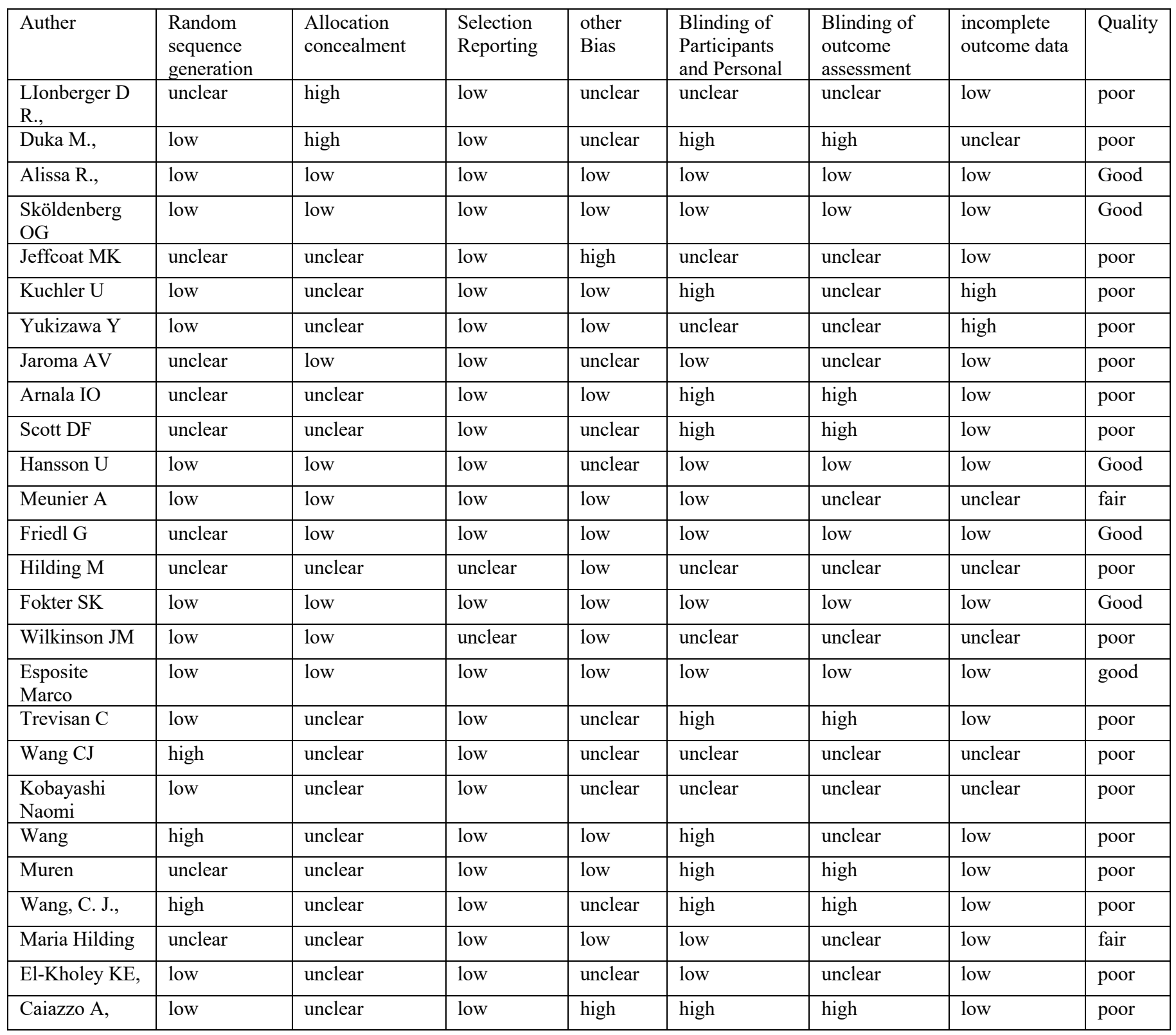


Appendix E: Quality assessment of observational studies

Table 9: STROBE quality assessment for the included studies of observational studies

\begin{tabular}{|c|c|c|c|c|c|c|c|c|c|c|c|c|c|c|c|c|c|c|c|c|c|c|c|}
\hline First Author & 1 & 2 & 3 & 4 & 5 & 6 & 7 & 8 & 9 & $\begin{array}{l}1 \\
0\end{array}$ & $\begin{array}{l}1 \\
1 \\
\end{array}$ & $\begin{array}{l}1 \\
2\end{array}$ & $\begin{array}{l}1 \\
3 \\
\end{array}$ & $\begin{array}{l}1 \\
4 \\
\end{array}$ & $\begin{array}{l}1 \\
5\end{array}$ & $\begin{array}{l}1 \\
6 \\
\end{array}$ & $\begin{array}{l}1 \\
7\end{array}$ & $\begin{array}{l}1 \\
8\end{array}$ & $\begin{array}{l}1 \\
9 \\
\end{array}$ & $\begin{array}{l}2 \\
0\end{array}$ & $\begin{array}{l}2 \\
1\end{array}$ & $\begin{array}{l}2 \\
2 \\
\end{array}$ & result \\
\hline Avedian RS & 0 & 1 & 0 & 1 & 0 & 1 & 0 & 1 & 1 & 0 & 1 & 0 & 0 & 0 & 1 & 0 & 1 & 0 & 1 & 0 & 0 & 0 & high \\
\hline Kasai T & 1 & 1 & 1 & 1 & 1 & 0 & 0 & 0 & 0 & 0 & 0 & 0 & 0 & 0 & 1 & 0 & 0 & 1 & 0 & 0 & 0 & 0 & high \\
\hline Kova'cs AF & 1 & 1 & 1 & 0 & 1 & 1 & 0 & 1 & 0 & 1 & 1 & 0 & 1 & 0 & 1 & 0 & 0 & 1 & 1 & 0 & 0 & 0 & $\begin{array}{l}\text { moderat } \\
\mathrm{e}\end{array}$ \\
\hline $\begin{array}{l}\text { Vassilis } \\
\text { Petsinis, }\end{array}$ & 1 & 1 & 1 & 1 & 0 & 1 & 0 & 0 & 0 & 1 & 0 & 0 & 1 & 0 & 1 & 0 & 0 & 1 & 1 & 1 & 0 & 1 & $\begin{array}{l}\text { moderat } \\
\mathrm{e}\end{array}$ \\
\hline $\begin{array}{l}\text { Daniel } \\
\text { Prieto- } \\
\text { Alhambra, }\end{array}$ & 1 & 1 & 1 & 1 & 1 & 1 & 1 & 1 & 1 & 1 & 0 & 1 & 1 & 0 & 1 & 0 & 1 & 1 & 1 & 1 & 1 & 1 & low \\
\hline Memon S, & 1 & 1 & 1 & 0 & 0 & 0 & 1 & 1 & 1 & 0 & 0 & 0 & 1 & 1 & 1 & 0 & 0 & 0 & 0 & 0 & 0 & 0 & high \\
\hline $\begin{array}{l}\text { Bao-Thy } \\
\text { Grant, }\end{array}$ & 1 & 1 & 1 & 1 & 1 & 1 & 0 & 0 & 0 & 1 & 0 & 0 & 0 & 1 & 1 & 0 & 0 & 1 & 0 & 0 & 0 & 0 & high \\
\hline Siebert T, & 1 & 1 & 1 & 1 & 0 & 1 & 0 & 0 & 0 & 0 & 0 & 0 & 0 & 1 & 1 & 0 & 0 & 0 & 0 & 0 & 0 & 0 & high \\
\hline $\begin{array}{l}\text { Fugazzotto } \\
\text { PA, }\end{array}$ & 1 & 1 & 1 & 1 & 1 & 1 & 1 & 1 & 0 & 0 & 0 & 0 & 0 & 1 & 1 & 0 & 0 & 1 & 0 & 0 & 0 & 0 & $\begin{array}{l}\text { moderat } \\
\mathrm{e}\end{array}$ \\
\hline Wu X & 1 & 1 & 1 & 1 & 1 & 1 & 1 & 1 & 0 & 1 & 1 & 1 & 1 & 0 & 1 & 1 & 1 & 1 & 1 & 0 & 0 & 1 & low \\
\hline Koka S & 1 & 1 & 1 & 1 & 1 & 1 & 0 & 0 & 1 & 1 & 0 & 0 & 1 & 1 & 0 & 0 & 0 & 1 & 1 & 1 & 0 & 0 & $\begin{array}{l}\text { moderat } \\
\mathrm{e}\end{array}$ \\
\hline Mozzati M & 1 & 1 & 1 & 1 & 0 & 1 & 0 & 0 & 0 & 0 & 0 & 1 & 1 & 1 & 1 & 1 & 1 & 1 & 0 & 1 & 0 & 0 & $\begin{array}{l}\text { moderat } \\
\mathrm{e}\end{array}$ \\
\hline $\mathrm{Wu} X$ & 1 & 1 & 1 & 1 & 1 & 1 & 1 & 1 & 0 & 1 & 1 & 1 & 1 & 1 & 1 & 1 & 1 & 1 & 1 & 1 & 0 & 1 & low \\
\hline $\begin{array}{l}\text { Daniel C. } \\
\text { Martin }\end{array}$ & 1 & 1 & 1 & 1 & 1 & 1 & 1 & 1 & 0 & 1 & 0 & 0 & 1 & 1 & 1 & 1 & 0 & 1 & 1 & 1 & 0 & 0 & $\begin{array}{l}\text { moderat } \\
\mathrm{e}\end{array}$ \\
\hline Brian M. & 1 & 1 & 1 & 1 & 0 & 1 & 1 & 1 & 0 & 1 & 0 & 0 & 0 & 0 & 1 & 0 & 0 & 1 & 1 & 0 & 0 & 0 & $\begin{array}{l}\text { moderat } \\
\mathrm{e}\end{array}$ \\
\hline Sakka S & 0 & 1 & 1 & 0 & 0 & 1 & 1 & 1 & 0 & 0 & 1 & 0 & 1 & 0 & 1 & 1 & 1 & 1 & 0 & 1 & 0 & 0 & $\begin{array}{l}\text { moderat } \\
\mathrm{e}\end{array}$ \\
\hline Famili P. & 1 & 1 & 1 & 1 & 1 & 0 & 0 & 0 & 1 & 1 & 0 & 0 & 1 & 0 & 1 & 1 & 0 & 1 & 0 & 1 & 0 & 0 & $\begin{array}{l}\text { moderat } \\
\mathrm{e}\end{array}$ \\
\hline $\begin{array}{l}\text { Brent } \\
\text { Winnett }\end{array}$ & 1 & 1 & 1 & 1 & 1 & 1 & 1 & 1 & 1 & 1 & 0 & 1 & 1 & 0 & 1 & 1 & 1 & 1 & 0 & 1 & 0 & 0 & $\begin{array}{l}\text { moderat } \\
\mathrm{e}\end{array}$ \\
\hline $\begin{array}{l}\text { Pyung Goo } \\
\text { Cho }\end{array}$ & 1 & 1 & 1 & 1 & 1 & 1 & 1 & 1 & 0 & 1 & 1 & 1 & 1 & 1 & 1 & 1 & 1 & 1 & 1 & 1 & 0 & 1 & low \\
\hline $\begin{array}{l}\text { Talal M. } \\
\text { Zahid }\end{array}$ & 1 & 1 & 1 & 1 & 1 & 1 & 0 & 0 & 0 & 1 & 0 & 1 & 1 & 1 & 1 & 1 & 0 & 1 & 1 & 1 & 0 & 1 & $\begin{array}{l}\text { moderat } \\
\mathrm{e}\end{array}$ \\
\hline $\mathrm{Fu} \mathrm{SH}$ & 1 & 1 & 1 & 1 & 1 & 1 & 1 & 0 & 0 & 0 & 0 & 1 & 1 & 0 & 0 & 0 & 0 & 1 & 1 & 0 & 0 & 0 & $\begin{array}{l}\text { moderat } \\
\mathrm{e}\end{array}$ \\
\hline $\begin{array}{l}\text { Prieto- } \\
\text { Alhambra } \\
\mathrm{D}^{\mathrm{b}}\end{array}$ & 1 & 1 & 1 & 1 & 1 & 1 & 1 & 0 & 1 & 0 & 1 & 1 & 1 & 1 & 0 & 0 & 1 & 0 & 0 & 0 & 0 & 1 & $\begin{array}{l}\text { moderat } \\
\mathrm{e}\end{array}$ \\
\hline Ji WP, & 0 & 1 & 1 & 0 & 0 & 1 & 0 & 1 & 0 & 0 & 0 & 0 & 0 & 0 & 1 & 0 & 0 & 1 & 0 & 0 & 0 & 0 & high \\
\hline Ohtori S, & 1 & 1 & 1 & 1 & 1 & 1 & 0 & 1 & 0 & 0 & 0 & 0 & 1 & 1 & 1 & 0 & 0 & 1 & 1 & 0 & 0 & 0 & $\begin{array}{l}\text { moderat } \\
\mathrm{e}\end{array}$ \\
\hline Lübbeke A, & 1 & 1 & 1 & 1 & 1 & 1 & 1 & 1 & 0 & 0 & 0 & 1 & 1 & 1 & 1 & 1 & 1 & 1 & 1 & 1 & 0 & 1 & low \\
\hline Iwamoto N, & 0 & 1 & 1 & 0 & 0 & 1 & 1 & 1 & 0 & 0 & 0 & 0 & 0 & 0 & 1 & 0 & 0 & 1 & 1 & 0 & 0 & 1 & high \\
\hline $\begin{array}{l}\text { Tapaninen } \\
\text { TS, }\end{array}$ & 1 & 1 & 1 & 1 & 1 & 1 & 0 & 0 & 0 & 0 & 0 & 0 & 1 & 0 & 1 & 0 & 0 & 1 & 0 & 1 & 0 & 0 & high \\
\hline Yamasaki S, & 0 & 1 & 1 & 0 & 0 & 1 & 0 & 1 & 0 & 0 & 0 & 0 & 0 & 0 & 1 & 0 & 0 & 1 & 1 & 0 & 0 & 0 & high \\
\hline Nishioka T, & 0 & 1 & 1 & 0 & 0 & 1 & 0 & 1 & 0 & 0 & 0 & 0 & 0 & 1 & 1 & 0 & 0 & 1 & 0 & 0 & 0 & 0 & high \\
\hline
\end{tabular}




\begin{tabular}{|c|c|c|c|c|c|c|c|c|c|c|c|c|c|c|c|c|c|c|c|c|c|c|c|}
\hline Moroni A, & 1 & 1 & 1 & 0 & 0 & 1 & 0 & 0 & 0 & 0 & 0 & 0 & 0 & 0 & 1 & 0 & 0 & 1 & 0 & 0 & 0 & 0 & high \\
\hline Persson PE, & 1 & 1 & 1 & 1 & 1 & 0 & 1 & 1 & 0 & 1 & 1 & 0 & 1 & 1 & 1 & 1 & 0 & 1 & 0 & 0 & 0 & 0 & $\begin{array}{l}\text { moderat } \\
\mathrm{e}\end{array}$ \\
\hline Kashani H, & 1 & 1 & 1 & 1 & 1 & 0 & 0 & 0 & 0 & 0 & 0 & 0 & 0 & 0 & 1 & 0 & 0 & 1 & 0 & 0 & 0 & 0 & high \\
\hline Peichl P, & 0 & 1 & 1 & 1 & 0 & 0 & 0 & 1 & 0 & 0 & 0 & 0 & 1 & 1 & 1 & 0 & 0 & 1 & 0 & 0 & 0 & 0 & high \\
\hline August M, & 1 & 1 & 1 & 1 & 0 & 1 & 1 & 1 & 0 & 1 & 0 & 0 & 1 & 0 & 1 & 1 & 1 & 1 & 1 & 1 & 0 & 0 & $\begin{array}{l}\text { moderat } \\
\mathrm{e}\end{array}$ \\
\hline Suzuki T, & 1 & 1 & 1 & 1 & 0 & 0 & 0 & 0 & 0 & 0 & 0 & 0 & 1 & 0 & 0 & 0 & 0 & 1 & 0 & 0 & 0 & 0 & high \\
\hline Huang TW, & 1 & 1 & 1 & 1 & 0 & 0 & 0 & 1 & 1 & 0 & 0 & 0 & 1 & 1 & 1 & 0 & 0 & 1 & 1 & 0 & 0 & 1 & $\begin{array}{l}\text { moderat } \\
\mathrm{e}\end{array}$ \\
\hline Kaneko T, & 1 & 1 & 1 & 0 & 0 & 1 & 1 & 1 & 0 & 1 & 0 & 1 & 1 & 1 & 1 & 0 & 0 & 1 & 0 & 1 & 0 & 0 & $\begin{array}{l}\text { moderat } \\
\mathrm{e}\end{array}$ \\
\hline Lee JK, & 0 & 1 & 1 & 0 & 1 & 1 & 1 & 1 & 1 & 0 & 1 & 1 & 1 & 1 & 1 & 1 & 0 & 1 & 1 & 1 & 0 & 0 & $\begin{array}{l}\text { moderat } \\
\mathrm{e}\end{array}$ \\
\hline $\begin{array}{l}\text { Arabmotlag } \\
\text { h M }\end{array}$ & 1 & 1 & 1 & 1 & 0 & 1 & 0 & 1 & 0 & 0 & 0 & 0 & 0 & 0 & 1 & 0 & 0 & 1 & 0 & 0 & 0 & 0 & high \\
\hline Yip JK & 1 & 1 & 1 & 1 & 1 & 1 & 0 & 0 & 0 & 1 & 0 & 0 & 0 & 0 & 1 & 1 & 0 & 1 & 1 & 1 & 0 & 0 & $\begin{array}{l}\text { moderat } \\
\mathrm{e}\end{array}$ \\
\hline Minsk L, & 1 & 1 & 1 & 1 & 1 & 0 & 0 & 1 & 0 & 0 & 0 & 0 & 1 & 1 & 1 & 0 & 0 & 1 & 1 & 0 & 0 & 0 & $\begin{array}{l}\text { moderat } \\
\mathrm{e}\end{array}$ \\
\hline $\mathrm{Wu} \mathrm{X}^{\mathrm{b}}$ & 1 & 1 & 1 & 1 & 1 & 1 & 1 & 1 & 0 & 1 & 1 & 1 & 1 & 1 & 1 & 1 & 1 & 1 & 1 & 1 & 1 & 1 & low \\
\hline Gen Inoue & 1 & 1 & 1 & 0 & 1 & 1 & 0 & 0 & 0 & 0 & 0 & 0 & 0 & 0 & 0 & 0 & 0 & 1 & 1 & 0 & 0 & 0 & high \\
\hline Knov et al, & 1 & 1 & 1 & 1 & 1 & 1 & 1 & 1 & 0 & 1 & 1 & 1 & 0 & 0 & 1 & 1 & 0 & 1 & 1 & 1 & 1 & 0 & $\begin{array}{l}\text { moderat } \\
\mathrm{e}\end{array}$ \\
\hline $\begin{array}{l}\text { Chrcanovic } \\
\text { BR }\end{array}$ & 1 & 1 & 1 & 1 & 1 & 1 & 1 & 0 & 0 & 0 & 1 & 0 & 1 & 1 & 1 & 0 & 0 & 1 & 1 & 0 & 0 & 1 & $\begin{array}{l}\text { moderat } \\
\mathrm{e}\end{array}$ \\
\hline Rainier A. & 1 & 1 & 1 & 1 & 1 & 0 & 0 & 0 & 0 & 0 & 0 & 0 & 0 & 0 & 1 & 0 & 0 & 1 & 1 & 0 & 1 & 0 & high \\
\hline Ramos B & 1 & 1 & 1 & 1 & 1 & 1 & 1 & 1 & 0 & 0 & 1 & 1 & 1 & 1 & 1 & 1 & 0 & 1 & 1 & 1 & 0 & 1 & low \\
\hline Jin Kyu Lee & 1 & 1 & 1 & 1 & 1 & 0 & 1 & 1 & 0 & 1 & 0 & 0 & 1 & 0 & 1 & 0 & 0 & 1 & 1 & 1 & 1 & 1 & $\begin{array}{l}\text { moderat } \\
\mathrm{e}\end{array}$ \\
\hline
\end{tabular}

